\title{
Understanding fruit and vegetable consumption: \\ A qualitative investigation in the Mitchells Plain sub-district of Cape Town.
}

\author{
by \\ Catherine Jane Pereira \\ Thesis presented in partial fulfilment of the requirements for the degree \\ Master of Nutrition at the University of Stellenbosch \\ Supervisor: Prof. Milla McLachlan ${ }^{1}$ \\ Co-supervisor: Dr. Jane Battersby ${ }^{2}$ \\ (1 - Stellenbosch University; 2 - University of Cape Town) \\ Faculty of Medicine and Health Sciences \\ Department of Interdisciplinary Health Sciences \\ Division of Human Nutrition
}

March 2014 


\section{DECLARATION}

By submitting this thesis electronically, I declare that the entirety of the work contained therein is my work, original work, that I am the sole author thereof (save to the extent explicitly otherwise stated), that reproduction and publication thereof, by Stellenbosch University will not infringe any third party rights and that I have not previously in its entirety or in part submitted it for obtaining any qualification.

Signature:

Date:

Copyright @ 2014 Stellenbosch University

All rights reserved 


\section{ABSTRACT}

\section{Introduction}

Adequate fruit and vegetable consumption can provide many health and nutrition benefits, and can contribute to nutritional adequacy and quality of the diet. Despite existing strategies, most people in South Africa do not consume the recommended intake of five fruits and vegetables per day, and micronutrient intakes remain low.

\section{Aim}

The aim of this study was to describe underlying factors that influence individual and household fruit and vegetable consumption, in an area of the Mitchells Plain sub-district, by engaging with community members in a participatory manner in accordance with a human rights-based approach.

\section{Methodology}

This study was cross-sectional and descriptive. Data collection was conducted from November 2012 until January 2013, in an area of Mitchells Plain. Focus group discussions were conducted to gain a broad understanding of factors that influence fruit and vegetable consumption in the community and to identify individuals for individual interviews. In-depth interviews were conducted with strategically selected community members considered to be influential in food preparation, distribution or consumption, in order to gain in-depth understanding of specific factors associated with fruit and vegetable consumption.

\section{Results}

Four focus group discussions were conducted with 40 participants in total, allocated to three different groups (18 to 29 year old females, 30 to 70 year old females, 18 to 60 year old males). Fifteen in-depth interviews were conducted with community leaders, individuals involved in food production (kitchen managers) or sale thereof (an informal vendor and a tuck shop owner), individuals involved in health education (a professional nurse) and basic education (a grade one educator), and others. Dominant themes discussed included fruit and vegetable consumption patterns (religious, cultural and traditional dishes, seasonal variation), fruit and vegetable preparation techniques and commonly prepared dishes, fruit and vegetable access (purchasing, vegetable gardens and direct provision) and changes in fruit and vegetable consumption patterns. Barriers to fruit and vegetable consumption included that although most participants considered them to be important, fruit and vegetables were not considered a priority food item (inadequate time and effort is allocated to food purchasing and preparation), negative side-effects of consumption, fruit and vegetables are perishable and benefits of fruit and vegetable consumption 
are not immediately apparent. Facilitators of fruit and vegetable consumption were personal preference, traditional dishes prepared that include fruit or vegetable ingredients, individuals who sell or grow fruit and vegetables having increased availability, use of convenience fruit and vegetable items, and modelling and discipline in children. Suggestions to improve consumption included education using practical advice such as fruit recipes to improve the appeal of fruit and vegetable dishes, and methods to decrease preparation time and cost.

\section{Conclusions}

Limited fruit and vegetable consumption is not simply determined by limited nutrition knowledge or poor decision-making by households, but rather by a much wider set of social, economic and spatial processes. Creative and innovative behaviour-changing strategies are required that target individuals but also take cognisance of wider structural barriers, and work to create an enabling environment that is supportive of healthy eating and an adequate consumption of fruit and vegetables. 


\section{OPSOMMING}

\section{Inleiding}

Voldoende inname van vrugte en groente hou baie gesondheids- en voedingsvoordele in, en kan bydra tot voedingstoereikenheid en kwaliteit van die dieet. Ongeag bestaande strategieë, neem die meeste mense in Suid-Afrika nie die aanbevole vyf vrugte en groente in nie, en mikronutriënt inname bly laag.

\section{Doelwit}

Die doel van hierdie studie was om die onderliggende faktore wat indiwiduele en huishoudelike vrugte- en groenteverbruik in 'n area van die Mitchells Plein subdistrik beïnvloed, te beskryf, deur met lede van die gemeenskap in 'n deelnemende manier betrokke te raak in ooreenstemming met 'n menseregte-gebaseerde benadering.

\section{Metodes}

Hierdie deursnee studie was beskrywend. Data-insameling het vanaf November 2012 tot Januarie 2013 in 'n gedeelte van Mitchells Plein plaasgevind. Fokusgroepbesprekings is gehou om 'n breër begrip van die faktore wat vrugte- en groenteverbruik in die gemeenskap beïnvloed, te bekom en om indiwidue te identifiseer vir indiwiduele onderhoude. In-diepte onderhoude is gevoer met strategies verkose gemeenskapslede wat beskou word as invloedryk in voedselvoorbereiding, verspreiding en verbruik, om 'n dieper begrip van spesifieke faktore wat met vrugte- en groenteverbruik verband hou, te bekom.

\section{Resultate}

Vier fokusgroep-besprekings is gehou met 'n totaal van 40 deelnemers, versprei oor drie verskillende groepe (18 - 29 jarige vroue, 30 - 70 jarige vroue, 18 - 60 jarige mans). Vyftien indiepte onderhoude is gevoer met gemeenskapsleiers (polities en godsdienstig), indiwidue betrokke by voedselverwerking (kombuisbestuurders) of verkope (informele verkoper en snoepwinkeleienaar), indiwidue betrokke by gesondheidsopvoeding (professionele verpleegster) en basiese onderrig (graad een opvoeder) en andere. Oorheersende temas sluit in vrugte- en groenteverbruikspatrone (godsdienstige, kulturele en tradisionele disse, seisonale wisseling in gebruik), vrugte en groente voorbereidingstegnieke en alledaagse disse, toegang tot vrugte en groente (aankoop, groentetuine en direkte voorsiening) en verandering in vrugte- en groenteverbruikspatrone. Hindernisse tot vrugte- en groenteverbruik sluit in dat hoewel die meeste deelnemers vrugte- en groenteverbruik belangrik ag, word vrugte en groente nie as 'n prioriteitsvoedsel gesien nie. Voldoende tyd en aandag word nie aan voedsel-aankope en voorbereiding afgestaan nie, daar is negatiewe newe-effekte aan verbruik, vrugte en groente is bederfbaar en die voordele van vrugte en groenteverbruik is nie duidelik waarneembaar nie. 
Persoonlike voorkeur is bevorderlik vir vrugte- en groenteverbruik, sommige tradisionele disse word met vrugte of groente bestanddele voorberei, asook die groter beskikbaarheid van indiwidue wat vrugte en groente verkoop of kweek, die gebruik van vrugte en groente gemaksitems, en die gedragsmodellering en dissiplinering van kinders. Voorstelle om verbruik te verbeter het ingesluit opvoeding met praktiese raad soos vrugte en groente resepte om die aantreklikheid van vrugte en groente disse te verhoog en metodes om voorbereidingstyd en onkoste te verminder.

\section{Gevolgtrekking}

Beperkte vrugte en groente verbruik word nie net bepaal deur beperkte voeding kennis of swak besluitneming deur huishoudings nie, maar deur 'n veel wyer reeks van maatskaplike, ekonomiese en ruimtelike prosesse. Skeppende en innoverende gedragsveranderende-strategieë wat gemik is op indiwidue is nodig, asook aandag aan wyer strukturele hindernisser. Sodoende kan ' $n$ bemagtigende omgewing geskep word om gesonde eetgewoontes en die verbruik van voldoende vrugte en groente te ondersteun. 


\section{ACKNOWLEDGEMENTS}

To my study leaders, Prof. Milla McLachlan and Dr Jane Battersby, thank you for your guidance throughout the duration of my thesis preparation, for your constructive comments and especially for your innovative ideas. I have been inspired and have learned from you both.

To Maritha Marais, Prof. Wenche Bard Eide, Prof. Per Ole Iversen, Prof. Joyce Kikafuna and the full NOMA team: thank you for allowing me the opportunity to do this special Master's programme (in Nutrition, Human Rights and Governance), and thank you to NOMA for the scholarship received to do this Master's (enabling me to study in Norway and Uganda).

To the Stellenbosch University Division of Human Nutrition staff: thank you to Janicke Visser for consistent guidance throughout the Master's course, thank you to all of the support staff, and all lecturers in the Division (particularly Maritha Marais, Lisanne du Plessis, Liesbet Koornhof and Lynette Daniels) for continued and valuable mentorship, guidance and support.

Thank you to NICUS for the use of the voice recorders.

To Dr Donald Skinner, thank you for the training on qualitative research methods (and support during the development of the research protocol); the Qualitative Research Methods for Health Sciences course was invaluable to me in the conducting of this research.

To the Western Cape Government and Klipfontein/Mitchells Plain Substructure, thank you for your support of my project and for the granting of extended study leave. In particular, to Hilary Goeiman, Leslie August, Patti Olckers and Florence Everts-Burger for your support during the time that I was completing the course work component of the Master's Degree.

Thank you to the Mitchells Plain community members who gave freely of their time to assist me in the conducting of my research and who shared their personal experiences with me.

Thank you to Natasha Kassen and Alvina Claassens for their assistance with the data collection and transcription components of the study.

To Mr and Mrs Kotze, thank you for the assistance with translation from English to Afrikaans.

To my previous colleagues in the Western Cape Department of Health and Intergated Nutrition Programme (particularly Quanita Salaam-Davids and Taryn Boonzaaier), to my current colleagues at JB Consultancy (Rosalyn Ford, Lara Sweet and Alison Feeley), to my current employer, Jane Badham, and my dear friend Kim Buchholtz, thank you for the important support, debriefing, ideas and advice that I received from all of you.

To my family (Dad, Isabel, Jessy, Jay, Hannah, Stijn and Gran), thank you for your support and caring during the time that I have been studying.

To my boyfriend, Tiaan, thank you for the unconditional love, support, patience, understanding and belief in me that you have shown during these three challenging years. 


\section{CONTRIBUTIONS BY MEMBERS OF THE RESEARCH TEAM}

\section{Members of the research team and their roles in the study}

\begin{tabular}{|c|c|c|}
\hline Team Member & Affiliation & Role in Study \\
\hline Ms Catherine Pereira & $\begin{array}{l}\text { Stellenbosch University } \\
\text { Western Cape Government }\end{array}$ & $\begin{array}{l}\text { Principal Investigator: } \\
\text { Developed the research idea and } \\
\text { protocol, planned the study, } \\
\text { undertook data collection, analysed } \\
\text { and interpreted the data, drafted } \\
\text { the thesis. }\end{array}$ \\
\hline Prof. Milla McLachlan & $\begin{array}{l}\text { Stellenbosch University } \\
\text { Division of Human Nutrition, } \\
\text { Faculty of Medicine and Health } \\
\text { Sciences }\end{array}$ & $\begin{array}{l}\text { Supervisor: } \\
\text { Provided input at all stages and } \\
\text { revised the protocol and thesis. }\end{array}$ \\
\hline Dr Jane Battersby & $\begin{array}{l}\text { University of Cape Town } \\
\text { African Centre for Cities }\end{array}$ & $\begin{array}{l}\text { Co-supervisor: } \\
\text { Provided input at all stages and } \\
\text { revised the protocol and thesis. }\end{array}$ \\
\hline Dr Donald Skinner & $\begin{array}{l}\text { Stellenbosch University } \\
\text { Faculty of Medical and Health } \\
\text { Sciences }\end{array}$ & $\begin{array}{l}\text { Provided guidance on qualitative } \\
\text { methods for protocol and during } \\
\text { pilot study. }\end{array}$ \\
\hline Ms Natasha Kassen & $\begin{array}{l}\text { Western Cape Government; } \\
\text { Tygerberg Sub-district }\end{array}$ & $\begin{array}{l}\text { Research Assistant: } \\
\text { Assisted with transcriptions and } \\
\text { with some logistics of data } \\
\text { collection. }\end{array}$ \\
\hline Mrs Alvina Classens & $\begin{array}{l}\text { Previously worked for the } \\
\text { Western Cape Government }\end{array}$ & $\begin{array}{l}\text { Note-taker for focus groups; } \\
\text { assisted with logistics for focus } \\
\text { groups. }\end{array}$ \\
\hline
\end{tabular}




\section{TABLE OF CONTENTS}

\section{Contents}

DECLARATION

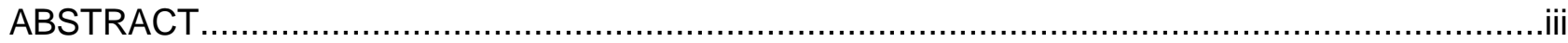

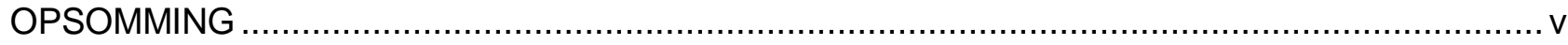

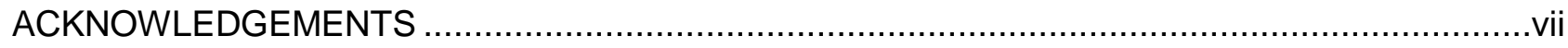

CONTRIBUTIONS BY MEMBERS OF THE RESEARCH TEAM ........................................ viii

Members of the research team and their roles in the study ................................................ vii

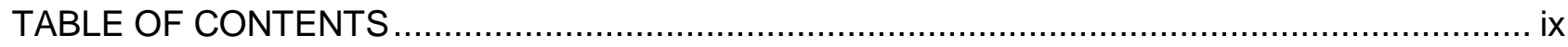

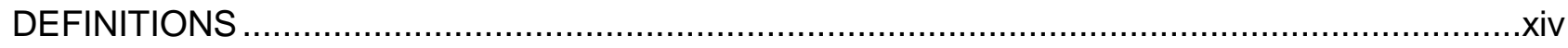

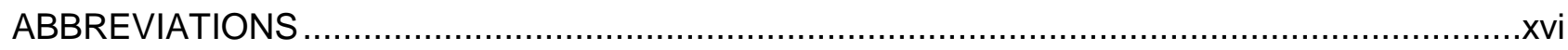

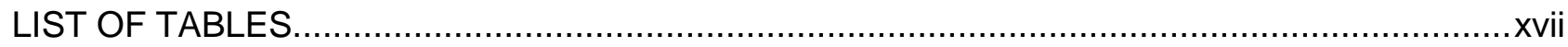

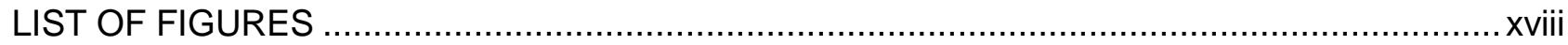

1 LITERATURE OVERVIEW AND MOTIVATION FOR THE STUDY ................................ 19

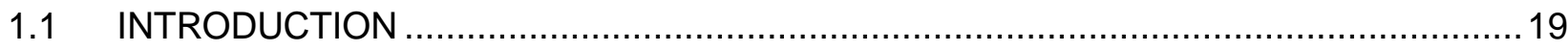

1.2 IMPORTANCE OF ADEQUATE FRUIT AND VEGETABLE CONSUMPTION ................20

1.2.1 Health benefits of adequate fruit and vegetable consumption ................................20

1.2.2 Functions of the nutrients present in fruit and vegetables .................................... 21

1.2.3 Contribution of fruit and vegetable consumption to food security and the human right

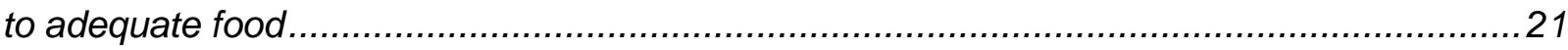

1.3 FOOD AND NUTRITION SECURITY AND FRUIT AND VEGETABLE CONSUMPTION 22

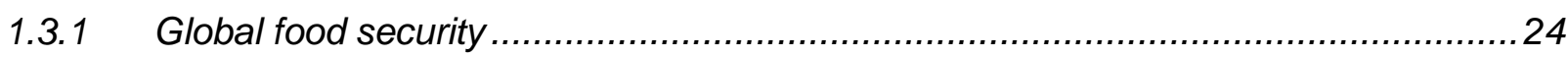

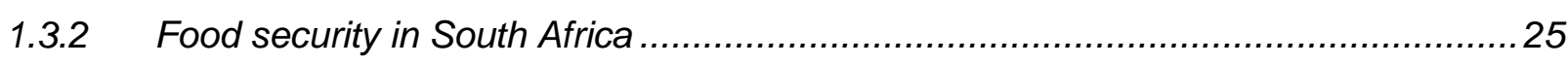

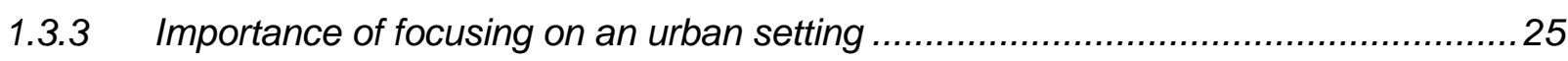

1.3.4 Impact of the food system on fruit and vegetable consumption .............................26

1.4 THE NUTRITION TRANSITION................................................................. 27

1.5 BURDEN OF DISEASE: CAUSES OF MORBIDITY AND MORTALITY ....................... 28

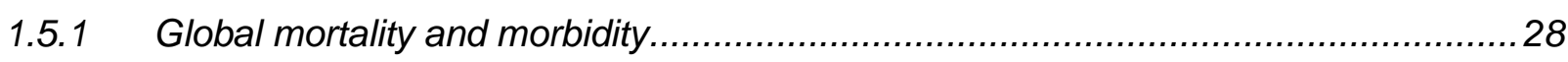

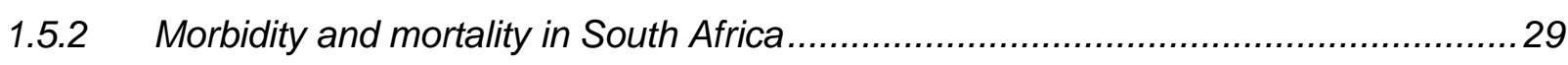

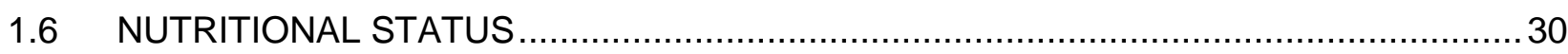

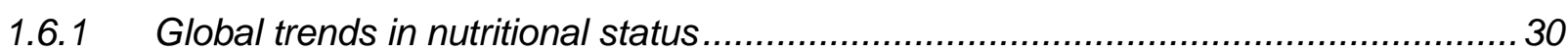

1.6.2 Nutritional status and micronutrient status in South Africa ..................................... 30

1.7 EXISTING GUIDELINES, POLICIES AND RECOMMENDATIONS ON FRUIT AND VEGETABLE CONSUMPTION 
1.7.1 Global evidence-based recommendations on adequate fruit and vegetable consumption

1.7.2 International guideline and strategy documents that include recommendations on fruit and vegetable consumption

1.7.3 National guidelines and strategies that include recommendations on fruit and vegetable consumption

1.8 CURRENT FRUIT AND VEGETABLE CONSUMPTION PATTERNS ........................... 41

1.8.1 Global fruit and vegetable consumption patterns .......................................... 41

1.8.2 Fruit and vegetable consumption patterns in South Africa .................................. 42

1.8.3 General eating patterns in South Africa ...................................................... 42

\subsection{FACTORS THAT POTENTIALLY INFLUENCE FRUIT AND VEGETABLE} CONSUMPTION

1.9.1 Previous research on factors influencing fruit and vegetable consumption: Global . . 43

1.9.2 Previous research on factors influencing fruit and vegetable consumption: South Africa 44

1.9.3 Behaviour change strategies.

1.10 RECOMMENDATIONS OF PREVIOUS RESEARCH ON FRUIT AND VEGETABLE

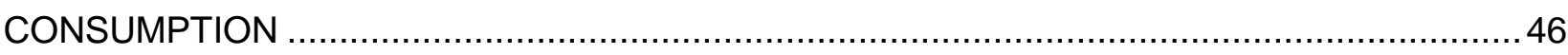

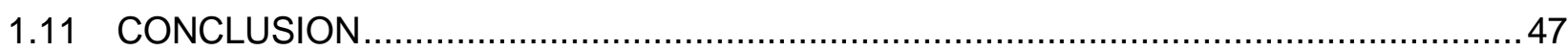

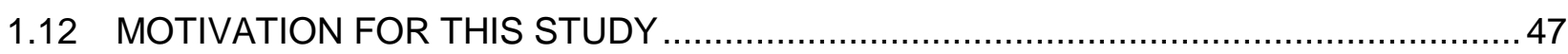

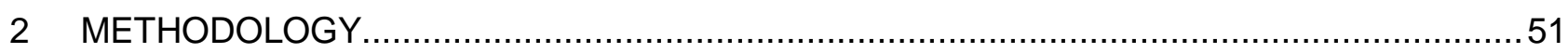

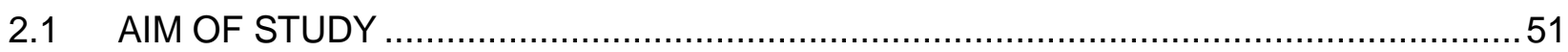

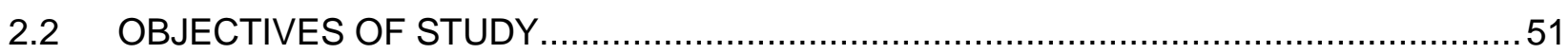

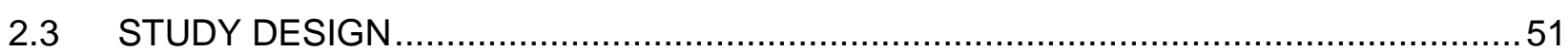

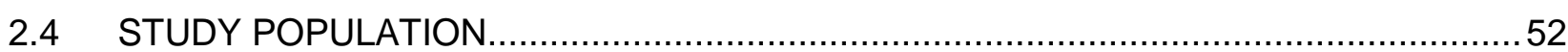

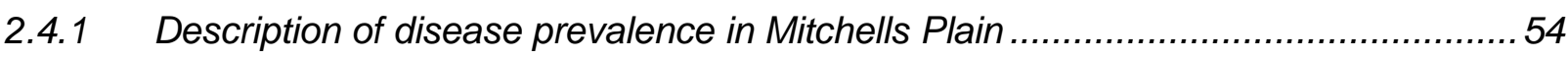

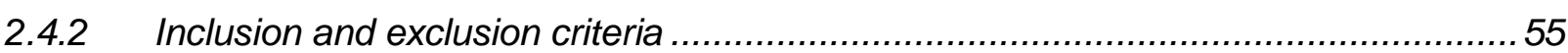

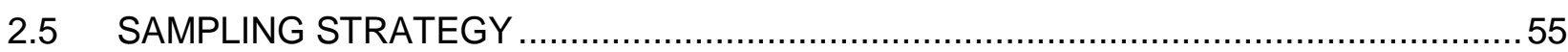

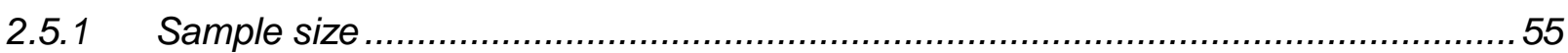

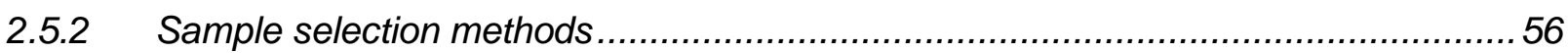

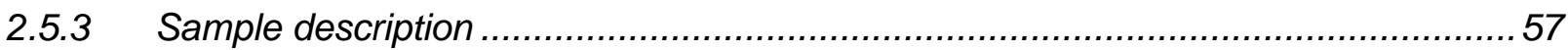

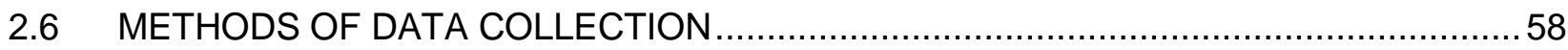

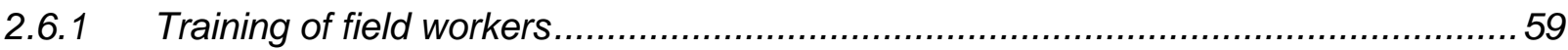

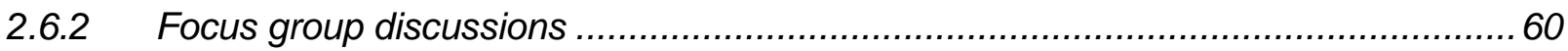

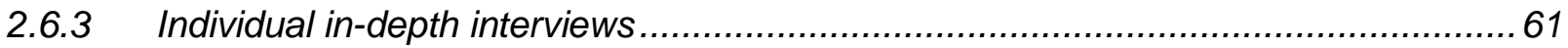

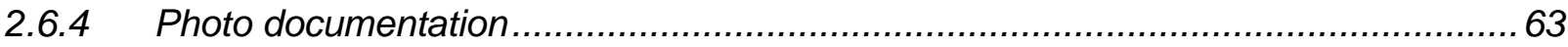

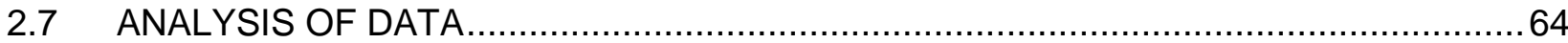




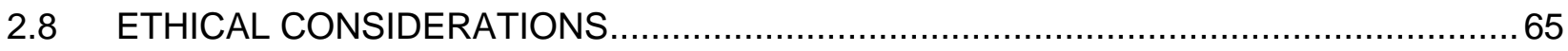

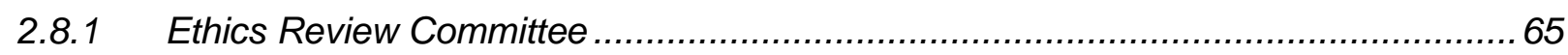

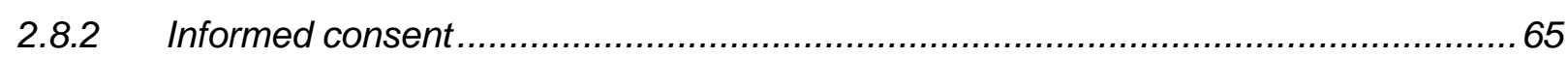

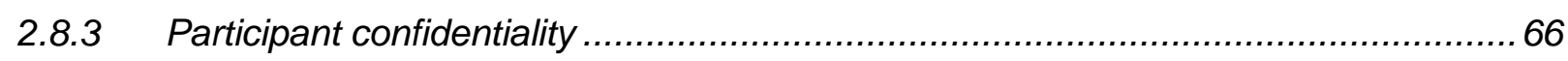

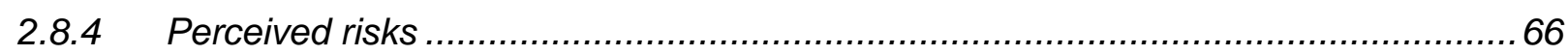

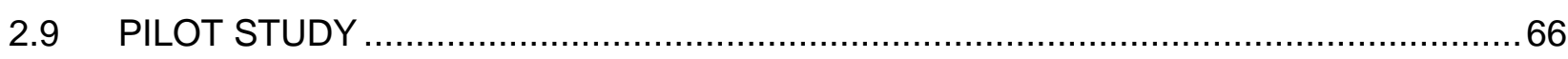

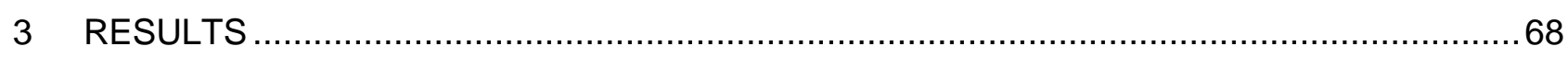

3.1 SOCIO-DEMOGRAPHIC PROFILE OF PARTICIPANTS ........................................ 68

3.2 CURRENT PRACTICES ASSOCIATED WITH FRUIT AND VEGETABLE

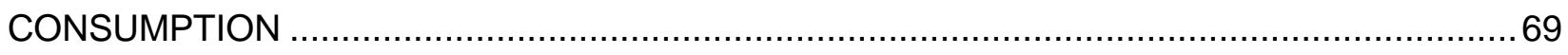

3.2.1 Fruit and vegetable consumption patterns ................................................... 70

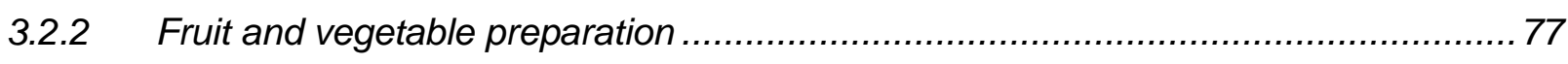

3.2.3 Fruit and vegetable access .................................................................... 81

3.2.4 Changes in eating patterns over the years.................................................. 87

3.3 POSSIBLE EXPLANATIONS FOR CURRENT PRACTICES: UNDERLYING FACTORS AFFECTING FRUIT AND VEGETABLE CONSUMPTION PATTERNS ................................. 92

3.3.1 Possible reasons for low fruit and vegetable consumption ..................................... 92

3.3.2 Individual preference for and aversion to specific fruit and vegetables.................... 99

3.3.3 Other factors that potentially influence fruit and vegetable consumption ................ 101

3.4 ATTITUDES AND PERCEPTIONS INFLUENCING FRUIT AND VEGETABLE

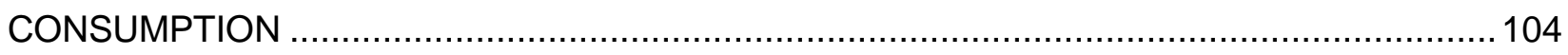

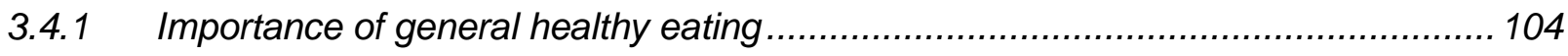

3.4.2 Importance of adequate fruit and vegetable consumption .................................. 106

\subsection{SUGGESTIONS OF WAYS TO INCREASE FRUIT AND VEGETABLE CONSUMPTION} 109

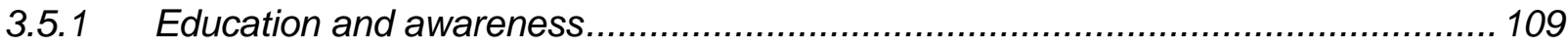

3.5.2 Practical suggestions and food preparation ................................................. 114

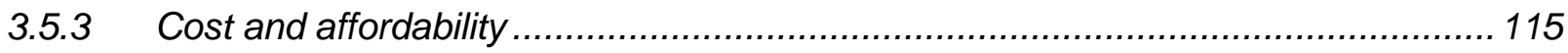

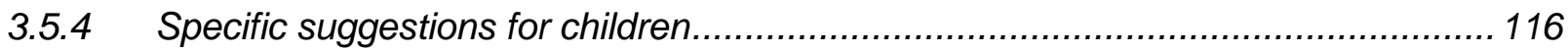

3.6 SUMMARY OF VARIOUS GROUPS' OPINIONS …...................................... 117

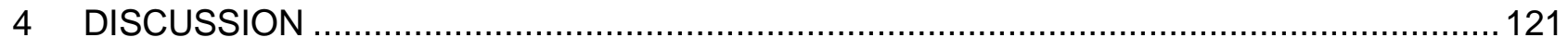

4.1 CURRENT PRACTICES ASSOCIATED WITH FRUIT AND VEGETABLE

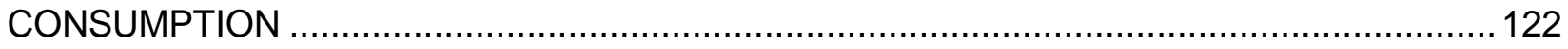

4.1.1 Influence of food availability on fruit and vegetable consumption ........................ 122

4.1.2 Influence of accessibility on fruit and vegetable consumption ............................. 125

4.1.3 Fruit and vegetable consumption and nutritional adequacy............................. 131

4.1.4 Influence of acceptability on fruit and vegetable consumption........................... 132 
4.1.5 Influence of agency on fruit and vegetable consumption.

4.1.6 Summary of underlying factors influencing fruit and vegetable consumption in the Mitchells Plain community.

\subsection{ATTITUDES AND PERCEPTIONS OF ADEQUATE FRUIT AND VEGETABLE} CONSUMPTION

4.2.1 Healthy eating and fruit and vegetable consumption is considered to be important 142

4.2.2 "Fruit and vegetable consumption is important, but not for me". 143

4.2.3 Healthy eating and fruit and vegetable consumption considered to be especially important for children

4.2.4 Some do not regard healthy eating and fruit and vegetable consumption as important 144

4.2.5 Popular perceptions about fruit and vegetable consumption. 144

\subsection{SUGGESTIONS FROM PARTICIPANTS TO INCREASE FRUIT AND VEGETABLE} CONSUMPTION

4.3.1 Practical suggestions provided by participants to increase fruit and vegetable

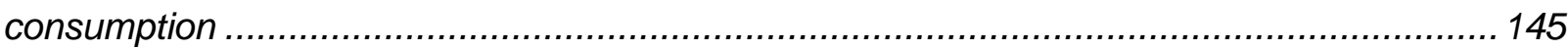

4.3.2 Suggested interventions to increase fruit and vegetable consumption ................... 148

4.4 LIMITATIONS OF THIS RESEARCH STUDY ....................................................... 152

5 SUMMARY CONCLUSIONS AND RECOMMENDATIONS …....................................... 154

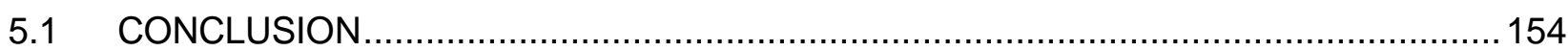

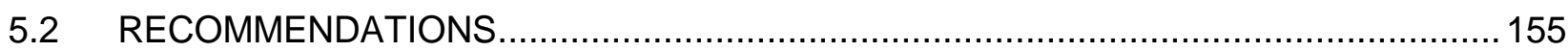

5.2.1 Recommendations for the Mitchells Plain community ....................................... 156

5.2.2 Recommendations for provincial and national policy....................................... 157

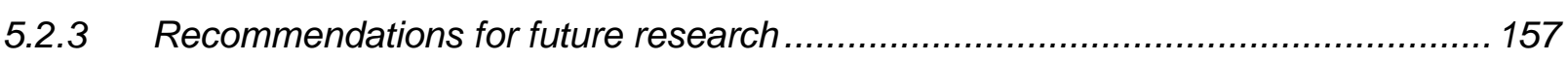

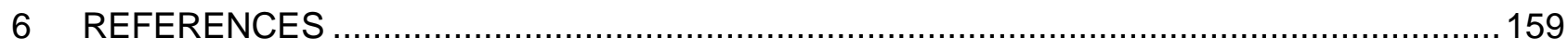

7 ADDENDA

ADDENDUM A: Map of the Cape Metropole District representing the division of the District into eight sub-districts (one of which is the Mitchells Plain sub-district) .................................. 178

ADDENDUM B: Map of the Mitchells Plain area representing the divisions of Mitchells Plain into smaller sub-areas.

ADDENDUM C: Letter to Ward Councillor to request permission to conduct research in Ward 79

ADDENDUM D: Information flyer to recruit participants (English) ..................................... 182

ADDENDUM E / BYLAE E: Information flyer to recruit participants (Afrikaans) / Inligtingsbiljet om

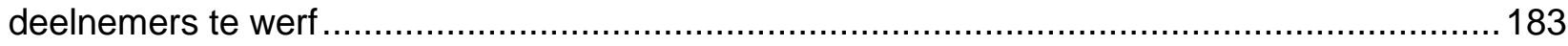

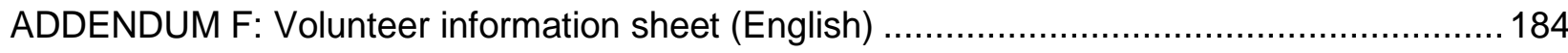

ADDENDUM G (BYLAE G): Volunteer information sheet (Afrikaans) / Inligtingsblad vir vrywilligers. 
ADDENDUM H: Volunteer written informed consent form (English). 189 ADDENDUM I (BYLAE I): Volunteer written informed consent form (Afrikaans) / Vrywilliger geskrewe ingeligte toestemmingsvorm 190

ADDENDUM J: Question guide for focus group discussions and in-depth interviews 191 ADDENDUM K: Information provided to participants 194 ADDENDUM L: Total budget expenditure for research study 199 


\section{DEFINITIONS}

Food and nutrition security: "Food and nutrition security exists when all people at all times have physical, social and economic access to food, which is consumed in sufficient quantity and quality to meet their dietary needs and food preferences, and is supported by an environment of adequate sanitation, health services and care, allowing for a healthy and active life." ${ }^{1}$

Food security: When all people, at all times, have physical and economic access to sufficient, safe and nutritious food to meet their dietary needs and food preferences for an active and healthy life. ${ }^{2}$ Nutritious foods can be described as having good quality (rich in micronutrients) and nutritional adequacy.

Fruit: Most definitions specify that fruit is the fleshy part around the seeds of a plant, has a sweet taste and is most often eaten raw as a dessert or snack.

Human right to adequate food: The right to adequate food is realised "when every man, woman and child, alone or in community with others, has physical and economic access at all times to adequate food or means for its procurement". ${ }^{3}$ Adequate food is food that is available in sufficient quantity and quality. ${ }^{3}$

Human rights-based approach: This refers to the use of human rights principles to guide "all phases of the programming process, including assessment and analysis, programme planning and design, implementation, monitoring and evaluation". ${ }^{4}$ These human rights principles include: universality and inalienability; indivisibility; inter-dependence and inter-relatedness; nondiscrimination and equality; public participation and social inclusion; accountability and the rule of law. Furthermore, a human rights-based approach includes the implementation of programmes to support the capacity of national duty-bearers to achieve their human rights obligations and to assist community members and rights holders to claim their rights. ${ }^{4,5}$

Nutrition security: Incorporates the components of appropriate utilisation of food, care and feeding practices and adequate sanitation and health, above and beyond access to sufficient food, in order to attain optimal nutritional status. ${ }^{1,6}$

Nutrition transition: Worldwide the so-called 'nutrition transition' is characterised by high rates of overweight and obesity, as well as undernutrition (including micronutrient deficiencies), also 
referred to as the 'double burden of malnutrition'. Sometimes this phenomenon is observed within the same community and even the same household, and is the consequence of changes in dietary and lifestyle patterns. South Africa appears to display the classic signs and symptoms of having undergone the nutrition transition. ${ }^{7}$

Vegetables: Definitions of 'vegetable' vary significantly between countries and regions. However, many definitions specify that vegetables are parts of a plant, are eaten cooked or raw with main meals, have different colours, are high in nutritional value and are good for health. Differences in definitions occur with respect to the inclusion or exclusion of starchy tubers, beans, lentils and corn.

Most fruit and vegetables are accurately identified as such, but there are two groups that can sometimes be disputed and need clarification. For the purposes of this study:

- Pulses/dry legumes (e.g. lentils and dry beans) will be excluded as vegetables, but fresh peas and green beans will be included as vegetables.

- Potatoes and sweet potatoes will be excluded as vegetables, due to their high starch content, and consistent with World Health Organisation (WHO) recommendations. ${ }^{8}$

For the purposes of this study, fruit and vegetables will not be differentiated according to fresh, frozen, canned or processed. However, during the group and individual discussions, certain questions were asked surrounding preparation methods and the form in which fruit and vegetables are purchased. 


\section{ABBREVIATIONS}

DALYs Disability-adjusted life years

DOH Department of Health

FAO Food and Agricultural Organisation

FBDG Food-based Dietary Guideline

FGD Focus Group Discussion

HREC Health Research Ethics Committee

ICESCR International Covenant on Economic, Social and Cultural Rights

IDI Individual In-Depth Interview

LDL Low Density Lipoprotein

LMIC Low and Middle Income Countries

MDG Millennium Development Goal

NCD Non-communicable disease

NFCS National Food Consumption Survey

PI Principal Investigator

SACRA South African Comparative Risk Assessment Survey

SANHANES South African National Health and Nutrition Examination Survey

UNSCN United Nations Standing Committee on Nutrition

VAD Vitamin A Deficiency

WHO World Health Organisation 


\section{LIST OF TABLES}

Table 1.1: Summary of dimensions and components of food security and nutrition security 23

Table 1.2: Comparison between the 2001 Food-based dietary guidelines and the 2012 Guidelines

for healthy eating 37

Table 2.1: Description of the Mitchells Plain population demographics 54

Table 2.2: Summary of methods used. 58

Table 3.1: Socio-demographic characteristics of participant selected for focus group discussions 68

Table 3.2: Description of participants selected for individual in-depth interviews 69

Table 3.3: Meals and dishes made on special occasions or for religious events 74

Table 3.4: Food eaten predominantly in winter or summer seasons .76

Table 3.5: List of commonly prepared vegetable dishes. 80

Table 3.6: List of commonly prepared fruit dishes 81

Table 3.7: Overview of the different groups interviewed and their opinions (in brief) on the main topics discussed

Table 4.1: Summary of barriers to adequate fruit and vegetable consumption 141

Table 4.2: Summary of factors that facilitate fruit and vegetable consumption 142

Table 7.1: Summary of budget expenditure 199 


\section{LIST OF FIGURES}

Figure 1.1: Framework displaying determinants and overlap of food security and nutrition security 23

Figure 1.2: The South African Department of Health Food Guide $49,50,51,52$ 37

Figure 3.1: The fruit and vegetables sold at the entrance to 'Mr X's' store 83

Figure 3.2: Fruit and vegetables sold by an informal vendor on a Mitchells Plain street corner ..... 84

Figure 3.3: Advertisement for a take-away establishment on a Mitchells Plain property wall......... 91

Figure 3.4: A plate of food dished up for the evening meal at the pastor's assistant's house......... 95

Figure 3.5: The food options available to learners at a Mitchells Plain primary school tuck shop 102 Figure 3.6: The fridge of a Mitchells Plain frail care institution.

Figure 3.7: A Department of Basic Education Life Skills text book displaying that healthy diet, including fruit and vegetables, is included as part of the curriculum

Figure 3.8: A Department of Basic Education Mathematics text book, using fruit and vegetables as examples in tasks or activities 


\section{LITERATURE OVERVIEW AND MOTIVATION FOR THE STUDY}

\subsection{INTRODUCTION}

There is substantial evidence to support the benefits of adequate fruit and vegetable consumption..$^{9,10,11,12,13}$ Fruit and vegetable consumption contributes to ensuring the nutritional adequacy of food consumed. Nutritional adequacy of food is one of the components that need to be fulfilled for the realisation of the human right to adequate food, ${ }^{3}$ thus leading to the achievement of food and nutrition security. Adequate fruit and vegetable consumption contributes to an optimal nutritional status and improved nutritional status can contribute to reduced morbidity and mortality. ${ }^{14,15,16,17}$ Most people do not achieve the recommended intake of five fruit and vegetables per day. ${ }^{18}$ There are various strategies that have aimed to increase fruit and vegetable intake in South Africa, such as the national Food-based dietary guidelines ${ }^{19}$ and the 5-a-day for Better Health Trust campaign. ${ }^{20}$ Yet despite these and other existing strategies, micronutrient intakes (which are largely influenced by fruit and vegetable consumption) in South Africa continue to remain low. ${ }^{21}$

To identify effective and long-term strategies to increase fruit and vegetable intake, it is important to investigate the underlying factors that contribute to why individuals do not consume the recommended amount of fruit and vegetables on a daily basis. Involving the community members in the process of identifying perceived barriers to and facilitating factors of fruit and vegetable consumption may contribute to the design of more focused, appropriate and sustainable nutrition intervention programmes, while ensuring that the research is conducted with a human rights-based approach. There has been some research conducted globally, and some limited research in South Africa, to identify the underlying factors that affect fruit and vegetable consumption. ${ }^{22,23,24,25,26,27}$ Due to gaps in the currently available evidence, the need was identified to conduct qualitative research in order to gain a deeper understanding of the many complex factors that are involved in determining why people do or do not consume an adequate amount of fruit and vegetables. It was decided to conduct this research in a community in the Western Cape in South Africa (Mitchells Plain), where high rates of communicable and non-communicable disease ${ }^{28,29}$ are influenced by, and themselves influence, the nutritional status of individuals. The study was informed by a human rights-based approach which relied on the direct engagement of community members and the inclusion of rights holders in the research, ${ }^{4,5}$ in order to ensure that a genuine understanding of the factors that influenced fruit and vegetable consumption in this community was achieved. 
This research study aimed to describe some of the underlying factors that influenced fruit and vegetable consumption in an area of the Mitchells Plain sub-district, by engaging with its community members in a participatory manner.

\section{The following was the main research question that guided this study:}

What are the factors that influence fruit and vegetable consumption of individuals and households in an area $^{a}$ of Mitchells Plain; and why do people eat fruit and vegetables in the ways that they do?

The literature overview uses available evidence on the importance of adequate fruit and vegetable consumption for food and nutrition security and health outcomes, as a rationale for greater attention to increasing fruit and vegetable consumption. Following this, evidence is presented on the nutrition transition and the escalating burden of disease related to nutritional factors, both globally and in South Africa, to further highlight the importance of fruit and vegetable consumption. A summary of existing global and national guidelines and policies on fruit and vegetable consumption is included. The literature overview then provides an assessment of available information on current fruit and vegetable consumption and the factors influencing it, and concludes by outlining gaps in available evidence and providing a rationale for the current study.

\subsection{IMPORTANCE OF ADEQUATE FRUIT AND VEGETABLE CONSUMPTION}

\subsubsection{Health benefits of adequate fruit and vegetable consumption}

There is substantial evidence to support the many benefits of optimal fruit and vegetable consumption. ${ }^{9,10,11,12,13}$ Fruit and vegetables contain many vitamins, minerals, fibre and other components which, as well as contributing to overall good health, are beneficial in the protection against cardiovascular disease $\mathrm{e}^{30,31}$ and certain cancers, ${ }^{12,30}$ and can result in improved gastrointestinal health and vision, improved bone health, and reduced risk of stroke, diabetes, anaemia, gastric ulcers, rheumatoid arthritis, and other chronic diseases. ${ }^{12}$ A World Health Organisation (WHO) study conducted in 2000 estimated that, globally, 2.7 million deaths in that year (i.e. $4.9 \%$ of deaths) were attributable to low fruit and vegetable consumption, and that 26.7 million (1.8\%) disability-adjusted life years (DALYs) were lost due to low fruit and vegetable consumption. ${ }^{32}$ Low fruit and vegetable consumption is ranked as the $12^{\text {th }}$ main risk factor for mortality in the world and the $16^{\text {th }}$ risk factor for DALYs lost. ${ }^{33}$ Therefore, there is sufficient evidence to justify a need for increased consumption of fruit and vegetables.

\footnotetext{
${ }^{a}$ Because the entire area that is contained in the Mitchells Plain sub-district is so big and includes the areas of Mitchells Plain, Crossroads and Philippi, it was decided to focus on Ward 79: the Beacon Valley, Eastridge and Mitchells Plain Central Business District areas or suburbs of Sub-council 12 (Mitchells Plain).
} 


\subsubsection{Functions of the nutrients present in fruit and vegetables}

Plant foods contain many bioactive components, with a variety of actions that are potentially linked to chronic disease prevention. ${ }^{34}$ The exact functions of all of the components of fruit and vegetables have not yet been fully understood and exhaustively investigated. ${ }^{12}$ Some functions of fruit and vegetable components include disease-related molecular processes, signalling pathways and cellular markers, ${ }^{11}$ while various components of whole fruit and vegetables contribute to their overall benefits. ${ }^{12}$ The vitamins, minerals and other nutrients (such as fibre and phytochemicals) found in fruit and vegetables are sometimes collectively referred to as phytonutriceuticals/phytonutrients and in some instances have been shown to offer long-term health benefits that cannot be found in nutritional supplements. ${ }^{35}$

A high fruit and vegetable intake has been shown to increase the stability of lipids towards oxidative damage, due to an increase in the activity of the enzyme glutathione peroxidase (which has an anti-oxidant function, protecting against free radical damage) in erythrocytes. ${ }^{34}$ Fruit and vegetable consumption also leads to decreased levels of total and low density lipoprotein (LDL) cholesterol, due to the function of certain components that modulate cholesterol synthesis and inhibit cholesterol absorption. ${ }^{34}$ This explains some of the protective effects of fruit and vegetable consumption against cardiovascular disease. Mechanisms by which fruit and vegetable components reduce cancer risk include the scavenging of free radicals, regulation of gene expression in cell proliferation and apoptosis, stimulation of the immune system and regulation of hormone metabolism. ${ }^{11}$ Specific nutrients found in fruit and vegetables have also been shown to demonstrate beneficial functions; for example, potassium contributes to blood pressure regulation, and dietary fibre contributes to the improvement of bowel transit, lowering of cholesterol, managing of blood glucose concentrations and transporting of minerals and phytochemicals through the gastro-intestinal tract. ${ }^{12}$ Fruit and vegetables, which are rich in micronutrients, also have a role to play in the management of communicable diseases such as HIV and TB, where individuals often suffer from micronutrient malnutrition. ${ }^{36}$ Fruit and vegetables therefore have many diverse and specific functions in the maintenance of health and prevention and management of disease.

\subsubsection{Contribution of fruit and vegetable consumption to food security and the human right to adequate food}

The adequate consumption of fruit and vegetables can contribute to the achievement of food and nutrition security as well as the realisation of the human right to adequate food. General Comment 12 (published in 1999) of the United Nations' 1966 International Convention on Economic, Social and Cultural Rights (ICESCR) defines the right to adequate food as being realised "when every man, woman and child, alone or in community with others, has physical and economic access at all times to adequate food or means for its procurement". ${ }^{3}$ General Comment 12 further describes the 
concept of 'adequate food' as being food that is available in sufficient quantity and quality. The optimal consumption of fruit and vegetables contributes to the quality, and therefore the adequacy, of food consumed. According to the Food and Agricultural Organisation's (FAO's) Voluntary guidelines to support the progressive realisation of the right to adequate food in the context of national food security (hereafter referred to as the Right to food guidelines), "Food security exists when all people, at all times, have physical and economic access to sufficient, safe and nutritious food to meet their dietary needs and food preferences for an active and healthy life." Nutritious foods can be described as having good quality (rich in micronutrients) and nutritional adequacy. Adequate fruit and vegetable consumption is essential for the quality and nutritional adequacy component of food security to be met.

\subsection{FOOD AND NUTRITION SECURITY AND FRUIT AND VEGETABLE CONSUMPTION}

Adequate fruit and vegetable consumption can contribute to the achievement of food and nutrition security, by ensuring an optimal intake of micronutrients and fibre (amongst other beneficial components), and therefore contribute to the 'food safety and quality' component of the utilisation dimension of food security, the 'care and feeding practices' component of both food and nutrition security and the 'access to adequate food' (see Table 1.1 and Figure 1.1)..$^{6,37,38}$ There has been a shift in the way that food security is conceptualised. Previously, food security was often assessed in terms of total availability of food, without sufficient attention or consideration given to accessibility and quality of the diet. ${ }^{40}$ Furthermore, given the focus on food production, often when food security strategies were promoted, gardens and home production were the first actions that were promoted, and rural food insecurity was often seen as the biggest problem. However, there is growing understanding that food security is much more complex than the manner in which it was initially treated; ${ }^{40}$ food and nutrition security needs to be considered and urban (as opposed to rural) food insecurity has become more of a predominant problem. The promotion of food gardens is not the only solution and one size does not fit all. ${ }^{41} \mathrm{~A}$ strategy that has shown success in Brazil involved the development of an alternative food system, whereby a variety of complementary policies and strategies (of which, support to urban agriculture was just one of many, that included subsidised food sales, food and nutrition assistance, supply and regulation of food markets, education for food consumption and others) were implemented over time, driven by government structures but with strong partnerships from civil society and the private sector, resulting in a unique form of governance for food security. ${ }^{42}$ 
Table 1.1: Summary of dimensions and components of food security and nutrition security

\begin{tabular}{|c|c|c|}
\hline \multicolumn{2}{|c|}{ FOOD SECURITY ${ }^{37,38}$} & NUTRITION SECURITY ${ }^{6}$ \\
\hline Dimensions & Determinants & Dimensions \\
\hline Availability of food & $\begin{array}{l}\text { Domestic production } \\
\text { Import capacity } \\
\text { Food stocks } \\
\text { Food aid }\end{array}$ & Access to adequate food \\
\hline Access to food & $\begin{array}{l}\text { Poverty / purchasing power } \\
\text { Transport and market infrastructure } \\
\text { food distribution }\end{array}$ & Care and feeding practices \\
\hline Utilisation & $\begin{array}{l}\text { Food safety and quality } \\
\text { Clean water } \\
\text { Health and sanitation } \\
\text { Care and feeding }\end{array}$ & Sanitation and health \\
\hline Stability & $\begin{array}{l}\text { Weather variability } \\
\text { Price fluctuations } \\
\text { Political factors } \\
\text { Economic factors }\end{array}$ & \\
\hline
\end{tabular}

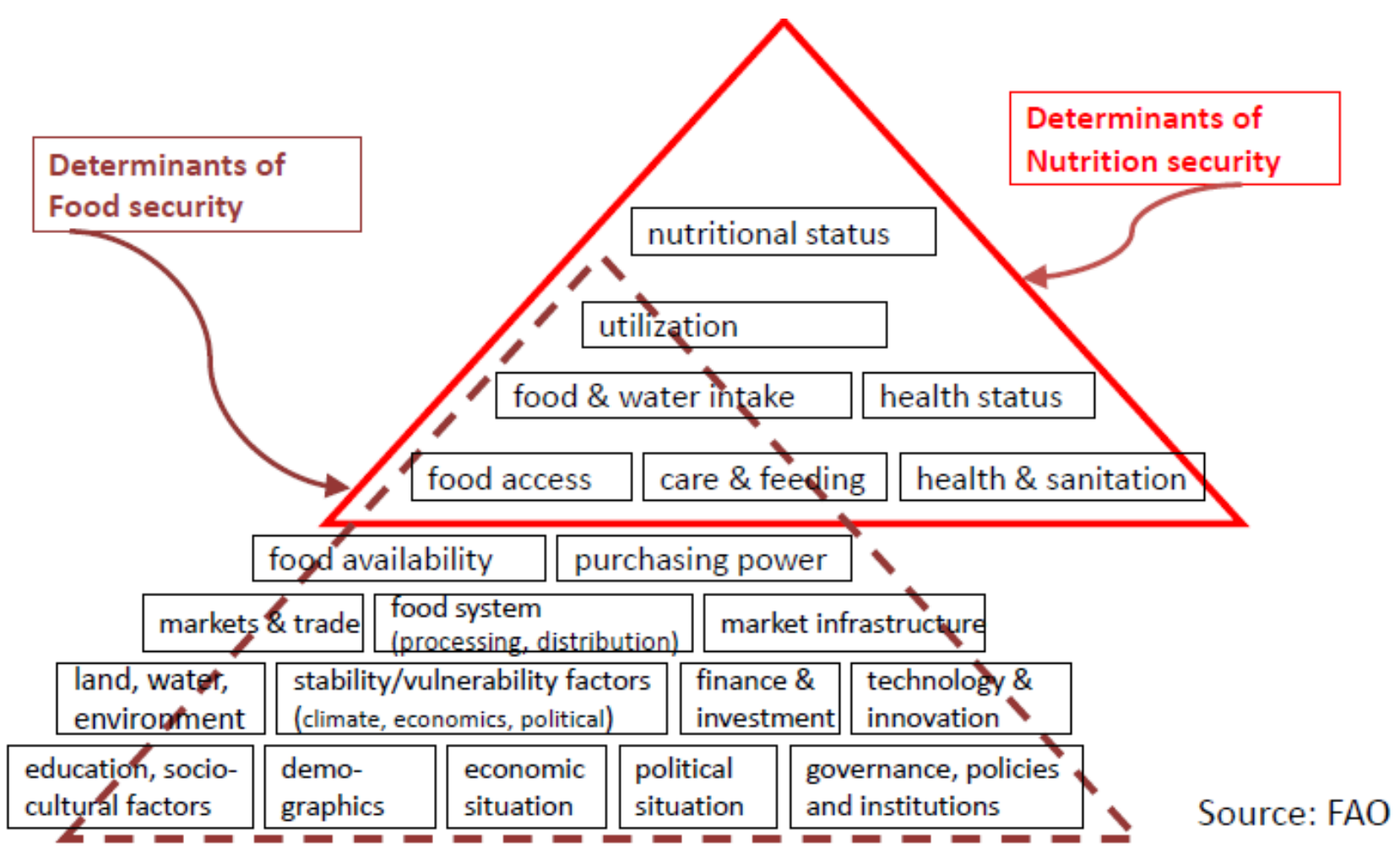

Figure 1.1: Framework displaying determinants and overlap of food security and nutrition security 
Wüstefeld proposed the following definition for food and nutrition security at a United Nations Standing Committee on Nutrition (UNSCN) meeting in March 2013:

Food and nutrition security exists when all people at all times have physical, social and economic access to food, which is consumed in sufficient quantity and quality to meet their dietary needs and food preferences, and is supported by an environment of adequate sanitation, health services and care, allowing for a healthy and active life. ${ }^{1}$

The Centre for Studies in Food Security at Ryerson University, Toronto, Canada, describes five components of food security: ${ }^{43}$ availability, accessibility, acceptability, adequacy and agency. Availability of food refers to when food is available in sufficient amounts, at all times, to meet people's needs. Accessibility is realised when all people have both physical and economic access to food at all times. Adequacy refers to food that is nutritious, diverse and safe, and that meets the needs to maintain health, as well as being produced in a manner that is environmentally sustainable. Acceptability means that food should be culturally acceptable, and produced and obtained in a manner that does not compromise people's dignity, self-respect and human rights. Finally, an important component that is not addressed by most definitions of food security, includes that of agency. Agency occurs when people are empowered by the food system and food environment, when policies and processes (driven by government and/or civil society) are implemented and accessible, in order to enable food security. The dimension of agency allows for the integration of communities' knowledge of the food system into the policies and processes that shape the food environment. ${ }^{43}$ This definition of food security, according to these five components, is useful because it allows for engagement with some of the wider systemic drivers of food security, and also ensures that food security is not simply discussed in terms of total amounts of food.

\subsubsection{Global food security}

In 2009, FAO projected that over a billion people globally suffer from hunger. ${ }^{44}$ This has been reported to have fallen to 842 million during 2011-2013, reflecting a prevalence of $12 \%$ of people globally that suffer from hunger. ${ }^{40}$ This suggests that progress is being made to reach MDG 1 of eradicating extreme hunger and poverty. However, there are differences across regions and even though progress is being made, according to the 2013 FAO State of Food Insecurity in the World report, Africa as a region has the highest rates of hunger, at $21.2 \%$, with Sub-Saharan Africa having the highest levels in the world, at $24.8 \% .{ }^{40}$ Food security is, however, more complex than simply measuring levels of hunger, and more comprehensive food security indicators are starting to be reported on, that cover the various dimensions of food security (such as the percentage of 
dietary energy supplied from cereals, roots and tubers, and average protein supply, as a measure of availability, or prevalence of anaemia among pregnant women and children, as a measure of utilisation) as is demonstrated in the 2013 State of Food Insecurity in the World Report. ${ }^{40}$

\subsubsection{Food security in South Africa}

The 1999 National Food Consumption Survey (NFCS) reported that only 25\% of households in South Africa appeared to be food secure ${ }^{45}$ while the 2013 South African National Health and Nutrition Examination Survey (SANHANES) reported $43.6 \%$ to be food secure and $26 \%$ of the South African population to be food insecure. ${ }^{7}$ The largest numbers of food insecure households were found in urban and rural informal areas. The Western Cape was reported to have the lowest prevalence of food insecurity, at $16.4 \%{ }^{7}$ National surveys that have measured food security have shown that food security in South Africa has improved since 1999, but the 2012 Global Hunger Index still rates South Africa as having a 'moderate' problem with regard to the severity of hunger. ${ }^{46}$ Although South Africa does have national food security, there is still a problem of household food insecurity. ${ }^{47}$ Research on the state of food insecurity in urban areas in southern Africa, including three different communities of Cape Town (one of which, Philippi, is adjacent to the Mitchells Plain area) showed that $80 \%$ of households in these three communities were either moderately or severely food insecure, and dietary diversity was also found to be poor. ${ }^{48}$ The study concluded that underlying factors affecting urban food insecurity are many and varied, and that alternative approaches need to be sought to reduce levels of food insecurity. ${ }^{48}$

\subsubsection{Importance of focusing on an urban setting}

Globally, populations are migrating from rural areas to cities and urban areas; with $50 \%$ of the world's population now residing in urban areas. ${ }^{49}$ South Africa is following this trend, with more than $60 \%$ of the population now urbanised. ${ }^{50}$ Urbanisation results in a change in health and lifestyle patterns that have been associated with negative health outcomes. More research is being conducted that attempts to understand factors that affect urban food insecurity. ${ }^{51,52}$ The UNSCN's Sixth report on the World Nutrition Situation of 2010, when discussing sustainable food and nutrition security, reported that "For the urban poor, low incomes and subsequent inability to access adequate supplies of safe and nutritious food threaten food and nutrition security. Volatile food prices and rising unemployment exacerbate the problem.." ${ }^{44}$ Therefore, individuals living in an urban setting face unique challenges with regard to the food choices that they have available to them, and unique challenges in their attempt to achieve food and nutrition security. ${ }^{53}$

Urban households have a lower capacity to produce their own food, in comparison to their rural counterparts, and are therefore more dependent on purchasing their food, which in turn makes 
them more vulnerable to food prices and food markets. ${ }^{53}$ An increase in urbanisation also contributes to the nutrition transition (described in more detail in section 1.4 Nutrition transition). Urban households allocate a very high proportion of their income to food ${ }^{54}$ and when people are under severe financial strain, often their dietary quality and dietary diversity is weakened. ${ }^{53}$ The 2012 UNSCN Statement on nutrition security for urban populations called for "increased attention, awareness and research on urban nutrition as well as for an effective engagement and intersectoral and multi stakeholder collaboration leading to an efficient use of urban resources". ${ }^{53}$ Attempting to understand why individuals in an urban setting do or do not consume an adequate amount of fruit and vegetables would therefore be important.

\subsubsection{Impact of the food system on fruit and vegetable consumption} Schuftan and Holla, in the 2012 Right to Food and Nutrition Watch, stated:

Good nutrition is about accessing a healthy diet that includes a wide range of fruit and vegetables which, in most cases, are more expensive than (fast) foods rich in oils, salt, sugars and fats. Any society where a healthy diet is more expensive than an unhealthy diet is a society that must mend its food system. ${ }^{55}$

When the nutrition transition and double burden of disease is explained, a characteristic of these changes, is that often, highly processed and high fat, high salt and high sugar foods become more widely available and cheaper. The food system refers to the entire food value chain, including agriculture, food production, food processing, food distribution, food consumption and food waste. ${ }^{56}$ Recently, it has been emphasised that when strategies are developed to address food insecurity, all stages of the food value chain need to be considered, including the minimisation of post-harvest losses, excessive consumption and waste. ${ }^{55,57}$

In South Africa, there has been a move to analyse the role of the food system and its contribution to food insecurity. Drimie and McLachlan suggest that innovative solutions need to be identified, because current strategies are not addressing the complex challenges of food security in South Africa. ${ }^{58}$ Innovative strategies include, amongst others, the engagement of stakeholders as a way in which to understand the underlying structural factors related to food insecurity. ${ }^{58}$ Research of this nature is currently being conducted in South Africa by Stellenbosch University's Food Security Initiative ${ }^{58,59}$ Furthermore, the Southern African Food Lab is an organisation that is attempting to bring about change to the food system, and its aim is to "bring together diverse role-players with passion and influence in the regional food system, in order to identify and pilot innovative means of enhancing long-term food security". ${ }^{60}$ Fruit and vegetable consumption needs to be 
understood as it exists as part of the entire food system, and there are initiatives that are currently underway in South Africa that attempt to do this. This will be briefly described in the Discussion.

\subsection{THE NUTRITION TRANSITION}

Worldwide the so-called 'nutrition transition' is characterised by high rates of overweight and obesity, as well as undernutrition (including micronutrient deficiencies), and is also sometimes referred to as the 'double burden of malnutrition'. Sometimes this phenomenon is observed within the same community and even the same household, and is the consequence of change in dietary and lifestyle patterns. South Africa appears to display the classic signs and symptoms of having undergone the nutrition transition. ${ }^{7}$ Possible reasons for nutrition transitions have been described and are interrelated. ${ }^{61}$ Physical activity levels have decreased due to many lifestyle factors and this is having a detrimental effect on health. Dietary changes that have occurred include a decrease in the so-called 'traditional diets' that were usually comprised of legumes, unrefined carbohydrates and fruit and vegetables, and an increase in fat and sugar consumption (due to an increase in the availability of cheap oils and an increased added sugar intake in diets), as well as increased production and consumption of animal source foods. ${ }^{44,61}$ These dietary changes have been influenced by changes in the food system, with improved technologies for food production, distribution and marketing, as well as the evolution of the supermarket and globalisation. ${ }^{61}$ Although these changes have come with some positive benefits, they have also been a contributor to the current global burden of disease. In some situations, economic growth and an increase in household income leads to more unhealthy food choices, yet poverty also contributes to food insecurity and can result in food choices being made based on the lowest cost and most filling options, usually without regard for nutritional adequacy. ${ }^{62}$

It has been established that malnutrition early on in the lifecycle combined with certain environmental factors is associated with adult obesity and the development of NCDs. ${ }^{16}$ An underweight mother is more likely to give birth to a stunted child. ${ }^{16}$ Poor foetal growth, being born with low birth weight, and stunting early on in childhood is associated with rapid weight gain later in childhood, an increased risk of developing obesity and an increased risk of developing NCDs later in life. ${ }^{16,63,64,65}$ Therefore, many recommendations are calling for preventative interventions that focus on the 'first 1000 days' (the critical 1000-day window period from conception through pregnancy and up to two years of life), when rapid physical and mental development takes place. ${ }^{16,66,67}$ Furthermore, research shows that maternal obesity is associated with adverse health outcomes, including increased all-cause mortality and premature death of adult offspring, as well as increased risk of obesity, cardiovascular disease, and diabetes later on in life. ${ }^{68,69}$ The nutrition 
transition and resultant 'double burden of malnutrition' is therefore a complex problem, with many interrelated causes, and requires innovative interventions.

Globally, many interventions have been recommended and attempted to reduce and reverse the nutrition transition with various levels of success. These include the direct provision of food to vulnerable groups, a focus on the food system (including private sector initiatives), the implementation of healthy public policies (including marketing and labelling regulations for unhealthy foods) and trade regulations. ${ }^{61}$ Adequate fruit and vegetable consumption could contribute to a reduction in both under- and over- nutrition, reduction in micronutrient deficiencies and an improvement in household food security, making the search for and implementation of sustainable interventions in this field so much more important.

\subsection{BURDEN OF DISEASE: CAUSES OF MORBIDITY AND MORTALITY}

\subsubsection{Global mortality and morbidity}

Globally, communicable, maternal, neonatal, and nutritional causes accounted for $24.9 \%$ of the 52.8 million total deaths at all ages in 2010 (this number had decreased steadily from 1990); whereas non-communicable diseases (NCDs) contributed 65.5\% (these have shown an increase since 1990), and injuries contributed $9.6 \%$, of mortality. ${ }^{70}$ The leading risks for global mortality are high blood pressure (13\%), tobacco use (9\%), high blood glucose $(6 \%)$, physical inactivity (6\%), and overweight and obesity $(5 \%){ }^{70}$ These risk factors have all contributed to increasing the incidence of chronic NCDs such as heart disease, diabetes and cancers. They affect countries across all income groups; high, middle and low.

Globally, health risks are in transition; populations are ageing, due to, amongst other factors, successes against infectious diseases, yet at the same time, patterns of physical activity and food, alcohol and tobacco consumption are changing and are having a negative impact on health. ${ }^{33}$ Lowand middle-income countries (LMIC) are now facing a 'double burden' of increasing NCDs, together with continued communicable diseases that traditionally affected the poor. Understanding the role of all of the inter-related risk factors involved in both communicable diseases and NCDs is important in order to develop clear and effective strategies for the improvement of global health. ${ }^{33}$ An unhealthy diet is considered to be a common, preventable, modifiable and behavioural risk factor for lifestyle related disease. ${ }^{71}$ The WHO Global strategy for the prevention and control of NCDs considers tobacco use, unhealthy diet and physical inactivity to be the three main risk factors for NCDs. ${ }^{71} \mathrm{~A}$ healthy diet, including the adequate consumption of fruit and vegetables has an important role in the prevention of many communicable and non-communicable diseases and therefore contributes to reducing morbidity and mortality. 


\subsubsection{Morbidity and mortality in South Africa}

South Africa is classified as a middle income country ${ }^{72}$ and similarly to other LMIC is facing an increase in the prevalence of many of the NCDs, as well as experiencing a high burden of communicable diseases. Some have described South Africa as facing a 'quadruple burden of disease' referring to the combination of high rates of HIVIAIDS and TB; maternal and child mortality; intentional and non-intentional injuries; and NCDs. ${ }^{73,74}$ South Africa's national HIV prevalence (of antenatal women aged 15 to 49 years) was $29.4 \%$ in $2008^{75}$ and the number of reported TB cases was 301079 in $2007 .{ }^{76}$ In 2000, NCDs were responsible for about 40\% of all deaths and approximately $35 \%$ of the burden of disease. ${ }^{77}$ Latest data has reported South Africa's under-five mortality rate to be 47 per 100000 and the maternal mortality ratio as 300 per 100000 , thus South Africa is described as 'not on track' to reach the millennium development goal (MDG) target by 2015 for both indicators. ${ }^{78}$ With regard to the burden of disease from intentional and nonintentional injuries, it is acknowledged that there are challenges with the data. Homicide is reported to be 31 per 100 000, traffic mortality 27.5 per 100000 and for gender-based violence, accurate statistics are not available but levels are reported to be high and not showing signs of decreasing. ${ }^{74}$

Cause for concern is further highlighted in the recently released South African National Health and Nutrition Examination Survey (SANHANES) that describes the South African population as follows: $10 \%$ of respondents had hypertension and a further $10.4 \%$ were pre-hypertensive; $25 \%$ had high total and high LDL cholesterol; 18.4\% had impaired glucose homeostasis and $9.5 \%$ had diabetes. ${ }^{7}$ Sixteen percent (16.2\%) of South African adults were daily smokers and $27.9 \%$ of males and $45.2 \%$ of females, respectively, were classified as unfit, indicating poor health risk profiles. ${ }^{7}$ In addition, in 2000, it was estimated that 8037 (3.2\%) of deaths and 176918 (1.1\%) of DALYs were attributable to low fruit and vegetable intake in South Africa ${ }^{77}$ and the South Africa Comparative Risk Assessment (SACRA) Study ranked low fruit and vegetable intake as the $11^{\text {th }}$ risk factor for the burden of disease in South Africa, causing $1.1 \%$ of the DALYs. ${ }^{79}$

A healthy diet that includes adequate fruit and vegetable consumption plays an important role in the management of both communicable and non-communicable diseases. Therefore, strategies to address dietary intake in South Africa are critically important. South Africa is seen to have adopted adequate tobacco control measures as a strategy to combat NCDs, but it is now recommended that prioritisation is needed on interventions for the other three main risk factors for NCDs, namely unhealthy diets (including low fruit and vegetable consumption), physical inactivity and increased alcohol use. $^{73}$ 


\subsection{NUTRITIONAL STATUS}

\subsubsection{Global trends in nutritional status}

Globally, undernutrition and overnutrition often coexist and both remain significant public health problems. As described in section 1.3.1 on Global food security, one in eight people globally are undernourished, ${ }^{40}$ while the negative consequences of micronutrient deficiencies (the so-called 'hidden hunger') affects two billion people worldwide. ${ }^{80}$ Even though childhood stunting and maternal undernutrition have shown a decrease over the past two decades, they still remain significant public health problems in LMIC (especially in specific regions, including SSA) ${ }^{82}$ Globally, 165 million children under the ages of five, are stunted, the impacts of which extend throughout the lifecycle. ${ }^{81}$ Sub-Saharan Africa (SSA) has some of the highest levels of stunting, iron deficiency anaemia and vitamin $A$ deficiency, ${ }^{80}$ all of which contribute to mortality and morbidity, including the failure of children to reach their development potential. ${ }^{16}$ Undernutrition, including foetal growth restriction, stunting, wasting, vitamin A and zinc deficiencies and suboptimal breastfeeding, were the causes of $45 \%$ of all child deaths in $2011 .^{82}$

In contrast, in 2008, 1.4 billion adults globally were estimated to be overweight (500 million of which were obese).$^{83}$ The prevalence of obesity is high in some SSA countries, but available data depicts wide ranges, from 0.4 to $43 \%$ across countries, and it is acknowledged that the scarcity of available data on NCDs and their risk factors in the region is a problem. ${ }^{84}$

\subsubsection{Nutritional status and micronutrient status in South Africa}

The latest statistics for South Africa describe that $54.3 \%$ of the population are either at risk of hunger or are experiencing hunger. ${ }^{7}$ Stunting was shown by the SANHANES study to be $26.9 \%$ for boys and $25.9 \%$ for girls under the age of three years, which was slightly higher than previous estimates. $^{45}$ Vitamin A deficiency (VAD) and anaemia are still both significant public health problems in women of reproductive age, and in children. ${ }^{7}$ The 2013 SANHANES data describes that women of reproductive age had a VAD of $13.3 \%$, which was considered a moderate public health problem, even though, compared to previous studies, there were improvements reported in the status of vitamin A and iron. However, the limitations of, amongst others, comparisons between cross-sectional surveys should be considered. Children had a national VAD of $43.6 \%$; the prevalence of anaemia was $23.1 \%$ in women of reproductive age and $10.5 \%$ in children. ${ }^{7}$

Sixty four percent (two-thirds) of adult females and 31.2\% (one-third) of adult males in South Africa were classified as being either overweight or obese (figures that have increased since previous population studies were undertaken in the 2003 SADHS), while only $4 \%$ of adult females and $13.1 \%$ of adult males were underweight, according to the 2013 SANHANES report. ${ }^{7}$ In children 
aged 2 to 14 years, $23.6 \%$ of girls and $16.2 \%$ of boys were overweight or obese, ${ }^{7}$ also representing an increase since previous estimates. ${ }^{21}$

The 2005 National Food Consumption Survey (NFCS) data described that $97 \%$ of households had salt that contained a significant amount of iodine. Four out of 10 women and five out of ten children had a urinary iodine concentration that was in the excessive category of iodine status, resulting in the conclusion that South Africa had achieved virtual elimination of iodine deficiency disorders; folic acid status appeared to be good across the country but $45.3 \%$ of children had inadequate zinc status. ${ }^{21}$ These parameters were not re-evaluated in the 2013 SANHANES study.

\subsection{EXISTING GUIDELINES, POLICIES AND RECOMMENDATIONS ON FRUIT AND VEGETABLE CONSUMPTION}

There are many existing global, regional and national strategies and guidelines that incorporate a recommendation to increase fruit and vegetable consumption as a component of healthy eating and a healthy diet. The following section describes such guidelines and recommendations that are considered to have been developed by global and national authorities (such as the WHO and the Department of Health). Commitments that incorporate the right to adequate food are also described.

\subsubsection{Global evidence-based recommendations on adequate fruit and vegetable consumption}

Fruit and vegetables are essential components of a healthy diet. The WHO recommends the intake of $400 \mathrm{~g}$ (or five servings of $80 \mathrm{~g}$ portions) of fruit and vegetables per day. ${ }^{8}$ Globally, fruit and vegetable consumption patterns vary, with most countries not meeting the recommended target. ${ }^{9}$

The increasing burden of NCDs is seen as a barrier to realising the goals of development, such as poverty reduction, health equity, economic stability and human security, and to realising the MDGs. ${ }^{14}$ Preceding a UN high-level meeting on NCDs in 2011, The Lancet NCD Action Group and NCD Alliance, consisting of a number of international experts in the field of NCDs, proposed five priority interventions to respond to the NCD crisis: tobacco control, salt reduction, improved diets and physical activity, reduction in alcohol use and essential drugs and technologies. ${ }^{14}$ These interventions were chosen due to their health effects, cost-effectiveness, political and financial stability and because the risk factors for most NCDs are modifiable. The NCD Action Group priority intervention towards 'improved diets' recommends that the consumption of foods low in saturated and trans-fats, salt and sugar should be promoted; the increased consumption of fruit and vegetables would contribute towards fulfilling these criteria. ${ }^{14}$ 
Other actions suggested by the NCD Action Group are increasing the price of foods determined to be unhealthy (or implementing food taxes on unhealthy foods), granting subsidies on healthy foods (such as fruit and vegetables), the full implementation of food labelling regulations and the restriction of the marketing of unhealthy foods. ${ }^{14}$ The implementation and practicality of such recommendations needs to be assessed and further research may be needed in order to evaluate how these recommendations could be achieved under various local situations.

Recent recommendations call for the implementation of nutrition-sensitive interventions and programmes, for which there is some evidence, but better quality evaluations are needed. ${ }^{85} \mathrm{~A}$ suggestion is that policies that could result in behaviour change need to be context-specific and need to include recommendations at various stages of the food system; for example, agricultural research to increase productivity of fruit and vegetable cultivation could contribute to reduce micronutrient deficiency, and taxes on sugar, sweeteners, and fat could contribute to the reduction of obesity. ${ }^{86}$ There are a range of other nutrition-specific and nutrition-sensitive recommendations suggested to improve maternal and child nutrition, including, amongst others, dietary diversity and a reduction in micronutrient deficiencies. ${ }^{87}$ Adequate fruit and vegetable consumption could contribute to both increasing dietary diversity and reducing micronutrient deficiencies.

\subsubsection{International guideline and strategy documents that include recommendations on fruit and vegetable consumption}

A meeting of the WHO Fruit and Vegetable Promotion Initiative held in 2003 seemed to catalyse combined efforts globally to increase the promotion of fruit and vegetables. This meeting prompted a review of the evidence on the benefits of fruit and vegetable consumption, and of existing interventions that aimed to increase fruit and vegetable consumption. The meeting culminated in recommendations on the role of various organisations as well as the development of a Road map for the fruit and vegetable promotion initiative, which detailed specific actions to be taken to promote the consumption of fruit and vegetables. ${ }^{88}$ Following this, a Joint FAO/WHO Workshop on Fruit and Vegetables for Health was held in September 2004 (one of the actions recommended in the Road map), and various background papers were presented and jointly published by the FAO and $\mathrm{WHO}^{9}$

Also in 2004, the important WHO Global strategy on diet, physical activity and health (hereafter referred to as the Global strategy) was endorsed at the Fifty-seventh World Health Assembly (WHA) ${ }^{18}$ The WHA is the decision-making body of the WHO, and the WHO is considered to be the international authority on health issues. There are currently 193 Member States of the UN General Assembly out of approximately 196 countries in the world. Member States generally take WHO 
resolutions and documents seriously and should take steps to ensure that they implement the provisions set out therein. The Global Strategy provided a list of recommendations for Member States, civil society organisations, non-governmental organisations and the private sector to implement into their national policies and action plans. The overall aim of the Global strategy is to improve diet and increase physical activity. ${ }^{18}$

The Global strategy recognised high blood pressure, high cholesterol, inadequate intake of fruit and vegetables, overweight or obesity, physical inactivity and tobacco use as the most important risk factors for NCDs. An unhealthy diet was described as being "the increased consumption of energy-dense, nutrient-poor foods that are high in fat, sugar and salt and low in micronutrients" (and by implication low in fruit and vegetables) and this, together with physical inactivity was stated as being amongst the leading causes of NCDs. ${ }^{18}$ The strategy conclusively stated that an integrated approach was required to reduce the burden of disease (and death) from NCDs. The first objective of the Global Strategy was "to reduce the risk factors for NCDs that stem from unhealthy diets and physical inactivity by means of essential public health action and healthpromoting and disease preventing measures". ${ }^{18}$ For diet, the recommendations made for populations and individuals included the following:

- achieve energy balance and a healthy weight;

- limit energy intake from total fats and shift fat consumption away from saturated fats to unsaturated fats and towards the elimination of trans fatty acids;

- increase consumption of fruit and vegetables, and legumes, whole grains and nuts;

- limit the intake of free sugars;

- limit salt (sodium) consumption from all sources and ensure that salt is iodized.

Therefore, the Global Strategy provided a direct recommendation for fruit and vegetable consumption to be increased.

The World Cancer Research Fund and NCD Alliance released a Joint Brief on Food, Nutrition, Diet and NCDs in 2013. ${ }^{17}$ This brief acknowledges the important role of fruit and vegetables in the prevention of NCDs, and suggests key actions for all stakeholders (national governments, civil society, donors and research funders).

The Global strategy on diet, physical activity and health also recommended that food security be addressed. ${ }^{18}$ Food and nutrition security and the realisation of the right to adequate food are issues that are dealt with in other international guidelines that were released at a similar time. In 2004, FAO released an important document entitled Voluntary guidelines to support the progressive realisation of the right to adequate food in the context of national food security. ${ }^{2}$ These Right to 
Food Guidelines were developed by an Intergovernmental Working Group as well as representatives of stakeholders and civil society, and the process was therefore considered to be consultative and comprehensive. ${ }^{2}$ The purpose of these guidelines was to assist countries that have national food security, but high levels of household food insecurity. A set of practical recommendations covering the full range of actions deemed necessary was provided to assist countries to achieve the realisation of the right to adequate food for all citizens. ${ }^{2}$ Guideline 10 of the Right to Food Guidelines document provides nutrition recommendations. States are advised to include all stakeholders (including communities) in the design, implementation and monitoring of programmes that aim to increase the availability and consumption of "healthy and nutritious foods, especially those that are rich in micronutrients" (which would include fruit and vegetables). ${ }^{2}$ The promotion of vegetable gardens and the implementation of food fortification programmes were recommended to combat micronutrient deficiencies. Nutrition education was also recommended to "prevent overconsumption and unbalanced diets that may lead to malnutrition, obesity and degenerative diseases" as well as to assist individuals and households to enable them to make full use of the dietary value in the food they eat and thus achieve nutritional well-being. ${ }^{2}$ Efforts to improve fruit and vegetable consumption could assist with the implementation of both of these recommendations.

\subsubsection{National guidelines and strategies that include recommendations on fruit and vegetable consumption}

With regard to general actions to decrease the burden of disease from NCDs (and not only targeted at increasing fruit and vegetable consumption) that have been recommended by the NCD Action Group (and described in section 1.7.1 on Global recommendations), South Africa has made some progress. Food labelling regulations have been established ${ }^{89}$ however, the monitoring and enforcement of this legislation remains a challenge. There have been increased taxes placed on alcohol and cigarettes $^{90}$ and certain fruit and vegetable items are tax-free, but this has not extended to an increase in tax on foods that are classified by policy-makers as unhealthy. Currently, the advertising of cigarettes has been restricted by law, but the marketing of foods is regulated by an industry watchdog organisation (the Advertising Standards Authority of South Africa $)^{91}$ and this body has not succeeded in adequately restricting the marketing of unhealthy foods.

A recent review of the evidence of increased fruit and vegetable intake and the burden of nutritionrelated disease in South Africa concluded that an increase in fruit and vegetable consumption in South Africa could potentially contribute to a reduction in the burden of nutrition-related disease in children and adults in South Africa. ${ }^{13}$ South Africa has existing strategies to promote the increased consumption of fruit and vegetables. The South African Food-based dietary guidelines (FBDGs), 
published in 2001, aimed to provide healthy eating guidelines that most people could understand and implement in a practical manner. ${ }^{92}$ The intended use of the FBDGs was to develop healthy eating plans, and for education purposes on healthy eating. One of the main aims of developing national FBDGs was to provide consistency in messages given to the public (by various sectors) on healthy eating. They were developed by a panel of experts with a series of technical support papers, and coordinated by the Nutrition Directorate of the National Department of Health (DOH). The process of development was based on the FAO/WHO recommendations for developing FBDGs. ${ }^{93}$ The guidelines were based on existing eating patterns and dietary cultures in South Africa and were designed to be used in a country undergoing a 'nutrition transition' and with problems of both under- and over-nutrition. The guidelines were tested on consumers and community members for appropriateness. ${ }^{23}$ It was concluded that women understood the FBDGs and could use them, practically, to construct a meal plan. There were some constraints identified by participants to the implementation of the guidelines, which have not yet been further explored. During 2013, the guidelines were reviewed and updated. ${ }^{94,95,96,97}$

\subsubsection{South African Food-based Dietary Guidelines (2001)}

One of the South African food-based dietary guidelines is to "Eat plenty of vegetables and fruit every day". ${ }^{19,22}$ The support materials for this guideline quantify 'plenty' to mean five servings of vegetables and fruit per day, ${ }^{22}$ consistent with WHO recommendations. The technical support paper for this guideline recommended promoting general increased vegetable and fruit consumption as opposed to focusing on individual vegetables and fruit or individual nutrients. As each fruit and vegetable contains a unique combination of beneficial nutrients, a diversity of fruit and vegetables should be consumed and this message also needs to be communicated. ${ }^{22}$ This is consistent with other recommendations. ${ }^{12}$ Steffen explained that "No single nutrient or food is responsible for overall health, but a food pattern including five or more fruit and vegetables each day is beneficial and an important strategy for improving the public's health" ${ }^{10}$

The South African FBDG on vegetables and fruit also listed individual and marketing strategies that could be used to overcome barriers to achieving optimal intake, and provided practical suggestions to increase vegetable and fruit consumption. ${ }^{22}$ Were the vegetable and fruit guideline implemented appropriately, it could contribute to assisting with the implementation of other guidelines, such as "Eat fats sparingly", "Use salt sparingly" and "Use food and drinks containing sugar sparingly and not between meals". The replacement of (less healthy) processed foods with fresh fruit and vegetables is an important strategy for optimising overall health and maintaining a healthy weight. It is assumed that an increased intake of vegetables and fruit would displace other unhealthy options, such as foods with a high fat content, and therefore lead to an even greater contribution to 
the improvement of eating practices. Ultimately, the ideal situation to reverse the negative effects of the 'nutrition transition' would be for individuals to replace unhealthy food (i.e. food high in saturated fat, salt and sugar), with healthier options (e.g. vegetables and fruit). This is, however a complex issue that involves many factors, including competing against the food industry, to encourage healthy eating practices.

An important human rights principle that should be used when policies and guidelines are developed, is that of public participation and social inclusion. ${ }^{2}$ With regard to the development of the South African FBDGs, the principle of public participation and social inclusion could have been implemented in a more comprehensive way, by involving community members in the guideline development process from the start, as opposed to merely doing consumer acceptability testing after the guideline development process was complete. The approach followed to develop the South African FBDGs was the formation of working groups, reviews of existing food consumption patterns in South Africa and a review of other available research, as well as limited consumer testing of the guidelines. ${ }^{92}$ This approach combined with additional evidence that could have been provided by consultation with various representative communities, and a thorough assessment of the implementation and use of the guidelines, may have produced guidelines that could have been implemented more effectively. The latest dietary intake study in South Africa (SANHANES) seems to indicate that the implementation of the current guidelines is limited. ${ }^{7}$

\subsubsection{South African Guidelines for Healthy Eating and the Food Guide (2012)}

During Nutrition Week (9-15 October) of 2012, the South African National Department of Health launched the South African Guidelines for healthy eating and the food guide, ${ }^{94,95,96}$ based on the proposed revised FBDGs. The wording for some of the FBDGs has been adapted slightly based on a review of latest research (the scientific technical support papers were published in 2013 for general public access ${ }^{97}$ ), but the vegetables and fruit guidelines remain the same (see Table 1.2). The updated guidelines and the food guide aim to provide more practical assistance to consumers in order to assist individuals to make healthier food choices. The food guide aims to be a simple graphic symbol, representing the Guidelines for healthy eating in a pictorial format, using examples of unbranded items that are commonly consumed in South Africa and showing food groups in various sizes, relative to how much of each food group should be consumed daily (see Figure 1.2) ${ }^{95}$ The food guide depicts vegetables and fruit as the second largest food group that should be consumed. Supporting documents were developed to enable nutrition educators to teach individuals how to construct meals using these guidelines and guide, including information on portion sizes, menu planning and other practical tools. 


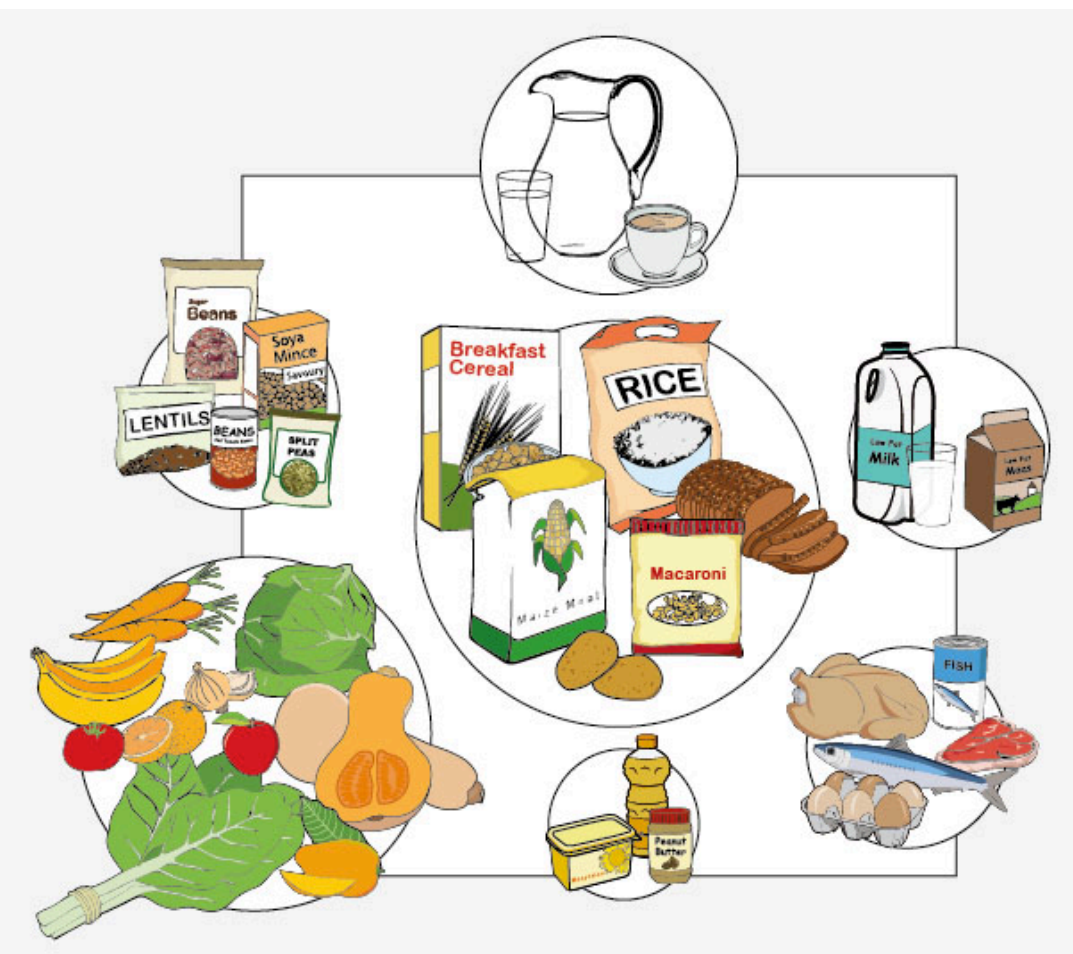

Figure 1.2: The South African Department of Health Food Guide ${ }^{94,95,96,97}$

Table 1.2: Comparison between the 2001 Food-based dietary guidelines and the 2012 Guidelines for healthy eating

\begin{tabular}{|l|l|}
\hline \multicolumn{1}{|c|}{ Food-based dietary guidelines (2001) } & \multicolumn{1}{c|}{ Guidelines for healthy eating (2012) } \\
\hline Enjoy a variety of foods & Enjoy a variety of foods \\
\hline Make starchy food the basis of most meals & Make starchy food part of most meals \\
\hline $\begin{array}{l}\text { Chicken, fish, meat milk or eggs could be eaten } \\
\text { daily }\end{array}$ & $\begin{array}{l}\text { Fish, chicken, lean meat or eggs could be eaten } \\
\text { daily }\end{array}$ \\
\hline & Have milk, maas or yoghurt every day \\
\hline Eat plenty of vegetables and fruit every day & Eat plenty of vegetables and fruit every day \\
\hline Eat dry beans, peas, lentils and soya regularly & $\begin{array}{l}\text { Eat dry beans, split peas, lentils and soya } \\
\text { regularly }\end{array}$ \\
\hline Use salt sparingly & Use salt and food high in salt sparingly \\
\hline Use fats sparingly & $\begin{array}{l}\text { Use fat sparingly; choose vegetable oils rather } \\
\text { than hard fats }\end{array}$ \\
\hline $\begin{array}{l}\text { Use food and drinks containing sugar sparingly } \\
\text { and not between meals }\end{array}$ & $\begin{array}{l}\text { Use sugar and food and drinks high in sugar } \\
\text { sparingly }\end{array}$ \\
\hline Drink lots of clean safe water & Drink lots of clean safe water \\
\hline Be Active! & Be Active! \\
\hline If you drink alcohol, drink it sensibly & \\
\hline
\end{tabular}

A recent analysis that assessed the cost to provide a daily diet that would comply with the FBDGs indicated that the consumption of such a diet would be unaffordable for most South Africans and the authors of the analysis therefore questioned the relevance of such guidelines in contributing to 
food and nutrition security in the South African population. ${ }^{98}$ The cost analysis conducted showed that the cost of one to two portions of vegetables per family member (far below the daily recommendation of five portions per day) was equivalent to the cost of the daily serving of maize meal porridge and was also equivalent to the cost of including one portion of protein. ${ }^{98}$ The cumulative cost of such components becomes unaffordable, and families therefore need to make decisions on what to spend their limited income. Families would probably not choose to substitute the starch or protein components of their meals (which are more likely to provide more energy and increase satiety) for vegetables or fruit. Recommendations made were that alternative interventions (such as improving the availability and accessibility of nutrient-dense foods and improving the sustainability of the food supply chain) need to complement FBDGs, and that FBDGs cannot be seen as a stand-alone strategy. ${ }^{98}$

\subsubsection{Other interventions and recommendations in South Africa}

There are other interventions that have been developed at various levels in South Africa that have aimed to contribute to increased fruit and vegetable consumption. The 5-a-Day for Better Health Trust was launched in 1995. This initiative was a non-profit organisation funded by a number of vegetable and fruit industry players "... with a sound science backing which aims, through education and promotion, to increase the consumption of vegetables and fruit (to at least five servings per person per day) in South Africa in order to promote better health". ${ }^{20}$ The website contained practical guidance, such as recipe ideas, guidelines for shopping and for the preparation and cooking of vegetables and fruit, and tips on how to achieve the recommended consumption of " 5 -aday". The organisation was involved in many promotion and advocacy initiatives including an endorsement logo for products that met their evidence-based criteria, that served to promote increased fruit and vegetable consumption. ${ }^{99}$ This was an example of a civil society organisation taking responsibility to promote healthy eating (in this instance, specifically aiming to increase the consumption of fruit and vegetables) which could lead to improved quality of the diet and increased food and nutrition security. This initiative had great potential to grow into an effective and influential public health campaign. Unfortunately, during 2011, the organisation was disbanded due to lack of financial commitment and limited support. ${ }^{99}$

A draft national Integrated food security strategy was developed by the Department of Agriculture, Forestry and Fisheries in 2002, and one of the categories for intervention of this strategy was to 'Improve nutrition and food safety' and to 'Enhance public education'. ${ }^{100}$ Also included as a recommendation in this strategy was the improvement of the micronutrient status (and therefore adequacy or quality of food consumed) of vulnerable groups. National agricultural policies seemed not to adequately consider the role of urban agriculture in contributing to food security. ${ }^{101}$ 
Unfortunately, this strategy remained in draft form for a decade, but it seems as if there are attempts being made to revitalise it, finalise the strategy and begin with its implementation. ${ }^{102}$ This has yet to happen, but according to the most recent Strategic Plan for the Department of Agriculture, Forestry and Fisheries, a Food Security Policy and Zero Hunger Programme are in the process of being adopted for South Africa. ${ }^{103}$

The City of Cape Town (in the Western Cape) has an Urban Agricultural Policy ${ }^{104}$ of which a strategic goal is "to enable the poorest of the poor to utilise urban agriculture as an element of their survival strategy, namely household food security." ${ }^{104}$ The Urban Agricultural Policy suggests that urban agriculture can assist to alleviate poverty and improve nutritional status. It also states that urban agriculture should be linked to other strategies, such as the Integrated Nutrition Programme of the Department of Health. This does not seem to be taking place at the moment and is an area where improvement in terms of integration of services would be beneficial. There are other provinces in South Africa that have incorporated urban agriculture into their policy. The Ekurhuleni Metropolitan Municipality in Gauteng developed an Agricultural development policy, strategy and process document in 2002, that contains a strong focus on the importance of urban agriculture. ${ }^{105}$ However, a recent report suggests that urban agricultural policies are not being implemented in an optimal manner in this metropolitan area, and that there would be many benefits for the upscaling of urban agricultural projects. ${ }^{101}$

\subsubsection{Declarations and political commitments in South Africa}

An interesting shift has started to take place in the political arena in South Africa, whereby health and nutrition have begun to gain increased relevance to leaders, and therefore have started to receive political commitment, which is essential to the implementation of effective strategies. In 2009 , food security was mentioned in the State of the Nation address. ${ }^{106}$ In 2011 , the National Department of Health hosted a landmark Non-communicable Diseases Summit. This was a multisectoral meeting of experts and role players in the field of NCDs and concluded with the signing of a South African Declaration on the Prevention and Control of Non-communicable Diseases. ${ }^{73}$ Two of the commitments included in this declaration that are relevant to improved nutrition and healthier eating practices, are: "To increase the numbers of people who have established family and community food gardens" and "To improve the quality of food available in South Africa by means of inter-sectoral collaborations". ${ }^{73}$ Healthy eating recommendations include the promotion of vegetable and fruit consumption. The South African NCD Declaration indicates political will at the highest level to improve the health status of the population, and this political will now needs to be translated into action. 
Consistent with this commitment at a national level, the Premier of the Western Cape, in November 2011, hosted a Provincial Wellness Summit, which resulted in the endorsement of the Cape Town Declaration on Wellness. ${ }^{107}$ A commitment of this Provincial Wellness Declaration was to mobilise members of society to facilitate individuals to make the right choices to eat healthy foods and increase physical activity, together with a list of other complementary actions that should contribute to the fulfilment of a healthy lifestyle. Even more recently, a political party issued a draft statement on the right of South Africans to be free from hunger. ${ }^{108}$ These various commitments all contribute to the creation of an opportune environment and time to focus on the quality of food being consumed by individuals in South Africa. South Africa, it would seem, now has the political context to enable health and nutrition to be a priority and that the time is right to focus on effective, longterm nutrition interventions and to commit resources to the development of such interventions.

However, despite these existing and fairly comprehensive strategies, micronutrient status continues to remain poor, and fruit and vegetable intakes have not reached adequate levels. ${ }^{7}$ This could indicate that strategies need to be re-focused and more appropriate and effective interventions identified, or that emphasis needs to be placed on the practical implementation of existing strategies. The NFCS report suggested that awareness should be created about general micronutrient intake from various sources, focusing on dietary diversity (of which, adequate fruit and vegetable consumption is a component), food fortification and supplementation. ${ }^{21}$ Reinforcement of the revised FBDGs was also recommended by the NFCS. The 2013 SANHANES study concluded that diets in South Africa are high in energy and low in micronutrients and recommendations included increased public awareness of micronutrients, dietary diversity and practices. ${ }^{7}$ Adequate consumption of fruit and vegetables would assist with the implementation of these recommendations.

\subsubsection{Human rights commitments that incorporate the right to adequate food in South Africa}

In 1996, South Africa adopted one of the most progressive constitutions in the world. Section 27 of the Constitution of the Republic of South Africa deals with health care, food, water and social security and states:

(1) Everyone has the right to have access to (a) health care services, including reproductive health care; (b) sufficient food and water; and (c) social security, including, if they are unable to support themselves and their dependants, appropriate social assistance.

(2) The state must take reasonable legislative and other measures, within its available resources, to achieve the progressive realisation of each of these rights. ${ }^{109}$ 
Section 28 deals with children and commits that every child (i.e. any person under the age of 18 years) has the right to, amongst other things "(c) basic nutrition, shelter, basic health care services and social services". 109

In terms of international human rights law, the International Covenant on Economic, Social and Cultural Rights (ICESCR) ${ }^{110}$ was signed by South Africa in 1994, ${ }^{111}$ and in October 2012, a statement was made by Cabinet that the ratification of the ICESCR would be tabled before Parliament, ${ }^{112}$ but as yet (almost 20 years after signing it), South Africa has not officially ratified the Covenant. ${ }^{111}$ One possible reason for the unwillingness of South Africa to ratify the Covenant is that many different government departments are responsible for the realisation of socio-economic rights. This means that reporting to the UN Committee on Economic, Social and Cultural Rights would require some form of communication and coordination between the various departments and this is possibly a challenge that the government has not yet found a way to overcome. This commitment to ratify the Covenant shows that the South African government is willing to improve the realisation of economic, social and cultural rights for its citizens, and was commended by many civil society organisations. ${ }^{113}$ By going through the process of ratifying the ICESCR, South Africa would legally bind itself, by international law, to work towards achieving the obligations set out in the ICESCR, and the country would also be accountable for its progressive realisation of these rights to international human rights organisations. In his 2011 mission to South Africa, the United Nations Special Rapporteur on the Right to Food listed as his first recommendation to the South African Government, that the ICESCR should be ratified, as an action that would assist the country to move towards the full realisation of the right to adequate food for all. ${ }^{114}$

\subsection{CURRENT FRUIT AND VEGETABLE CONSUMPTION PATTERNS}

\subsubsection{Global fruit and vegetable consumption patterns}

Despite the overwhelming evidence for the benefits of adequate fruit and vegetable consumption, intakes still remain inadequate. A World Health Survey conducted during 2002-2003 determined that $78 \%$ of the population in 52 mainly LMIC, consumed less than the recommended five servings of fruit and vegetables per day. ${ }^{115}$ The UNSCN $6{ }^{\text {th }}$ report on the World Nutrition Situation attempted to explain the reasons why this is the case. ${ }^{44} \mathrm{~A}$ combination of factors, including high food prices, trade agreements and a reduction in funding available for development assistance were all thought to contribute to suboptimal fruit and vegetable consumption patterns. ${ }^{44}$ Furthermore, families coped by replacing animal source foods and fruit and vegetables with high carbohydrate staple foods and other foods that are generally sufficient in energy but of low micronutrient content as well as by reducing meal frequency, and reducing the amount of food consumed or portion size. ${ }^{44}$ The end result is deterioration in the quality of the diet. . 


\subsubsection{Fruit and vegetable consumption patterns in South Africa}

In South Africa, most people do not consume adequate amounts of fruit and vegetables on a daily basis. Meta-analyses and calculations done on secondary data from the main dietary surveys conducted in South Africa (including the National Food Consumption Survey of 1999) from 1983 to 2000 estimated that in South Africa, intakes of fruit and vegetables are on average, $235 \mathrm{~g} /$ day for males and $226 \mathrm{~g} /$ day for females (equal to just under three servings per day) and that $80 \%$ of adults consume less than the recommended $400 \mathrm{~g} /$ day of fruit and vegetables. ${ }^{116,117}$ The National Food Consumption Survey Fortification Baseline 1 (NFCS-FB1) revealed that the status (of women and children in South Africa) of key micronutrients remains inadequate. ${ }^{21}$

The 1999 NCFS showed that most children in South Africa consumed a diet that was too low in energy and of poor micronutrient density. ${ }^{21}$ The five most commonly consumed foods were determined to be maize, sugar, tea, whole milk and brown bread. These findings showed a clear lack of fruit and vegetables in the diet. The 2013 SANHANES measured fruit and vegetable consumption scores, which were calculated based on the reported daily intake of fruit and vegetables. ${ }^{7}$ A score of 6 to 8 was considered high, 3 to 5 moderate, and 0 to 2, low. The total fruit and vegetable consumption scores were 3.77 for the entire South African population, 3.60 for the Western Cape and 3.70 for the coloured population. ${ }^{7}$ Therefore, the total population, the Western Cape population and the coloured population all had fruit and vegetable consumption scores that were considered to be at the low end of moderate.

\subsubsection{General eating patterns in South Africa}

Rapid rates of urbanisation, together with globalisation, have been associated with deterioration in the quality of dietary intake and the accompanying deterioration of nutritional status of populations. In South Africa, the NFCS concluded that this was characterised by high rates of food insecurity, coexisting undernutrition and overnutrition, and micronutrient deficiencies. ${ }^{21}$ The 2013 SANHANES showed that $39.7 \%$ of South Africans consumed a diet low in dietary diversity (i.e. of poor nutrient quality) and $25.6 \%$ had a low fruit and vegetable score. ${ }^{7}$ The overall general nutrition knowledge score was on average 5.3/10. ${ }^{7}$ Even though the SANHANES results display poor overall eating habits, $63.8 \%$ of respondents believed that what they ate or drank was healthy enough, and that they did not need to make any changes. ${ }^{7}$ It was also determined (from the NFCS FB-1) that even though micronutrient status was found to be inadequate, nationally, $80 \%$ of women had a sound to very good basic nutrition knowledge score on vitamins and minerals and that at least $60 \%$ of women had a positive to very positive attitude with regard to healthful eating. ${ }^{21}$ Therefore, even 
though women seemed to have a relatively good knowledge on nutrition, this was not being translated into adequate practices.

A national review conducted on the presence of large commercial companies in the food and beverage environment of South Africa argued that large pre-packaged food and beverage manufacturers, large retailers and food outlets, as well as smaller informal sellers of food and beverages, were both significant contributors to the food supply and environment in South Africa. ${ }^{118}$ A significant increase in the sale of packaged foods (many of which are considered to be less healthy items such as sweets and snack bars) in South Africa between 2005 and 2010 was demonstrated, and the availability and consumption of soft drinks was shown to be widespread. ${ }^{118}$ The authors acknowledged that there were some policy efforts by government (such as the food labelling legislation) but suggested that there should be a higher degree of engagement with and regulation of the food industry, in order to create an environment that allowed for healthy foods to become more available, affordable and acceptable to the population. ${ }^{118}$

\subsection{FACTORS THAT POTENTIALLY INFLUENCE FRUIT AND VEGETABLE CONSUMPTION}

Previous research has been done on factors that potentially influence fruit and vegetable consumption, including the identification of barriers to and facilitators of fruit and vegetable consumption.

\subsubsection{Previous research on factors influencing fruit and vegetable consumption: Global} Studies done on factors that facilitate or prevent adequate fruit and vegetable consumption have identified various targets for intervention. Commonly perceived barriers to eating a more healthy diet have been identified to be the time factor involved in trying to prepare a healthier meal, taste factors, whereby people perceive that healthier food does not taste as nice as unhealthy food, as well as cost. ${ }^{24,25} \mathrm{~A}$ lack of knowledge on healthy eating is not necessarily considered a barrier to healthy eating, but often, people perceive their own diets to be already healthy. ${ }^{24}$ Recommendations from previous research include that interventions should focus on teaching consumers how to evaluate their diet. Some individuals feel that nutrition guidelines are either unattainable and therefore unrealistic, or not personally relevant to them, and people therefore assume that recommendations are "aspirational in the sense that it was purposefully exaggerated to simply encourage greater overall consumption". ${ }^{25}$ People overestimate what five servings of vegetables are, and therefore perceive it to be unrealistic, and people do not perceive any greater health benefit of consuming more fruit and vegetables daily. ${ }^{25}$ This suggests that either more and better education on fruit and vegetable consumption recommendations are needed, or that the 
existing recommendations and the manner in which they are described need improvement in order to achieve better understanding and implementation.

Some research has shown that perceived access to fruit and vegetables is associated with increased consumption, and community interventions could consider environmental factors, and should attempt to increase physical access to fruit and vegetables. ${ }^{26}$ Strategies that focus on increasing the accessibility of fruit and vegetables may show some degree of success. Economic accessibility to fruit and vegetables is also a problem, especially in poor households, and household income has been shown to be an important determinant of fruit and vegetable consumption. ${ }^{119}$

Recent cohort studies conducted in Europe on the critical periods for the development of eating habits have reported that longer duration of breastfeeding is associated with higher fruit and vegetable intakes in children, and that maternal diet was associated with the consumption of fruit and vegetables in children ${ }^{120}$. These cohort studies form part of a body of research being conducted to determine factors and critical periods in food habit formation in early childhood, using a multidisciplinary approach. ${ }^{121}$ This research is attempting to understand how food habits and eating patterns form, and then to identify determinants of behaviour change. ${ }^{121}$

\subsubsection{Previous research on factors influencing fruit and vegetable consumption: South Africa}

Studies done in South Africa show that constraints to eating fruit and vegetables are affordability or economic accessibility (many people perceive healthy foods to be expensive, and unhealthy foods to be cheaper), availability and household taste preferences. ${ }^{22,23}$ Other factors include time for preparation and storage capacity (only $40 \%$ of the population have fridges). ${ }^{122}$ Sometimes social status is associated with the consumption of certain types of unhealthy food that individuals may not have previously been able to afford. Participatory research done in Khayelitsha, that analysed personal barriers to healthy living, revealed a lack of availability of fruit and vegetables and other healthier alternatives (in informal settlements), as a barrier to eating healthily. ${ }^{27}$ The South African Comparative Risk Assessment (SACRA) study conducted in 2000 concluded that:

...a high intake of fruit and vegetables can make a significant contribution to decreasing mortality from certain diseases. The more difficult part, however, is persuading people to change their behaviour, to eat more fruit and vegetables and to eat a greater variety thereof. $^{77}$ 
This study made recommendations that a multi-sectoral approach was needed (including public and private initiatives), and that interventions aimed at changing diet should include educating individuals, undertaking community interventions, modifying the food supply, changing the environment and introducing supportive economic policies. ${ }^{123}$

As described in section 1.8.3, on General eating patterns in South Africa, two large national nutrition surveys determined that nutrition knowledge is not always associated with optimal eating habits. It is therefore necessary to investigate the underlying causes of this disjuncture. The first step towards ensuring increased fruit and vegetable consumption could therefore be to identify underlying factors that contribute to the less than adequate fruit and vegetable consumption practices that have been identified by previous research.

Therefore, there are many strategies and interventions, globally and in South Africa, that aim to address malnutrition and provide recommendations for adequate fruit and vegetable consumption, yet consumption still remains inadequate. It seems that little account has been taken of consumer attitudes to and perceptions of existing guidelines on healthy eating, and the consumption of fruit and vegetables. This implies that an alternative approach is needed and in-depth research on consumer's understanding of guidelines may be important. Furthermore, a more comprehensive understanding of how human behaviour change occurs and the implications for behaviour change strategies is required.

\subsubsection{Behaviour change strategies}

Eating, and consequently the consumption of fruit and vegetables, is a human behaviour. Efforts to improve fruit and vegetable consumption need to influence a change in the eating behaviour of individuals, households and communities. Behaviour change is a complex field and factors such as the physical environment and the psychology of behaviour patterns need to be considered. There has been recent interest in the application of behavioural economics and psychology principles to influence health-related behaviour change. ${ }^{124,125,126}$ For individuals to change behaviour, it is suggested that the following three principles are necessary: capability, opportunity and motivation. ${ }^{125}$ Capability includes knowledge (on the consequences of the particular behaviour) and skills to plan the behaviour change as well as to be able to develop strategies to cope with difficult situations. Capability with regard to food choice is also dependent on the five components of food security listed previously: availability, accessibility, adequacy, acceptability and agency, ${ }^{43}$ being present. Opportunity involves discussing the behaviour with others and understanding how the social and physical environment may affect behaviour. Motivation is influenced by personal relevance of and attitudes towards the behaviour, beliefs about one's own capabilities, intentions 
and goals and positive or negative reinforcement received upon implementation of the behaviour change. ${ }^{125}$ There are various other models that describe individual behaviour change. ${ }^{126}$ The consideration of behaviour change theories can assist to understand research findings that, for example, report that people perceive their diets to be of a better quality than they actually are. ${ }^{127}$

Certain behaviour change models focus on the individual and include techniques to be used in one-on-one counselling (such as motivational interviewing and cognitive behavioural therapy) ${ }^{128}$ whereas others consider behaviour change at the community and population level, and it is this that will be focused on in this discussion. The 'behaviour change wheel' suggested by Michie et al. following the review of a number of behaviour change models suggests three levels of intervention: the policy level (guidelines, environmental and social planning, communication and marketing); intervention functions (such as education, persuasion and enablement); and sources of behaviour (physical, psychological and social) that are influenced by capability, opportunity and motivation. ${ }^{126}$

Another behaviour change strategy that has been suggested is the 'nudge' principle, which is described as a technique that changes the social or physical environment to enable people to make healthier choices without making a conscious decision or deliberate change to do so. ${ }^{129} \mathrm{~A}$ 'nudge' is intended to assist to ensure that the better choice is the easier choice. Examples of interventions would be strategic placement of fruit and vegetables in stores (i.e. near the entrance or at eye level), the provision of incentives for certain behaviours or subconscious priming using subtle messaging. ${ }^{124}$ It is known that knowledge alone is not enough to change behaviour and therefore these briefly described concepts need to be taken into account when an attempt is made to understand behaviour and eventually influence behaviour change.

\subsection{RECOMMENDATIONS OF PREVIOUS RESEARCH ON FRUIT AND VEGETABLE CONSUMPTION}

Studies on different aspects of fruit and vegetable consumption make various recommendations. The NFCS-FB 1 Panel recommendations include the continuation of the food fortification programme, and that other approaches (such as nutrition education, the increased consumption of vitamin A-rich foods, food diversification and nutrient supplementation, as well as improved complementary feeding practices) should be strengthened. ${ }^{21}$ General recommendations of the NFCS were that a comprehensive strategy is needed to address immediate and medium term issues; increased consumer awareness of adequate micronutrient intake is needed; the foodbased dietary guidelines need to be used appropriately for nutrition education, and that training of health care workers on healthy eating and good food choices (including those high in micronutrients) is essential. ${ }^{21}$ These are all examples of interventions that can be used in strategies to improve fruit and vegetable consumption. Recommendations from the SACRA were 
to implement tax and agricultural policies to promote production and availability of fruit and vegetables; to implement school programmes that integrate nutrition into curricula and healthy nutrition into school feeding schemes; to develop and evaluate social marketing strategies to promote regular eating of fruit and vegetables; and to promote home and community vegetable gardens. $^{123}$

These are consistent with some international recommendations, as described in section 1.7 on Existing guidelines, policies, and recommendations on fruit and vegetable consumption. Policy and programmatic changes are required that work towards improved education, increased regulation of food labelling and the marketing of foods, implementation of tax on unhealthy foods, as well as the implementation of policies that address the progressive realisation of the right to adequate food for all. ${ }^{115}$ Much work still needs to be done to achieve the implementation of these recommendations.

\subsection{CONCLUSION}

It is clear that, both globally and in South Africa, the general population is not consuming an adequate amount of fruit and vegetables, even though the evidence of their health benefits is extensive and conclusive. It is also evident that there have been many strategies and guidelines that have attempted to rectify this situation, but there are new, increasing and unique challenges that are being experienced by individuals and households when it comes to consuming enough fruit and vegetables as well as achieving a nutritionally adequate diet. Alternative and interdisciplinary approaches are therefore needed in order to inform strategies and interventions and to ensure that they are implemented and have long-term success in improving nutrition and health outcomes of populations and individuals. A strong recommendation from previous research is for stakeholders to be engaged in order to understand various levels of factors that are contributing to current nutrition and health problems. The improvement of fruit and vegetable consumption will contribute to improved nutritional status, as well as improved quality and nutritional adequacy of the diet. Therefore, the engagement of key community members, in order to understand underlying factors that influence fruit and vegetable consumption, is considered an important start in trying to identify where interventions are required.

\subsection{MOTIVATION FOR THIS STUDY}

If individuals consumed the recommended amount of fruit and vegetables daily, this could assist to reduce both over- and under-nutrition and result in an overall improvement of nutritional (including micronutrient) status and in the long term, would result in overall improved health and reduced morbidity and mortality. Adequate fruit and vegetable consumption can also contribute to the 
achievement of food and nutrition security. There is therefore a need to understand why fruit and vegetable consumption continues to remain inadequate in South Africa.

As detailed in the literature overview, current strategies do not appear to be working. Therefore, it is necessary to gain a more in-depth understanding as to why individuals and households do or do not consume the recommended amount of fruit and vegetables. Qualitative research plays an increasingly important role with regard to understanding behaviour. ${ }^{130}$ In order to gain a more indepth understanding of behaviours so as to be able to inform the required behaviour change, it is essential to engage with the affected stakeholders by employing this type of research methodology. This study consulted with key community members and therefore ensured the active participation of rights-holders in the research process. This is consistent with research conducted using a human rights-based approach. ${ }^{4,5}$ It is hoped that this research will guide interventions based on the needs of the community members that will be required to implement such interventions, as well as ensuring that the interventions are both acceptable to community members and sustainable in the long term. Article 11 of General Comment 12 (of the ICESCR) describes that part of the normative content of the right to adequate food is "cultural or consumer acceptability", which is defined as the "perceived non-nutrient based values attached to food..." ${ }^{3}$ It was therefore important to also determine the cultural values associated with fruit and vegetable consumption, and an attempt was made to identify which fruit and vegetables were consumed at specific times or events, in order to describe some of the underlying factors influencing when fruit and vegetables are consumed.

The motivation for conducting the research in an area of the Mitchells Plain sub-district was that the structure of this community is similar to many other communities in South Africa and so the results could be more widely interpreted; this is an urban setting with formal and informal housing, population density is high, there are high levels of poverty and food insecurity, and there are high levels of NCDs. ${ }^{28,131,132,133}$ The principal investigator had worked as a dietitian in this community for a number of years and intends to provide feedback on the results to policy-makers and others working in this area.

It is anticipated that this research will contribute to the available evidence and could potentially assist in guiding the State in its duty to facilitate the progressive realisation of the right to adequate food through the promotion of increased fruit and vegetable intake, as part of their 'fulfil/facilitate' obligation to contribute to improvement in the national nutritional adequacy of food consumed.

The intention is that the results of this research will provide greater understanding of reasons for current low levels of fruit and vegetable consumption in the Mitchells Plain area of Cape Town. 
These results could then be used to guide future research, to adapt existing nutrition strategies to be more effective, and to design nutrition interventions that would more effectively lead to increased fruit and vegetable consumption. Given the known benefits of adequate fruit and vegetable consumption, and research findings of inadequate consumption by the South African population, finding ways to improve fruit and vegetable consumption is a priority. There are existing policies, guidelines and recommendations that include fruit and vegetable recommendations (such as the South African FBDGs) and interventions to address food security in South Africa (such as the recent Food Security Policy and Fetsa Tlala programmes of the Department of Agriculture, Forestry and Fisheries ${ }^{134}$ ). Where South Africa is failing, is in the consultation with various stakeholders and the involvement of the community in the development of strategies, and in the implementation phase. Attention needs to be focused on implementation, and how to ensure that health behaviour change takes place in order to realise the desired benefits.

Article 23 of General Comment 12 (of the ICESCR) recommends that "The formulation and implementation of national strategies for the right to food requires full compliance with the principles of accountability, transparency, people's participation, decentralization, legislative capacity and the independence of the judiciary." ${ }^{3}$ This research study could fulfil some of these principles by implementing a participatory approach that follows a transparent process, which could lead to the implementation of more successful and sustainable programmes. The findings of this study will contribute to the current academic knowledge on fruit and vegetable consumption in South Africa and will be submitted for publication in a peer-reviewed journal. The findings of this study could stimulate further research in the field. It is important that the findings of this research are shared with relevant stakeholders (as detailed in the next paragraph). In the long term, the results from this study and future research done as a result of this study, could have an impact on the improvement of individual eating behaviours and result in improved quality and nutritional adequacy of the diet, improved food and nutrition security, and the resultant improved nutrition and health status of individuals, households, communities and ultimately, the South African population.

The intention is to present the results of this research to the Western Cape's Health Departments (specifically, the Western Cape Province: Nutrition Sub-directorate and the Klipfontein/Mitchells Plain Substructure: Comprehensive Health Programmes management), as well as the City of Cape Town and the Mitchells Plain Health Council Forum. This could contribute to an improved understanding of those involved in nutrition and health service delivery in the area. Following this, nutrition and health staff working in the area could design and implement more locally relevant strategies that are more acceptable to the community, address the challenges experienced by the community and focus on positive habits to increase vegetable and fruit consumption. Further 
research could then be conducted on interventions that address the needs of the community and that are designed using the findings of this study. 


\section{METHODOLOGY}

\subsection{AIM OF STUDY}

The main aim of this study was to describe underlying factors that influence individual and household fruit and vegetable consumption in an area of the Mitchells Plain sub-district, by engaging with community members in a participatory manner. This thesis argues that knowledge and motivation are often insufficient to result in a desired behaviour, such as the adequate consumption of fruit and vegetables. The need was therefore identified to gain an in-depth understanding of the multitude of factors that can influence fruit and vegetable consumption at individual, household and community levels and furthermore, to identify structural and environmental factors that influence fruit and vegetable consumption. It was felt that the direct engagement of community members, using qualitative research methods, would provide a deeper and more comprehensive understanding of all the relevant factors that influence fruit and vegetable consumption in this particular community, and would also ensure that the research was conducted with a human rights-based approach.

\subsection{OBJECTIVES OF STUDY}

The objectives of this study were the following:

- To gain a broad understanding of factors that influence fruit and vegetable consumption in the Mitchells Plain community, by conducting focus group discussions with different groups of community members.

- To use main themes identified in the focus group discussions, together with photographs taken by participants, to stimulate discussion during in-depth interviews with key individuals of the Mitchells Plain community, and to gain an in-depth understanding of underlying factors that influence fruit and vegetable consumption at the individual and household level.

\subsection{STUDY DESIGN}

This was a qualitative research project that was descriptive and cross-sectional in nature. The reason for conducting qualitative research in this study was to gain a deeper understanding of individual beliefs, perceptions and behaviours surrounding fruit and vegetable consumption. Individuals' actions are influenced by their beliefs, attitudes and perceptions. ${ }^{130}$ Thus, to encourage change in behaviours that would result in improved nutrition, and therefore improved health status, qualitative research assisted in providing some of the underlying information on the factors that would guide individuals' actions. This study aimed to provide a comprehensive description of underlying factors that influence fruit and vegetable consumption in a sub-section of the Mitchells 
Plain community. This study was observational in nature; the research was exploratory and investigated some of the underlying factors affecting fruit and vegetable consumption in a community; no interventions were performed. The data collection for this study took place over seven weeks (December 2012 to January 2013), but data collection was performed with each participant only once, and this therefore made it cross-sectional in nature. Four focus group discussions (FGDs) were conducted, with an average of ten participants per FGD, followed by 15 individual in-depth interviews (IDIs).

\subsection{STUDY POPULATION}

The study population consisted of individuals residing in the Mitchells Plain sub-district, during the months of December 2012 and January 2013. The City of Cape Town divides the Metropole District (of the Western Cape Province) into eight sub-districts (see Addendum A for a map of the Metropole District and eight sub-districts). Sub-districts are divided into sub-councils. Each subcouncil consists of between three and seven Wards, and a Ward consists of a group of between 13000 to 15000 voters. Since the Mitchells Plain sub-district is quite large (it includes the areas of Mitchells Plain, Crossroads and Philippi, comprising 14 Wards in total), ${ }^{135}$ it was decided to choose a sub-section of the Mitchells Plain area within which to conduct this research. In order to determine in which sub-section of Mitchells Plain the research would be conducted, convenience sampling was used. Sub-council 12 was chosen, comprising the areas of Rocklands, Westridge, Portlands, Tafelsig, Eastridge, Beacon Valley, Lentegeur, Woodlands, Weltevreden Valley, Colorado Park and Strandfontein (see Addendum B for a map of the Mitchells Plain area, with its various divisions). Within sub-council 12, Ward 79 (Beacon Valley, Eastridge and Mitchells Plain Central Business District) was chosen as the specific sub-section of the Mitchells Plain area within which to carry out this research. These areas were chosen for their central location and for ease of access, because the Principal Investigator was based in Lentegeur and was working in the Mitchells Plain sub-district at the time.

Mitchells Plain was created in the 1970s as a 'coloured township' for middle-income families. Since then there has been a strong investment in the area, and Mitchells Plain has a well-developed transport network. Population density is high and living conditions consist of a combination of formal housing and informal settlements. ${ }^{131}$ Since its establishment there has been an increase in gangsterism and drug use in the area. ${ }^{136}$ (See Table 2.1 for a description of certain aspects of the demographics of the Mitchells Plain population.) The structure and composition of Mitchells Plain shares many similarities (such as high population density, high rates of unemployment and a high prevalence of disease) to other communities in the Western Cape Province and in South Africa ${ }^{137}$ which made it a relevant area within which to conduct this research. Although there are also many 
differences between the Mitchells Plain community and other communities in South Africa, there are some characteristics of the food system in Mitchells Plain that may bear similarities to those in other communities in South Africa. Results could therefore be useful to describe certain factors underlying fruit and vegetable consumption that may be relevant to other communities in South Africa, although the specific demographics of the Mitchells Plain area will influence the findings of this research, and this should be recognised when the results of this research are discussed and conclusions are drawn.

The information presented in Table 2.1 is from the City of Cape Town's analysis of Census 2001 data, as well as results provided from the Census 2011 data, and provides a description of certain aspects of the population residing in Mitchells Plain. ${ }^{131,132}$ 
Table 2.1: Description of the Mitchells Plain population demographics

\begin{tabular}{|c|c|c|}
\hline DEMOGRAPHIC & $\begin{array}{l}\text { MITCHELLS PLAIN } \\
2001 \text { CENSUS }\end{array}$ & $\begin{array}{l}\text { MITCHELLS PLAIN } \\
2011 \text { CENSUS } \\
132,133\end{array}$ \\
\hline Total population & 283196 people & 310485 people \\
\hline $\begin{array}{l}\text { Total number of } \\
\text { households }\end{array}$ & $\begin{array}{l}61248 \text { households } \\
\text { Mean of } 4.6 \text { people/household }\end{array}$ & $\begin{array}{l}67995 \text { households } \\
\text { Mean of } 4.57 \text { people/household }\end{array}$ \\
\hline Race / Population group & $\begin{array}{l}\text { 89.6\% Coloured } \\
9.4 \% \text { Black African }\end{array}$ & $\begin{array}{l}\text { 90.8\% Coloured } \\
7.3 \% \text { Black African }\end{array}$ \\
\hline First language & $\begin{array}{l}\text { 52.8\% Afrikaans } \\
\text { 39.5\% English } \\
7 \% \text { isiXhosa }\end{array}$ & $\begin{array}{l}\text { 46.6\% Afrikaans* } \\
\text { 47.1\% English* } \\
\text { 3.3\% isiXhosa* }\end{array}$ \\
\hline Age distribution & $\begin{array}{l}55 \% \text { are between } 18-54 y r s \\
37.3 \% \text { are under } 18 y r s\end{array}$ & $\begin{array}{l}51.2 \% \text { are between } 20-54 y s^{*} \\
36.3 \% \text { are under } 20 y r{ }^{*}\end{array}$ \\
\hline Education levels & $\begin{array}{l}50 \% \text { of the adult population have } \\
\text { schooling of at least Grade } 11\end{array}$ & $\begin{array}{l}35 \% \text { of those }>20 y r s \text { have completed } \\
\text { Grade } 12 \text { or higher }\end{array}$ \\
\hline Unemployment & $\begin{array}{l}26.5 \% \text { of the population are } \\
\text { unemployed }\end{array}$ & $\begin{array}{l}24.1 \% \text { unemployed } \\
76 \% \text { of the labour force (aged 15-64 } \\
\text { yrs) are employed }\end{array}$ \\
\hline Income distribution & $\begin{array}{l}\text { 40.9\% of working people earn } \\
\text { between R0 - R1 600/month 53.8\% } \\
\text { earn between R1 } 601 \text { - R6 } \\
\text { 400/month }\end{array}$ & $\begin{array}{l}41.6 \% \text { of working people earn } \\
\text { between R0 - R1 600/month } \\
38 \% \text { earn between R1 } 601 \text { - R6 } \\
400 / \text { month } \\
36 \% \text { of households have a monthly } \\
\text { income of R3 } 200 \text { or less }\end{array}$ \\
\hline Housing & $\begin{array}{l}67.1 \% \text { live in a free-standing house / } \\
\text { brick structure } \\
22.3 \% \text { live in a town / cluster / semi- } \\
\text { detached house }\end{array}$ & $\begin{array}{l}57.5 \% \text { live in a free-standing house / } \\
\text { brick structure } \\
34.8 \% \text { live in a town / cluster / semi- } \\
\text { detached house }\end{array}$ \\
\hline Electricity & $\begin{array}{l}98.7 \% \text { of households use electricity } \\
\text { for lighting }\end{array}$ & $\begin{array}{l}99.3 \% \text { of households use electricity } \\
\text { for lighting } \\
84.5 \% \text { of households use electricity } \\
\text { for heating }\end{array}$ \\
\hline Water and sanitation & $\begin{array}{l}88.4 \% \text { of households have piped } \\
\text { water inside their dwelling } \\
96.3 \% \text { have a flush toilet connected } \\
\text { to a sewerage system }\end{array}$ & $\begin{array}{l}95.9 \% \text { of households have piped } \\
\text { water inside their dwelling } \\
95.5 \% \text { have a flush toilet connected } \\
\text { to a sewerage system }\end{array}$ \\
\hline
\end{tabular}

Source: Census 2001 ${ }^{131}$; Census 2011 ${ }^{132,133}$

* Census 2011 information for first language and age distribution is from personal communication; other data is from the CoCT website and analyses.

\subsubsection{Description of disease prevalence in Mitchells Plain}

The top ten causes of premature mortality, or years of life lost, in the Mitchells Plain sub-district are homicide (17.7\%), HIVIAIDS (14.5\%), tuberculosis (TB) (8.7\%), road traffic accidents (5.9\%), lower-respiratory tract infections (4.6\%), diabetes mellitus (3.9\%), low birth weight and respiratory distress syndrome (3.6\%), diarrhoeal disease (3.4\%), ischaemic heart disease (2.8\%) and stroke $(2.5 \%){ }^{28}$ These statistics show that certain areas of the Western Cape also experience the 
quadruple burden of disease experienced by the rest of the country, which is characterised by a high prevalence of HIVIAIDS and TB, maternal and childhood illnesses, intentional and nonintentional injuries and NCDs. ${ }^{107}$ The prevalence of HIV in the Mitchells Plain sub-district is $13.3 \% .^{29} \mathrm{HIV}$ prevalence increased in Mitchells Plain, from 5.1\% in 2005 to $13.3 \%$ in 2010, but seems to have stabilised from 2008 until 2010. ${ }^{138}$ In the Metropole District, a positive correlation has been suggested between increased HIV prevalence and living in an urban, informal area; having a lower education level and a lower total income. ${ }^{139}$ The 2009 HIV prevalence for the Western Cape Province was $16.9 \%,{ }^{140}$ so the Mitchells Plain HIV prevalence is relatively close to the Provincial prevalence. During 2010, TB incidence in the Western Cape was 909 per $100000 .{ }^{141}$ The infant mortality rate in Mitchells Plain was 21.3 per 1000 in $2007 .{ }^{141}$ According to the SANHANES report, in the Western Cape, $26.9 \%$ of males were overweight and $16.1 \%$ obese (both higher than the national averages), while $24.5 \%$ of women were overweight and $37.9 \%$ obese (both similar to national averages). ${ }^{7}$

\subsubsection{Inclusion and exclusion criteria}

Individuals who could speak either English or Afrikaans were considered for the study. Based on the most recent data available, the majority of the population in Mitchells Plain speak either English or Afrikaans. ${ }^{131,132,133}$ The Principal Investigator (PI) speaks English and Afrikaans, and personally conducted the IDIs in order to gain research experience. This, combined with the fact that it would take too many resources (financial and time) to be able to include individuals who could speak only Xhosa (and this comprises the minority), motivated the decision to include individuals who could speak Afrikaans and/or English only. Participants needed to be women or men between the ages of 18 and 60 years. Individuals excluded from the study were those who could speak only Xhosa, and those under the age of 18 or over the age of 60 years.

\subsection{SAMPLING STRATEGY}

\subsubsection{Sample size}

Sample size determination in qualitative methodology can be dependent on the researcher continuing with data collection until there is enough information to answer the research question, or until no more new information is being extracted (i.e. the data has been 'saturated' or information obtained seems repetitive). ${ }^{130}$ More often, however, sample size is dependent on available funding and time constraints. ${ }^{130} \mathrm{~A}$ typical number of FGDs can range from two or three up to six or seven FGDs. ${ }^{142}$ For this research project, a combination of the two factors, ('saturation principle' and available resources) was used to determine sample size. 
It was initially proposed that three FGDs of approximately eight individuals each would suffice, followed by ten IDIs. This would have resulted in a total sample size of 24 individuals for the FGDs and ten individuals for the IDIs. During the research process, however, it was determined by the PI that an additional FGD was needed, and therefore four FGDs were conducted, with between nine and eleven participants each, resulting in a total of 40 participants taking part in the four FGDs. It was initially proposed that ten IDIs be conducted, but during the research process it was determined by the PI that more IDIs were necessary because it was felt that 'data saturation' had not yet been reached. Eventually, a total of 15 IDIs took place. This was due to the fact that quite a number of key informants were identified from the FGDs. It was felt by the PI that more people could have been interviewed to ensure that the amount of information obtained was appropriate for a mini-dissertation for a Master's degree, but the final number was limited by time constraints.

\subsubsection{Sample selection methods}

For qualitative research, sampling usually takes a targeted or purposive approach ${ }^{143}$ as opposed to formal random sampling. The depth of information obtained is more important than selecting a strictly representative sample from which statistical inferences can be made. ${ }^{130}$ Certain efforts were made to deliberately choose individuals who reflected the range of possible characteristics displayed by members of the study population (as opposed to haphazardly selecting the sample based on convenience). For this study, an attempt was made to choose a range of key individuals from the population that represented some of the important subgroups of the population, as well as individuals who were influential at various stages of the food system.

In order to gain access into the community, consultation with and permission from the Ward Councillor was obtained. A letter, providing a brief summary of the study and requesting permission to conduct data collection in the area, was sent to the Ward Councillor of Ward 79 (see Addendum C) and permission to conduct the research was granted. The Ward Councillor also assisted with the recruitment process. A flyer was developed that contained information about the study and this was used for recruitment (see Addenda D and E, in English and Afrikaans, respectively). The Ward Councillor recommended the use of pre-existing groups of individuals in the community. For the older female category, ten women were selected from a senior support group, consisting of women and men between the ages of 50 and 70 years who regularly met at the Eastridge library hall. The first group of younger females was selected by attending a youth event in the Beacon Valley and recruiting ten women between the ages of 18 and 30 years who attended the event. The logistics around the organisation of the second FGD were not good, and it was felt that this negatively impacted on the quality of information obtained from this FGD. Reasons for this were that the women had not been notified prior to the time, and there was a lot of 
background noise from the youth event that was taking place at the same venue. It was therefore decided to conduct a second FGD with women in the 18 to 30 years category. The method of selection of participants for the second younger female and the male group was the same. Flyers were displayed at the Beacon Valley and Eastridge Community Centres (for approximately one week), together with a list where volunteers could write down their names and contact details. The $\mathrm{PI}$ then contacted the individuals and those that were in the correct age range and were available to attend the FGD at the set time were invited to participate. Approximately 12 individuals were invited to each FGD (with the assumption that a few would not arrive on the day). This resulted in a total of 11 participants for the second younger female group, and ten participants for the male group arriving for the FGDs on the day.

\subsubsection{Sample description}

The four FGDs were conducted with three different groups of community members: young females (18 to $29 \mathrm{yrs}$ ), older females (50 to $70 \mathrm{yrs}$ ) and men (18 to $60 \mathrm{yrs}$ ). The second FGD conducted (involving young females) did not obtain as much information as was anticipated, and so it was decided by the Principal Investigator to re-do this FGD with another group of women in order to obtain better quality information, which is why four FGDs were conducted instead of the originally proposed three. Results from both of these FGDs are considered in the results and data analysis sections of this thesis. The aim of the FGDs was to obtain broad information from community members on factors affecting fruit and vegetable consumption, as well as to identify relevant key informants for the IDIs. Information obtained from the FGDs was used to guide the formulation of questions to be used for further, more in-depth probing of the IDIs.

With regard to the first FGD, women up to the age of 70 years were in fact used (and not only women up to the age of 60 years as was initially proposed), due to the fact that the women were recruited from a senior group that consisted of women who were mostly over the age of 60 years. This is something that was determined just as the FGD was about to be conducted. This is different to what was indicated in the protocol but, although women older than 60 years may not be as involved in decision-making around food purchasing and preparation, it was considered not to be something that would affect the results negatively, and it was felt that they had valuable prior experience.

Following the FGDs, 15 IDIs were conducted with individuals who were considered to be the key informants of the community, with regard to fruit and vegetable consumption. For the selection of individuals for the IDIs, a more targeted approach was taken. An attempt was made to purposefully select individuals who had a certain degree of influence over the food consumed in households or 
institutions and therefore had some influence on whether or not people were eating fruit and vegetables. Information obtained from the FGDs provided guidance as to the types of individuals that should be interviewed individually and in-depth. It was anticipated that people such as caregivers, shop owners and health workers may have emerged as those who exerted some influence over whether or not individuals consumed fruit and vegetables. The following categories of individuals were finally selected for the IDIs: the Ward Councillor, people involved in selling fruit and vegetables, educators, religious leaders, health care staff and managers of kitchens, amongst others. Tables 3.1 and 3.2 in the Results section display a full description of the individuals selected for the FGDs and IDIs.

\subsection{METHODS OF DATA COLLECTION}

Table 2.2: Summary of methods used

\begin{tabular}{|c|c|c|c|c|c|}
\hline OBJECTIVE & PARTICIPANTS & $\begin{array}{c}\text { TIME } \\
\text { FRAME }\end{array}$ & VENUE & METHODOLOGY & FIELD WORKERS \\
\hline $\begin{array}{l}\text { 1. Gain broad } \\
\text { understanding of factors } \\
\text { that influence fruit \& } \\
\text { vegetable (F\&V) } \\
\text { consumption in Mitchells } \\
\text { Plain (MP) }\end{array}$ & $\begin{array}{l}\text { Four groups: } \\
\text { - } \quad \text { Young women } \\
\text { (18-29 yrs) X } 2 \\
\text { - } \text { Older women } \\
\text { (30-70 yrs) } \\
\text { - Men } \\
\text { (18-60 yrs) }\end{array}$ & $\begin{array}{l}10 \\
\text { December } \\
2012- \\
23 \\
\text { January } \\
2013\end{array}$ & $\begin{array}{l}\text { Community } \\
\text { sites } \\
\text { (library, } \\
\text { school or } \\
\text { church } \\
\text { hall) }\end{array}$ & $\begin{array}{l}\text { FGDs } \\
\text { (recorded using a } \\
\text { voice recorder) }\end{array}$ & $\begin{array}{l}\text { Principal Investigator } \\
\text { was facilitator; two } \\
\text { research assistants } \\
\text { assisted with } \\
\text { observing, note- } \\
\text { taking, } \\
\text { transcribing. }\end{array}$ \\
\hline $\begin{array}{l}\text { 2. Gain in-depth } \\
\text { understanding of } \\
\text { underlying causes of low } \\
\text { F\&V consumption at } \\
\text { individual \& household } \\
\text { (HH) level; Use main } \\
\text { topics identified in FGDs } \\
\text { as starting point for } \\
\text { interviews }\end{array}$ & $\begin{array}{l}\text { Targeted key } \\
\text { individuals, to } \\
\text { represent } \\
\text { community } \\
\text { members who } \\
\text { have some } \\
\text { influence on F\&V } \\
\text { consumption }\end{array}$ & $\begin{array}{l}4-23 \\
\text { January } \\
2013\end{array}$ & $\begin{array}{l}\text { In HHs, at } \\
\text { workplaces } \\
\text { (e.g. for } \\
\text { shop } \\
\text { owners, } \\
\text { the shop } \\
\text { where they } \\
\text { sell F\&V) }\end{array}$ & $\begin{array}{l}\text { IDIs } \\
\text { (recorded using a } \\
\text { voice recorder) }\end{array}$ & $\begin{array}{l}\text { Principal Investigator } \\
\text { was interviewer and } \\
\text { one of the assistants } \\
\text { did the } \\
\text { transcribing. }\end{array}$ \\
\hline
\end{tabular}

A combination of two types of qualitative methodologies was used, namely focus group discussions (FGDs) and in-depth interviews (IDIs). An attempt was made to use photo documentation as a complementary technique together with the IDIs to stimulate discussion and enrich the data, but this was not successful (see section 2.6.4 on Photo documentation for an explanation of this). This research was conducted with a people-centred, participatory approach, to gain in-depth information on the immediate, underlying and basic factors that influenced fruit and vegetable consumption in this area, and to be able to understand some of the reasons why fruit and vegetable consumption remained low. Qualitative methodologies are more flexible in nature, and allow the conceptual frameworks to be adapted during the research process. ${ }^{144}$ Therefore, the question guides that were developed (see Addendum J) provided broad themes and topics, with 
examples of questions to be asked, however, more specific and exact questions were developed during the data collection process. Some questions from the question guide were adapted slightly, following the pilot study (see section 2.9 for a description of the pilot study), as is common in qualitative research. The question guide was further slightly adapted between each FGD and then in between the IDIs, based on responses received. This is an important characteristic of qualitative research, which allows for the acquisition of more in-depth information. Instead of asking the same questions over and over and getting similar answers, the approach that was taken was to try to focus on specific topics raised by participants and probe various topics in more depth. The PI also removed certain questions that were felt to provide meaningless or superficial information.

All participants were provided with refreshments (juice, nuts and dried fruit) after they had taken part in the FGDs and IDIs. All participants were presented with a bag of three or four different types of vegetables (for example, one participant could be given a bag of carrots, a pack of three green peppers and a container of blueberries) as a token of appreciation for giving up some of their time to take part in the study. An effort was made to provide participants with 'appealing' vegetables and fruit that were more expensive than what they may normally purchase, as a way of showing appreciation. Participants were also given suggestions on how to improve fruit and vegetable consumption and recipes that included fruit or vegetable ingredients (see Addendum K).

\subsubsection{Training of field workers}

The Principal Investigator (PI) was the facilitator for the FGDs and the interviewer for the IDIs, and was assisted by two trained field workers. Initially, it was the intention of the PI to recruit community health workers who work and/or live in the Mitchells Plain area to be trained and then assist with the data collection process. However, during the research process it was realised that the field workers would need to assist with the transcription of the FGDs and IDIs, and would therefore need to be computer literate. Upon investigation of the community health workers available (which was done by the PI together with the Community Based Services Co-ordinator in the Mitchells Plain area), no community health workers were computer literate and other avenues had to be explored to recruit assistants for the data collection process. A Nutrition Advisor who had worked in Mitchells Plain and a dietitian wanting to gain some research experience were identified by the PI to assist (as field workers) with data collection and data capturing (i.e. transcription).

Before data collection began, these two assistants were trained to assist with the recruitment of participants, facilitation of the discussions and interviews, note-taking and observation during the FGDs and IDIs, and to assist with the transcription of the FGDs and IDIs. Training was provided by the Principal Investigator, based on the United States Department of Agriculture (USDA) Food 
Security Assessment Toolkit: Focus Group Guide ${ }^{145}$ and the Family Health International (FHI) Qualitative Research Methods: Data Collectors Field Guide. ${ }^{146}$ The PI also used the skills gained and material provided from the Qualitative Research Methods for Health Sciences short course as tools for providing training to the field workers. The PI wanted to be involved in as much of the data collection and transcription as possible, and the field workers were used to assist where necessary. The Nutrition Advisor was used to facilitate the FGDs and was used for a total of three full days. The dietitian assisted with some of the recruitment of individuals for the IDIs and most of the transcription and was used for a total of approximately 28 days. Transcription of each FGD and IDI took approximately one full day (eight hours) and there were 19 transcriptions in total.

Because this was the first time that the field worker had transcribed interview recordings, the PI reviewed each recording by listening to the recording and reading through the transcript and made any corrections where necessary, as a form of quality control. This also formed part of the PIs immersion in and familiarisation with the data, as is recommended in qualitative data analysis. ${ }^{147}$

\subsubsection{Focus group discussions}

The FGDs were separated according to age and gender, in order to keep them as homogeneous as possible, so that all participants were made to feel that they could contribute honestly and were not intimidated by other group members. The aim of the FGDs was to stimulate group discussion and not merely to allow for questions and answers between the moderator and individuals in the group. ${ }^{142}$ An attempt was made to allow individuals to agree or disagree with each other in order to allow for a range of opinions and ideas to be expressed on beliefs, knowledge and practices surrounding fruit and vegetable consumption. The PI tried to set the tone of the FGDs to allow for people to speak openly and honestly without fear of criticism or judgement. (See Addendum $\mathrm{J}$ that describes the explanation that participants were given as to how the FGDs should be conducted.)

The manner in which a FGD is conducted is important, and the following principles were followed in the facilitation of the FGDs for this study. The moderator started by informing the participants that the researchers were interested in asking some questions around eating practices. When starting with the research questions, the moderator started with simple, easy questions and then moved onto more complex questions. Participants were not made to feel as though they should know the answers. During the process, the moderator needed to re-word questions, or ask them again in a different way when they were not understood clearly. The moderator used the list of potential guiding questions (Addendum J). The note-taker was present and made notes on nonverbal communication (that may have influenced the interpretation of recorded information), and 
wrote down main points that were discussed. Each FGD took approximately one hour. The optimal length for a FGD is between 60 and 90 minutes. ${ }^{130}$

The question guide (presented in Addendum J) provides a list of possible guiding questions to direct the interviewer. Participants were asked questions to determine the following: whether or not participants considered healthy eating and fruit and vegetable consumption to be important, reasons why participants eat fruit and vegetables, a summary of favourite fruit and vegetable dishes, a description of purchasing patterns of fruit and vegetables, and predominant preparation techniques of fruit and vegetables. These questions served as a guide for the interviewer, and were not necessarily asked in the exact order that they appear in the Addendum. The interviewer asked broad, open questions, and then allowed the participants to discuss in depth certain issues that they felt to be more important. Therefore, different themes from the question guide were dominant in different interviews.

A voice recording of every FGD was made, to represent a true account of what was discussed by the participants. These recordings were then fully transcribed and listened to again and again, while data analysis took place. This was important to allow for good quality data and it allowed the data to be analysed in detail. All transcriptions were completed four months after the FGDs had been conducted. The fieldworkers took longer than anticipated to complete the transcriptions, due to their limited experience and other demands on their time. The FGDs were not all transcribed and analysed before the IDIs took place (due to time constraints for data collection). However, the question guide was adapted slightly after the FGDs were conducted. Two FGDs (the older female and one of the younger female groups) were done before the IDIs started, but two FGDs (the second younger female and the mixed male) were done in between the IDIs (i.e. not after all of the IDIs had been completed). This was due to time constraints and the logistics of organising the FGDs and getting the appropriate participants together. The PI felt that the IDIs could not be delayed until after all FGDs had taken place, otherwise it would not have been possible to do all of the IDIs in time, due to time and resource constraints.

\subsubsection{Individual in-depth interviews}

The next step of the data collection process was to conduct the IDIs. The questioning for these interviews was based on the same question guide as the FGDs (Addendum J), with adaptations as the interviews progressed. However, the approach with the IDIs differed slightly in comparison to the FGDs. Because participants were selected for the IDIs based on their influence on the food system, they were first questioned on their role with regard to food preparation, provision and distribution, as well as any influence they may have had on other community members due to their 
position as a community leader. They were also asked to provide their opinion on possible underlying reasons for certain community behaviours that could influence fruit and vegetable consumption. The question guide was continuously updated during the data collection process. One of the aims of the FGDs was to provide guidance on topics and themes that needed to be explored in greater detail during the IDIs. During the IDIs, further adaptations to the question guide were made. When it was felt that certain questions had been satisfactorily answered and were producing similar responses, those questions were removed and additional questions were added, based on previous discussions or issues raised by participants. The IDIs were also recorded on a voice recorder (with permission from the interviewees). The interviewer directed the discussions, so that the necessary information could be obtained, but still allowed respondents flexibility to cover topics from their own perspective, and as they deemed important. ${ }^{130}$ The interviewer allowed spontaneity and the interviews were not overly structured.

The interviews took place in people's homes or at people's workplaces (e.g. when interviewing a shop owner, the interview took place at the shop where fruit and vegetables were sold), to make it easier for the interviewee, as well as to allow the researcher to observe certain practices in the household or workplace (such as if there was any fruit and vegetables present, and if so in what form). The atmosphere was comfortable, open and professional. The interviews all lasted approximately one hour. The initial phase of the interview was quite important, to build up trust between the interviewer and interviewee in order to ensure that accurate and honest information was obtained. Privacy and confidentiality were important factors and treated as such. The interviewer asked open questions and used techniques of summarising and clarification to ensure that the correct meaning, understanding and perceptions of the interviewees was obtained. ${ }^{130}$ Summarising involved repeating back to the interviewee (after the answer had been given) to ensure that the interviewer had understood the interviewees' opinions accurately, as well as to allow the interviewee to think further on the topic. Clarification aimed to elicit explanations on issues that were raised by the interviewee, of which the interviewer was not entirely clear. At the end of the interview, the interviewees were informed of what would be done with the data, were assured that confidentiality would be maintained and were told where they could get feedback of the results, at a later stage if they wished.

Initially, ten IDIs were to be conducted, but 15 IDIs were done in total. This was because some interviews were quite short and not much information was obtained, but also because some interviewees recommended other people to be interviewed (i.e. the 'snowballing' approach to sampling was used) and this resulted in slightly more IDIs than were initially anticipated. 


\subsubsection{Photo documentation}

An attempt was made to employ photo documentation ${ }^{148,149,150}$ as a methodology to complement the IDIs. The intention was for participants to take photographs of any situation involving fruit and vegetable consumption, and that this could have stimulated or directed discussion during the interviews. Unfortunately logistical challenges were encountered with the physical taking and developing of the photographs using disposable cameras. Some participants struggled to take photographs with the equipment provided, and it was a challenge to find services to develop the photographs quickly. The use of photo documentation proved to be labour intensive and due to time constraints, it was therefore not possible to make full use of this methodology.

Two participants who were selected for an IDI were given disposable cameras one week before their interview, and asked to take photographs of any situation involving food purchasing or the sale of food, food preparation and consumption, in order to make use of 'participant generated photographs'. These photos were then developed before the interview took place. The aim was to use these photographs to stimulate discussion on the consumption (or lack of consumption) of fruit and vegetables, during the interviews. The use of visual images together with in-depth interviews was intended to provide further insight into some of the barriers to and facilitating factors of fruit and vegetable consumption.

Unfortunately, challenges were encountered with this form of data collection. Due to time constraints, not all participants were issued with disposable cameras. The PI initially wanted to use digital disposable cameras, but these were difficult to obtain. Therefore ordinary (film) disposable cameras were obtained. In Cape Town, there was only one shop that could develop disposable camera photographs within one hour. All other stores sent the spool away and it could take up to ten days to be developed. There were therefore many more activities involved in using photo documentation than was initially anticipated. Furthermore, with the two participants who did take photos and that the PI managed to have the photos developed before the interviews, not all of the photos could be printed. The PI suspects that the camera may have been opened in the process of taking the photographs, therefore damaging the spool. This could have been due to the fact that most people are now unfamiliar with how to operate these types of cameras. The few photos that were printed were used for the discussion. As a last resort, the PI requested some participants to record photos on their personal mobile phones or cameras, but one participant forgot to do this before the interview and another participant forgot to bring the camera that was used to take the photos. 


\subsection{ANALYSIS OF DATA}

The approach for analysing data from the FGDs and IDIs was similar. The data analysis for qualitative research follows a content analysis approach, as opposed to rigorous statistical analysis. Content analysis involves examining the data for common themes, and these themes are grouped into units of meaning (or groups of similar information). These are then coded (categorised according to topics). ${ }^{130}$

The first step of the data analysis process was the full transcription of all recorded interviews i.e. everything discussed during the interviews was typed out, word for word. This was done by one of the field workers and checked for accuracy by the Principal Investigator. Analysis started taking place while transcription was being done, by identifying major opinions and attitudes while reading through the transcripts. ${ }^{142}$ The next step was to code common themes in the data. Coding organises the data and provides a means to interpret it. Each segment was labelled with a 'code', which is a word or phrase (a summary or label) that suggests how the data segments relate to the research objectives. Coding can be considered as the process during which data is broken down, conceptualised and integrated to form a theory. Segments with similar content were then assembled into broader categories (this is how conceptualisation takes place). Core categories were then identified and compared to other categories or segments. Coding can start as quite simple, broad or over-arching categories, but data can then be classified according to more complex sub-categories. As the codes became more complex, it was necessary to start summarising and interpreting the data, for example, by identifying themes that were often mentioned (by various different interviewees).

After coding, the PI then summarised the results and started to identify major common themes. Themes were regarded as strong or weak, based on a combination of how much discussion was focused on the particular theme, as well as on whether the theme was mentioned by many or few participants. The researcher took care not to simply reduce the qualitative data and remove its depth, richness and individual character while trying to identify the common or strong themes. The data was linked to underlying codes, and with the presentation of the data, quotes or key statements made by some of the participants were included, to explain the content of what the code stood for. No software tool was used for data analysis, but rather the thematic content analysis approach that the PI had been taught during the qualitative research course attended.

Throughout the process, data was compared to the research objectives and when there was new information that was not listed in the project aims, it was also coded and interpreted. The researcher kept records of code lists, which were summaries of what codes were used to describe specific topics. This allowed the researcher to log each response made under a specific code. 
Results for each FGD were initially kept separate and analysed separately, and then all of the FGDs were analysed together for common themes, as is recommended in the literature. ${ }^{142}$

With the writing up of the results, responses that were made most often were included. Since a large amount of information was obtained, information needed to be prioritised and decisions were made on what information was summarised, and what was quoted verbatim, as is recommended in the literature. ${ }^{142}$ An attempt was made for interpretation to take place at all stages of the research process.

Data analysis for qualitative research does not use statistical analysis and therefore, the use of a statistician was not necessary. There was consultation with an expert in the field of qualitative research, in an attempt to ensure the validity and accuracy of the data analysis. Furthermore, the Principal Investigator took an elective short course at Stellenbosch University (Qualitative Research Methods for Health Sciences) in order to improve her skills in the data collection and analysis phases of qualitative research. ${ }^{151}$

\subsection{ETHICAL CONSIDERATIONS}

\subsubsection{Ethics Review Committee}

A research protocol was submitted and ethics approval was obtained from the Stellenbosch University Health Research Ethics Committee in October 2012 (Reference number: S12/08/211). Ethical approval was obtained prior to the pilot study and data collection. As per the Guidelines for approval of health research in the Western Cape, a study of this nature (i.e. a community-based study) did not require approval from the Provincial Health Research Committee. ${ }^{152}$ However, a community leader (the Ward Councillor) was contacted in order to gain access to the community.

\subsubsection{Informed consent}

All participants took part of their own free will. If a person was unwilling to take part, this was respected with no negative consequences, and if participants wished to leave at any stage before the data collection process was complete, this was allowed. No participants declined to take part in the research because they objected to being involved, but rather two participants had to leave early due to logistical issues and prior commitments. Once individuals were selected, they were presented with the Volunteer information sheet (Addenda F and G, in English and Afrikaans, respectively) and were allowed to decide whether or not they would like to participate in the research study. They then signed the Volunteer informed consent form (Addenda $\mathrm{H}$ and $\mathrm{I}$, in English and Afrikaans, respectively) before any data collection took place. Individuals were 
adequately informed with regard to the time and where they were expected to be available to participate.

\subsubsection{Participant confidentiality}

The Principal Investigator ensured that confidentiality was maintained. Participants were numbered and not referred to by name during the data analysis and presentation of results. The FGDs and IDIs were conducted in a private manner. The FGDs were done in a room, with the door closed and people were not allowed to move in and out while the discussions were taking place. The IDIs were conducted in people's houses or workplaces, but a quiet room was chosen, where minimal interruptions were expected. Data was not presented and discussed in a manner that exposed or identified individuals (by ensuring that the name of the individual or any other revealing information did not appear on the interview transcript; interview data is referred to by code, and care was taken in writing up the analysis to ensure that identities were protected). Information was represented as accurately as possible, to avoid misrepresentation of the data. The researcher attempted to refrain from giving advice or information during data collection, and when participants requested such information, they were referred appropriately. For example, if a participant started to ask questions on how to determine whether or not their child was underweight, the PI would refer the participant to their nearest clinic and, once the FGD/IDI had been completed, the PI would provide the participant with the appropriate information.

\subsubsection{Perceived risks}

There were no perceived risks associated with taking part in this study. The proposed benefits were that the study would provide understanding as to why people in the Mitchells Plain area do or do not consume the recommended amount of fruit and vegetables on a daily basis, and to identify some of the underlying factors that influence fruit and vegetable consumption in this area. This information would be passed on to relevant stakeholders and could hopefully be used to guide future nutrition interventions, as well as to inform future research that will enable individuals to increase their consumption of fruit and vegetables. The long-term benefit would be improved eating habits that would result in improved micronutrient and nutrition status, with the concomitant improved health outcomes (and reduced disease).

\subsection{PILOT STUDY}

The pilot study took place during October and November 2012, and the participants were health care workers in the Mitchells Plain sub-district. One group (six individuals) of health care workers (three health promoting officers, one breastfeeding peer counsellor and two HIV counsellors) was selected from the Mitchells Plain Community Health Centre for a pilot FGD. Two individuals (a 
Nutrition Advisor at Crossroads Community Health Centre and an HIV counsellor at Mitchells Plain Community Health Centre) were selected, with whom IDIs were conducted. Unfortunately, the photo documentation phase of the data collection was not piloted.

The participants for the pilot study were strategically selected based on their role in nutrition education in Mitchells Plain. An attempt was made to ensure that the participants selected for the pilot study were similar in characteristics to the study population. The sample consisted of 'lay' health workers who had received no tertiary level training, because the majority of the community members in Mitchells Plain do not have tertiary education. ${ }^{131,132,133}$

The first participant chosen for the IDIs was the Nutrition Advisor, because Nutrition Advisors should be the most knowledgeable about nutrition and spend the most amount of time providing nutrition education and therefore be able to provide good quality information on perceptions surrounding fruit and vegetable consumption. Since the Nutrition Advisor was female, for the purposes of consistency, females only were included in the pilot study. The second individual selected was an HIV counsellor at the Mitchells Plain Community Health Centre Anti-retroviral site, because although HIV counsellors are expected to give information on wellness (that should include nutrition education), they receive limited nutrition training. Both interviews lasted approximately 30 minutes. The PI learned invaluable lessons in conducting the interviews, most notably that she did not give the respondents enough time and prompting to respond adequately to the questions, and that the interviewer spoke too much. This ensured a shift in the manner in which the FGDs and IDIs were conducted for the actual data collection component of the research, to ensure improved quality. The interviews were transcribed and analysed. The first time the PI developed a theme list, it was reviewed by a qualitative research expert, and not considered to be done adequately, but the second attempt was much improved and assisted to ensure that data analysis of the actual research was of an appropriate standard. The results were written up (to allow the PI to practice this part of the process), using discussion that included the presentation of relevant quotes from each interview.

The question guide was slightly adapted following the pilot study. The pilot study also allowed for the practice of methods to be used including facilitation, observation and transcription. 


\section{RESULTS}

The Results chapter begins by providing a description of the socio-demographic profile of the participants of this study. Following this, the themes that developed from all discussions are described. Predominant themes from the FGDs and IDIs were grouped together. The results start by explaining current practices associated with fruit and vegetable consumption. These include the description of common dishes using fruit and vegetables that were consumed in various settings, fruit and vegetable preparation methods, fruit and vegetable access and the changes in eating patterns that have occurred over a generation. Possible explanations for current practices are then provided. The predominant attitudes and perceptions that influence fruit and vegetable consumption are discussed. Finally, suggestions to increase fruit and vegetable consumption that were provided by the participants themselves are reported.

\subsection{SOCIO-DEMOGRAPHIC PROFILE OF PARTICIPANTS}

Of the individuals who participated in the IDIs, the mean age was 47.4 years and the age range was from 30 to 68 years; there were seven females and eight males; 14 coloured and one black African participant; eight participants for whom Afrikaans was their first language, six who were first language English speakers and one first language Xhosa speaking participant; 13 who were married and two unmarried, and 14 employed and one unemployed participant (Table 3.1).

Table 3.1: Socio-demographic characteristics of participant selected for focus group discussions

\begin{tabular}{|c|c|c|c|c|}
\hline & Older females & Younger females 1 & Younger females 2 & Mixed men \\
\hline $\begin{array}{c}\text { Age (years) } \\
\text { Mean } \\
\text { Range }\end{array}$ & $\begin{array}{c}64.2 \\
52-72\end{array}$ & $\begin{array}{c}24.6 \\
17-34\end{array}$ & $\begin{array}{c}26.3 \\
20-38\end{array}$ & $\begin{array}{c}37.3 \\
20-58\end{array}$ \\
\hline $\begin{array}{l}\text { Gender } \\
\text { Female } \\
\text { Male }\end{array}$ & $10(100)$ & $9(100)$ & $11(100)$ & $10(100)$ \\
\hline $\begin{array}{c}\text { Ethnicity } \\
\text { Coloured } \\
\text { Black African }\end{array}$ & $10(100)$ & $\begin{array}{l}8 \text { (88.9) } \\
1 \text { (11.1) }\end{array}$ & $11(100)$ & $\begin{array}{l}9(90) \\
1(10)\end{array}$ \\
\hline
\end{tabular}


Table 3.2: Description of participants selected for individual in-depth interviews

\begin{tabular}{|c|c|c|c|}
\hline AGE & GENDER* & RACE** & POSITION IN COMMUNITY \\
\hline 56 & M & C & Sports and recreation coordination and body building trainer \\
\hline 54 & $\mathrm{~F}$ & C & Informal vendor selling fruit and vegetables \\
\hline 50 & $\mathrm{~F}$ & $\mathrm{C}$ & Crèche manager and person in charge of food provision \\
\hline 48 & M & $\mathrm{C}$ & Imam at a mosque (Muslim religious leader) \\
\hline 38 & $\mathrm{~F}$ & $\mathrm{C}$ & Professional nurse responsible for nutrition programmes at a clinic \\
\hline 68 & M & $\mathrm{C}$ & Member of a health committee forum \\
\hline 30 & M & $\mathrm{C}$ & Ward councillor \\
\hline 50 & M & $\mathrm{C}$ & Manager/owner of convenience store selling fruit and vegetables \\
\hline 45 & M & $\mathrm{C}$ & Tuck shop manager at a primary school \\
\hline 39 & M & $\mathrm{B}$ & Urban farmer managing a school garden project programme \\
\hline 33 & $\mathrm{~F}$ & $\mathrm{C}$ & Private hospital kitchen manager \\
\hline 59 & M & $\mathrm{C}$ & Pastor's assistant (Christian religious leader) \\
\hline 47 & $\mathrm{~F}$ & $\mathrm{C}$ & Manager of a catering company (caters for functions in Mitchells Plain area) \\
\hline 50 & $\mathrm{~F}$ & $\mathrm{C}$ & Grade 1 educator (teaches Lifeskills Orientation) \\
\hline 44 & $\mathrm{~F}$ & $\mathrm{C}$ & Frail care centre (old age home) kitchen manager \\
\hline
\end{tabular}

${ }^{*} \mathrm{M}=$ Male, $\mathrm{F}=$ Female; $\quad$ ** $\mathrm{C}=$ Coloured, $\mathrm{B}=$ male

The main themes identified during the FGDs and IDIs could be grouped into four over-arching categories: current practices associated with fruit and vegetable consumption; underlying factors affecting current fruit and vegetable consumption patterns; attitudes and perceptions that influence fruit and vegetable consumption; and suggestions (provided by participants) of ways to improve fruit and vegetable consumption.

\subsection{CURRENT PRACTICES ASSOCIATED WITH FRUIT AND VEGETABLE CONSUMPTION}

During the FGDs and IDIs, when current fruit and vegetable consumption practices were discussed, dominant themes that were explained by participants included their respective individual, family and community eating patterns (and how these impacted on fruit and vegetable consumption), as well as fruit and vegetable consumption associated with religious, cultural or traditional activities, and seasonal variations in fruit and vegetable consumption. 


\subsubsection{Fruit and vegetable consumption patterns}

\subsubsection{General eating patterns and fruit and vegetable consumption: personal, family and community}

Some issues were discussed around general eating and meal patterns in order to understand how the consumption of fruit and vegetables fit into daily eating patterns. Participants' responses were explained in terms of their own personal eating patterns, family eating patterns and general eating patterns of the community.

\subsection{Personal eating patterns}

Some participants explained that their working days were erratic and unpredictable, so they could not always plan meal times and this could result in meals being skipped as well as eating whatever was available to them. One participant stated that he never eats take-aways at home, but sometimes at work, where his colleagues would order take-aways and he would then join them. Two participants ate more fruit and vegetables compared to others, by default, because they chose to eat little or no red meat: one participant became vegetarian after working at an urban agriculture project for a few years; another participant tried not to eat red meat because of the health impact (she believed that eating a lot of red meat was not healthy) but also because of the negative impact on the environment.

\subsection{Family eating patterns}

The discussion around family eating patterns reflected that often the whole family's eating patterns could be influenced (positively or negatively) by one individual. Some participants explained that a family member "had become more health conscious" (either because they were diagnosed with a NCD and needed to change their eating behaviours or due to influence from someone else). This individual therefore started preparing healthier meals, which tended to include more fruit and vegetables, and this impacted positively on the rest of the family. One participant hardly ate vegetables when he was married to his first wife, but since marrying his second wife, had eaten vegetables every day because his second wife was of the opinion that it was very important in the prevention of NCDs. One participant had a son who had adopted a Rastafarian lifestyle, and when he came to visit or stayed with them, they then ate more vegetables, because he did not eat meat.

One participant explained that she was overweight but did not want her children to be overweight, so she prepared healthy food and ensured that they ate fruit and vegetables daily. Another participant explained that he had three children and started realising how expensive education and general living costs were, so the family started to make a conscious effort to decrease take-aways and eat more home cooked meals as a strategy to save money. Still another participant thought 
healthy eating was very important, and saw that some family members did not eat as healthily as they could but “...doesn't want to disturb anyone" and therefore does not say anything about it to them. (Male, health committee member, IDI)

Many participants were involved in some form of food production or sale, and this had an impact on what they ate. For example, the two participants who sold fruit and vegetables explained that they always had vegetables in the house and therefore probably had a relatively high fruit and vegetable consumption, whereas the person who managed the tuck shop sometimes took some of the unhealthier meals that had been prepared at the tuck shop and were left over, home for the family to eat.

\subsection{Community eating patterns}

In terms of the general eating habits of the community, a participant explained that there were some dishes commonly prepared (and considered to be 'cultural') that were unhealthy, such as koeksisters $^{b}$ or vetkoek ${ }^{c}$ but that there were also some 'cultural dishes' prepared that were healthier, such as bredies, vegetable stews and lentils and rice. (Female, clinic nurse, IDI)

There are therefore a diverse range of factors that interact to influence the eating patterns of individuals, families and communities. Some specific factors that potentially influence fruit and vegetable consumption were discussed during the FGDs and IDIs and will be explained further.

\subsubsection{Fruit and vegetable consumption: religion, culture and traditions}

Participants were asked to discuss whether or not fruit and vegetables were eaten at certain religious, cultural or other traditional events or at specific time periods. They were also asked what types of fruit and vegetable dishes were commonly consumed at these times.

\subsection{Religion}

With regard to Christian religious practices that involve fruit and vegetable consumption, two participants spoke about the 'Daniel Fast' which was explained to be periods of time where individuals eat only fruit and vegetables, the purpose of which is "to clean your body". It was also stated that the Bible refers to the importance of fruit and vegetables:

\footnotetext{
b 'Koeksisters' are similar to doughnuts and are either twisted, deep fried and covered in syrup or are prepared in an oval shape, fried and covered with dried coconut.

c 'Vetkoek' (which directly translates to 'fat cakes') are balls of dough that are deep fried in cooking oil (similar to a doughnut). They are either eaten on their own, or filled with mince or spread with jam.
} 
“...fruit and veg, and I mean even biblically... You know, its, it's healthy. Coz it even detoxes your body, takes out all the toxins, according to the, you know, Bible." (Male, sport and recreation coordinator, IDI)

An older female participant who was a Seventh Day Adventist explained that healthy eating, exercise and a general healthy lifestyle were specifically important as part of the specific religion. (Female, grade 1 educator, IDI)

With regard to the Muslim faith, Ramadan is an annual practice which involves a month of fasting during the day, every day. A few participants explained that they break the fast in the evening with fruit or vegetables. For example, some participants explained that they break the fast in the evening with an orange, others with a banana, some dates or vegetable soups. Some participants felt that they ate more fruit and vegetables during the month that they fasted, while others felt that they ate less fruit and vegetables and more unhealthy food, such as 'fried tidbits' which were explained to be samosas, spring rolls and pies, as well as mini pizzas and other similar fried and high fat foods. One participant mentioned that Indian people (as part of the Hindu faith), at religious times, would only eat vegetables and no meat. Some even exercised this practice one day a week. (Male, pastor's assistant, IDI)

\subsection{Culture and tradition}

For one participant (an older female), when there had been a death in the family, it was tradition to make the affected family a pot of food or stew, containing vegetables. She explained that if she made the stew when there had not been a death, then her family members would question her as to why she was making it:

“...especially the carrots and, and the pea stew, and they would always say in our culture, it is like, somebody dies in our culture. Then, the first food they would make was the, that veggie food. And they [family members] will always tell me, o jy, wiet daai dood kos gemaak ${ }^{d}$ No I love that food!" (Female, crèche manager, IDI)

Possible reasons provided for taking someone a pot of stew when they had a death in the family were that stew is something that is cheap to make, the ingredients are available, the food "goes far" and it is healthy.

Many people explained that they traditionally eat vegetables on a Sunday and this seemed to be quite important in households. One participant explained:

\footnotetext{
d "Oh you, who made that 'dead food'?"
} 
"We would go through, you know on, let's call it, coloured people, on our Sunday table, you will always find beetroot, squash, peas, beans, potatoes, you would have carrots, and so forth." (Male, health committee member, IDI)

One reason provided for eating vegetables on a Sunday was that in case no vegetables were eaten during the week, then at least you would get vegetables on a Sunday. Another tradition was the consumption of snoek (fish) and sweet potato on a specific day of the week, for example on Mondays:

"Daai is die ou mense se kos. Ja, patat en snoek. Elke Maandags". (Older female, FGD)

Participants were asked to describe specific dishes and meals that were made on special occasions (religious, cultural, traditional or other). Table 3.3 provides a full list of all fruit or vegetable dishes that were listed by participants to be eaten on special occasions or religious events.

\subsection{Job-specific eating patterns}

One participant who was involved in the taxi industry in Mitchells Plain, explained that because of the nature of their jobs, taxi drivers work from very early in the day and then at mid-morning will have a meal of fried chicken and chips (considered by the participant to be very unhealthy) and then later on might have a sausage with bread. Their eating times are dependent on how busy they are and when the quieter times are. The participant also explained that the drivers tend to buy food from informal vendors as opposed to bringing their own food from home. (Male, health committee member, IDI)

\footnotetext{
e "That is the old people's food. Yes, sweet potato and snoek. Every Monday."
} 
Table 3.3: Meals and dishes made on special occasions or for religious events

\begin{tabular}{|c|c|}
\hline Occasion & Meals and dishes commonly consumed \\
\hline Christmas & $\begin{array}{l}\text { - Meat is the priority: tongue, corned beef, braaied }{ }^{f} \text { meat, roast lamb, pork or turkey. } \\
\text { - Salads often accompany the meat: potato, four bean, baked beans, carrot, coleslaw. } \\
\text { - There are not usually vegetable side dishes like carrots or pumpkin served; but } \\
\text { sometimes people will have broccoli/cauliflower and white sauce. } \\
\text { - Pudding is often trifle (containing tinned fruit and decorated with strawberries or fresh } \\
\text { fruit), cake, fruit cake, Christmas cake or fridge tart with fruit. } \\
\text { - Watermelon is often eaten around this time. } \\
\text { - Dried fruit is usually available (often given as gifts). }\end{array}$ \\
\hline New Year & - Braai (meat) is the priority served with various salads ${ }^{g}$ (similar to Christmas). \\
\hline Easter & $\begin{array}{l}\text { - } \quad \text { Pickled, baked or curried fish, with onions. } \\
\text { - Served with buns, raisin bread or freshly baked bread. } \\
\text { - Not many vegetable dishes, except sometimes soup (might include vegetable soup). }\end{array}$ \\
\hline Weddings & $\begin{array}{l}\text { - Fruit is often served in the form of platters or used as table decorations. } \\
\text { - Salads are often served as a side dish. } \\
\text { - Traditionally, common dishes served are akhni (similar to breyani }{ }^{\mathrm{h}} \text { ), samoosas, spring } \\
\text { - } \text { rolls, pies and other fried foods, mini pizzas and to drink, tea, coffee and fruit juice. } \\
\text { - Sometimes broccoli/cauliflower and white sauce or other vegetables are served. }\end{array}$ \\
\hline Funerals & $\begin{array}{l}\text { - Sandwiches (with tinned fish, polony or cheese, tomato and lettuce as toppings). } \\
\text { - } \quad \text { Rice and chicken or breyani, depending on the budget; vegetables are not common. } \\
\text { - Vegetables (e.g. carrots, peas) in a stew are considered a custom of the older people. } \\
\text { - Indian funerals: entirely vegetarian dishes served (as with all Hindu religious events). }\end{array}$ \\
\hline $\begin{array}{l}\text { Death in } \\
\text { family }\end{array}$ & $\begin{array}{l}\text { - Community members should take the affected family a pot of food, "make the family a } \\
\text { pot of veggie food" [i.e. carrots/pea stew with meat, rice, potatoes]. }\end{array}$ \\
\hline Birthdays & $\begin{array}{l}\text { - } \quad \text { Potjiekos' (usually containing mixed vegetables). } \\
\text { - } \quad \text { Braais including meat such as chops or chicken with rolls and various salads and } \\
\text { - } \quad \text { Curry (meat or sugar beans, spices, not many vegetables) and roti with sambals. } \\
\text { - } \quad \text { Roast chicken with butternut and roasted vegetables. } \\
\text { - Meat, roast lamb (with onions and garlic inside the lamb), potatoes, carrots, roast } \\
\text { - } \quad \text { Pegetables, or broccoli/cauliflower cheese. } \\
\text { - } \quad \text { Might decorate the table with fruit. }\end{array}$ \\
\hline $\begin{array}{l}\text { Children's } \\
\text { parties }\end{array}$ & $\begin{array}{l}\text { - Cakes, sweets, chips and sometimes fruit. } \\
\text { - Do not give salads or cooked food. } \\
\text { - Hot dogs or burgers are often served (no fruit or vegetables). } \\
\text { - Sometimes watermelon is served; party packs sometimes contain a piece of fruit. }\end{array}$ \\
\hline Ramadan & $\begin{array}{l}\text { - A banana, orange or date is often used to break the fast. } \\
\text { - Soups are often eaten in the evening (often containing vegetables). } \\
\text { - Some people eat more fruit and vegetables during the fast, some eat less. }\end{array}$ \\
\hline
\end{tabular}

\footnotetext{
f 'Braai' is the South African term for a barbeque, where meat is cooked on an open fire.

${ }^{\mathrm{g}}$ Table 3.5 provides a full description of all salads that participants described as being commonly consumed.

h 'Breyani' is a dish of Indian origin with chicken, meat or vegetables and prepared with curry, spices, rice and lentils.

i 'Potjiekos' is a South African term for food that is cooked (usually in the form of a type of stew including meat, chicken and / or vegetables) in a round, cast iron, three-legged pot that is placed on a fire.
} 


\begin{tabular}{|c|c|}
\hline Occasion & Meals and dishes commonly consumed \\
\hline Sundays & $\begin{array}{l}\text { - Will always sit down and have a cooked meal and there will always be vegetables. } \\
\text { - } \quad \text { Braai, curry, breyani or stew with vegetables. } \\
\text { - } \text { potatoes, carrots, on a Sunday, mainly with roast chicken (if you can afford it), people } \\
\text { would see you as someone who had money, something to be proud of. } \\
\text { - Roast chicken and vegetables (carrots, pumpkin, squash, broccoli/cauliflower and } \\
\text { - } \quad \text { Mhite sauce); 'Everyone' makes chicken with rice, vegetables (pumpkin, fried potato). } \\
\text { - Vegetable pogetjie (sometimes with chicken or meat, but always with lots of vegetables). }\end{array}$ \\
\hline $\begin{array}{l}\text { Special } \\
\text { occasions }\end{array}$ & $\begin{array}{l}\text { - Seafood, crayfish or prawn curry and rice. } \\
\text { - Braai with potatoes, sweet potatoes, vegetables (pre-cut mixed packs), salads } \\
\text { (potato, beans, tossed), sausages and rolls. }\end{array}$ \\
\hline
\end{tabular}

\subsection{Reasons for serving specific meals or dishes at certain times}

- Christmas and New Year: It was explained that meat is the priority because "Throughout the year, people worry about vegetables, but not at Christmas or New Year." (Female, clinic nurse, IDI)

- Easter: Soup is sometimes served at Easter because it is starting to get closer to winter at that time of the year.

- Weddings: "...there used to not be a lot of vegetables and more meat; now they are serving more vegetables because meat is so expensive". (Female, clinic nurse, IDI)

- Death in the family: The reason for taking a pot of food is that it is healthy, cheap, available and "goes a long way".

- Birthdays: The reason why braais are favoured is that if other people come over, then at least the person whose house it is does not have to prepare all of the food, everybody will bring something and everyone will assist with the braai-ing, and it is social. It is therefore considered less effort to organise a braai than to prepare a cooked meal.

- Children's parties: Salads or cooked food is not given "because the children mess"; hot dogs or burgers are provided because they are the easiest to prepare and feed to children.

\subsubsection{Seasonal variation in fruit and vegetable consumption}

Some participants explained that certain fruit and vegetable dishes were eaten predominantly in winter, while others were eaten more commonly in summer. Table 3.4 provides a list of all of the fruit and vegetables that were mentioned with seasonal variation. 
Table 3.4: Food eaten predominantly in winter or summer seasons

\begin{tabular}{|c|c|}
\hline Season & Meals and dishes commonly consumed \\
\hline Winter food & 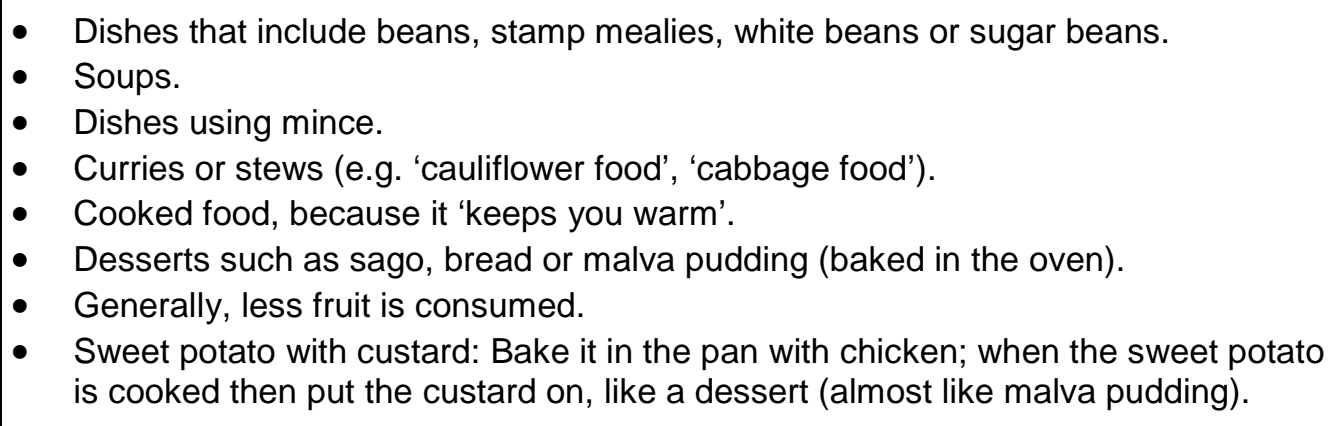 \\
\hline Summer food & $\begin{array}{l}\text { - } \quad \text { Desserts: Jelly and trifles (that could include fruit). } \\
\text { - } \quad \text { Various types of salads. } \\
\text { - } \text { - } \text { Roast with mixed vegetables and potatoes. } \\
\text { - } \text { Frikkadels (meatballs) and mashed potato. } \\
\text { - Steak and a Panini/roll with salad. } \\
\text { - } \quad \text { Fruit in season, often watermelon. } \\
\text { - } \quad \text { Mealies (especially in December). } \\
\text { - } \quad \text { Braais and potjies are common. }\end{array}$ \\
\hline
\end{tabular}

Table 3.4 provides some generalisations, and some participants explained that some people would have salads in winter or soup in summer. Some items were eaten during both winter and summer (e.g. cauliflower was provided as an example).

An association that was made by one participant, was that often when soup is made, it is associated with someone being sick or in hospital:

"Like in the winter you make soup ...then the children ask 'who's in hospital?" (Female crèche manager, IDI)

\subsubsection{Other}

Other themes related to fruit and vegetable consumption patterns that were discussed (and will not be dealt with in detail here) included the frequency and amount of fruit and vegetables consumed, and this varied from daily, to once per week. The time of day that it was eaten was also something that was discussed by participants, with fruit commonly eaten as a snack between meals and vegetables usually eaten as part of the main or evening meal.

\footnotetext{
${ }^{\mathrm{j}}$ Table 3.5 provides a full description of all salads that participants described as being commonly consumed.
} 


\subsubsection{Fruit and vegetable preparation}

The preparation of fruit and vegetables was discussed as an important theme. With regard to preparation, the techniques used to cook vegetables were discussed, as well as the time and amount of effort required in preparing certain fruit or vegetables; participants provided examples of dishes that included fruit and vegetables that were commonly made and that were liked.

From conversation with all of the participants, it seemed that in most households, a woman (particularly a wife or mother) was responsible for all food preparation, including the preparation of fruit and vegetables, and occasionally was assisted by someone else.

Fruit was generally eaten raw, as a snack between meals, and was either eaten as is, or required peeling or chopping before consumption. There were therefore not many factors that impacted on the preparation of fruit. There were, however, many more variables to consider with the preparation of vegetables. The manner in which vegetables were prepared could have a big impact on whether individuals chose to consume the vegetables or not:

"But that's why I say, if you prepare it the right way for them, and make it more interesting, like you say, and I'm sure they will eat it." (Female, frail care kitchen manager, IDI)

There was more in-depth discussion around the preparation of vegetables. Some participants boiled their vegetables:

"We still do it the old school style here, we boil it in water." (Younger female, FGD)

Some participants used to boil vegetables, but realised that there were some negative factors associated with the boiling of vegetables, such as the destruction of nutrients:

"And she [participant's wife] used to, she used to cook it before, man, you know many years ago, I found out also by hearsay, that all the vitamins are cooked out, man. I do believe that all the vitamins and things are boiled out, I definitely, to me that, it makes sense, and it's true." (Male, sport and recreation co-ordinator, IDI)

Another negative impact of boiling that was mentioned was that it negatively affected the appearance of vegetables: 
"Uh look, you can't just boil the vegetables for the sake of boiling. You must have it appetising. If it comes out of the pot, the colour, the appearance makes you look..." (Male, health committee member, IDI)

Many participants stated that they steamed their vegetables, and this seemed to be thought of as the healthiest way of preparing vegetables. Some participants used an actual steamer; others explained that vegetables could be steamed in the microwave. Reasons why steaming was felt to be healthier included nutrient retention, and was explained in the following manner:

"I steam it because then you can, like, the how do you call? ... Nutritious state" and "I cook it in the steamer and then all the nutrition is in". (Female, community volunteer, IDI)

Another common and desirable preparation technique for vegetables was to roast or grill the vegetables in the oven.

In terms of making vegetables more appetising, some participants explained that they or family members preferred it when vegetables were cooked in a stew or potjie (i.e. mixed with other food, as opposed to being prepared as a side dish on their own). Some participants described ways of making vegetable dishes more appetising, such as adding a white sauce to broccoli and cauliflower, adding cinnamon, sugar and butter or margarine to butternut, squash, pumpkin and carrots, as well as seasoning the vegetables (with salt, pepper, herbs or spices). See Tables 3.5 and 3.6 for a full list of fruit and vegetable dishes that were described as commonly prepared in households of this community.

With regard to the addition of seasoning to vegetables, there were some differences in opinion. While some participants explained that vegetables should be prepared plainly (i.e. no salt, butter, sugar or seasoning added) because that is healthier, especially for people with an NCD, others explained that a bit of seasoning should be added, to ensure that family members consumed the vegetables.

"Now, I believe if you put just a pinch of salt in it for them and just make it a little taste in it even melt butter and throw it over it, and maybe a little mixed herbs over it and then I'm sure they will eat it." (Female, frail care centre kitchen manager, IDI)

In terms of the 'form' of vegetables used, a few participants explained that frozen vegetables were convenient to use because they decreased preparation time: "that is convenient especially if I was working maybe" (Female, clinic nurse, IDI), they do not expire as quickly as fresh vegetables and a 
pack can be opened and re-used again: "The frozen, because you can use the frozen, you can open a pack, freeze it again, it's more convenient..." (Male, ward councillor, IDI) and if the person responsible for food purchasing did not get a chance to buy fresh vegetables, at least there were some frozen vegetables available in the house to use. Tinned vegetables (such as mixed vegetables, sweet corn or peas) were sometimes used because they are quick to prepare. There was disagreement on whether tinned vegetables were cheaper or more expensive than fresh vegetables and this could depend on which vegetables were 'in season' at a particular time and therefore cheaper. 


\section{Table 3.5: List of commonly prepared vegetable dishes}

Soups: Mixed vegetable soup (potatoes, carrots, turnips, onion, celery and anything else that is available), mushroom soup, butternut soup, pea/split pea soup and beans (sugar beans) soup.

Salads: Tossed salad (lettuce, tomato, cucumber or as many vegetables as possible, with lemon juice and pepper/salad dressing), mixed beans salad, four bean/baked beans salad, noodle salad (onion, tomato, green pepper, noodles, mayonnaise, sometimes condensed milk), carrot salad (grated carrot and pineapple), potato salad, beetroot salad and coleslaw

Main meals:

- Stews with meat or chicken and sometimes with one main vegetable (e.g. "cauliflower/cabbage/ green beans food'); made by braising onions, add meat, then potatoes, cauliflower, parsley, spinach, garlic, chilli, naaltjies, all-spice; sometimes stews with mixed vegetables (any vegetables available).

- Vegetable potjie

- Tomato bredie

- Avocado on toast or bread; avocado mixed with lemon juice, salt, pepper/condensed milk and water

- Marrow or cabbage with mince

- Frikkadel (meatballs) with cabbage

- Beans curry

- Gatsby (roll containing various combinations of meat, chips, salads and sauce)

- Mixed vegetables with rice; Vegetable paella

- Roast vegetable lasagne

- Vegetable stir fry with rice

- Tandoori vegetable wrap

- Spinach and feta pie

Side dishes:

- Broccoli and/or cauliflower with white sauce

- Butternut, squash, pumpkin or carrots with cinnamon, sugar, butter and/or margarine

- Pour fruit juice on the vegetables

- Add cayenne pepper to carrots or broccoli

- Add black pepper, all spice, nutmeg, cloves, bay leaves, garlic, parsley to vegetables

- Carrots with custard powder (to make a glaze)

- Carrots with sugar and butter

- Make a sauce of butter, chillies, garlic and coriander and pour over vegetables

- Squash with sweetcorn and cheese

- Spinach with white sauce

- Spinach with onion, garlic, chillies, mushrooms

- Mixed frozen vegetables (McCain's garden mix or Country crop ${ }^{k}$ )

- Vegetables steamed together with chicken (to get flavour from chicken) and spices

- Tinned vegetables: mixed vegetables, sweetcorn, baked beans, peas

- Grilled mealies on the braai

- Roast or baked mixed vegetables

- Pre-cut vegetables, steamed with cheese

- Sweet potato chips

- Tomato and onion smoor

- Vegetable ('veggie') bake (mixed vegetables with white sauce and cheese)

- Raw vegetables (small corn, carrots, cucumber, tomato) with dip

- Mixed vegetables with 1000 island sauce poured over

- Beetroot - boiled or ready made in the jar

- Pumpkin or butternut fritters

- Pumpkin with custard

\footnotetext{
${ }^{k}$ It was noticed by the PI that in Mitchells Plain, people sometimes refer to food items by a brand name, even if they do not use that specific brand. In this example, McCain's is quite an expensive brand of frozen vegetables. It was not necessarily the most commonly used brand, but was referred to because it was the most recognised brand.
} 
Table 3.6: List of commonly prepared fruit dishes

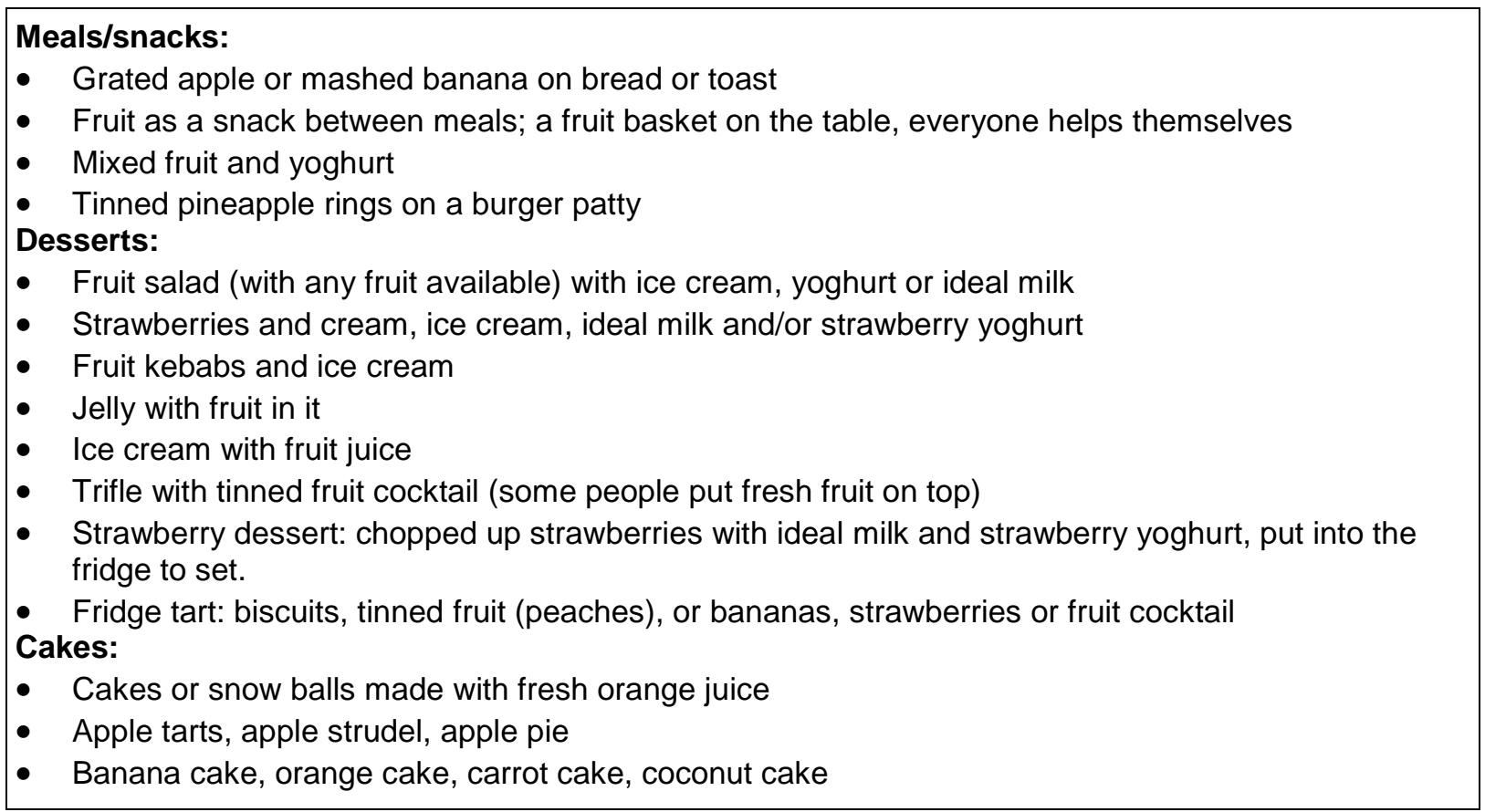

\subsubsection{Fruit and vegetable access}

Much discussion took place on how people purchase their fruit and vegetables and participants also volunteered a lot of information on vegetable gardens, including the fact that people seldom grew their own vegetables; reasons were provided as to why this was the situation.

\subsubsection{Fruit and vegetable purchasing}

Fruit and vegetable purchasing was discussed in depth and was evidently important to people, possibly due to financial constraints being such a problem in this area. Various members of the household were responsible for fruit and vegetable purchasing; commonly, either the person responsible for preparing food, or the person who was earning the main income. Fruit and vegetables were generally either purchased from supermarkets or from informal vendors, and reasons were provided by participants both for and against each option.

Many reasons were provided for the purchasing of fruit and vegetables from supermarkets:

- The vegetables in supermarkets were usually fresher than from the informal vendors (possibly because they are kept in a fridge) and therefore last longer.

- Some people prefer to buy all of their groceries from one place and not go to a supermarket for general groceries and then to an informal vendor for fruit and vegetables, therefore it was more convenient to buy everything at a supermarket.

- The fruit and vegetables from supermarkets were of a better quality, and some participants were prepared to pay more for better quality vegetables: 
"Yes, l'd rather pay a bit more for nice fruit. Not just the way it looks, it must look nice and fresh and last a bit longer." (Female, catering manager, IDI)

- At a fruit and vegetable supermarket chain, there were often valuable specials (e.g. once a week there were adverts in the community newspapers for combo bulk packs of vegetables like potatoes, onions and butternut that could last longer because they are less perishable, and were a lot cheaper on special and in bulk; these items could last for up to a month). There was a fruit and vegetable supermarket chain in Mitchells Plain, but it was closed due to mismanagement and many participants mentioned this as a negative factor, because many people used to do their fruit and vegetable shopping there. One participant described her feelings about this:

"I was very upset when they took Fruit and Veg away from us! I couldn't believe it! It's like taking a hospital away from, from the people." (Older female, FGD)

Only one reason was provided for not buying fruit and vegetables from a supermarket, and that was that fruit and vegetables were usually more expensive at supermarkets.

A few reasons were provided for buying fruit and vegetables from informal vendors:

- Informal vendors were usually cheaper; one participant mentioned that everything is "at least R2 cheaper" at an informal vendor and that "you can get good deals" at the informal vendors (Male, pastor's assistant, IDI).

- Some participants felt that it was more convenient to buy their fruit and vegetables from informal vendors at the side of the road, because it was on their way home.

- Some participants explained that, at an informal vendor, they could see what they were buying and how much it cost. In a supermarket, when vegetables need to be weighed per kilogram, people did not want to do that because they did not know how much they would have to pay:

“...if you go outside, you pay $R 5$ for $X$ amount of stuff... they rather go buy it outside then know, I only paying R5 for this bag of onions, it's also a psychological thing." (Male, ward councillor, IDI)

There were also a few reasons provided for not buying fruit and vegetables from informal vendors:

- Some participants felt that fruit and vegetables purchased from informal vendors did not last as long and they perish quicker (partly because often they were out in the sun all day).

- Some felt that they did not taste as nice as vegetables bought from a supermarket.

- Some felt that it was not as convenient:

"I mean, if you go to Town Centre [where informal vendors sell fruit and vegetables] and you buy veggies, you gonna to have to prepare it the day that you buy it, because it's not 
going to last, you understand, so to have money for the ordinary guy every day to go buy. So you have to go every day, which is a waste - it's not going to happen." (Older male, FGD)

During the first FGD that took place with younger women, many participants explained that they purchased their fruit and vegetables from 'Mr X's' store'. For this reason, Mr X was selected as one of the participants for the IDIs. Mr X's store could be considered to be a convenience store, selling a variety of items, and sold fruit and vegetables in a manner similar to informal vendors (whereby some items are pre-packaged as opposed to weighed, and customers paid a certain amount per number of items). See Figure 3.1 for the variety of fruit and vegetables that were available at the entrance to Mr X's store.

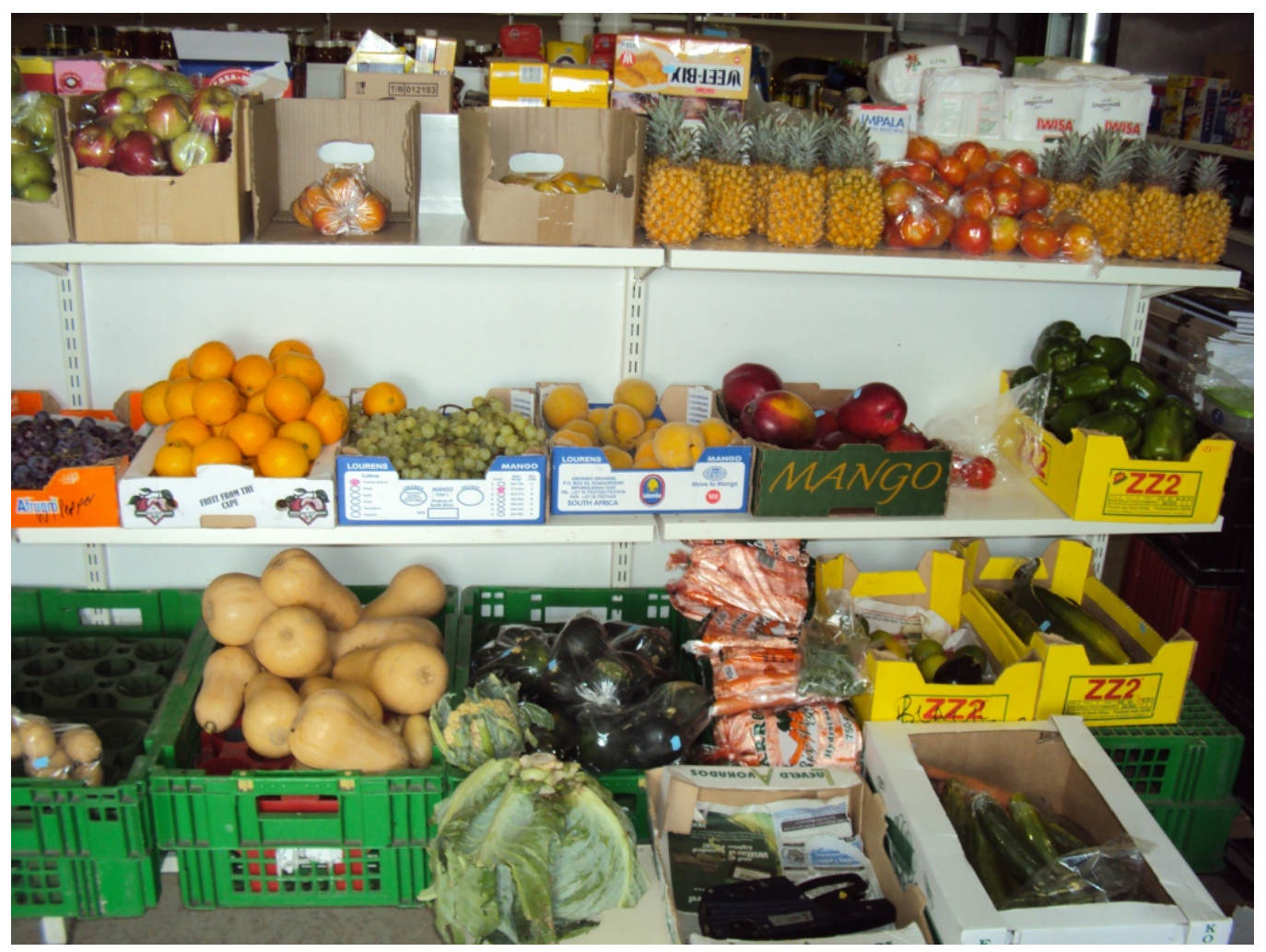

Figure 3.1: The fruit and vegetables sold at the entrance to 'Mr X's' store

While at Mr X's store, it was noticed that in the same street, approximately 100 metres away on the street corner, there was an informal vendor who also sold fruit and vegetables. Therefore, on one street in Beacon Valley, there were two places where residents could buy fresh fruit and vegetables. See Figure 3.2 for the variety of fruit and vegetables available at the informal vendor located at a street corner in Beacon Valley.

\footnotetext{
'The store is referred to as ' $\mathrm{Mr} \mathrm{X}^{\prime} \mathrm{s}$ ' store so that the actual name of the store is not revealed, for the purpose of maintaining confidentiality, since the store is named after its owner.
} 


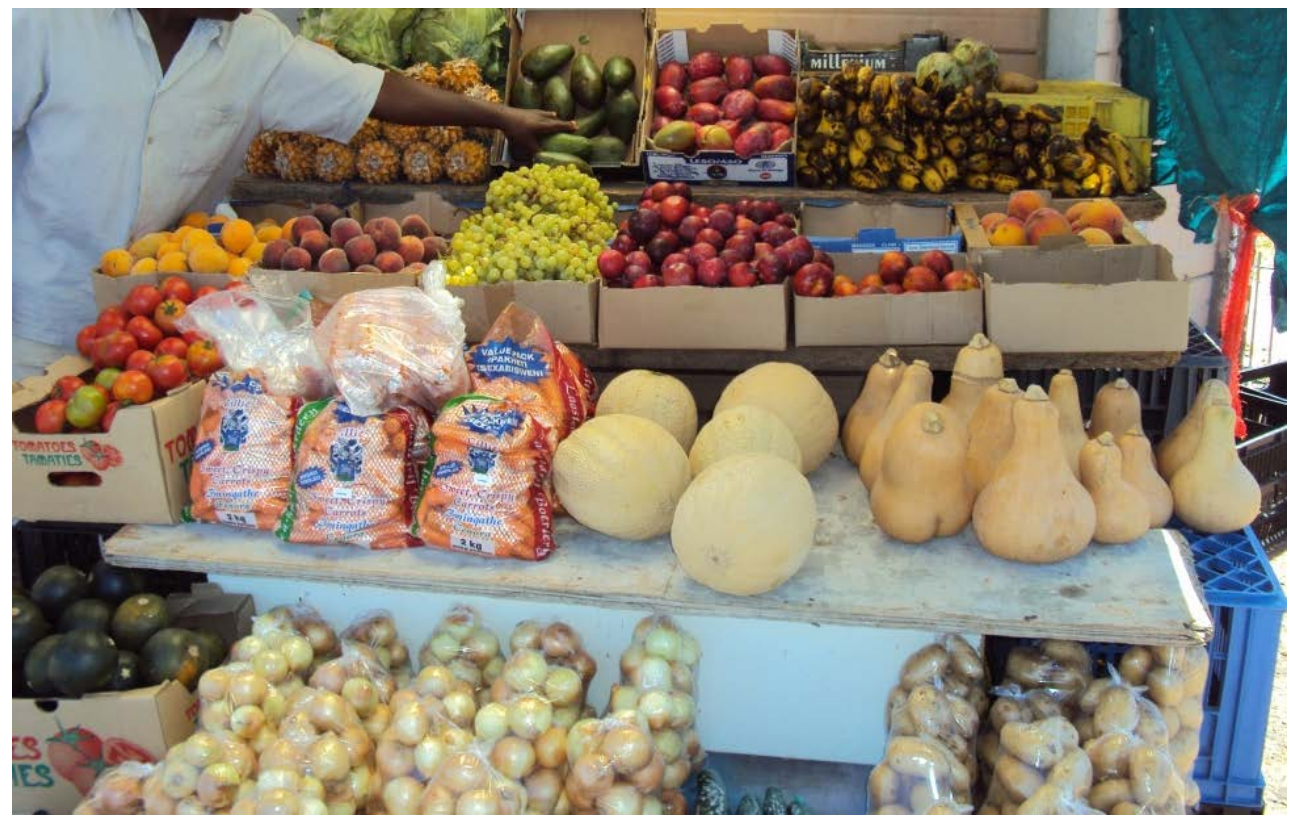

Figure 3.2: Fruit and vegetables sold by an informal vendor on a Mitchells Plain street corner

Another factor described by participants to impact on how people purchase their fruit and vegetables was how they earned or received their income. People who earned a weekly income would buy smaller amounts of fruit and vegetables more often, whereas those who earned a monthly income could buy in bulk (therefore making use of the savings that could be achieved by buying in bulk).

Lastly, a factor raised when fruit and vegetable purchasing was discussed, was the opinions of neighbours. The male FGD raised some different issues that people experience when they come home from grocery shopping. One participant explained that if people came home with a lot of food, neighbours would wonder where they got all of the money from:

“...jealousy it could be, sometimes hey. Oh jy't weer 'n klomp geld ne! Waar't jy die geld gesteel?"m (Older male, FGD)

Neighbours would then come around to ask if they could 'borrow' food, and for this reason, some people tried not to let their neighbours see what they had bought:

Participant 1: “...something like that [laughing], or what normally happens is, die ene kom oor; hi my ma vra $n$ bietjie suiker [laughing] or my ma vra 'n paar artappels, jy kannie sê

\footnotetext{
m 'Oh, you've got a lot of money again! Where did you steal the money from?'
} 
nee nie, want hulle het nou gesien jy ko met sakkies $\mathrm{in}^{n}$ [laughing] you see like that, that is what happens."

Participant 2: "It's, what [participant name]'s saying now, it seems funny but, I buy groceries and I buy every month, monthly now I'll buy, and when I come home with the goods and then I'm told, you can't just reverse in, you must go around the back way because, ja, people mustn't see. Cause as he says, as soon as people know then... Ja, I was advised to put my things in a black bag [laughing]." (Older male, FGD)

\subsubsection{Vegetable gardens}

The growing of one's own vegetables is one method of accessing vegetables. This was not a question that was directly asked, but rather information that participants volunteered themselves, either while discussing the changes in eating patterns between the previous generation and today, or when discussing fruit and vegetable purchasing.

A few participants mentioned that fruit and vegetables were "not the same as they used to be" (Female catering manager, IDI; Older female, FGD), and gave the following explanations as to why home-grown vegetables were better than vegetables purchased from a store:

- One participant explained that it is good to "...eat out of the garden, people like to eat veg they have grown." (Older female, FGD)

- Another described "...like when you grow fruit in your personal garden, it's more healthier than buying it from the shops, basically, you understand. It [fruit and vegetables purchased from shops] doesn't even last as long as normal fruit and veg, that you would grow in your garden" (Older male, FGD).

Some participants described vegetable gardens that they or family members had. A common theme was that people used to grow their own vegetables, but do not do so anymore:

"You discover that the older people, like her mother, would have had a spice garden. Herbs and... the old baths' [indicating the use of old, unused and empty bath tubs to grow fruit and vegetables]. (Male, pastor's assistant, IDI)

Many reasons were provided as to why people do not currently grow their own vegetables. Space was described as a major constraint, both at people's homes, as well as public open spaces. At

\footnotetext{
$\mathrm{n}$ 'The one comes over - Here, my mother is asking for a little bit of sugar, or my mother is asking for some potatoes. You can't say no, because they saw you come in with your packets.'
} 
homes, it was described that the garden was sometimes used to park the car for fear of it being stolen if it were parked on the pavement, or a Wendy house (small, usually wooden garden shed type structure) was erected in the garden for an extended family member to live in, as well as the fact that in many urban areas, population density is high and properties are small:

"... if you look at the older areas, the back yards were large." (Male, pastor's assistant, IDI)

Sometimes family properties did not have grass, but only cement. In terms of public space, access to land had become a big problem and participants felt that because it was a requirement to obtain permission, there was too much paperwork and expense involved nowadays in trying to access land for communal gardens. Participants also mentioned fear of their produce being stolen as a barrier to growing vegetables:

“...so it's quite dangerous, because your cabbage will walk." (Male, pastor's assistant, IDI)

Change in lifestyle was also listed as a prohibiting factor to vegetable gardens, and that people would rather work longer hours to earn more money to support their family, and then did not have time to come home and work in a garden. A male participant who had been involved in community garden projects in the area explained that, in Mitchells Plain, having a garden is associated with poverty, whereas where he was from (the Eastern Cape), everyone had a garden. He further described Mitchells Plain as a "difficult community to work in", in part because of this. (Male, urban farmer, IDI) Access to resources, such as water, seed and equipment, as well as the technical knowledge of how to grow vegetables, was also described as a problem:

"I think also, there's most people that doesn't know, doesn't have the know-how. It seems simple enough, put something in the ground and grow it, but there's many, many that doesn't know..." (Older male, FGD)

Laziness was listed by a participant as a constraint to growing vegetables, as well as the fact that, these days, it is "too easy" to buy fruit and vegetables.

Other participants described community garden projects, that either they were involved in or that they knew about. Reasons provided for successful garden projects were funding and commitment. A major factor that was described that could improve the success of communal gardens was the provision of incentives (in the form of money) for people to work in the gardens. Furthermore, equipment and resources were necessary. A source of possible funding that was suggested was large supermarket chains. 


\subsubsection{Changes in eating patterns over the years}

There was much discussion on the change in eating patterns over the years, particularly comparisons between participants who were grandparents or parents, and participants who were parents or children, i.e. the previous generation compared to the present generation ('then' vs. 'now'). The general feeling by all groups of participants was that there had been a change in eating patterns over the last generation, and that people were eating more unhealthily now than the way that they used to eat years ago, and this was having a negative impact on health.

"It's cheese and chalk, it's not the same, that's the reason why you find so much of sicknesses..." (Male, imam, IDI)

"I was much thinner when I was home. I was much thinner, to compare to now." (Male, ward councillor, IDI)

Participants also felt that the quality of fruit and vegetables had decreased. Many reasons were provided for this change and some of these will be discussed in more detail.

\subsubsection{Food preparation}

It was explained that people used to eat healthier, more home-cooked meals, such as stews and other dishes that included vegetables. This was described in a positive manner:

"And stews, we had lots of stews, you have your Irish stew with cabbage, not cabbage the, you have carrots and the peas, and potatoes. It was fantastic, ja." (Male, pastor's assistant, IDI)

People also used to eat at home more often; one participant explained that his mother "didn't want me to go to that part of family, and eat wrong food" (Male, health committee member, IDI).

The current generation was described as eating food that was quicker to prepare, such as bread, take-aways, fried chicken, sausages or chops, i.e. meals that could just be put into the oven and cooked quickly, or that the person preparing the meal could do something else while the food was cooking in the oven. It was also felt that 'nowadays', people had more variety available to them, but that they ate less of stews and home-cooked meals that included vegetables.

“...but [then] you didn't have this variety of things, so you make a pot of food because it go longer...it stretch further, with your potatoes and rice. You know we always did the cabbage 
stew, or you call it bredie, or whatever you call it, I don't eat it as often anymore." (Male, ward councillor, IDI)

“...you don't hear people saying anymore, I'm going to put on a pot of cooked food." (Female, crèche manager, IDI)

Furthermore, it was described that people used to be taught to cook by their parents and Home Economics was taught as a subject at school, so children were taught to cook, but this did not seem to be happening as much anymore.

\subsubsection{Financial and socio-economic situation}

A common theme was that people grew up with less money than they had currently, but that they ate more healthily then in comparison to now; stews (which were often eaten) were cheap, filling and generally, healthy. As people's access to money and their socio-economic situation improved, eating habits changed too, sometimes for the worse. A reason for this was described as growing up in an environment where families did not always know if they would have food available every day. One older female explained:

"I mean, my children grew up knowing... That you don't know if you going to have a plate of food tomorrow, you don't know what's going to be available tomorrow. So you eat what you have and whatever is on your plate, you eat it all up. Because we don't waste food. So that has been something that has been very important to me for a long time, I mean since I became a mom." (Female, grade 1 educator, IDI)

Now that some people had more money available to them, it meant that they could purchase more of the so-called 'luxuries':

"So you go with sweets, ice cream and that, because why, now you can afford it these days..." (Male, health committee member, IDI)

A further reason provided for the decrease in cooking and preparation of healthy meals was that in previous years, most women were at home during the day and had enough time to prepare 'proper', healthy meals. These days, however, more women tend to work and they get home and need to prepare something, with much less time available to them. 
“...sometimes, especially where kids [are] considered and there's no one at home, maybe, if the husband and wife both works and then at night, wie gaan lus het om kos te maak?" (Older male, FGD)

\subsubsection{General lifestyle factors}

A number of various general lifestyle factors were discussed that have changed over the years but that were seen to negatively impact on healthy eating and fruit and vegetable consumption.

It was described that previously, families ate together at the table, but now, everyone dishes up their food and eats by themselves, while watching television or doing something by themselves (for example, sitting at the computer or on their phone). Some of the older female participants felt that current general lifestyle factors impacted negatively on eating behaviours:

"The parent must stop sitting by the damn TV... sit by the table, and the family meals, and the children will have their..., that's how we grew up. They don't do that anymore, each one got their own corner. Sit on your own corner. Everybody get a plate of food and just go. But we don't sit by a table." (Older female, FGD)

The older female FGD was also of the opinion that these days parents were young, that the younger generation did not take as much responsibility for their children (including with regard to the provision of healthy food) as the older generation used to, and that the younger generation could be lazy:

Participant 1: "Yes we had no option."

Participant 2: "Because I was responsible..."

Participant 1: "They don't, they too lazy this young people." [Laughter]

Participant 2: "And everything is so easy today..." [Group laughs and talks at once]

Participant 1: "Fast-food. They give the children noodles." (Older females, FGD)

A male participant (responsible for running a school tuck shop and quite involved in the community) explained:

“...most parents now days are youngsters. And they don't take that responsibility. They don't think to the future, the children, they not actually thinking about their children. And being involved in our community, it's difficult, when you there it's like, you can have their kid for 24 hours a day, then they the happiest person." (Male, tuck shop manager, IDI)

\footnotetext{
○ "Who will want to prepare food?"
} 
Other lifestyle factors that were described as contributing to decreased fruit and vegetable consumption included that people were more rushed and did not have adequate time to prepare food; that people did not plan ahead (i.e. did not plan meals or spending); and that people did not budget appropriately. This last is related to cost and affordability. Often if people have a limited amount of money, they purchase the most that they can afford for the immediate time period. A further theme that was mentioned by a few participants was that formerly, people used to follow routines or traditions and that they were healthier than those of today.

"Ons het baie lekker geëet ${ }^{p}$. Fridays was a rice and fried fish and braised tomato and squashy...now Friday is a chip roll...Gatsby..." (Older female, FGD)

It also seems that the availability and variety of take-aways and unhealthy food options is much higher now than it used to be.

'You know the Western Cape and Cape Town people seems, yoh, fast-food, ja, it's like a drug.' (Male, health committee member, IDI)

It therefore appears that time and levels of effort are important constraints to healthy eating in general, including adequate fruit and vegetable consumption. The catchy phrase "Why Cook 'Cause I Cook' depicted in Figure 3.3 reflects the general feeling of participants that the consumption of fast-foods has drastically increased over the years and that the 'younger' generation did not prioritise the preparation of food at home. This phrase captures the general attitude or culture towards food preparation and fast-foods.

\footnotetext{
p "We ate very nicely."
} 


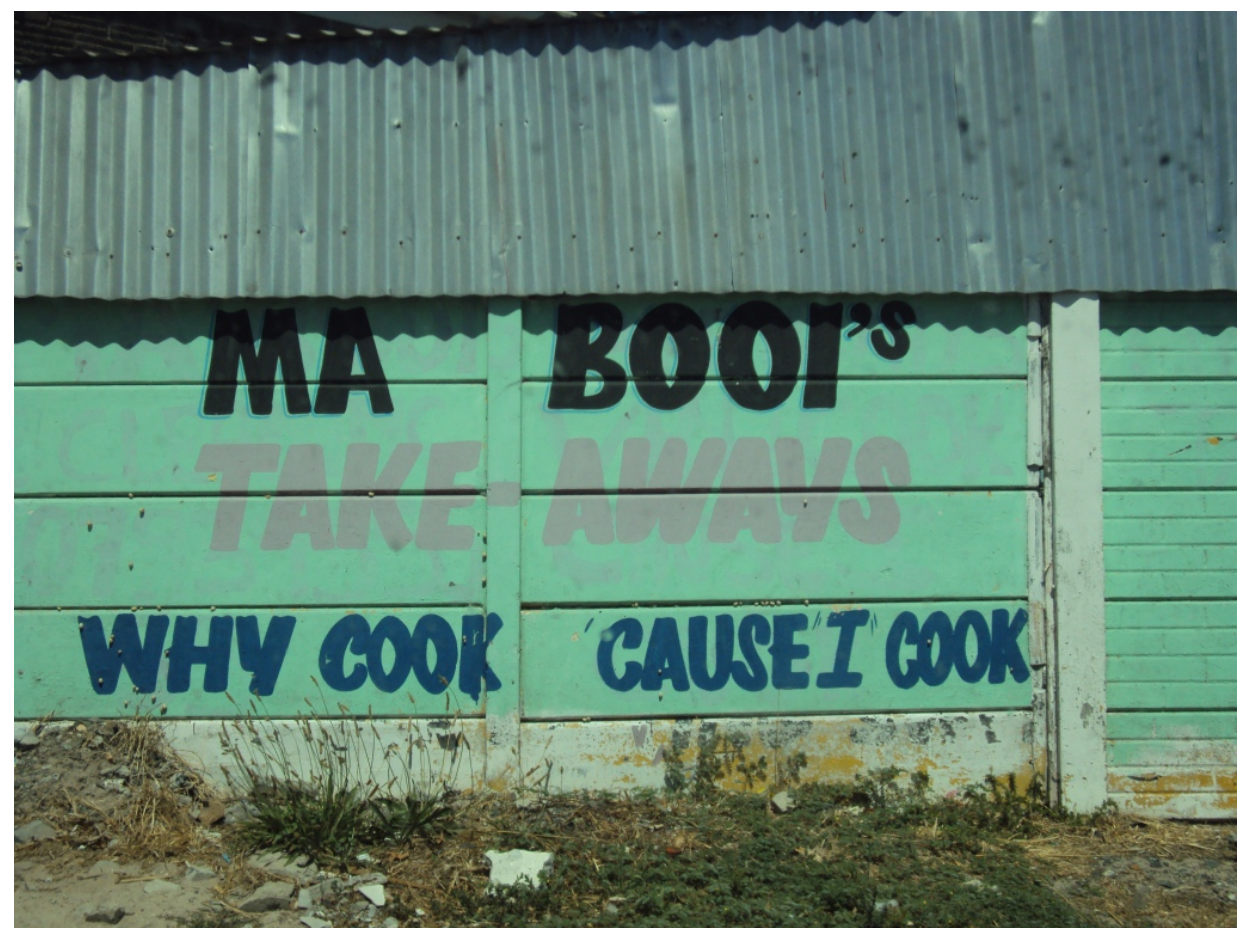

Figure 3.3: Advertisement for a take-away establishment on a Mitchells Plain property wall

\subsubsection{General discipline}

The lack of discipline in children in general was a fairly strong theme and it was felt that undisciplined behaviour spilled over into their eating behaviours. Many participants felt that parents lacked adequate control over their children's behaviour in general:

"...but the parents also give their kids like, more leeway than what's necessary, like the way we were brought up, discipline..." (Older male, FGD)

One older female participant explained the situation when she grew up:

“...no l'm just saying we were all kids, and our parents used to put all the vegetables on our plate, whether you liked it or not it was there, and yes I can say to you when growing up we never liked broccoli, but we had to eat cauliflower food, we had to eat cabbage food. We had to eat what was there available..." (Older female, FGD)

Another participant explained that, in comparison, these days:

“... a lot of parents, I have discovered, if a child says, I don't want to eat that, they just leave them. I think parents are just not firm enough anymore." (Female, grade 1 educator, IDI) 
A possible reason for this relaxing of discipline was explained by a participant:

“Look, we were forced to eat things. And we just rebelled against that. I don't do that. It's their choice, I tell them, look you know this is not good for you. So they have the freedom to choose, within the confines of what we serving..." (Male, pastor's assistant, IDI)

An older male participant understood this in terms of general manners and explained:

“... I will think what grandma has taught me, and I will say, ok so I'll eat. Because why, she said never let someone feel offended. Even if it's just a glass of water, don't refuse it. You take it for that moment because why, it's not part of your diet. But for that person's feelings." (Male, health committee member, IDI)

\subsection{POSSIBLE EXPLANATIONS FOR CURRENT PRACTICES: UNDERLYING FACTORS AFFECTING FRUIT AND VEGETABLE CONSUMPTION PATTERNS}

\subsubsection{Possible reasons for low fruit and vegetable consumption}

Many reasons were provided as to why fruit and vegetable consumption is not adequate and some of these are presented in detail.

\subsubsection{Cost and financial constraints}

Cost and financial constraints were listed by many respondents as a barrier to eating fruit and vegetables. Respondents mentioned that unemployment and poverty was a problem in the area (Beacon Valley and Eastridge), and often one salary or social support grant would support an entire extended family. Some respondents explained that they would eat fruit and vegetables more often if there was more money available, or that they would buy fruit and vegetables when they were on special, but that it was not financially possible to eat fruit and vegetables every day. One explanation provided was:

"I think for a lot of people, when it comes to fruit and vegetables, it's an issue coz its expensive to buy, and I don't think every group can afford to buy fruit and vegetables, I mean they can hardly afford the basics, which is your meat or your chicken, so I would say, if it was cheaper, yes people would buy it." (Female, catering manager, IDI) 
Others explained that they did not have a lot of choice when it came to food, and often had to eat whatever was available, especially when the individual was not the income earner:

"As jy nie werk nie, jy moet you mond hou, jy moet net iet wat jy moet iet en kla"." (Younger female, FGD)

Although not having enough money available was a predominant reason for low fruit and vegetable consumption, one participant described that even when people did have more money available, it did not directly result in increased fruit and vegetable consumption, because sometimes people would choose to rather spend their money on take-aways or eating out as opposed to buying more fruit and vegetables. Some contrasting opinions were, however, provided:

- It was one participant's opinion that: "...some of the people here they not working, they don't work but when they have money they would go to Kentucky". (Male, health committee member, IDI)

- Another participant felt that: "you would see that those that are not economically strong, like poorer folk, they would eat what they get, you know, so stuff like that, so that's what they do, and even those who don't have the money would try to eat as healthy as they can." (Male, pastor's assistant, IDI)

\subsubsection{Food priorities: purchasing and preparing}

An explanation that was provided throughout the discussions was that fruit and vegetables were not a priority when it came to food purchasing and food preparation, and some explained that fruit and vegetables were not necessarily very expensive, but that once certain priority items had been purchased (or prepared), there was not enough money or time left to purchase or prepare fruit and vegetables. One participant explained:

"You see, what people normally do man, like people in this surrounding areas, ne, they in the house, the first thing they do, they need to let say, if it's under privileged or whatever, they would buy bread, and they would buy meat or polony and eggs. That's the basic requirements man, you won't really first go buy fruit, now I'm speaking of our area... they would buy that, and coffee and tea, buy the basic things that you need first. ... Say extra, and you could say a luxury, although it's not expensive." (Male, sport and recreation coordinator, IDI)

\footnotetext{
q "If you don't work, then you must keep your mouth shut, you must just eat what you must eat and finished."
} 
Therefore, again, it was explained that fruit and vegetables were not considered part of the 'basics' when people purchased or prepared food. Another participant explained:

"The first, first thing they buy is their meat, the rice, and the potatoes, and the onions, that's the more important thing the people buy... Something to make the... the pot full." (Younger female, FGD)

Furthermore, it emerged that fruit and vegetables were not considered the main component of a meal, but rather a condiment or add-on. Fruit and vegetables are not 'food':

"En my man het vir my gese, nee [participant's name] jy gee nie vir my daai kossie [salad or vegetables]; ek will kos he, maak vir my kos.'." (Older female, FGD)

When the pastor's assistant (who was diabetic and considered himself to be a 'healthy eater') was interviewed, the family was about to eat dinner after the interview, so a photograph of what they dished up to eat was taken (see Figure 3.4). This photograph clearly displays the theme on food priorities as described by participants, whereby during food purchasing and preparation, the starch and protein are the priority (as in this photograph, the majority of the plate is comprised of rice, mashed potato and chicken pieces) and vegetables are an added extra or condiment. In this photograph, only a spoonful of mixed vegetables was served on the plate.

\footnotetext{
r "And my husband said to me, no [participant's name], you mustn't give me that food; I want food, make food for me."
} 


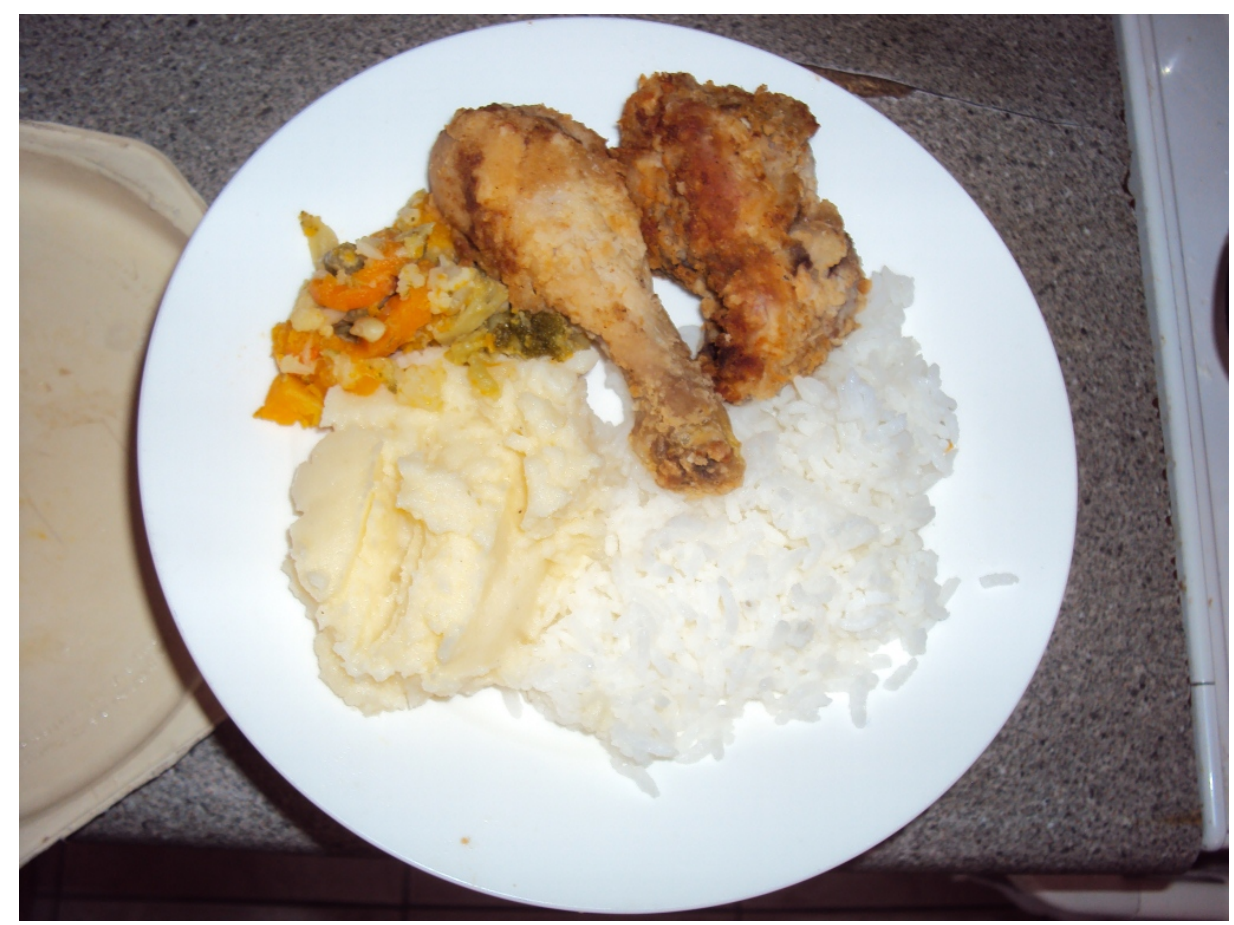

Figure 3.4: A plate of food dished up for the evening meal at the pastor's assistant's house

Participants also explained that when people had limited money, they would choose to buy something that was cheaper and more filling:

"You have a 50c in your pocket at the time, and you buy 5 bob chips, that's it, so what's gonna make the child happy now, a apple? Or a packet of chips? What's the cheapest? Two apples or 10 packets of chips? What is gonna look better?" (Older male, FGD)

A strong theme that emerged in general from this discussion was that fruit and vegetables were not a priority in comparison to other food items or household expenses.

\subsubsection{Practical logistics of fruit and vegetable consumption}

Practical logistics of fruit and vegetable preparation and purchasing that were listed as constraints to fruit and vegetable consumption included the time and effort needed to prepare vegetables, as well as the fact that fruit and vegetables do not have a long shelf life. Some of these practical logistics of fruit and vegetable consumption could provide the underlying reasons as to why certain fruit and vegetables are or are not consumed.

A strong theme was that fruit and vegetables take extra effort (especially time) to prepare and that many people would rather prepare something quickly (such as sandwiches or bread, that does not require any cooking). One older female participant explained: 
"I like your butternut, but I don't always like cooking it. I'll cook something that goes quick, because I mean, if you must prepare all your different veggies, it takes a bit longer, and when it comes to me, it's important to do something quick." (Female, catering manager, IDI)

A male participant who was vegetarian, himself, further explained that:

“... maybe vegetables are not that tastier, then maybe it comes to how we cook... So really, meat, you don't have to put much effort. Whereas vegetables... You have to put a little bit of effort." (Male, urban farmer, IDI)

In contrast, a few participants stated that they thought that some fruit and vegetables were actually quick and easy to prepare.

Another constraint in terms of the practical logistics of having fruit and vegetables available for consumption was that fruit and vegetables are perishable and that if they were not used in time, would decompose and need to be thrown away:

"... so basically at the end of the day, the people don't buy, because it doesn't last as long, cause they don't always have the right essentials to prepare a pot of food, so the food goes wasted." (Older male, FGD)

The perishability of fruit and vegetables was also described by a tuck shop manager as a barrier to stocking and selling fruit at the tuck shop. He explained that he therefore needed to buy fruit daily, which increased the level of effort required to have fruit available at the tuck shop:

"So I don't want to buy now, and you stuck with it, and you throw it away, you got rotten after a few days, I rather buy every day." (Male, tuck shop manager, IDI)

\subsubsection{Personal preferences}

A few respondents indicated that they simply did not like vegetables specifically, as opposed to fruit that most people indicated they did like the taste of and that many vegetables did not taste nice or were not prepared in a way that tasted nice. A few of the male participants responded that they were simply "not a veggie person" or "not a veggie lover". A female participant explained: 
"As ek begin te iet en dan dink ek soema ek is vol nou, en as ek die kos aankyk is ek nou vol... Ja it is important especially ... ek kry net nie lus daar voor nie."s (Young female, FGD)

Once again, even though someone may think it is important to eat fruit and vegetables, this did not always translate into actual fruit and vegetable consumption. Further detail on underlying reasons as to why individuals do or do not like fruit and vegetables are discussed in 3.3.2 Individual preferences and aversions.

\subsubsection{No negative consequences of low fruit and vegetable consumption}

Some participants felt that they did not eat fruit and vegetables regularly and did not experience any negative effects of low fruit and vegetable consumption:

"...there's a lot of fruit and veg, veg more, that I don't eat and, to my knowledge I think I'm still healthy... because I don't like them, I don't like the taste of it [laughing] and no one is gonna force me to eat it." (Older male, FGD)

A further explanation was that:

“...people don't eat vegetables or don't take it serious until they've been diagnosed with something." (Male, ward councillor, IDI)

\subsubsection{Specific factors related to children's fruit and vegetable consumption} When asked questions about fruit and vegetable consumption, many respondents volunteered explanations for fruit and vegetable consumption practices in children, including the impact and role that parents had on what children ate.

A manager of a crèche described that when mothers first brought their children to the crèche, they told the staff working at the crèche that their children did not eat certain things, including fruit and vegetables. The manager had quite strong feelings about this and stated:

"...because I actually hate it when the parent come to you and tell you - oh teacher, my child doesn't eat fruit at all. Try to give the child some fruit. Because here, we don't enforce it, but they can see their friends eat it." (Female, crèche manager, IDI)

\footnotetext{
s "When I start eating then I think I'm full, and if I look at the food, I am full. Yes, it is important, especially... I just don't want it."
} 
The crèche manager felt that when children came to the crèche, their fruit and vegetable consumption probably increased, because they started eating more fruit and vegetables when they saw their peers doing so.

Furthermore, a professional nurse at a well-baby clinic, who was involved in nutrition education, felt that parents did not do enough to encourage children to eat vegetables. She explained that:

“... a lot of people say that children don't like veggies but I think it's not something that they don't like, they weren't taught from an early age that you must eat veggies and... You know it's almost like it's an acquired taste. And I mean, I don't believe that a child can tell you that they don't want to eat..." (Female, clinic nurse, IDI)

It therefore appears that a problem exists due to a lack of effort from parents, as well as a lack of discipline exerted by parents with regard to feeding fruit and vegetables to their children. This same participant was also however sympathetic to the position that some parents in this area find themselves in, and explained:

"I tell them, just take some time and, you know, make it like a game with the kiddies, because why, people have a lot going on here in this place... so sitting with the child that doesn't want to eat... is the last thing that they actually have to worry about." (Female, clinic nurse, IDI)

Many participants felt that today's generation of parents were not firm enough with children and that general discipline was weak (and this therefore impacted on discipline with regard to eating behaviours):

“... the other thing also, I think why a lot of our people, especially the children, don't eat vegetables, it's because if the mommies, they cook vegetables, and the children don't want to eat it, they don't force the children to eat it, so the children grows up so when they big, then they don't eat that kind of vegetables. ...some parents, if the child doesn't want to eat, if the child want, say the child want Kentucky, then they will buy them Kentucky. Instead of giving that vegetables or that nice pot of bredie." (Male, health committee member, IDI)

This was similarly described when changes in eating patterns over the years was reported on (see 3.2.4.4 General discipline).

A primary school educator also felt that parents did not exert enough discipline: 
"I find that when I interact with parents, I find a lot of parents just allow their children to walk all over them."

The same participant also felt that fruit and vegetable consumption was not important enough to parents:

"In my discussion, when I am talking about what they need to eat and so on, because it's, it's amazing how many parents just don't take notice of it. They just don't seem to see the need of it. I don't know, I think it's [pause] probably economic reasons, and also the fact that a lot of parents come home late, and a lot of the time its quick meals." (Female, grade 1 educator, IDI)

Some participants felt that parents were lazy and did not take the time to prepare healthy food for children:

"But these young mothers don't give them veg every day. That's why grandmas are now there, man. They just get fast-food. They lazy to make food. The grandchildren, they just eat fast-food..." (Older female, FGD)

Furthermore, the older women felt that when young mothers introduced solid food, they provided commercially produced complementary foods instead of making it themselves, and this was seen (by the older women) as a negative practice. One participant explained:

"But I think the young mothers, they go more for the jar now. Coz it's easy. The young mothers don't cook, they go more for Purity. And sometimes they don't know how long did that food stand in the shop. Say for instance, the expiring date, you bought that food last year, and the expiring date is this year, but then it was standing for a whole how many months in a in a shop!" (Older female, FGD)

\subsubsection{Individual preference for and aversion to specific fruit and vegetables}

Participants listed many fruit and vegetables that they liked or disliked, due to various reasons. The reasons that were provided as to why certain fruit and vegetables were liked or disliked are now discussed. 
A predominant theme was that participants ate vegetables either because they knew that vegetables were important or because it was something that they are 'supposed' to do, whereas fruit was more commonly consumed because participants generally liked the taste of fruit.

"I don't [think] like any of us want to eat vegetables... because it's something that your body needs and, its important because of all the vitamins and minerals and things like that, and fruit, basically, we eat because it tastes nice." (Female, clinic nurse, IDI)

Specific reasons were given as to why participants liked fruit. In general, fruit was described to be naturally sweet tasting. One female participant explained why she liked yellow peaches:

"When it's so nice and sweet, die geel perske. Moenie my sour goed gee nie, arght!" (Female, crèche manager, IDI)

Another older female participant who wore dentures explained that she preferred bananas because they were soft and easy to eat. Some participants felt that some fruit, like apples and bananas, could be filling. Fruit and vegetables were also described as being refreshing and light:

"I would just, l'd say it's refreshing the vegetables, or the fruits are refreshing, I mean if you make a tossed salad not a tossed salad, sorry a fruit salad... It's nice and cooling, when it's been in the fridge ... and light, and you don't feel as bloated when you have your fruit, same with the vegetables." (Female, catering manager, IDI)

With regard to vegetables, fewer reasons were provided by participants as to why vegetables were liked. Some mentioned that they liked the taste, for example that pumpkin is sweet. Some participants explained that they sometimes used frozen and tinned vegetables because they were convenient (quicker to prepare than fresh vegetables).

Some fruit (such as oranges and kiwi fruit) were described as being too acidic and not sweet enough. One participant described mangoes as being too stringy, but explained that she did like mango juice; therefore texture seemed to play a role in individual preferences. One participant explained that sometimes children did not like to eat certain fruits (for example, apples) because "of them [children] don't want to really choose to chew the apples" and the same participant also explained that she struggled to eat apples because "...l got blunt teeth, man" (Female, crèche manager, IDI). Similarly to fruit, a reason provided for not wanting to eat vegetables was related to

\footnotetext{
t “...the yellow peaches. Don't give sour things to me. Argh!”
} 
the effort of having to chew certain vegetables. An older male participant explained that he did not like to eat salad, particularly because "I can't chew properly, I got false dentures, man, and also the chewing is difficult And I'm always in a hurry, I have to eat quickly, so eating the lettuce takes time." (Male, sport and recreation coordinator, IDI) One older female participant believed that she should limit certain fruit and vegetables that could be acid-forming (for example, she explained that she loves bananas but limits them because she is concerned about the acid content).

Quite a few reasons were provided as to why participants did not like vegetables. One participant explained that his wife sometimes used frozen vegetables, but he did not like the taste because he felt that they were bitter and watery in comparison to fresh vegetables. One younger male participant explained that there were some vegetables that he ate too often as a child, and it had now caused him to dislike those vegetables as an adult. Since he is in a better financial position at the moment compared to when he was growing up, he chooses not to eat them.

"Right, I will say this, if you grew up with something only, like string beans for instance, it's not something I'll eat easily." (Male, ward councillor, IDI)

Another male participant explained that he did not eat certain vegetables because he had eaten them in the past and they were not prepared nicely, and he was now "scared to experience that taste again", so would rather not eat those vegetables (Older male, FGD). Gastrointestinal discomfort from certain vegetables, such as cabbage, was described as a deterrent to eating certain vegetables. One older female participant explained that, even though she liked the taste of cabbage, because it "makes you gassy and your tummy feel uncomfortable", she rarely prepared or ate cabbage (Female, clinic nurse, IDI).

Therefore, even though people might have had physical and economic accessibility to a variety of fruit and vegetables, personal preferences were also described that influenced fruit and vegetable consumption.

\subsubsection{Other factors that potentially influence fruit and vegetable consumption}

\subsubsection{Extreme sport}

One participant interviewed was involved in high level body-building training and coaching. He described that he was extremely healthy and predominantly ate fruit and vegetables during the time when he was training. However, in the 'off-season' when he was not training, he ate unhealthily and did not worry about fruit and vegetables, indicating a contradiction in knowledge and regular fruit and vegetable consumption practices. (Male, sport and recreation coordinator, IDI) 


\subsubsection{People who rely on food provision}

Two participants described food parcel programmes that they had been involved in and described the type of food that was provided. Sometimes at soup kitchens, vegetable soup was provided, but otherwise, there were rarely fruit or vegetables provided in food parcels (Male, ward councillor, IDI and Male, pastor's assistant, IDI).

\subsubsection{School tuck shops}

The manager of a primary school tuck shop was interviewed because the school was trying to implement a 'healthy tuck shop' initiative. He explained that he could not stock a large amount of fruit because, firstly it is perishable, and therefore if not sold, it would expire and be wasted (and this meant that money would directly be lost), but also that there was limited demand for fruit options at the tuck shop. He explained that it was often the educators who bought fruit and not the learners (Male, tuck shop manager, IDI). See Figure 3.5 for the variety of items sold at the school tuck shop. The middle photograph contains three small bowls of fruit and the rest of the items are high fat, high sugar options.
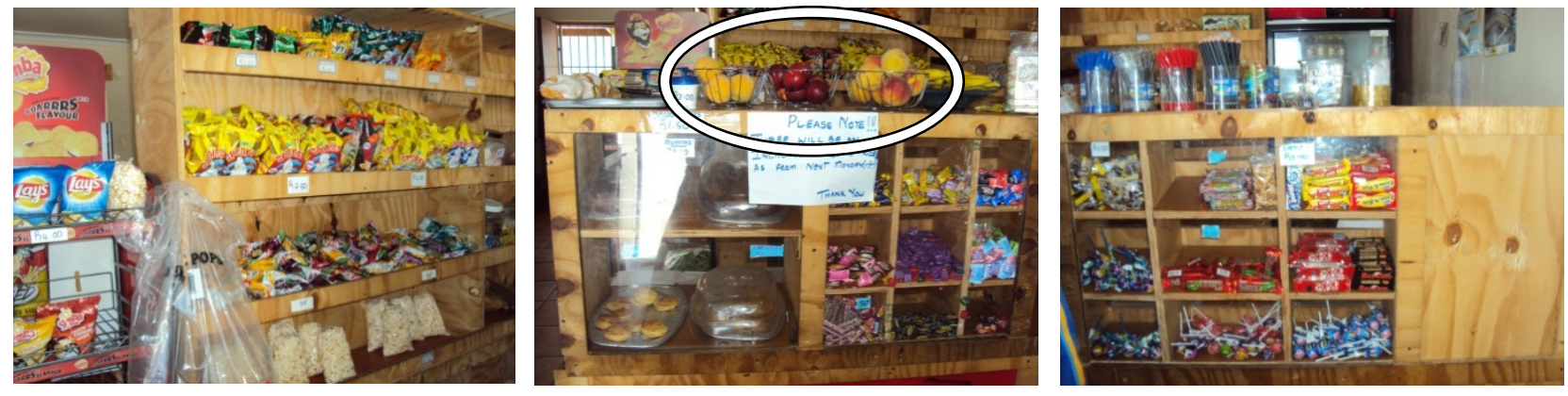

Figure 3.5: The food options available to learners at a Mitchells Plain primary school tuck shop

\subsubsection{Institutional kitchens}

Two kitchen managers were interviewed. The manager of a public frail care facility explained that they did not provide fruit daily, due to expense and financial constraints, while the private hospital manager explained that they did provide fruit and vegetables daily, but needed to work hard to ensure that the dishes served were acceptable and liked by patients. (Female, frail care centre manager, IDI and Female, private hospital kitchen manager, IDI)

Figure 3.6 is a photograph from the fridge of the kitchen at the frail care centre (old age home) in Beacon Valley, showing some packets of onions and one packet of butternuts as the only 
vegetables or fruit in the entire kitchen. Residents in a setting like this do not have any influence or choice over what is consumed. At this particular institution, the serving of fruit was not routine and the frequency of serving of fruit was described to be once per month when donations were received. The kitchen manager explained that residents were responsible for having their own fruit brought in (for example, from relatives) and that frozen mixed vegetables were often served.

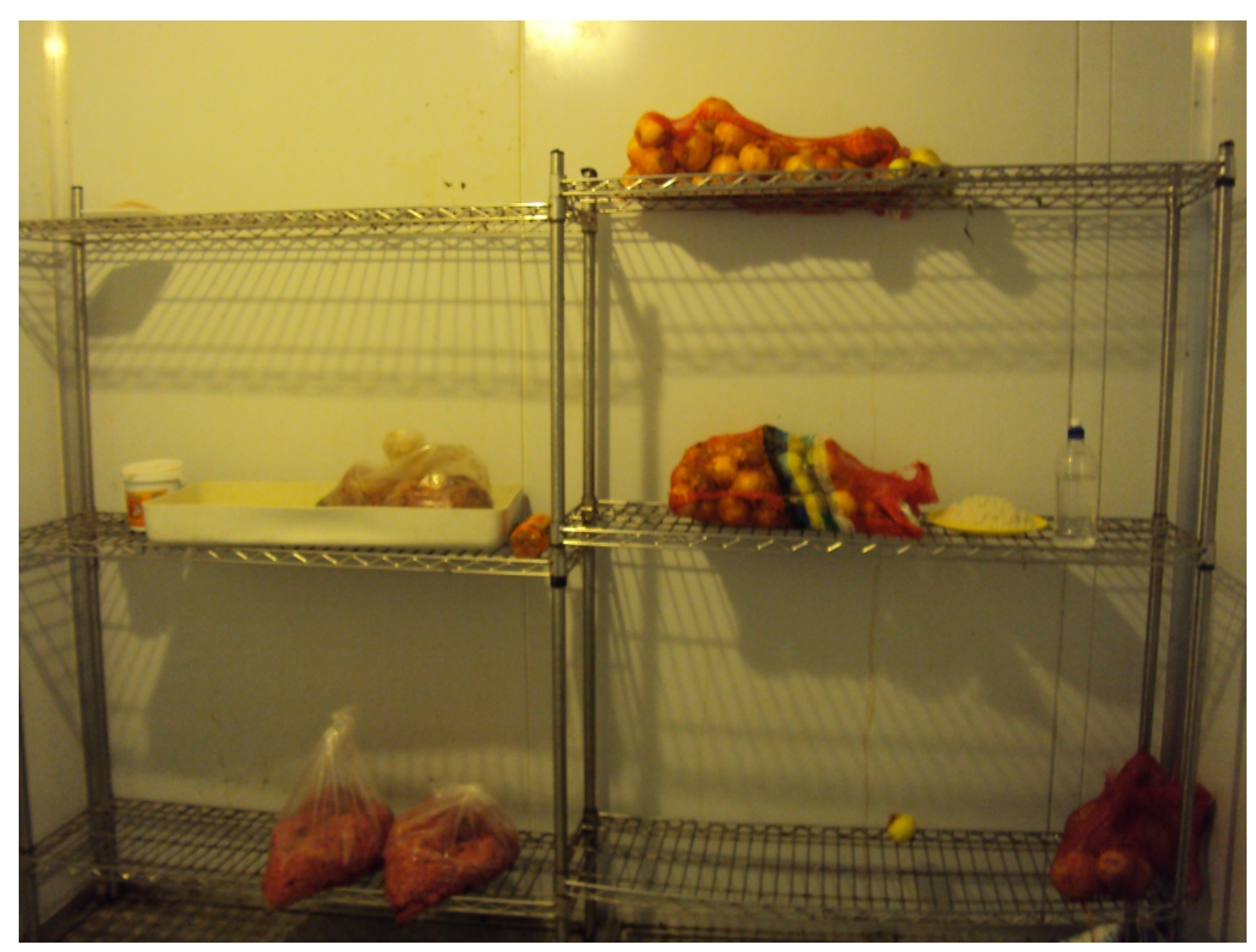

Figure 3.6: The fridge of a Mitchells Plain frail care institution

\subsubsection{School}

A Grade 1 educator explained that she had made attempts to implement healthy eating rules, such as that no chips or sweets should be sent to school and that children should eat their lunch from home in class before going out to break when they are able to access the tuck shop. She listed a few challenges in the implementation of these rules, amongst others that parents did not always abide by the rules.

Therefore, individuals who are dependent on others for their food provision do not always have any degree of choice over what they consume, including fruit and vegetables. The examples provided by the participants of this study showed that some groups in this community lacked the agency to determine whether or not they consumed fruit and vegetables. 


\subsection{ATTITUDES AND PERCEPTIONS INFLUENCING FRUIT AND VEGETABLE CONSUMPTION}

\subsubsection{Importance of general healthy eating}

A predominant theme during discussions was that healthy eating was generally considered to be important, and the main reasons provided for this were some general benefits, including the development of a healthy body and adequate brain function and specific benefits in terms of disease prevention. Healthy eating was also specifically discussed as being important for children.

\subsubsection{Benefits of healthy eating: general, disease prevention and for children}

Participants felt that if they ate healthily, their bodies would have enough energy to function properly and feel strong, and that they would generally be healthy. Another benefit of healthy eating was that it would 'stimulate thinking' and ensure good brain function.

In terms of disease prevention, a few respondents described that healthy eating was important for the general health and could assist specifically in preventing NCDs (such as obesity, diabetes and hypertension), and that it was also important to maintain a healthy weight. A few respondents acknowledged that healthy eating should be maintained on an on-going basis and for a period of time, in order to experience its benefits. One participant, a health worker herself, felt that most health workers spent their time trying to treat illness and that more effort should be spent on disease prevention, of which healthy eating is an important component (Female, clinic nurse, IDI).

A fairly strong theme was that healthy eating was particularly important in children, to provide enough energy and nutrients for their growth and development, including brain development, and to prevent children from getting sick.

"Yes, the children must eat, every day a fruit, it's very important for them, for the health, vitamin C, vitamin B... Obviously [they are] still growing up." (Female, informal vendor, IDI) "I see those children who don't really eat, they don't have that energy" (Female, crèche Manager, IDI)

"...but I mean a child is growing, and we need to have the foundation laid properly, you understand. Because if a child doesn't eat healthy when he's small, it's gonna grow up to be an adult that's not gonna be healthy as well." (Female, clinic nurse, IDI) 


\subsubsection{Healthy eating is not that important}

A weak theme was that healthy eating was not important. A senior citizen (grandmother) explained that she did not feel that healthy eating was important because she ate anything that she liked but she was not sick; the 'only' problem that she had was high cholesterol, which did not affect how she felt and she did not believe that healthy eating could improve that.

"The tablet breaks the fat down, because, why? I don't feel sick... Yes, yes, you can eat anything but you mustn't overdo it." (Older female, FGD)

Another participant explained:

"I know a few people that were eating very healthy, day by day, and they died sooner than those that not eating well, healthy; they also got high blood sugar, cholesterol all that." (Older male, FGD)

\subsubsection{Other opinions on healthy eating}

Some respondents were resigned or despairing in their opinions on healthy eating:

“...but some people can't afford it. What can you do?" (Male, imam, IDI)

Many respondents explained that they thought healthy eating was important and made statements such as:

"We all know using olive oil is wonderful... Its healthy, but some people can't afford it." (Male, imam, IDI)

The use of olive oil was consistently mentioned when healthy eating was discussed, as something that people aspired to but could not afford. Some felt that the majority of people did eat healthily:

"I must say that within our society, having spoken to many people, there are a lot of healthy eaters out there." (Male, pastor's assistant, IDI)

It appears that with hindsight, people realised that healthy eating was important, but sometimes only when it was already too late:

"Hy [respondent's husband, after being diagnosed with a non-communicable disease] het siekte op, toe, op die einde van die dag, toe se hy vir my, jinne [participant name] weet jy 
as ek geëet het soos jy geëet... was ek vandag gesond." (Older female, FGD)

\subsubsection{Importance of adequate fruit and vegetable consumption}

A strong theme was that fruit and vegetables were important, however, there was often a 'but' attached to the explanation:

\footnotetext{
"Yes it is important, but, it's not at the top of my list." (Female, catering manager, IDI)

"I think it's healthy but I don't eat veg." (Older male, FGD)

"We'll eat veg, but it's not like, it's not a routine in my diet." (Male, ward councillor, IDI)

"I'll eat it, but I won't eat it every day or so." (Female, informal vendor, IDI)
}

\subsubsection{Importance of fruit and vegetable consumption for health and disease prevention}

Fruit and vegetable consumption was described as being important for improved health, and for disease prevention; a younger female participant explained:

“...I don't like basically, the use of medication ...I'm trying to go more the natural route, so if I can do it the natural route, and what better way to use food to basically do that?" (Female, private hospital kitchen manager, IDI)

Increased fruit and vegetable consumption was described as contributing to the prevention of colds and 'flu, and the reason provided for this was that fruit and vegetables strengthen the immune system.

\subsubsection{Specific functions of fruit and vegetables}

Some participants mentioned specific functions of fruit and vegetables, or their specific reasons for eating fruit and vegetables. For example, carrots were described as being important for eyesight, a few participants noted that:

"The fruit I would say, is also very good for us, for, let go of the stools you know" (Female, informal vendor, IDI)

Vegetables were described as being important for the skin. Further specific reasons that were provided for why people believed fruit and vegetables to be important included:

\footnotetext{
" "He got a sickness and then at the end of the day, he said to me, wow, [pariticipant name], do you know that if I ate as you were eating, then today I would be healthy."
} 
“...even doctors even, recommend veg, fruit and veg, fruit and veg, and I mean even biblically... You know, it's healthy... Coz it even detoxes your body, takes out all the toxins, according to the, you know, Bible." (Male, sport and recreation coordinator, IDI)

"Groente en vrugte is gesond want dit word uit die grond uit, hulle se mos die goetes wat uit die grond kom is 'n baie goeie ding." (Younger female, FGD)

\subsubsection{Importance of fruit and vegetable consumption in children}

As with general healthy eating, the importance of fruit and vegetables was discussed particularly for children's health and growth:

"The children is picking up from healthy food and vegetables and all the stuff." (Older female, FGD)

"Those who are underweight, some of them don't want to eat their veggies." (Female, crèche manager, IDI)

Some participants described that they did not regularly consume fruit and vegetables, but felt that it was important for children to do so.

"Groente en vrugte is goed vir 'n kind..., ek eet nie groente nie. ${ }^{w}$. I just don't like it, maybe it's because one day I did eat it by someone and it didn't taste nice so I don't eat it." (Younger female, FGD)

\subsubsection{Fruit and vegetable consumption is not that important}

Similar to the theme "Healthy eating is not that important" the theme that fruit and vegetable consumption was not important, was also weak. A few reasons were provided for this. With regard to fruit and vegetable consumption in children, one participant felt that:

"...even if the children don't want to eat fruits and veggies, you can buy that Nesquik and that Milo and that, it has the same nutrients and vitamins in it." (Younger female FGD)

Another participant described:

\footnotetext{
$\checkmark$ "Vegetables and fruit are healthy because they come out of the ground, they say that things that come out of the ground is a very good thing."

w "Vegetables and fruit are good for a child... I don't eat vegetables."
} 
"But in today's life, it doesn't matter where and what, what you eating, where you buy it from, all the veggies and fruit is generically improved [genetically modified]." (Older male, FGD)

\subsubsection{Other opinions on the importance of fruit and vegetable consumption}

A participant who was involved in fairly extreme sport training felt that fruit was not as important as vegetables, because:

"You see fruit, ne, is also, it's a simple carbohydrate, but it stores fat also. The fruit is like a cheat meal, man... And a banana is too much carbohydrates in, man." (Male, sport and recreation coordinator, IDI)

This same participant, who was also involved in sport coaching and provided nutrition education to people, did not seem to think that he needed to eat healthily all the time and throughout the year, but only during his peak training season.

In general, when discussing the importance of fruit and vegetables, many participants incorrectly classified potatoes as a vegetable and referred to potatoes as a 'basic' and a source of energy. When the interviewer probed further and asked if participants thought potatoes were a starch or a vegetable, one participant still felt they were a vegetable and another explained that she did not classify foods as starches or vegetables.

Some participants were contradictory in their opinions. One participant responded

"...it is important, though myself, you always say that, you know, you have to be honest, myself you know, I don't eat a lot of vegetables... I'm not a lover of that," and a few minutes later explained "...it is imperative, do you know healthy eating is important." (Female, crèche manager, IDI)

This displayed a discord between her knowledge and practices. Another participant explained:

“...even the spinach, the same... Very healthy, but like I say... You see, I say it's not it's not my cup of tea, but we know it's healthy." (Male, imam, IDI) 
In general, it seemed that many participants seemed to know what they should be doing, but their practices and behaviours did not correspond to their knowledge or they did not feel that healthy eating guidelines were applicable to them.

\subsection{SUGGESTIONS OF WAYS TO INCREASE FRUIT AND VEGETABLE CONSUMPTION}

During the FGDs and IDIs, participants were asked to provide suggestions of what they felt could contribute to an increase in fruit and vegetable consumption in the Mitchells Plain community. The following section describes the suggestions that were provided in response to this question.

\subsubsection{Education and awareness}

A very strong theme was the need for more education, awareness, advocacy and promotion on fruit and vegetable consumption to the general population and to the Mitchells Plain community in particular.

\subsubsection{Education through the media}

Participants suggested various forms of media to be used for education and awareness:

\subsection{Television}

Some participants suggested the use of television (TV) to promote fruit and vegetables, because many people watched TV, and participants explained that there were many adverts for unhealthy behaviours on TV, but that they did not see advertising that promoted fruit and vegetable consumption.

Participant: "People can be educated, you know, sometimes what you see on television, we are too lazy to read, that the problem those years we grew up. We loved to read, but the young generation, no. So still through our media, meaning television more so..."

Interviewer: "Ja, and we don't see fruit and vegetables on television?"

Participant: "Nothing. It's just liquor everything... liquor, liquor, everything, smoking." (Male, imam, IDI)

\subsection{Radio}

Some participants suggested adverts on the radio to promote fruit and vegetable consumption:

Participant 1: "Why don't they make a ad, to make the fruit and veg more...?"

Participant 2: “...appropriate..."

Participant 1: "...attractive..." 
Participant 2: "Advertise it in a funny way or whatever to make it more appealing."

Participant 1: "...en miskien oo die radio ook, want hulle praat mos baie nonsense..." $x$

Participant 2: "Hulle kan oo die radio like, announce..." (Older males, FGD)

\subsection{Community newspapers}

A participant suggested that information be available in a community newspaper, because many people accessed the community papers, and furthermore, he explained that the column should be regular, as opposed to once-off:

Participant: "What I was thinking of, isn't it also possible to... put a piece of, I mean a regular discussion in our, what's that community paper? That comes up every week and... Then it's a wider scope... Yes, more visible, ja, and it, and it reaches more people... They know where to go to, or they know who to contact. If they don't get the help or anything, this is, then you get consistency... Now people read, I've seen sometimes that, sad to say it happens in your upper class area... Like in town, I at times make it a point to read their newspaper... And I say ok here's a little small about healthy eating, where and its purpose and requirements... Now by us, there's a portion perhaps in the Peoples Post or Plainsman, but just a portion to say, like the New Year they started up a healthy..., what you gonna do? But it's not an on-going thing. It's just once-off. It don't influence someone else." (Male, health committee member, IDI)

\subsubsection{Education through health facilities}

Various ways for education to be provided at health facilities were suggested and these are described in this section.

\subsection{Talks}

Some participants suggested more talks on healthy eating at health facilities:

"I think if there, they get more educated, if the clinics can even, you know, they speak about diarrhoea fine, I always hear about that, and they speak about the importance of the children's injections, but also if they can speak to parents, the mothers and fathers, about the diets of the children." (Female, crèche manager, IDI)

\footnotetext{
$x$ "...and maybe also on the radio? Because they talk a lot of nonsense..."

$\mathrm{y}$ "...they can also, like, announce on the radio..."
} 


\subsection{Education materials}

A suggestion was made for pamphlets to be developed and distributed, but it was emphasised that they should be appropriate:

"Yes because I think also the pamphlets that comes out ne? It, it will tell them this and that and that but they need to take into consideration the community that you addressing. Like I can tell people that visit the private hospital, you must drink fresh fruit juice. And you must eat that. But try to think now what are these people here, they, a bottle of fruit juice, like 10, 12 rand. They rather gonna buy bread from that money. Cause they not gonna buy juice. But I will tell them give your child enough water to drink. If you don't have juice, you understand." (Female, clinic nurse, IDI)

Other suggestions were for posters on healthy eating to be put up in the clinic, as well as individual counselling on healthy eating to be given when mothers are with the health workers.

\subsubsection{Education through other community structures}

A few other community structures were suggested as potential platforms for education on fruit and vegetable consumption:

- Schools: One participant suggested that schools should educate learners on fruit and vegetable consumption and should actually give children fruit to eat.

When the Grade 1 Educator was interviewed, she shared some of the National Department of Basic Education text books that have been developed for Grade 1 (see Figures 3.7 and 3.8). These show that healthy eating and fruit and vegetable consumption is being incorporated into the curriculum at some level. Figure 3.7 shows the incorporation of a healthy diet, including fruit and vegetables, into the Life Skills curriculum and Figure 3.8 shows the use of fruit and vegetables as examples of items in mathematics exercises. 

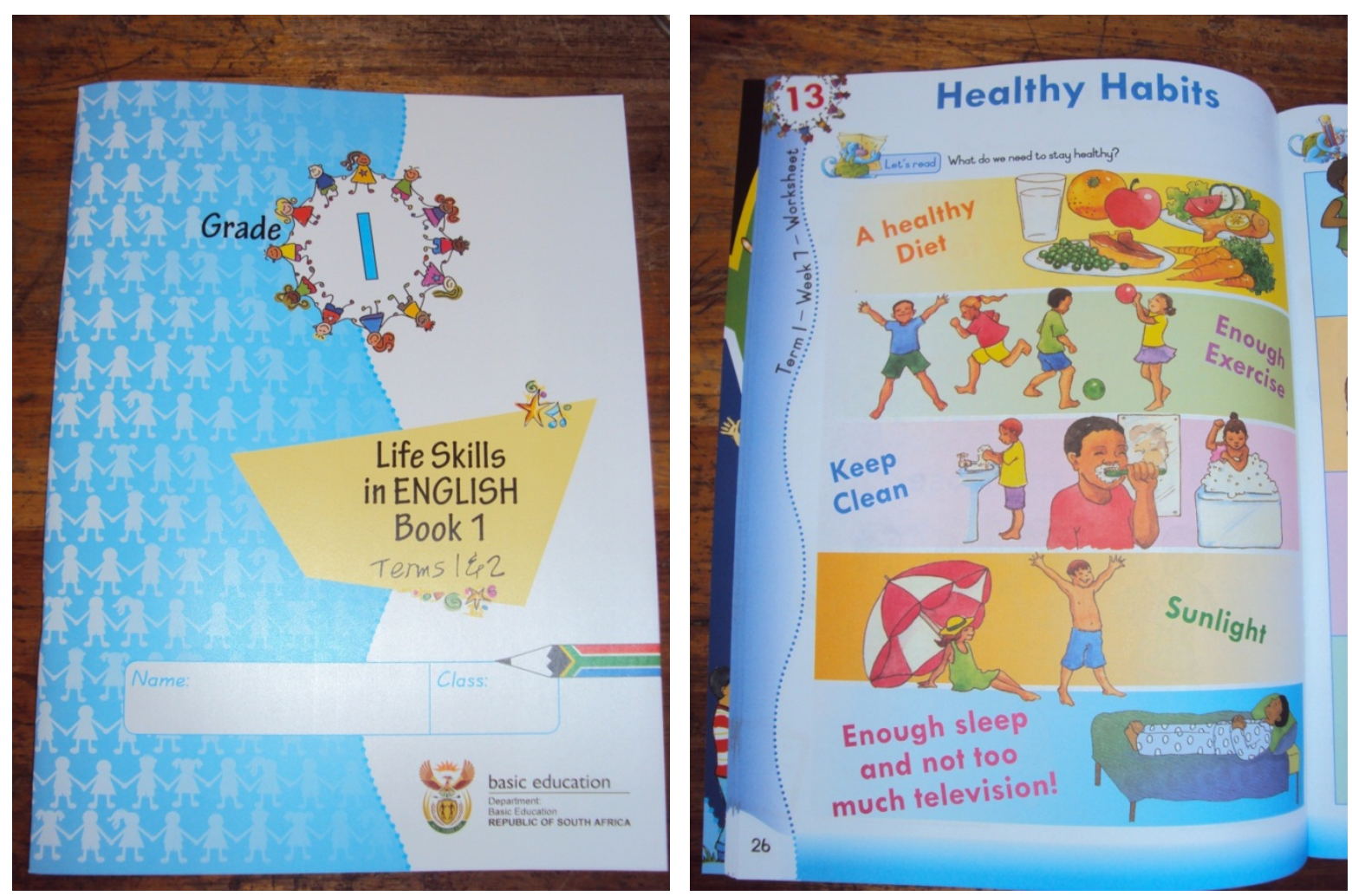

Figure 3.7: A Department of Basic Education Life Skills text book displaying that healthy diet, including fruit and vegetables, is included as part of the curriculum
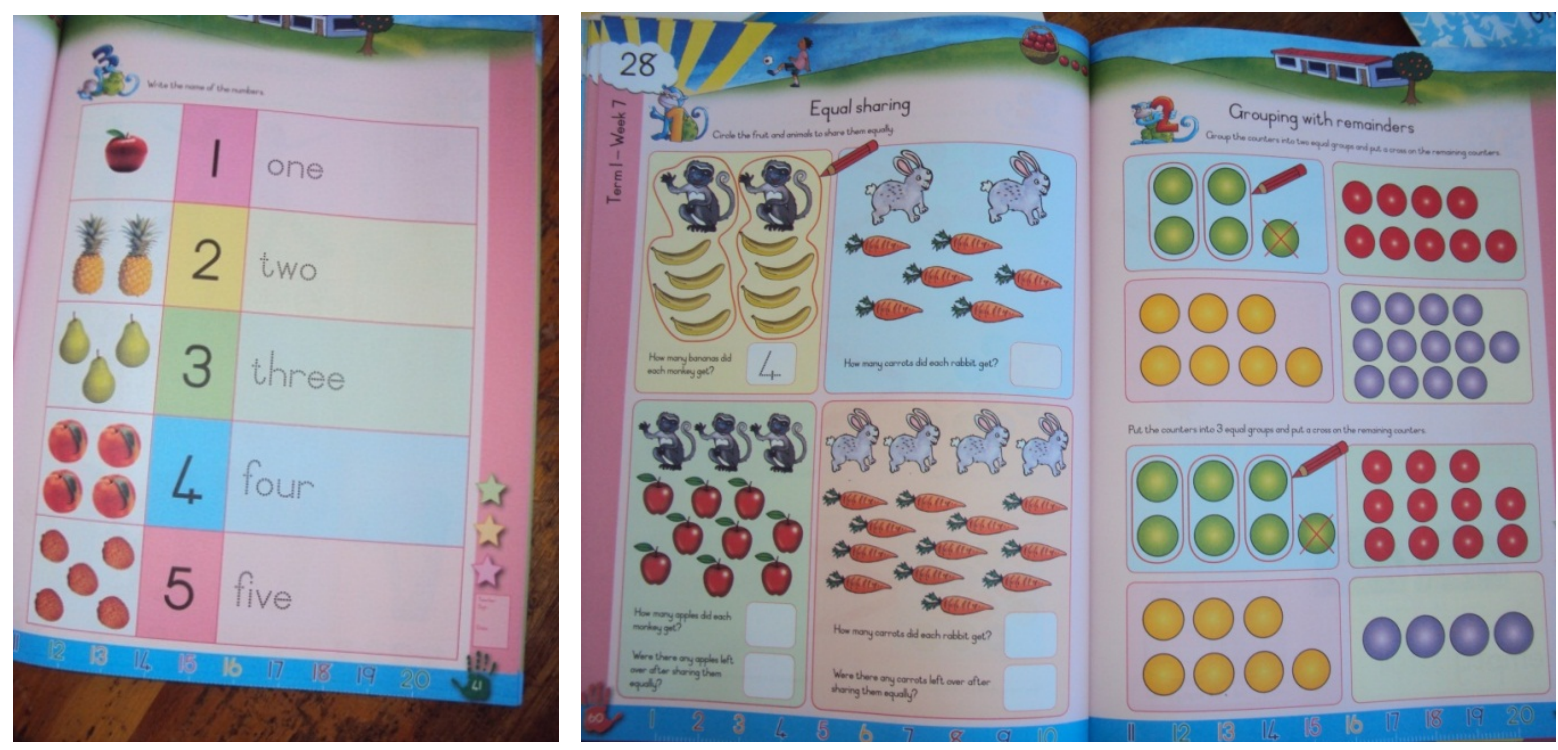

Figure 3.8: A Department of Basic Education Mathematics text book, using fruit and vegetables as examples in tasks or activities

- Religious teachings: After discussion about possible ways to increase fruit and vegetable consumption, both the imam of a mosque and the pastor's assistant from a church suggested that healthy eating and fruit and vegetable consumption could, and should, be incorporated into religious teachings. 
- Crèches: A crèche manager explained that often when children came to crèche and saw other children eating fruit and vegetables, then they would eat more fruit and vegetables:

"The mother will say you know teacher, my child don't really eat... Then we will say, that's not a problem, uh, that you will find, with most of our new children but amazingly when they see their peers, their friends are eating, then they also start to eat." (Female, crèche manager, IDI)

\subsubsection{Special events and activities}

The participants in the male FGD suggested a variety of community events or activities that could be organised, and that could encourage fruit and vegetable consumption in the community:

- A form of education called 'edutainment':

"...have make it an event type of thingy, you know, I always call it edutainment, have something like that, and then, what l've learnt is the best way to teach people is a joke, a comedic way and that way they grasp also..." (Older male, FGD)

- Competitions:

Participant 1: "... you tackle every road and start, let them start something in their road, so that's how you, that's how you can start something and then tell them listen here at the end of the day we can have competitions the best road or the fittest road or things like... the healthiest road."

Participant 2: "...ja but there must be..."

Participant 1: "...they must get something out of there as well, ja they get..." Interviewer: "If there's a competition?"

Participant 1: "Ja."

Interviewer: "If they can win something?"

Participant 1: "There we go, they love those kind of things..."

Interviewer: "And if they started like a competition, for a veg garden?"

Participant 1: "The best veg garden, ooo they will love that, seriously!" (Younger and older males, FGD)

- Targeting of children:

"I think with the kids as well, to target the kids, just to have after school programmes as well like community centres, you know, when I was a kid the community centre there where I 
grew up in, there was always something happening, and it was always full, taking a lot of information home as well." (Older male, FGD)

- A specific example of an event was provided:

Participant: "...hmm, and that would be good also to have it like, an event on a Saturday maybe, even in your community, where people look forward to it..." Interviewer: "If you look at the TV, like Master Chef?"

Participant: "Not like a lot of meat [laughing]..."

Interviewer: "No, they get all their ingredients and they must make a dish, and I mean it's a variety of dishes..."

Participant: "They must have a competition, like giving you all the stuff, green onion, hieso gaan te keure ${ }^{z}$." (Older males, FGD)

\subsubsection{Practical suggestions and food preparation}

A number of suggestions were provided by participants on various aspects related to food preparation that could encourage increased consumption of fruit and vegetables.

\subsubsection{Improve the taste or appeal}

A number of suggestions were provided on how to increase the appeal and taste of the dish as a way to encourage people to eat more fruit and vegetables, such as providing alternative preparation techniques (boil, steam, roast, cook in a stew) instead of using the same preparation technique all of the time. Another suggestion was to add something to the dish to make it taste better (e.g. add grated cheese to vegetables or add salt, pepper or herbs to vegetables) and this was seen as especially important because:

"You eat with your eyes, that is the first thing they going to go for, because they going to look at it and see ok, it doesn't look too good so I'm not even going to go for it." (Female, private hospital kitchen manager, IDI)

A further suggestion was to provide information on ways to add vegetables to dishes (e.g. when preparing a hamburger, add tomato, lettuce and/or pineapple).

\footnotetext{
z "...here, they will go crazy."
} 


\subsubsection{Practical ideas}

Some participants explained that people need more practical ideas of how to prepare fruit and vegetables, and in an economic manner:

"So that is more practical ways of doing it, and simple things that's in your cupboard, for instance, usually and make, use, that you can replace maybe with the same value of something. If you used to buy a bag of potatoes, how can we replace the something else, you know, so that kinda, that kinda things or if you buy 10 kilos, say listen, you only need $x$ amount of potatoes, like you can buy 7 kilos and replace that R5 or whatever rand for something else for instance." (Male, ward councillor, IDI)

Other practical information that was suggested included the provision of healthy recipes and guidance on how to budget appropriately.

\subsubsection{Convenience}

In terms of convenience, one participant suggested the use of fruit and vegetables such as avocado that does not need to be cooked, and is quite versatile to use in many different ways. Another participant explained:

"I suppose, if the prepared vegetables like they sell at Checkers and those places, if it's a bit cheaper, yes l'd probably buy the pre-cut, which would be more convenient to use." (Female, catering manager, IDI)

\subsubsection{Cost and affordability}

Some participants stated that if the cost of fruit and vegetables were less, or if they earned more money, then they would eat more fruit and vegetables, whereas one participant explained that vegetables are actually less expensive than meat (implying that if people spent less money on meat, they would be able to buy more vegetables):

Participant: "More education, more awareness and also, the value in terms of money. Ja, I mean meat is expensive. It's so expensive, and I look at it. I go to shops and look at, are you so expensive?"

Interviewer: "Ja, the amount of vegetables you can get for that..."

Participant: "It's ridiculous, you know, actually you, I mean you, most of it you can actually grow it [laughs]. You know? So easy, so cheap, so straightforward [vegetables]." (Male, urban farmer, IDI) 


\subsubsection{Specific suggestions for children}

Many suggestions provided to increase fruit and vegetable consumption in children were related to behaviour and the encouragement of more action and effort by parents. One participant suggested that parents should introduce vegetables at an early age, so that the child would get used to it. Other participants suggested preparing the vegetables in a way that was interesting or appetising to children, such as pouring juice over the vegetables:

'If I, if he wants to eat, if I make him eat the veg, then he said mama put on juice, juice on.... Then I know that he will eat it, because he likes juice, then I put it on, and then he eats it.' (Older female, FGD)

Another suggestion was that if children prefer fruit then rather encourage them to eat fruit. Suggestions for behaviour change strategies in children varied:

- One participant stated: "You have to have patience with a child." (Female clinic nurse)

- $\quad$ Another said that "All children, you must force them." (Older female, FGD)

- $\quad$ An alternative suggestion was "Bribe them is the only way." (Older female, FGD)

A suggestion to target parents and attempt to convince them to make more effort to feed fruit and vegetables was made by a clinic nurse:

"So I will tell them that if you eat healthy you, your child will be more healthy and you will have to come and sit in this long line at the clinic less frequently." (Female, clinic nurse, IDI)

Another suggestion was that parents should eat vegetables in front of their children, as a way of 'modelling' and that hopefully then the child would copy them.

A specific activity for children to do was suggested:

“...I think that, very important for us, is to really educate our little ones... for them, to do activities, with the fruit especially. Like erh, I know they love that activity, where we tell them ok now not everybody though, the bigger ones, you can cut up your fruit yourself. And then we have the kebab sticks. And then we let them put on whatever is available for that day. And you know how proud they are, of that fruit kebab that they made now." (Female, crèche manager, IDI) 
It seemed that when suggestions to increase fruit and vegetable consumption were provided, most people provided suggestions that could be used for others, and did not discuss suggestions that would help themselves to increase fruit and vegetable consumption.

\subsection{SUMMARY OF VARIOUS GROUPS' OPINIONS}


Table 3.7: Overview of the different groups interviewed and their opinions (in brief) on the main topics discussed

\begin{tabular}{|c|c|c|c|c|}
\hline $\begin{array}{l}\text { RESEARCH } \\
\text { QUESTION }\end{array}$ & THEMES & $\begin{array}{c}\text { Older women } \\
\text { (1 focus group; } \\
7 \text { individual interviews) }\end{array}$ & $\begin{array}{l}\text { Younger women } \\
\text { (2 focus groups) }\end{array}$ & $\begin{array}{c}\text { Men } \\
\text { (1 focus group; } \\
8 \text { individual interviews })\end{array}$ \\
\hline \multirow{2}{*}{$\begin{array}{l}\text { How do } \\
\text { residents in } \\
\text { an area of } \\
\text { Mitchells } \\
\text { Plain rate the } \\
\text { importance of } \\
\text { fruit and } \\
\text { vegetable } \\
\text { consumption? }\end{array}$} & $\begin{array}{l}\text { Importance } \\
\text { of healthy } \\
\text { eating }\end{array}$ & $\begin{array}{l}\text { Important for health } \\
\text { Disease prevention } \\
\text { (obesity, diabetes, } \\
\text { hypertension) } \\
\text { Important in children } \\
\text { (growth, development) } \\
\text { Healthy eating not } \\
\text { important }\end{array}$ & Important in children & $\begin{array}{l}\text { Very important } \\
\text { Disease prevention } \\
\text { Healthy eating not } \\
\text { important }\end{array}$ \\
\hline & $\begin{array}{l}\text { Importance } \\
\text { of fruit and } \\
\text { vegetables }\end{array}$ & $\begin{array}{l}\text { Important } \\
\text { Disease prevention } \\
\text { (obesity, diabetes, } \\
\text { hypertension, cancer, } \\
\text { colds and flus) } \\
\text { Specific functions of } \\
\text { fruit and vegetables } \\
\text { Important for children }\end{array}$ & $\begin{array}{l}\text { Important for health } \\
\text { Disease prevention } \\
\text { (colds) } \\
\text { Specific functions of } \\
\text { fruit and vegetables } \\
\text { Important for children } \\
\text { Fruit and vegetables not } \\
\text { that important }\end{array}$ & $\begin{array}{l}\text { Important } \\
\text { Disease prevention } \\
\text { Functions of fruit and } \\
\text { vegetables } \\
\text { Fruit and vegetables not } \\
\text { important }\end{array}$ \\
\hline $\begin{array}{l}\text { What are } \\
\text { some } \\
\text { underlying } \\
\text { factors that } \\
\text { influence fruit } \\
\text { and vegetable } \\
\text { consumption? }\end{array}$ & $\begin{array}{l}\text { Reasons why } \\
\text { people do } \\
\text { not eat } \\
\text { enough fruit } \\
\text { and } \\
\text { vegetables }\end{array}$ & \begin{tabular}{|l} 
Not educated on the \\
importance \\
Cost/affordability \\
Do not prioritise fruit \\
and vegetables \\
Practical logistics (take \\
long to prepare, lazy) \\
Children do not like \\
vegetables \\
Impact of parents on \\
children (do not make \\
an effort, lack discipline) \\
Personal preference \\
Negative consequences \\
(some vegetables \\
cause gas, heartburn)
\end{tabular} & $\begin{array}{l}\text { Not educated on the } \\
\text { importance } \\
\text { Cost/affordability } \\
\text { Not a priority } \\
\text { Practical logistics (takes } \\
\text { long to prepare) } \\
\text { Children } \\
\text { Personal preferences }\end{array}$ & $\begin{array}{l}\text { Cost/affordability } \\
\text { Fruit and vegetables not } \\
\text { a priority (buy/prepare } \\
\text { other foods first, not } \\
\text { part of the 'basics') } \\
\text { Not important enough } \\
\text { (no negative impact of } \\
\text { not eating fruit and } \\
\text { vegetables) } \\
\text { Practical logistics } \\
\text { (people do not have } \\
\text { time to prepare) } \\
\text { Children (parents do not } \\
\text { make enough effort) } \\
\text { Personal Preference } \\
\text { Negative perceptions } \\
\text { Other (take-aways } \\
\text { available, meat tastes } \\
\text { nicer, etc.) }\end{array}$ \\
\hline
\end{tabular}




\begin{tabular}{|c|c|c|c|c|}
\hline $\begin{array}{l}\text { RESEARCH } \\
\text { QUESTION }\end{array}$ & THEMES & $\begin{array}{c}\text { Older women } \\
\text { (1 focus group; } \\
7 \text { individual interviews) }\end{array}$ & $\begin{array}{l}\text { Younger women } \\
\text { (2 focus groups) }\end{array}$ & $\begin{array}{c}\text { Men } \\
\text { (1 focus group; } \\
8 \text { individual interviews) }\end{array}$ \\
\hline & $\begin{array}{l}\text { Factors that } \\
\text { could } \\
\text { increase fruit } \\
\text { and } \\
\text { vegetable } \\
\text { consumption }\end{array}$ & $\begin{array}{l}\text { Education (on why fruit } \\
\text { and vegetables are } \\
\text { important, how to } \\
\text { prepare) } \\
\text { Ways that parents can } \\
\text { encourage children to } \\
\text { eat vegetables } \\
\text { School } \\
\text { Interaction with parents } \\
\text { Practical advicel } \\
\text { information (ways to } \\
\text { prepare easier, make it } \\
\text { more appetising, etc.) } \\
\text { Other (change in mind- } \\
\text { set and behaviour) }\end{array}$ & $\begin{array}{l}\text { Education (on why fruit } \\
\text { and vegetables are } \\
\text { important) } \\
\text { Ways that parents can } \\
\text { encourage children to } \\
\text { eat vegetables } \\
\text { Practical logistics/ } \\
\text { purchasing (fruit and } \\
\text { vegetable are cheaper } \\
\text { than meat, buy when } \\
\text { have money) } \\
\text { Other (specific } \\
\text { times/reasons when } \\
\text { people start to eat fruit } \\
\text { and vegetables) }\end{array}$ & $\begin{array}{l}\text { Education/Awareness } \\
\text { (TV, radio, community } \\
\text { papers, many } \\
\text { opportunities, on-going) } \\
\text { Children } \\
\text { Practical logistics } \\
\text { (recipes, preparation } \\
\text { techniques) } \\
\text { Ideas/projects (consult } \\
\text { community, } \\
\text { competitions, events) } \\
\text { Specific reasons why } \\
\text { people eat more fruit } \\
\text { and vegetables (when } \\
\text { diagnosed with illness) } \\
\text { Other (lead by example) }\end{array}$ \\
\hline & $\begin{array}{l}\text { Changes in } \\
\text { eating } \\
\text { patterns over } \\
\text { the years }\end{array}$ & $\begin{array}{l}\text { Then: spent more time } \\
\text { preparing food, ate } \\
\text { healthier even though } \\
\text { had less money, more } \\
\text { discipline } \\
\text { Now: much less time } \\
\text { spent preparing meals, } \\
\text { rushed, less healthy } \\
\text { eating, do not eat } \\
\text { enough vegetables }\end{array}$ & $\begin{array}{l}\text { Then: food was better } \\
\text { Now: children eat } \\
\text { bread, young people do } \\
\text { not cook }\end{array}$ & $\begin{array}{l}\text { Then: was more } \\
\text { vegetables available, } \\
\text { better quality, had less } \\
\text { money but ate more } \\
\text { healthily, forced to eat } \\
\text { what was available } \\
\text { Now: more luxuries, } \\
\text { take-aways, lifestyles } \\
\text { changed, laziness, } \\
\text { poorer quality, people } \\
\text { are too busy to prepare } \\
\text { food, less discipline, } \\
\text { people eat less } \\
\text { vegetables) }\end{array}$ \\
\hline & $\begin{array}{l}\text { Fruit and } \\
\text { vegetables: } \\
\text { preparation }\end{array}$ & $\begin{array}{l}\text { Methods of preparation } \\
\text { Ways to disguise/make } \\
\text { interesting/taste nice } \\
\text { Do not overcook (will } \\
\text { not taste good) }\end{array}$ & $\begin{array}{l}\text { Methods of preparation } \\
\text { Add things to make it } \\
\text { taste nice }\end{array}$ & $\begin{array}{l}\text { Methods of preparation } \\
\text { Make it appetising } \\
\text { Preparation is important }\end{array}$ \\
\hline & $\begin{array}{l}\text { Fruit and } \\
\text { vegetables: } \\
\text { purchasing }\end{array}$ & $\begin{array}{l}\text { Reasons for buying } \\
\text { from an informal } \\
\text { vendor/stalls } \\
\text { Supermarket } \\
\text { Farms } \\
\text { Quality is important } \\
\text { (willing to spend more) }\end{array}$ & $\begin{array}{l}\text { Stalls/informal vendors } \\
\text { Supermarkets } \\
\text { Wherever its cheapest } \\
\text { Farms }\end{array}$ & $\begin{array}{l}\text { Supermarkets (reasons) } \\
\text { Informal vendors } \\
\text { (reasons for buying } \\
\text { there) }\end{array}$ \\
\hline
\end{tabular}




\begin{tabular}{|c|c|c|c|c|}
\hline $\begin{array}{l}\text { RESEARCH } \\
\text { QUESTION }\end{array}$ & THEMES & $\begin{array}{c}\text { Older women } \\
\text { (1 focus group; } \\
7 \text { individual interviews) }\end{array}$ & $\begin{array}{l}\text { Younger women } \\
\text { ( } 2 \text { focus groups) }\end{array}$ & $\begin{array}{c}\text { Men } \\
\text { (1 focus group; } \\
8 \text { individual interviews) }\end{array}$ \\
\hline \multirow[t]{3}{*}{$\begin{array}{l}\text { Why do } \\
\text { individuals in } \\
\text { Mitchells } \\
\text { Plain eat the } \\
\text { amount and } \\
\text { variety of fruit } \\
\text { and } \\
\text { vegetables } \\
\text { that they do? }\end{array}$} & $\begin{array}{l}\text { Vegetable } \\
\text { gardens }\end{array}$ & $\begin{array}{l}\text { People used to grow } \\
\text { vegetables, not } \\
\text { anymore } \\
\text { Reasons for not } \\
\text { growing: lack of space, } \\
\text { time, seed, water }\end{array}$ & $\begin{array}{l}\text { Parents grow } \\
\text { vegetables } \\
\text { Reasons for not } \\
\text { growing: will be stolen, } \\
\text { do not have grass, no } \\
\text { space }\end{array}$ & $\begin{array}{l}\text { Reasons for not } \\
\text { growing: no time, no } \\
\text { space, other priorities, } \\
\text { easier to buy, } \\
\text { associated with poverty, } \\
\text { access to land, do not } \\
\text { know how to, will be } \\
\text { stolen } \\
\text { Should encourage } \\
\text { people to grow } \\
\text { vegetables } \\
\text { Successes: some } \\
\text { community projects } \\
\text { Suggestions: } \\
\text { incentives, sponsorship, } \\
\text { resources, equipment }\end{array}$ \\
\hline & $\begin{array}{l}\text { General } \\
\text { eating } \\
\text { patterns }\end{array}$ & $\begin{array}{l}\text { Community } \\
\text { Family } \\
\text { Personal }\end{array}$ & & $\begin{array}{l}\text { Family } \\
\text { Community } \\
\text { Personal } \\
\text { Differences in cultures }\end{array}$ \\
\hline & $\begin{array}{l}\text { Personal } \\
\text { preferences I } \\
\text { aversions }\end{array}$ & $\begin{array}{l}\text { Preferences: soft fruit } \\
\text { (bananas), sweet fruit } \\
\text { (nectarine/peaches), } \\
\text { apples/bananas (filling) } \\
\text { Aversions: acidic fruit } \\
\text { (oranges, kiwi), do not } \\
\text { like taste of some } \\
\text { Positives: colourful, } \\
\text { light, healthy, } \\
\text { refreshing, cooling, } \\
\text { quick prepare } \\
\text { Negatives: expensive, } \\
\text { 'bok kos'aa, time } \\
\text { consuming, some fruit } \\
\text { too sweet }\end{array}$ & $\begin{array}{l}\text { Preferences: banana } \\
\text { (filling) } \\
\text { Aversions: some do not } \\
\text { like the taste } \\
\text { Positives: healthy, } \\
\text { prevents illness } \\
\text { Negatives: makes } \\
\text { tummy work or causes } \\
\text { gas, perishable }\end{array}$ & $\begin{array}{l}\text { Preferences: sweet } \\
\text { fruit, vegetables in } \\
\text { stews } \\
\text { Aversions: do not like } \\
\text { taste of some } \\
\text { vegetables } \\
\text { Positives: healthy, feel } \\
\text { better } \\
\text { Negatives: fruit stores } \\
\text { fat, ate too much of } \\
\text { some vegetables when } \\
\text { younger }\end{array}$ \\
\hline
\end{tabular}

\footnotetext{
aa "Animal food" (direct translation is "buck food")
} 


\section{DISCUSSION}

The Discussion chapter will assess and interpret the results of this study in the context of previous research that has been conducted. The factors that were reported to influence fruit and vegetable consumption patterns will be discussed within the framework of the five components of food security (described in section 1.3 of the Literature Overview). Attitudes and perceptions of adequate fruit and vegetable consumption revealed by participants will be further deliberated. Suggestions provided from participants to increase fruit and vegetable consumption will be evaluated. Finally, limitations of the study will be reported.

The recent SANHANES report describes South Africa as a population with a high burden of NCDs and states: "There is therefore a great need for a better understanding of both the prevalence of NCDs and the associated risk factors among South Africans and a need to translate such information into effective health policies, health programmes and services." It is known that there is an association between low fruit and vegetable consumption and morbidity and mortality. ${ }^{32,33}$ The overall benefits of fruit and vegetable consumption are also widely known and accepted. ${ }^{11,30,31}$ South Africans do not consume enough fruit and vegetables. ${ }^{116,117}$ Adequate fruit and vegetable consumption is one factor that could contribute to disease reduction, as well as to the improvement of the quality and nutritional adequacy of the diet and dietary diversity in South Africa. ${ }^{13}$ Therefore, evidence-based information that could be used to contribute to increased fruit and vegetable consumption of the South African population would be beneficial.

This study aimed to identify underlying factors that influence individual and household fruit and vegetable consumption in an area of Mitchells Plain, by directly engaging with key community members in a participatory manner. South Africa has a food-based dietary guideline that recommends "eat plenty of vegetables and fruit every day," ${ }^{22,153}$ yet the population is not following these guidelines. ${ }^{116,117}$ Conducting interviews with members of a community to gain a deeper understanding of factors that influence fruit and vegetable consumption was considered to be an important starting point in attempting to understand why overall fruit and vegetable consumption patterns are not optimal. The process of consulting with community members is an important component of attempting to address a problem using a human rights-based approach. An attempt to understand the challenges faced by community members in consuming an adequate amount of fruit and vegetables, as well as to identify facilitators of fruit and vegetable consumption, would provide information that could ultimately assist to design programmes or strategies to contribute to the progressive realisation of improved dietary quality and nutritional adequacy of food consumed. 
The general perception from participants of this study was that improved education, awareness and advocacy on fruit and vegetables are needed in order to increase consumption, and a variety of suggestions were provided on how this could be done. However, some of the results show that the problem is more complex than a lack of knowledge, and that there are certain aspects of the environment that need to be considered, as well as societal norms and attitudes towards fruit and vegetable consumption. This chapter describes the factors reported to influence fruit and vegetable consumption in this community in terms of the various components of food security, as well as to suggest potential areas of intervention that could facilitate the progressive realisation of this community's right to adequate food, including adequate fruit and vegetable consumption.

\subsection{CURRENT PRACTICES ASSOCIATED WITH FRUIT AND VEGETABLE CONSUMPTION}

The factors that were reported to influence current fruit and vegetable consumption patterns from the participants of this study are discussed according to the five components of food security (defined in section 1.3 of the Literature Overview), namely: availability, accessibility, adequacy, acceptability and agency. ${ }^{43}$ These five components of food security are all interconnected and although they are dealt with separately, there is some overlap in the discussions. Following this, a summary of barriers to and facilitators of fruit and vegetable consumption in this community will be provided at the end of this section.

\subsubsection{Influence of food availability on fruit and vegetable consumption}

The achievement of food security requires that sufficient amounts of food are available to meet the needs of all people in the population at all times. ${ }^{43}$ It is also necessary to consider the types of foods that are available in a community's environment. In the Mitchells Plain community, participants described the increased availability and consumption of fast-foods as well as the perishability of fruit and vegetables as the two main factors related to availability that negatively influence fruit and vegetable consumption. Those participants involved in the selling of fruit and vegetables have higher household availability of these products. Individuals who live in institutions can have limited availability of fruit and vegetables, a factor outside of their control, and this is discussed in section 4.1 .5 when the component of agency is dealt with.

\subsubsection{Increased availability and consumption of 'fast-foods'}

Participants reported that one of the major changes in dietary patterns that has taken place over the years is the increased consumption of fast-foods. With the increased availability of unhealthy fast-foods, the impact on individual food consumption is the gradual replacement of items such as fruit and vegetables with fast-foods that typically contain limited or no fruit and vegetables. 
Although many people remain under great financial strain, some participants indicated that increased available household funds, combined with the increased availability of fast-foods such as take-aways and ready-to-eat meals, have contributed to deterioration in eating practices. This is consistent with other research that has shown that the 'nutrition transition' and 'urbanisation' of communities tends to have a negative impact on eating practices and health. ${ }^{154,155}$ It is necessary to consider this reported practice of increased fast-food consumption in the context of other research on fast-food consumption conducted in South Africa.

Research conducted on fast-food intake in adolescents in Soweto and Johannesburg (urban areas in Gauteng, South Africa) as part of the Birth to Twenty cohort study, described fast-food consumption in these adolescents as ranging from 0 to 23 times per week, with an average of 8.1 times per week in males and 7.2 times per week in females. ${ }^{156}$ Furthermore, almost all participants ate more than one fast-food item per week, with more than $50 \%$ of males and $38 \%$ of females eating more than eight fast-food items per week. The most commonly consumed 'fast-food items'

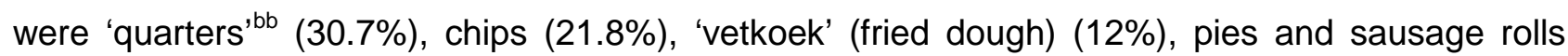
(6.8\%), 'boerewors' (sausage) rolls (6.7\%), fried fish (5.6\%), hotdogs (4.8\%); pizzas (4\%) and hamburgers (3.9\%). ${ }^{156}$ Consequent data from the Birth to Twenty study described the five most popular 'snacks' of adolescents to be bread or crisps, fruit, sweet biscuits, and chocolate (which accounted for more than $80 \%$ of snacks consumed) and sweets, crisps, and soft drinks were the three most popular confectionery/beverage items consumed. ${ }^{157}$ This data also assessed changes in the dietary habits and eating practices of adolescents in this area over time, and reported that regular lunch box use was not common, and had decreased from $17.4 \%$ at age 13 to $8.6 \%$ at age 17, while conversely, tuck shop consumption increased with age, with more than $85 \%$ of participants buying food from the school tuck shop. ${ }^{157}$ The most popular lunch box items (>50\% of foods) were cheese, bread, fruit and fruit juice, while the five most popular tuck shop purchases included sweets, crisps, cold drink, fried chips, and white bread (62\% of purchases). ${ }^{157}$ For boys and girls, the number of snacks consumed while watching television increased by $86 \%$ over the five year study period. It was shown that eating practices were well established by age $13 .{ }^{157}$ The structure of Soweto bears some similarities to Mitchells Plain, in that there are high levels of poverty, the area can be considered a 'township' and has a very high population density. The key difference between the areas is that the population of Soweto is predominantly black African, whereas the population of Mitchells Plain is predominantly coloured. ${ }^{132}$ Cultural differences can therefore be expected, including eating patterns and behaviours, but similarities might also be evident due to the nutrition transition.

\footnotetext{
${ }^{\mathrm{bb}}$ A typical 'quarter' consists of a quarter-loaf of white bread, chips, a slice of cheese and any number of delicatessen meats and sauces ${ }^{156}$ and is therefore high in energy and low in micronutrients.
} 
In South Africa, fast-foods are obtained from large stores (supermarkets) and informal outlets (street vendors and community tuck shops). Informal vendors in Soweto sold a single vetkoek for 60c and portion of chips for R8 (during 2011); informal vendors are therefore considered to sell items at a lower price, making fast-foods more accessible and affordable to those on low incomes. ${ }^{157}$ The availability of sweets, crisps and beverages was found to be widespread at schools (from tuck shops that were either in or outside school grounds) and in the community (street vendors, tuck shops, and supermarkets). This study identified the three environments of risk to be home, school and in the community, and in all of these environments the participants' desire for energy-dense, micronutrient-poor foods was high. ${ }^{157}$

A national survey conducted in all provinces of participants older than 16 years, assessing the consumption of street and fast-foods found that frequent street food consumption (classified as two or more times per week) ranged from $1.8 \%$ in the Northern Cape to $20.6 \%$ in Limpopo, and frequent fast-food consumption ranged between $1.5 \%$ in the North West Province to $14.7 \%$ in Gauteng. ${ }^{158}$ The highest intake of street food was in the medium socio-economic category (14.7\%), while the highest intake of fast-foods was in the high socio-economic category (13.2\%). ${ }^{158}$ Overall, fruit was the most commonly purchased street food by all ethnic groups over the previous week and this practice was found to be highest in black participants (35.8\%). ${ }^{158}$ Purchases of soft drinks ranged from $4.8 \%$ in white participants to $16.4 \%$ in black participants and savoury snacks from $2.3 \%$ to $14.5 \%$ in white and black participants, respectively. ${ }^{158}$ Fast-food intake was much higher in the highest socio-economic group compared with the lowest, while those in the middle category were the highest consumers of street foods. ${ }^{158}$

Steyn et al. (the authors of the national survey conducted in 2011) suggested that the purchasing of food from informal vendors needs to be considered in the context of the fact that food obtained from informal vendors is convenient and many people in South Africa, especially around big cities, live far from where they work. ${ }^{158}$ Therefore, it is difficult to consume regular meals at home. In such cases, a source of ready-prepared, immediately accessible and low-cost food will meet their immediate needs. The authors suggested that there may be ways in which vendors could be encouraged to sell healthier food items (such as fresh or dried fruit, nuts, vegetables and roasted maize cobs) and that this could be especially relevant in schools in poor areas where often there are many vendors selling products to children at break times and, currently, most items sold are energy-dense, high in fat and low in micronutrients. ${ }^{158}$ 


\subsubsection{Decreased availability of fruit and vegetables}

The predominant methods of accessing fruit and vegetables in Mitchells Plain were described as purchasing, either from supermarkets or informal vendors. With regard to the purchasing of fruit and vegetables from supermarkets, there was considerable discussion on the closing of a large fruit and vegetable supermarket that occupied a central location in the township. This was reported to be of concern since many savings could be made by purchasing from such a supermarket, as they had weekly specials to buy vegetables in bulk, often of vegetables that are commonly consumed and have a long shelf life (such as onions, potatoes and butternut). The explanation by one participant that the closing of this supermarket was "like taking the hospital away from the people" suggested that there is understanding of the role that healthy eating, including fruit and vegetable consumption, can have in health promotion and disease prevention. Although there are other means for community members to purchase fruit and vegetables, the removal of this particular supermarket was argued by participants to have had an influence on fruit and vegetable availability in Mitchells Plain.

Therefore, participants reported an increased availability and consumption of fast-foods, which is consistent with research conducted in various parts of South Africa. Fruit and vegetables are still available in this community in absolute terms, but it may seem that fast-foods and convenience foods might be more accessible to community members than healthier alternatives such as fruit and vegetables.

\subsubsection{Influence of accessibility on fruit and vegetable consumption}

In order for food security to be realised, it is necessary for food to be both physically and economically accessible to all community members at all times. ${ }^{43}$ Factors related to accessibility of fruit and vegetables reported by participants will be described according to economic and then physical accessibility, and the influence of both on fruit and vegetable consumption will be discussed. The influence of perishability on the accessibility of fruit and vegetables, as described by participants, will also be explored.

\subsubsection{Physical and economic accessibility of fruit and vegetables: Factors influencing purchasing}

Factors reported to influence fruit and vegetable purchasing are discussed, as they influence both the physical and economic accessibility of fruit and vegetables. A predominant theme that generated a lot of discussion and was important to participants was the purchasing of fruit and vegetables and factors that influenced where participants purchased their fruit and vegetables. This should be considered within the context that only $46.2 \%$ of the population in the Mitchells 
Plain area are employed, and $42 \%$ of employed people in the study area earn an income of less than R1 600 per month. ${ }^{132}$

The predominant manner of accessing fruit and vegetables reported by participants in this study was by purchasing them. Factors that affected where participants purchased their fruit and vegetables included cost, whether or not people received a monthly or weekly income, convenience, taste and perishability. There seemed to be a divide in responses, whereby some participants clearly preferred to purchase fruit and vegetables from supermarkets, whereas others predominantly purchased their fruit and vegetables from informal vendors.

The recently released SANHANES report described the predominant factors influencing food choices when shopping in South Africa to be price (64.5\%) and taste (17.5\%), while less dominant factors were health aspects in terms of nutrient content of the food item; how well or long the food item would keep (all approximately 14\%); safety/hygiene (9.6\%); convenience (9.6\%); and lastly, easy preparation (7.1\%). ${ }^{7}$ In this study, participants reported that predominant factors influencing where individuals purchased items included cost and convenience, with a few participants mentioning quality of items purchased and how long the food would keep. Some participants explained that fruit and vegetables purchased from informal vendors perish much more quickly than those purchased from supermarkets. Factors that were considered to influence food choices regarding fruit and vegetables in this study included personal preference (which shares some similarity to taste), nutrient content and how long it took to prepare.

Many reasons were provided by participants who preferred to purchase their fruit and vegetables from supermarkets. One reason provided was that vegetables and fruit from supermarkets are usually fresher (due to improved storage conditions) and of a better quality than those purchased from informal vendors, and would therefore have an increased shelf life and be less likely to be wasted. Another reason provided for preferring to purchase from supermarkets was convenience, because all groceries could then be purchased at once. The predominant reason provided for not buying from supermarkets was the higher cost of their fruit and vegetables.

With regard to the purchasing of fruit and vegetables from informal vendors, one reason provided for the preference was that at informal vendors, people know exactly what they are going to pay for a certain number of items, whereas at most supermarkets, some fruit and vegetables need to be weighed before purchasing, and then people will find out what they will be paying only after the items have been weighed. Furthermore, informal vendors may sell fruit and vegetables in packaging of a smaller size in comparison to what is available in supermarkets, which makes the packaging more economically accessible to people who have a limited amount of money to spend. 
For an area such as Mitchells Plain, where many households experience financial strain, this could be an important factor in determining where individuals purchase their fruit and vegetables. When people have a limited amount of money to spend, it seems to be important that people are able to ensure that they do not overspend on this amount. It could be useful to conduct a cost analysis to determine the difference in prices between pre-packaged fruit and vegetables and those that need to be weighed, in order to determine which method of purchasing fruit and vegetables would be cheaper and more acceptable for community members in Mitchells Plain.

Research conducted in three diverse communities in Cape Town described the main sources of purchased food (during the previous year) to be supermarkets (94\%), small shops, restaurants and 'take-aways' (75\%) and informal vendors (66\%). ${ }^{48}$ Supermarkets were usually visited once per month for bulk purchases when people are paid, whereas informal vendors were visited daily or weekly for smaller item purchases, with both the formal and informal sectors being important sources of food purchases. ${ }^{48}$ Similar responses were provided by the participants from Mitchells Plain in this research study, suggesting that the decision on where to purchase fruit and vegetables may be influenced by how income is earned. Previous research conducted in communities in Cape Town reported that the physical access to markets (and not only income) was also an important factor influencing food access, and it was suggested that consideration should be given to the environmental and structural factors (such as the food supply chain) that impact on household food security. ${ }^{48}$

Another factor related to purchasing was a discussion that took place within the male FGD, whereby men seemed not to want neighbours to know when or how much they had purchased after they had been shopping for food. This seemed to be an important concern for residents in this community. Previous research has shown that in similar areas, a significant number of households acquire food via sharing of meals, receiving it from others or the borrowing of food, which places strain on community resources. ${ }^{48}$ There is not enough evidence to suggest that people do not want to share food, but this may be something that could be further explored in future research.

\subsubsection{Economic accessibility of fruit and vegetables: Affordability}

With regard to the economic accessibility of fruit and vegetables, cost and financial constraints were definitely identified as a major barrier, but this seemed to be more complex than simply not being able to afford fruit and vegetables. Participants described that during the planning of meals (in the form of grocery shopping when food is purchased, and during food preparation) priority is given to what was described as 'the basics'. It seems that protein (meat or chicken) and starch (bread, rice, or potatoes), constitute 'the basics' when meals are being prepared, and this extends 
to items such as coffee, tea, sugar and other common household items while shopping for food. Some participants directly stated that fruit and vegetables are not necessarily considered expensive, but it appears that once 'the basics' (which do not include fruit and vegetables) are purchased or prepared, there is usually no time or money left to consider the purchasing or preparation of fruit or vegetables. It seems as if fruit and vegetables are considered an added extra or condiment, but not as an essential component of a meal.

Some participants regarded fruit and vegetables as simply unaffordable and therefore, economic accessibility could be considered to be a barrier to fruit and vegetable consumption. With regard to the affordability (and therefore economic accessibility) of healthy foods in general, research previously conducted in South Africa has shown that, although healthier foods are commonly perceived to be (and sometimes are) more expensive than unhealthy foods, there are some food items commonly available in supermarkets that have a relatively low energy density, high nutrient density and low cost. ${ }^{159}$ Smaller, more informal stores were described as having a limited availability of healthy food choices. ${ }^{159}$ When a diet made up of commonly consumed foods was replaced by healthier foods, the healthier diet cost on average $69 \%$ more. ${ }^{159}$ However, further calculations demonstrated that this cost could be reduced by up to $50 \%$ by substituting some items with more cost-effective items (e.g. replacing meat with legumes). This study showed that foods such as oats, lentils, dry beans, brown or whole-wheat bread and peanut butter are both low cost and healthier and that milk, certain vegetables and fruits (apples, oranges), baked beans and tinned pilchards are of intermediate cost and healthier. ${ }^{159}$ The authors suggested that when healthy diets are advocated, they need to be affordable and that a healthy diet is economically accessible, but people need to be informed and motivated to choose to consume it. However, Schönfeldt et al. reported that a diet based on the South African Food-based dietary guidelines to construct the basic food plate in South Africa is not affordable for the majority of the population. ${ }^{98}$

Further explanations that were provided for the deterioration in eating practices and related to finances were that often people would evaluate the amount of money available to them and choose to purchase food items that would be the most satisfying and filling, as opposed to considering the health benefits of the food items being purchased. This is consistent with results reported elsewhere, whereby people who could not afford enough food, chose the least expensive foods that were the most filling, and that often these were energy-dense items. ${ }^{62}$ This finding, in conjunction with the fact that the benefits of fruit and vegetable consumption are only visible in the long-term, and that some participants had explained that they observed no negative impact from not consuming adequate fruit and vegetables, should be considered when educational messages are developed. However, in this same community, even though people were under financial strain, they were prepared to pay more for fruit and vegetables of a higher quality. This finding could be 
explained by the ramification that in the longer term, households could possibly save money because the better quality vegetables and fruit would last longer and would not perish (and therefore be wasted) before they could be used.

\subsubsection{Physical accessibility of fruit and vegetables}

Participants reported to predominantly access their fruit and vegetables by purchasing them, therefore the location of the various supermarkets and informal vendors in relation to where people live is an important factor that would influence the physical accessibility of fruit and vegetables. Participants were not asked about the relative distance from their houses to the supermarkets or vendors and it was not discussed by participants. This is something that would need further consideration, because often food retail is not evenly distributed throughout communities which can result in some community members having limited physical accessibility to food, including fruit and vegetables.

The option of acquiring vegetables by growing one's own is another route of physically accessing vegetables. This was a factor discussed by many participants and often raised by the participants themselves (as opposed to responding to direct questions being asked on this topic). Participants seemed to have the opinion that having a vegetable garden is a desirable, but it was felt that the prevalence of households growing their own vegetables has decreased and many reasons were provided as to why this was the case. Space was listed as a major, basic constraint, together with limited access to resources, limited time and knowledge and the risk of theft of the produce. There were also other more complex barriers included in the challenges associated with community gardens, such as that while there is communal space available, the administrative effort involved in trying to access the land is a barrier. Participants also often want monetary incentives (since urban settings depend on cash economies) and not just to receive some vegetables as compensation for working in the garden. Research in three communities (Khayelitsha, Ocean View and Philippi) of Cape Town showed that only $5 \%$ of households in the study area were involved in urban farming or growing some of their own food, as a method to access their vegetables. ${ }^{52}$

Challenges of urban agriculture (including household food production and community gardens in urban areas) have been reported elsewhere to include inadequate support services such as extension services, access to credit and infrastructure development, limited access to resources such as water, fertiliser and access to land. Land access is a significant problem in densely populated urban areas and often the land that is available does not have optimal soil quality ${ }^{160}$ Other challenges include inadequate fencing (which can result in theft of produce, as well as the destruction of crops by animals) and pests. ${ }^{161}$ The promotion of agricultural production is often a 
priority intervention when household food security strategies are developed, and could be a strategy to be strengthened in order to increase fruit and vegetable consumption. However, it comes with many challenges, which need to be considered in the much wider context of other important interventions.

Crush et al conducted research in southern African cities on urban food production and household food security, and they concluded that: “...despite decades of experience with urban food production, its full potential as a source of food for home consumption and market is hampered by the absence of an enabling and supportive national and local policy environment." ${ }^{52}$ Therefore, even though there is an urban agriculture policy in this metropolitan area, the policy may not be comprehensive or supportive enough and it does not seem as if the policy is being implemented as well as it could be. The finding that people in Mitchells Plain do not consider fruit and vegetables a priority food for consumption could indicate that even if people do grow their own vegetables, they may not use the vegetables for household consumption, but might want rather to sell the vegetables in order to be able to buy other priority items. The promotion of home vegetable gardens and urban agriculture has often been a suggested strategy to combat urban household food insecurity. However, it has been recognised that home production does not necessarily translate to improved household food security. ${ }^{162}$ The research conducted by Crush et al. in various southern African cities demonstrates that in most of the communities included in the study area, over $70 \%$ of households that grew their own food were also food insecure. ${ }^{52}$ The authors suggested that at the household level, urban food production is only one possible component of broader household food access and security strategies, and that urban agriculture needs to be contextualised within the urban food system. An improved understanding of the urban food system is needed. ${ }^{52}$

\subsubsection{Perishability of fruit and vegetables influences accessibility}

Another common issue raised, related to both cost and practical logistics, is that fruit and vegetables are perishable. Therefore there is relatively high risk involved in having fruit and vegetables available (whether at the household or institution level) since it cannot always be predicted how quickly the fruit or vegetables will be consumed, and if they begin to decompose before they are used, they will need to be thrown away and will be wasted. Furthermore, when people do not have adequate refrigeration, this could lead to increased perishability of fruit and vegetables. Perishability seemed to be a deterrent to people having fruit and vegetables available, especially in a community under financial strain. When people have limited disposable income, they would rather purchase items that they know will last longer than risk purchasing something that might expire before it can be used. From the results of this study, it appears that many people 
have chicken and meat available on a consistent basis, and these items are perishable. This could be influenced by the stronger priority that is allocated to meat and chicken in comparison to fruit and vegetables.

Therefore, in this Mitchells Plain community, there are many interrelated factors that influence both physical and economic accessibility to fruit and vegetables. Even though fruit and vegetables may seem to be available, accessibility may be a challenge for many people. Further understanding of the physical location of supermarkets and vendors that sell fruit and vegetables would be beneficial in order to determine the true physical accessibility to fruit and vegetables by all community members. An additional area where research could provide further understanding would be to determine what amount of money and percentage of income is being spent on food and of this, to determine the amount and percentage of money spent on food that is allocated to fruit and vegetables.

\subsubsection{Fruit and vegetable consumption and nutritional adequacy}

Nutritional adequacy is realised when food is nutritious, safe and in accordance with what is needed to maintain health. ${ }^{43}$ Therefore, the nutritional adequacy component of food security considers the quality and nutrient content of food consumed, including the micronutrient content of food, as well as total caloric sufficiency. Furthermore, food should be obtained and produced in a manner that is environmentally sustainable. A strong theme discussed by participants in this study was how the preparation of fruit and vegetables influences their nutritional adequacy, and this will be further explored in this section.

\subsubsection{Influence of fruit and vegetable preparation on nutritional adequacy}

Participants seemed to have some knowledge on how various preparation techniques can impact the nutritional adequacy of fruit and vegetables. With regard to the preparation of vegetables in particular, some participants felt that preparation in a manner that retains nutrient content was important (especially, for example for individuals with an NCD), whereas for other participants, preparation in a manner that provides an appealing appearance was more important. Furthermore, with regard to the addition of ingredients to vegetables during preparation, there was also a difference in opinion, whereby some participants felt that it was important to prepare vegetables as healthily as possible (with limited or no addition of salt, margarine, butter or oil and sugar) whereas others felt that it was more important to make the vegetables appetising by adding certain herbs, spices and additional ingredients so that family members would at least eat the vegetables. This seemed to be an unresolved issue, and participants seemed unsure of whether vegetables should be prepared in the healthiest way possible and result in the risk that family members may choose 
not to eat the vegetables, or that vegetables should be prepared in a more interesting and appealing manner, and at least have some guarantee that family members would eat the vegetables, even if it involved the addition of less healthy ingredients. This is an important issue that needs to be addressed, and may indicate that nutrition education messages are currently not achieving the desired goal, but rather contributing to confusion. Nutrition guidelines may be promoting practices that seem unrealistic and unobtainable to most people. Research conducted in Australia confirms that participants felt that nutrition recommendations were purposefully exaggerated and aspirational in order to elicit improved overall fruit and vegetable consumption. ${ }^{25}$

A few participants felt that the use of frozen or tinned vegetables was appropriate, since they are more convenient, but there was not a lot of consensus on the nutritional value of these forms of vegetables. The form of vegetables and their various nutrient contents are topics that should be included in education on fruit and vegetable preparation, since the use of frozen (where feasible) or tinned vegetables (in addition to fresh vegetables) could reduce the time and effort required to prepare vegetables. In South Africa, the 2001 Census showed that $51.2 \%$ of households contained a working refrigerator, ${ }^{131}$ while a 2007 Community Survey reported this figure to be higher, at $63.9 \% .{ }^{163}$ Therefore, the use of frozen vegetables may not be something that would be achievable by everyone, but those who do not have freezers could incorporate tinned vegetables into their food purchasing and preparation in order to reduce preparation time of certain vegetables, although often tinned vegetables are more expensive than the fresh option.

Therefore, there was some discussion on nutritional adequacy with regard to how it is influenced by various preparation techniques, but this seemed to be the extent of the discussion. Participants did not discuss variety or quantity of fruit and vegetables as determinants of nutritional adequacy.

\subsubsection{Influence of acceptability on fruit and vegetable consumption}

Food needs to be culturally acceptable and produced or obtained in ways that do not compromise people's dignity, self-respect and human rights. ${ }^{43}$ Many factors that can be considered a component of acceptability were discussed by participants, ranging from personal preferences and aversions at an individual level, to commonly prepared dishes at religious or cultural events at a community level, and extending to shifts in dietary eating patterns over generations at a societal level. Practices alluded to were the increase in the availability and consumption of fast-foods as well as a weakening of parental discipline (extending to food behaviours), both of which are now considered as acceptable practices in this Mitchells Plain community, and have been reported to have a negative impact on fruit and vegetable consumption. Participants' responses to reasons for 
individual, household or community variation in fruit and vegetable consumption patterns are now discussed.

\subsubsection{Acceptable fruit and vegetable consumption practices at an individual or household level} Personal preferences or aversions were quite strong factors that were described as influencing fruit and vegetable consumption, with stronger preferences for fruit due to its general sweetness, and stronger aversions to vegetables, due to a variety of factors including previous exposure to vegetables that did not taste nice. Furthermore, some of the older participants explained the challenges of eating fruit and vegetables that are not soft, and specifically for those individuals who had dental problems, as any foods that are hard may be a challenge to consume and many fruits and vegetables could be difficult to chew. Research conducted in Brazil assessing the impact of the use of dentures in an elderly community showed reduced fruit and vegetable consumption when elderly individuals with dental problems did not use dentures in the correct manner. ${ }^{164}$ Therefore, improved oral health in general, including in children ${ }^{165}$ and the elderly could contribute to improved fruit and vegetable consumption. Some participants described direct negative effects of consuming certain fruit and vegetables; for example bananas causing heartburn.

A few participants described some positive connotations associated with the consumption of fruit and vegetables, including that they are 'refreshing', 'cooling' and 'light'. Some described fruit as an easy and convenient snack to eat between meals. Fruit can generally be eaten raw, meaning that preparation time is low, although sometimes chopping or peeling is required. These are potential attributes that could be used in educational campaigns, when attempting to educate communities and populations on how to improve fruit and vegetable consumption.

With regard to individual eating patterns, it appeared that personal beliefs and practices could, by default, influence fruit and vegetable consumption. For example, individuals who choose a vegetarian lifestyle or choose to decrease meat consumption (for reasons related to religion, environmental impact or health benefits) reported consuming high amounts of fruit and vegetables. In contrast, some individuals reported that due to their lifestyle or working conditions, they cannot always make healthy food choices. Many participants described difficulty in encouraging children to consume an adequate amount of fruit and vegetables. Results from cohort studies in Europe show that early, varied and repeated exposure to vegetables is the most successful technique to promote acceptance and preference for vegetables in young children. The introduction of a variety of vegetables in the first year of life is therefore recommended as the optimal manner in which to encourage habitual vegetable intake, since the acceptance of new foods is much more difficult after two years of age. ${ }^{166}$ With regard to family eating patterns, it appeared that sometimes, one 
family member had the potential to influence a positive change in the whole family's eating patterns (for example, when a family member had been diagnosed with an NCD). This was, however, not always the case, as some participants explained that in some households, if certain dishes were made (particularly those including vegetables) then some family members would choose to remove and not eat the specific items that they did not like.

When participants were asked to discuss dishes that were often prepared in homes and that contained fruit and vegetable ingredients, a wide variety and large number of dishes was listed. This is a surprising finding, considering the financial constraints that many people live under and in relation to the finding that fruit and vegetables are not considered priority foods in most households. This wide variety of fruits and vegetables as well as dishes containing fruits and vegetables mentioned, strengthens the potential for the promotion of these products in health education and promotion messages and campaigns, since there are commonly prepared fruit and vegetable dishes known to be liked by the participants. An attempt should be made to encourage the dishes that are prepared in a healthy manner and that contain a variety of fruit and vegetables. For example, many different salads were described by participants, but an emphasis should be placed on those that contain many fresh fruits and vegetables (such as fruit salad or mixed/tossed green salad), as opposed to those that are predominantly starch-based with large amounts of mayonnaise added (for example, potato or noodle salad).

\subsubsection{Acceptable fruit and vegetable consumption practices at a community level}

When community eating patterns were discussed, some participants acknowledged that certain popular 'cultural' dishes such as 'vetkoek' are not healthy, while others are healthier, such as stews, bredies and other similar dishes that usually include some vegetables. There were some religious, cultural and traditional events and beliefs reported that involved increased consumption of fruit and vegetables, for example, the Daniel Fast of the Christian religion involves eating only fruit and vegetables for a limited time, and during the month of Ramadan in the Islam faith, people often break their daily fast with a piece of fruit or a vegetable soup. Other events were mentioned where it seemed that less fruit and vegetables were consumed, for example at Christmas, New Year and birthdays, where braais are traditional and a lot of meat is consumed, with some salads as side dishes and where the predominant salads seem to be starch-based potato and noodle salads. During these types of celebratory events, fruit and vegetables seemed not to be a priority. Previous research has examined the influence of socio-demographic factors such as age, sex and household income on fruit and vegetable consumption, ${ }^{167,168}$ but not the influence of different religious or celebratory practices. 
The older participants spoke fondly of the traditions and dishes that they used to prepare. Participants also described that less cooking is taking place in households. There is therefore a risk that the traditional dishes that have been prepared for many years (some of which include fruit and vegetable ingredients) will be prepared less often and will eventually be 'lost'. Therefore, the documentation of these practices (as has been done in some of the tables in the results section), and the use of this information to revitalise the eating patterns that used to be followed, may positively impact on current eating practices. An inventory of dishes that are served at various times, as well as dishes that are prepared that use fruit and vegetable ingredients, is provided in the Results chapter of this study (Tables 3.3, 3.4, 3.5, 3.6). This inventory could be useful in the development of future nutrition interventions in the area. Specific recommendations that could also appeal to young community members are provided in section 4.4.2 of this Discussion.

There were some basic differences reported with regard to seasonal variation in the types of fruit and vegetables consumed. These appeared to be related to the weather or temperature and personal preferences, in that soups and more cooked vegetables were reported to be consumed during winter, whereas salads (i.e. raw vegetables) and more fruit were reported to be consumed during summer, as opposed to the physical availability of different fruit and vegetables (which would have been related to seasonal production and availability).

It therefore appears that, with regard to fruit and vegetable consumption, individuals can be surrounded by similar environmental factors, but respond differently. For example, some participants reported to eat more fruit and vegetables during Ramadan, whereas others reported the opposite, and described a lower consumption of fruit and vegetables during the same religious event. Further examples of contrasting practices within similar environments have already been provided. Environmental factors have an important influence on eating behaviours and this suggests that even within a community, individuals will react in different ways to similar exposures and this needs to be considered when attempts are made to encourage positive behaviour change and the increased consumption of fruit and vegetables. Furthermore, many of the traditional or cultural practices reported by participants in this study are either associated with decreased fruit and vegetable consumption, or dishes are prepared that decrease the nutrient content and therefore nutritional adequacy of the vegetables being consumed.

4.1.4.3 Changes in fruit and vegetable consumption patterns influenced by a shift in food priorities Similar to the discussion that took place on affordability (see 4.1.2.2 Economic accessibility: affordability), many participants described the preparation of fruit and vegetables as a barrier to their consumption. However, once this was probed further, it appeared that fruit and vegetables are 
not necessarily very time-consuming to prepare but when a meal is prepared, priority is given to the starch and protein components, and to then pay attention to another component of the meal, i.e. fruit and vegetables, feels like additional effort. Furthermore, in order to make fruit and vegetables more attractive and appetising requires some creativity, even more effort, and possibly more time. It seems that fruit and vegetables are considered to be a condiment as opposed to a main item of a meal, and therefore, when served, they are provided in small quantities. The finding that most community members do not see fruit and vegetables as a priority or part of 'the basics' (as described in the Results, section 3.3.1.2), was a strong attitude and societal norm that emerged, and it would be difficult to change such a perception.

\subsubsection{The influence of weakened discipline on fruit and vegetable consumption patterns in children}

Another theme that older participants felt very strongly about was the inadequacy of the current generation's general parenting skills. Many older participants criticised today's parents for not making enough effort to entice their children to eat fruit and vegetables, as well as a lack of effort to instil general discipline in the home. This was explained by some of the participants who are currently parents, and the feeling was that those who are now parents were often brought up in a strictly disciplined home or in poor conditions, and they do not want their children to have the same experience. Many of the first inhabitants of Mitchells Plain (which could include some of the participants of this research study) were evicted from their houses elsewhere and forced to move to Mitchells Plain by the apartheid government. Current parents are therefore sometimes described as 'over-compensating' their children because of negative experiences that they themselves had when they were growing up. This is an understandable response by parents. However, it could result in an unintentional, long-term negative impact on their children's nutrition and health status. Therefore, food consumption behaviours have to be understood within the context of much broader social, economic and political processes that influence food consumption patterns.

\subsubsection{Reported dietary changes in the Mitchells Plain community in the context of population dietary shifts in South Africa}

There were strong opinions that eating patterns have changed over the past few decades, and have become less healthy. Many reasons were provided for this. Some of the older participants were quite critical of the 'younger' generation, describing parents of today as being lazy and less interested in the health of their children, and also describing drastic changes in eating behaviours that have occurred between the two generations. Makiwane described South Africa as having 'intergenerational disjuncture' (disconnection between generations), which is largely because current (older) parents and grandparents who grew up in the apartheid regime are parenting children, as are younger parents, who are now living in a very different socio-political environment, 
and this has created a 'social distance' between the generations. ${ }^{169}$ This social distance is evident in food behaviours that have been described in this study, whereby the older generation described vast changes in eating behaviours between themselves and the younger generation and in general, held negative attitudes towards these changes, therefore displaying a distance and lack of understanding of the younger generation's eating behaviours. It is necessary to discuss the changes in dietary patterns that have been reported by participants in this study as having taken place in the Mitchells Plain community within the context of population shifts in dietary patterns that have been reported for South Africa as a country.

A review conducted in 2006 that analysed dietary changes in South Africa described that for black adults living in an area of Cape Town, there was a decrease in the percentage of carbohydrate intake, a decrease in total fibre intake and an increase in the percentage of fat intake, which was associated with increased time living in the city (while protein intakes remained the same, although the contribution of animal protein increased). ${ }^{170}$ The review reported that in urban areas of Gauteng, mean fat intake increased from $17 \%$ in 1962 to $25.8 \%$ in 1999 , and carbohydrate intake decreased from $72 \%$ to $60.3 \% .{ }^{170}$ These results demonstrate that the dietary shifts that have taken place in areas of South Africa are consistent with populations in the so-called 'nutrition transition', and describe that the diet is generally becoming less healthy.

Further analyses conducted from the review by Steyn, et al. showed that the availability of staple cereals, vegetable oils and meat per capita has gradually increased in South Africa, accounting for the overall increase in energy intake. ${ }^{170}$ However, vegetable availability was reported to remain constant and overall fruit and vegetable (excluding starchy roots) availability was reported to be $205 \mathrm{~g} /$ day, which does not meet the WHO/FAO recommended intake of $400 \mathrm{~g} /$ day. ${ }^{170}$ Recommendations from this review included a review of fiscal policies and levies, school-based interventions, food labelling, marketing and advertising standards, policies aimed at improving the environment, nutrition and health logos, and nutrition education at primary health care facilities. ${ }^{170}$ Although some of these recommendations have been addressed, many have yet to receive adequate consideration.

It appears that the consumption of fast-foods has become a societal norm, rather than the exception that is should be. In this community, it seems that increased consumption of fast-foods has been a significant generational shift in food consumption patterns that is considered to be a negative change by the older generation. 
Therefore, there are many factors that influence whether or not certain food items are considered to be acceptable to individuals. This needs to be acknowledged because it means that even when people do have physical and economic access to an adequate diet, including an adequate amount of fruit and vegetables, food choice is influenced by many diverse factors that can influence acceptability. Therefore, availability and accessibility of fruit and vegetables are not enough to guarantee consumption, and acceptability is an important factor that influences the consumption of fruit and vegetables, as has been described by participants of this study, for this community.

\subsubsection{Influence of agency on fruit and vegetable consumption}

Agency refers to the structural factors such as policies and processes that influence the food environment and can therefore act either as barriers to or facilitators of the achievement of food security and the consumption of fruit and vegetables. ${ }^{43}$ In this research study, groups that were identified to have limited agency with regard to fruit and vegetable consumption were those institutionalised or dependent on others for food provision, children dependent on parents for food provision, and families where the primary caregiver does not have enough time for food preparation.

\subsubsection{Lack of agency in individuals who rely on food provision as a barrier to fruit and vegetable consumption}

It was described that food parcels issued to destitute households most often do not contain fruit or vegetable items. The issuing of food parcels is considered to be an obligation of the state and other relevant stakeholders to directly supply food to households who have no other means of obtaining it themselves. An effort should be made to ensure that in situations where individuals are reliant on direct food provision, this food is of sufficient quality and nutritional adequacy. Furthermore, the results of this study described that tuck shops, institutional kitchens and schools, when responsible for food provision in various forms, often do not provide many fruit and vegetable items. People who are dependent on others (those who rely on food hand-outs, or those residing in institutions) do not always have a choice with regard to what they eat. The people responsible for food purchasing and production at such organisations and structures should be assisted to find ways to ensure that food of a good quality and nutritional adequacy is provided, and they may well benefit from exposure to the concepts of the right to adequate food and the implementation of a human rights-based approach that includes the provision of food to individuals in a dignified manner. It appears that there is a combination of financial constraints for such organisations (who sometimes rely on limited government and/or donor funding) as well as a lack of knowledge, skills and training on food provision. 


\subsubsection{Lack of agency in children as a barrier to fruit and vegetable consumption}

There seemed to be a general perception that adequate fruit and vegetable consumption is a challenge to children, and a few participants attributed this to parents either not making enough of an effort to feed fruit and vegetables in an appropriate manner, or parents having too many other demands to be able to give enough attention to their children in general. Children were described as consuming more fruit and vegetables when they were exposed to other children (at crèche) or adults (parents at home) eating fruit and vegetables. Some participants were of the opinion that if fruit and vegetables were introduced appropriately to children, this would increase consumption in children. Recent research on the establishment of food habits shows that early exposure to vegetables, and the use of vegetables as a starter complementary food, is essential to establish acceptance and preference for vegetables in children. Furthermore, repeated exposure and familiarisation to vegetables is necessary to promote preference for vegetables in young children. ${ }^{166}$

\subsubsection{Limited time for food preparation as a structural barrier to fruit and vegetable consumption} In general, it appears that the time and effort required for food preparation, and consequently fruit and vegetable preparation, is a constraint to adequate fruit and vegetable consumption. One explanation provided was that women are now spending more time working and less time at home, in an effort to increase the household income. This could inevitably improve food security, but may result in less time spent preparing meals at home (and increased reliance on convenience foods). This can be considered to be a structural shift in society that has negatively influenced food preparation and therefore food consumption patterns. Due to this shift taking place, many women in this study reported that the type of food they prepare is very much dependent on how much time they have available, and therefore their agency, in terms of what types of foods they can serve to their family, has been compromised. Time constraint in relation to food preparation is not unique to South Africa. Research that has been conducted in other countries on the impact of time constraints on food consumption is now described.

Research conducted in America with parents of adolescents showed that full-time employed mothers reported fewer family meals, lower encouragement of adolescents' healthy eating behaviour, a lower fruit and vegetable intake and less time spent on food preparation compared to part-time and unemployed mothers. ${ }^{171}$ Furthermore, higher work-life stress amongst both parents was associated with a less healthy food environment at home that included fewer family meals and increased consumption of sweetened beverages and fast-foods. This study concluded that although the employment of parents is associated with benefits for the family, there should be policy strategies developed to reduce parents' work and life stress in order to positively impact the family food environment. ${ }^{171}$ Other research conducted with working parents of school age children 
in an urban community in America described time constraints (due to work schedules and children's extra-curricular activities) as a dominant theme when describing challenges to meal preparation. Parents felt the need to make meals quickly with what they had available, because they often multi-tasked while making the evening meal and were often tired by the time they needed to prepare food. ${ }^{172}$ Suggestions from this research included that there was a need for creative programmes (such as the provision of tips or recipes and meal planning or preparation information) and nutrition guidance to facilitate family engagement in the preparation of meals and the cooking of quick, healthy meals. ${ }^{172}$

\subsubsection{Summary of underlying factors influencing fruit and vegetable consumption in the Mitchells Plain community}

A summary of the barriers to fruit and vegetable consumption is provided in Table 4.1 and is categorised according to the five components of food security (described in section 1.3 of the Literature Overview) that have been used as a framework to discuss the factors reported by participants to influence fruit and vegetable consumption. Although factors have been categorised according to the predominant component of food security that they affect, these five components are interconnected and therefore some factors could contribute to more than one component. For example, influence that parents have on children's fruit and vegetable consumption has been categorised as agency because children are dependent on parents for their food and therefore have limited agency over their own food choices, but at the same time, parents may experience time or financial constraints with regard to food purchasing and preparation, and therefore this factor could also be considered as affecting household accessibility to fruit and vegetables. 
Table 4.1: Summary of barriers to adequate fruit and vegetable consumption

\section{Barriers to adequate fruit and vegetable consumption}

Availability:

- Increased availability of convenience foods and a shift in the dietary patterns of the community to increased convenience food consumption (which could displace fruit and vegetable consumption).

Accessibility:

- For some, fruit and vegetables are not affordable (i.e. not economically accessible).

- Fruit and vegetables are perishable and might expire before being used (risk of being wasted).

Adequacy:

- Time constraints: some fruit and vegetable dishes take time to prepare, especially after the starch and protein (i.e. priority) portions of a meal are considered.

- Certain cultural and traditional practices are associated with decreased fruit and vegetable consumption that result in decreased nutritional adequacy of food consumed.

Acceptability:

- Personal preference (do not like the taste).

- Negative side-effects associated with eating certain fruit and vegetables (e.g. heartburn).

- For special occasions and religious events, fruit and vegetable dishes are usually not the priority.

- It is a societal norm that certain food items are prioritised to comprise 'the basics' (and this does not include fruit and vegetables).

- Some incorrect knowledge and beliefs or negative associations with fruit and vegetables.

- Benefits of fruit and vegetable consumption not immediately experienced.

Agency:

- Some individuals are dependent on others for what they eat (e.g. those in institutions or children).

- Parents do not make enough effort to encourage children to eat fruit and vegetables.

A summary of the factors that were mentioned by participants to facilitate fruit and vegetable consumption in this community is provided in Table 4.2. Again, there are certain factors that could affect more than one component of food security. For example, access to refrigeration has been categorised to affect accessibility because it prolongs the longevity of the fruit and vegetables that households purchase, but it could also influence nutritional adequacy because it prevents the fruit and vegetables from spoiling and losing nutrients, as would occur if they were not refrigerated. 
Table 4.2: Summary of factors that facilitate fruit and vegetable consumption

Facilitators of adequate fruit and vegetable consumption

Availability:

- People who sell or prepare fruit and vegetables have increased availability.

- Increased urban agriculture could improve availability.

Accessibility:

- Households that are in close proximity to supermarkets or informal vendors that sell fruit and vegetables have increased physical accessibility.

- Households that grow vegetables have increased physical accessibility.

- Households that have access to refrigeration have the capacity to store their fruit and vegetables for a longer time (and could have decreased waste of fruit and vegetables).

- Employment or guaranteed income would facilitate economic accessibility.

- $\quad$ Sales or discounts on fruit or vegetables improve economic accessibility (affordability).

Adequacy:

- $\quad$ Preparation techniques that result in minimal nutrient losses (such as steaming or quick preparation).

- Access to refrigeration could improve nutrient retention while fruit and vegetables are stored in households.

- $\quad$ Use of frozen or tinned vegetables (usually quicker to prepare).

Acceptability:

- $\quad$ Personal preference (liking the taste of certain fruit or vegetables).

- $\quad$ Personal beliefs (e.g. being vegetarian) can result in increased fruit and vegetable consumption.

- Individual diagnosis with a NCD usually results in increased family fruit and vegetable consumption.

- Preparation and serving of fruit and vegetable dishes that taste nice and are visually appealing.

- Religion:

o Christianity: The Daniel Fast involves consumption of fruit and vegetables only

o Islam: During Ramadan, some people break the fast with fruit or vegetables

o Hinduism: Most religious events are vegetarian

- $\quad$ Some traditional and cultural dishes commonly prepared include fruit or vegetable ingredients.

- Seasonal variation: during summer, more salads are eaten; during winter more soups are consumed. Agency:

- $\quad$ Children observing others eating fruit and vegetables (encourages them to do so).

\subsection{ATTITUDES AND PERCEPTIONS OF ADEQUATE FRUIT AND VEGETABLE CONSUMPTION}

Predominant attitudes towards fruit and vegetable consumption were discussed and include the fact that some participants felt that fruit and vegetable consumption is important (either for themselves, or for others, or specifically for children); a few participants felt that fruit and vegetable consumption is not important; and there was some popular media information on fruit and vegetables that was discussed and will be evaluated.

\subsubsection{Healthy eating and fruit and vegetable consumption is considered to be important} The way in which participants defined healthy eating was not something that was probed or questioned in depth. Rather, an effort was made to determine the participants' attitudes towards healthy eating. Healthy eating and the consumption of fruit and vegetables was described as being important by participants when they were directly questioned on this, specifically for the prevention of NCDs. This is understandable since Mitchells Plain has a high burden of mortality caused by $\mathrm{NCDs}^{28}$ and many participants have probably had either direct or indirect exposure to information 
on the prevention and management of NCDs, including the promotion of healthy eating. A few participants stated that they did not experience any direct negative consequences of not consuming an adequate amount of fruit and vegetables and this seemed to be an acceptable reason not to have a desire to increase their fruit and vegetable consumption. This therefore highlights the challenge that the benefits of adequate fruit and vegetable consumption are not immediately observed but rather are a lifestyle factor, the benefits of which are demonstrated in the long term.

\subsection{2 "Fruit and vegetable consumption is important, but not for me"}

Some participants stated that they did not consume fruit and vegetables daily, even though they thought it important. There were also some contradictions during individual responses, such as individuals stating that they knew fruit and vegetable consumption to be important, but that it did not necessarily apply to them on a daily basis. This ambivalence is not necessarily unique to the Mitchells Plain community. It was further expanded upon when suggestions for ways to improve fruit and vegetable consumption were provided, because mostly, participants provided suggestions that were relevant for others but not directly applicable to themselves.

It generally appeared that many participants had good knowledge on healthy eating and adequate fruit and vegetable consumption. This is consistent with the SANHANES report that described $22.6 \%$ of respondents as having a high nutrition knowledge score and $62.9 \%$ having a medium score. ${ }^{7}$ Yet, practices and behaviours do not correspond to knowledge, which has also been reported elsewhere. ${ }^{21,173}$ Therefore, campaigns to change behaviour need to be designed to assist individuals to implement the knowledge that they have, rather than assuming that people lack knowledge. A common theme that arose when issues were further probed is that (although not unique to this community) healthy eating and the regular consumption of fruit and vegetables is not a priority activity in households in the Mitchells Plain area.

\subsubsection{Healthy eating and fruit and vegetable consumption considered to be especially important for children}

Whenever participants were asked questions, they inevitably discussed the relevance to children. It was felt that healthy eating and fruit and vegetable consumption is especially important for the growth and development of children. Therefore, there already seemed to be a positive orientation towards healthy eating for children in this community. However, the provision of food to children could be improved considerably, and the involvement of parents is imperative for this to be achieved. It is a parent's responsibility to ensure adequate food provision for their children, and if they cannot do so, the state should assist them. Entry points into the community where children 
can be reached for interventions, include crèches, schools (targeting educators, managers of tuck shops and vendors selling items at the fences), community centres, sport training programmes (sports coaches of popular sports such as soccer or swimming) mother support groups, clinics or health facilities and informal vendors.

\subsubsection{Some do not regard healthy eating and fruit and vegetable consumption as important} In contrast to the widely held views of most participants that healthy eating and fruit and vegetable consumption is important, there were some respondents who did not feel this way. One explanation provided was that the nutrients in fruit and vegetables can be replaced by other products such as Milo or Nesquik, which are sweetened beverages that are fortified with certain micronutrients. This reflects the success of well-constructed marketing campaigns by companies that manufacture such products. As described by the participants of this study, such advertising and branding of items is not seen or heard of for fruit and vegetables. Fruit and vegetable consumption, in combination with other healthy behaviours, are not marketed, promoted and made visible at the same level that many unhealthy items are. Another reason provided for the lack of importance associated with the consumption of fruit and vegetables was that fruit and vegetables are not of as good a quality as they used to be, implying that the nutrients in fruit and vegetable do not seem beneficial anymore.

\subsubsection{Popular perceptions about fruit and vegetable consumption}

There were a few instances where participants provided slightly inaccurate reasons for some of their practices, displaying incorrect knowledge, or where some participants expressed popular perceptions about certain fruit and vegetables. For example, the explanation by some participants that fruit and vegetables 'detoxify' the body could result in increased fruit and vegetable consumption, whereas the opinion that certain fruit is too high in sugar could result in unnecessary restriction of fruit when people do not fully understand the nutrient content of various fruits, or do not consider portion size appropriately. There are currently many popular media sources of health and wellness information that include recommendations on healthy eating, in the form of websites, social media, magazines, and other such platforms, and these clearly influence some individuals in this area. Sometimes, recommendations provided by popular media sources are not evidencebased, and an effort therefore needs to be made to ensure that media outlets are used by health professionals to counteract some of the incorrect information that members of the public receive.

Many participants described potatoes as a vegetable that is predominantly consumed in households. Although potatoes do have some nutritional benefits, they lack the range of nutrients 
commonly found in other vegetables and it is therefore concerning that potatoes are often the only or primary vegetable consumed in households.

\subsection{SUGGESTIONS FROM PARTICIPANTS TO INCREASE FRUIT AND VEGETABLE CONSUMPTION}

Participants were asked to provide suggestions they felt would increase fruit and vegetable consumption in this Mitchells Plain community and many ideas were discussed, mainly involving education, awareness and advocacy. These suggestions are discussed and evaluated in the following section.

\subsubsection{Practical suggestions provided by participants to increase fruit and vegetable consumption}

Participants mainly suggested actions that could be implemented at an individual or household level, as well as some community activities. By far the strongest theme discussed by participants was that education, awareness, advocacy and promotion of healthy eating and fruit and vegetable consumption is desperately needed. This is consistent with recommendations from large studies that have been done in South Africa, such as the NFCS and SACRA studies. ${ }^{21,123}$ It seemed that there is a level of knowledge on the importance of fruit and vegetables, but that what is needed is more practical information on how to incorporate an adequate amount of fruit and vegetables into existing lifestyles, as well as the creation of an environment that is more supportive of regular and adequate fruit and vegetable consumption. Participants mentioned that unhealthy practices such as smoking, alcohol and unhealthy foods are often advertised on television, the radio and in community papers but that fruit and vegetable advertising is neither seen nor heard. Participants suggested a wide range of communication channels that could be used to share messages on the promotion of fruit and vegetable consumption.

\subsubsection{Individual or household factors that could improve fruit and vegetable consumption} Participants explained that practical suggestions on fruit and vegetable preparation, including recipes and information on how to prepare food healthily, in a way that is appetising, are needed. There are some examples of such material that has been developed and is available in South Africa. For example, the Heart and Stroke Foundation of South Africa has developed a healthy recipe book entitled Cooking from the Heart. ${ }^{174}$ This book was developed by consulting with community members from various cultural backgrounds and requesting them to provide traditional South African recipes that are commonly prepared; food scientists were then consulted to provide appropriate ways to adapt the recipes to be healthier and at the same time ensure that the appearance and taste of the dish was maintained. Often, fruit and vegetable ingredients were 
added to recipes. ${ }^{174}$ The book also provides other useful practical advice such as shopping tips, suggestions for substitution of ingredients and how to interpret food labels. A limited number of copies of the book were printed when it was launched, and it is available free of charge online. This book was, however, probably inaccessible to the majority of the Mitchells Plain community, since there were only limited copies printed and not many people have internet access where such large documents can be downloaded. This book is therefore an existing tool that has not been adequately utilised and has limited accessibility.

\subsubsection{Community activities that could improve fruit and vegetable consumption}

Participants suggested sites where community promotion of fruit and vegetables could be done, including health facilities, schools and crèches. The SACRA recommendations also included that nutrition should be integrated into school curricula. ${ }^{123}$ It was acknowledged by participants in the current study that there were sometimes education materials available and accessible in Mitchells Plain, for example at health facilities, but that they were not always appropriate to this particular community. This suggests that the process followed in the development of such materials probably did not involve consultation with community members, or comprehensive consumer testing in order to determine whether or not the material was appropriate for its target audience. Furthermore, the development of generic materials for South Africa as a country may not be appropriate, since there are many diverse socio-demographic groups with varying cultural practices and beliefs. Future interventions may therefore need to be more community-specific. The results provided from this study could form the starting point for the development of community-specific materials and interventions for the Mitchells Plain community.

With regard to national education materials and tools, the Nutrition Directorate of the South African Department of Health has released updated national food-based dietary guidelines and developed more supporting material to be used in education on healthy eating, namely the food guide and General healthy eating guidelines for adults and children 5 years and older. This package was launched during Nutrition Week, 9-15 October 2012 $94,95,96$ but the scientific technical support papers for the guidelines were only published for general access in November $2013 .{ }^{97}$ The materials produced by the Department of Health provide practical guidance on meal planning using culturally appropriate food items. Due to the delay in the publishing of the technical support papers, not much promotion has been done on the revised guidelines, using these available materials. This again provides an example of appropriate tools being developed but not being available and accessible to the communities that need them. The publishing of the revised guidelines provides an opportune environment to revitalise efforts to appropriately communicate the guidelines (including "Eat plenty of vegetables and fruit every day") to the South African population. There 
should be more sharing of materials and experiences, and there is definitely a need for these documents to filter down to households in communities.

There were also suggestions by participants for fun events, activities and competitions to be used to promote fruit and vegetable consumption, using prizes as incentives and popular trends to encourage people to become involved. This suggests that community members would be interested in fruit and vegetable promotion campaigns if they were designed in an exciting, appealing and innovative manner. It should be considered that events of this nature can take time and financial resources to organise, but these suggestions could be incorporated into the organisation and planning of other community events.

\subsubsection{Environmental factors that could improve fruit and vegetable consumption}

The suggestions provided by participants to improve fruit and vegetable consumption were limited to actions at the household and community level. There was no discussion that took place on actions that are needed at the structural level to create an enabling environment that is supportive of adequate fruit and vegetable consumption. This is a gap, since these structural factors may be significant barriers to fruit and vegetable consumption in communities such as Mitchells Plain. Therefore, some recommendations that have been provided, nationally and internationally, and that could be relevant for a community such as Mitchells Plain will be discussed.

There has been international guidance to South Africa to improve education on healthy eating and vegetable consumption, as well as to consider environmental factors that influence food consumption, provided by the Special Rapporteur on the Right to Food, who visited South Africa in July $2011 .{ }^{114}$ One of the recommendations of his country mission report was: "Indeed, in a holistic perspective - focusing not only on informing consumers' choices but also on transforming the obesogenic environment - the Government could consider as part of the strategy educational campaigns to encourage continued reliance on traditional diets, combined with... "114 Efforts should therefore be combined between all stakeholders to use existing education and promotion materials to assist households with the practicalities surrounding regular consumption of fruit and vegetables. At the same time, the impact of the food environment on eating practices needs to be considered.

In terms of general international guidance, the World Cancer Research Fund and NCD Alliance joint brief on food, Nutrition, Diet and NCDs (released in 2103) has, as its first recommendation to national governments to "Develop and implement a comprehensive range of well-targeted policy actions to provide an environment conducive to nutritious, healthy diets". ${ }^{17}$ The brief also suggests 
the adoption of the NOURISHING framework (still in the process of being fully developed), which provides 10 recommended policy actions (the first letter of each action provides the acronym NOURISHING) for nutrition and NCDs, grouped according to the food environment (such as the setting of incentives and rules for retailers and traders to ensure a healthy retail environment and improve the quality of the food supply), the food system (harness the supply chain and actions across sectors to ensure coherence with health) and behaviour change communication (recommendations on nutrition education, awareness and skills building). ${ }^{17,175}$ These recommended policy actions incorporate much broader structural and environmental actions that could contribute to the facilitation of improved fruit and vegetable consumption.

\subsubsection{Evaluation of suggestions provided by participants}

The predominant suggestions provided by participants, to increase education and advocacy efforts at the individual and household level provides a starting point, but lacks the more comprehensive consideration of all of the components that influence food security, including availability, accessibility, adequacy, acceptability and agency. It needs to be acknowledged that inadequate fruit and vegetable consumption is not only caused by inappropriate food choices at an individual level. Fruit and vegetable consumption patterns are influenced by a much wider range of social, cultural, economic and systemic factors. Therefore, the increasing of education and advocacy on fruit and vegetable consumption to individuals and households will not be enough to facilitate improved consumption. A broader set of policy and programmatic responses are required in order to facilitate a change in behaviour.

\subsubsection{Suggested interventions to increase fruit and vegetable consumption}

Based on the responses from participants as well as recommendations from the literature, this section provides some suggestions on potential alternative interventions that could be piloted or investigated in order to determine whether or not these actions could result in improved fruit and vegetable consumption.

Health promotion and education needs to form part of a wider package of behaviour change interventions. This includes actions at an individual level (education, counselling and motivational interviewing), household level, community or social level (activities and fun events such as those suggested by participants in the Results section 3.5.1.4) and population or environmental level (policy and decision-making). Different strategies will be more effective in different situations or communities. The provision of education and key messages needs to be combined with a supportive environment, and adequate consideration needs to be given to removing social and environmental barriers to healthy behaviours (such as adequate fruit and vegetable 
consumption). ${ }^{176}$ Potential interventions that will be discussed are the building of educational activities around existing positive traditions and the use of social media and marketing to promote fruit and vegetable consumption. Another approach could be to advocate for stricter regulations such as a ban on the availability of foods and beverages that are classified as unhealthy at schools, as well as stricter regulations on the general marketing of food and beverages to children. Strict regulations often produce varying responses from a wide range of stakeholders, and also require comprehensive plans for monitoring and enforcement. The WHO provides recommendations and an implementation framework for the marketing of foods and non-alcoholic beverages to children which recommends the restriction of all marketing to children of foods with a high content of saturated fat, trans-fatty acids, free sugars or salt especially in settings where children gather, such as schools ${ }^{177,178}$ In 2013, the United States Department of Agriculture (USDA) implemented a law that described minimum standards for food that is allowed to be available for sale at schools. ${ }^{179}$ This law was first sent for comments and received a large volume of varied feedback from relevant stakeholders. ${ }^{180}$ The guidelines have, however, been legislated, with a one year period until implementation is required.

\subsubsection{Building of educational activities around existing positive traditions}

A potential intervention aimed at increasing fruit and vegetable consumption at times of traditional and cultural events, could be education on increasing the importance of salads at Christmas, New Year and when braais are the tradition on the menu, and to focus on salads that include more vegetables and fruit (such as carrot, beetroot and tossed salads) and to lessen the focus on starchbased (potato and noodle) salad. Positive traditions, such as the use of fruit as table decorations at certain events and the tradition of having vegetables on a Sunday should be encouraged and continued, but the importance of daily vegetable consumption should also be emphasised. Education and promotion could also include seasonal variation of dishes including fruit and vegetables that are consumed. During winter time, the focus could be the addition of various vegetables to stews and soups, whereas in summer, various fresh fruit based desserts could be promoted and a variety of salad options suggested. Some participants indicated that they were involved in growing their own vegetables, but this seemed to be an activity that was declining. Participants suggested that community vegetable gardens could be strengthened by the provision of incentives to volunteers and suggested that supermarket chains could be a source of potential funding. The funding of community projects is a challenge and alternative solutions are needed to guarantee the success of community projects such as communal vegetable gardens. 


\subsubsection{Experimenting with social media and social marketing strategies to promote fruit and vegetable consumption}

The use of conventional and non-conventional communication techniques should be considered when health promotion strategies are developed. This is also a recommendation of the SACRA study $^{123}$ and there is great potential for social marketing strategies to promote fruit and vegetable consumption but not enough has been done to explore the many options that are available. Talks and food preparation demonstrations could be provided in various community settings (such as health facilities, community halls, libraries, shopping centres or supermarkets). The predominant places where people purchase their fruit and vegetables (supermarkets and informal vendors) could be engaged to pilot such techniques (point-of-sale promotions for or in-store marketing of fruit and vegetables) as marketing strategies to increase their sale of fruit and vegetables. The use of social marketing and social networking should be further explored, considering that an increasing number of people use mobile phones and have access to internet. In South Africa, mobile phone usage has increased from $17 \%$ of adults in 2000 to $76 \%$ of adults in 2010 , with South Africa ranking fifth in the world for mobile data usage that includes downloading of information, internet and social media usage. ${ }^{181}$ The creation of a page on Facebook or Twitter, or the sending of bulk SMSs that promote fruit and vegetable consumption (for example by sending a daily recipe or tip) could have appeal to the younger generation, and pilot programmes could evaluate the impact of such actions on fruit and vegetable consumption.

Alternative communication strategies that could appeal to young children should be fostered, especially since the participants of this study often made reference to children when healthy eating and fruit and vegetable consumption was discussed. Potential interventions that could be tested include activities (such as competitions, demonstrations, the incorporation of healthy eating messages into songs and games) and these could be presented at the community centre, by the Sports and Recreation department, who already present after school and school holiday programmes or at shopping centres. At Primary or High School level, when lessons on culture or history are taught, recipes that use fruit and vegetable ingredients could be incorporated into the curriculum, or learners could be asked to do tasks or projects that include the use of these kinds of recipes.

Other strategies that could be considered to promote increased fruit and vegetable consumption include role modelling, whereby sport or other celebrities could be portrayed or represented as drinking water and eating an orange, instead of using sports drinks, after exercise sessions. Other settings where fruit and vegetable consumption could be promoted could be on TV and local soap operas, where characters could be visibly displayed as consuming fruit and vegetables. A challenge with this form of social media is that usually the companies promoting sports drinks and 
other less healthy products provide the funding for such shows. It may be difficult to source funding to promote fruit and vegetable consumption, and this was a challenge encountered by the 5-a-day For Better Health Trust that eventually resulted in this organisation's work coming to an end. Efforts should be made to identify funding sources for the promotion of healthy behaviours and the revival of campaigns such as the 5-a-day For Better Health Trust should be encouraged.

Social mobilisation is described by UNICEF as

... a process that engages and motivates a wide range of partners and allies at national and local levels to raise awareness of and demand for a particular development objective through face-to-face dialogue. Social mobilization seeks to facilitate change through a range of players engaged in interrelated and complementary efforts. ${ }^{182}$

Therefore, social mobilisation is an important strategy to assist with the behaviour change process as the community level. The National Department of Health has started to incorporate social mobilisation principles into some health (for example, HIV and TB) strategies. ${ }^{183,184}$ The latest national nutrition policy, the Roadmap for Nutrition in South Africa 2013 - 2017 identifies behaviour change interventions for nutrition as an integral component of a comprehensive package of key nutritional interventions. ${ }^{185}$ The Western Cape has periodically conducted community dialogues, and there has been a move to incorporate advocacy, social mobilisation and communication into strategies such as breastfeeding promotion. These beginning efforts to incorporate behaviour change strategies into policies need to be expanded upon.

Further international guidance is provided in the form of the UNSCN Statement on the nutrition security of urban populations, which recommends that "Vulnerable households require social protection, adult education including nutrition education and legal protection to realize and protect optimal nutrition." 53 South Africa has legislation that guarantees some degree of social protection in the form of the social grant system. Nutrition education has been discussed previously in this document. With regard to legal protection to realise and protect optimal nutrition, the right to adequate food is guaranteed in the Constitution of the Republic of South Africa and there are many policies and laws that protect and fulfil various aspects of the right to food, but it is acknowledged that there is much room for improvement. ${ }^{114}$ Suggestions for improvement include, amongst others, improved collection of food security data, the strengthening of existing food security policies including the incorporation of a rights-based approach, the review of agricultural and rural development policies, improved access to markets for small-scale farmers and the re-building of local food systems to strengthen the food supply chain between small-scale producers and urban consumers. ${ }^{114}$ South Africa has signed but not ratified the ICESCR and has received strong 
recommendations to formally ratify the ICESCR in order to ensure international legal accountability.

A key message of the 2013 Right to Food and Nutrition Watch is that

People's participation in the planning, development and implementation of alternatives to dominant policies in food, agriculture and nutrition is needed to challenge the current balance of power and effectively tackle hunger. It is of utmost importance to engage rights holders - people, communities and their organizations - in the design and implementation of policies that affect their daily lives. ${ }^{186}$

If government departments started to genuinely engage various stakeholders, including community members, during the development of food and nutrition policies, this could mark a significant shift towards the creation of effective interventions to combat malnutrition and food insecurity in South Africa.

There are many possible entry points into the community and interventions that could be implemented that could potentially contribute to improved fruit and vegetable consumption. A coordinated effort is needed to evaluate and adapt the various interventions that are available. Furthermore, when policies and strategies are developed, it is necessary for the various possible actions suggested to be tested in different settings in order to be able to recommend specific strategies that would be effective in different communities.

\subsection{LIMITATIONS OF THIS RESEARCH STUDY}

There were various limitations to this research study, including in the sampling strategy, methods, data analysis, and limitations that are common to qualitative research in general.

With regard to the sampling, due to time constraints, not all relevant categories of individuals were included (as reported on in section 2.5.3 Sample description). It was felt by the PI that additional categories of individuals could have been selected for the IDIs, but the number of participants needed to be limited due to the volume of data that would be gathered. It may have been beneficial to also have interviewed a medical doctor and a dietitian working in either a public or private setting, as well as a manager of a supermarket chain and a fast-food chain. Furthermore, it may have been beneficial to conduct more IDIs with community members in the younger (i.e. 18-30 year old) age group. Additional information may have been obtained if these additional individuals were interviewed and therefore the restriction on the number of participants could be regarded as a 
limitation of this study. An additional FGD was included to supplement information from one of the FGDs that was poorly attended due to logistical problems.

Due to time constraints, it was not possible to analyse the FGDs for themes to inform the IDIs, as initially proposed. It is thus possible that relevant themes may have been excluded from the IDIs. The principal investigator did, however, revise the discussion schedule to shift the focus of the interviews away from themes that were exhausted onto newer themes that were being raised by participants.

With regard to the methods used, it was initially proposed to use photo documentation to complement the IDIs. As described in the Methods chapter, this did not take place as planned, and therefore the data may not have been as rich or in-depth as it could have been, if photographs had also been used to complement the IDIs. Photographs of situations where fruit and vegetables were consumed, that would have been taken by participants preceding the interview, may have altered the content of some of the interviews and added to the themes of the discussions.

There are certain limitations to qualitative research in general. The results from the FGDs and IDIs cannot be generalised to the wider community because the sample was small and was not chosen to be representative of the population but was rather, strategically selected. With regard to FGDs, there are certain limitations in data collection. Participants may simply agree with other group members' opinions, due to power dynamics, and this could therefore bias the results (social desirability bias); it is felt that this did start to happen, especially in the male FGD, but the interviewer attempted to address the dominance of one participant by asking for others' opinions. In both FGDs and IDIs, the moderator may guide answers, and elicit answers that are desired by the researcher and therefore, the moderator could bias results (interviewer bias); the moderator in this research study made an attempt to be as objective as possible, in order to minimise bias but in reviewing the transcriptions, there may have been some instances where the moderator was leading in the line of questioning. In general, however, the moderator attempted to allow participants to discuss what they felt to be important and to not judge participant responses while still guiding the conversation to address the questions in the guide. FGDs could describe what is socially acceptable as opposed to what is actually happening and certain aspects of the data analysis stage of FGDs can be subjective. ${ }^{142}$ 


\section{SUMMARY CONCLUSIONS AND RECOMMENDATIONS}

\subsection{CONCLUSION}

Many different explanations were provided to explain the immediate, underlying and basic factors that influence fruit and vegetable consumption. Some factors have already been described in research and the literature elsewhere, whereas others were described in more depth in this research and have provided further understanding of some of the eating behaviours of this community. Although participants revealed basic knowledge on healthy eating and an awareness of inadequate fruit and vegetable consumption, there are factors such as social aspirations that can sometimes override decision-making on food choices, and the impact of the food environment that can influence food consumption patterns.

Certain barriers to fruit and vegetable consumption that were described are similar to those having been reported previously in the literature (such as the time and effort required to prepare vegetables in an appetising manner, as well as the fact that when people have limited money available they will choose items that are cheap and filling, and often this does not include vegetables or fruit). There were a number of key and unique insights revealed from this research that were reported to influence fruit and vegetable consumption and that have not been reported in depth from previous research. The findings from this research suggest a need for a shift in the societal attitudes and cultural norms of this community with regard to fruit and vegetables. Certain insights on fruit and vegetable access were learned by the researcher, such as the reasons provided for where participants purchase their fruit and vegetables, as well as the discussions surrounding home vegetable gardens. There has been a generational shift in eating patterns, and this was discussed by participants. Measures could be taken to attempt to preserve some of the healthy and desirable eating patterns that were described by the older generation and that seem to be disappearing. An important finding was that although fruit and vegetable consumption, as a component of healthy eating, is considered to be important by community members in Mitchells Plain, fruit and vegetables are not considered to be priority items when food is purchased and prepared.

Some information obtained from this research (such as the lists of dishes prepared using fruit and vegetable ingredients, as well as a summary of barriers to and facilitators of fruit and vegetable consumption in this community) could be useful for future interventions and behaviour change communication strategies. 
Eating is a behaviour influenced by many physical, psychological, social, economic and other factors. Behaviour change is therefore complex. It is evident that in a community such as Mitchells Plain, with high levels of crime, poverty, disease and other stress factors, health and nutrition are not daily priorities for individuals and households. This needs to be considered when strategies are developed to address malnutrition and food security. As described by these participants, solutions that have often been suggested, such as the promotion of urban agriculture to increase household food production, or more nutrition education, are not always the most appropriate, and some valid reasons have been provided to explain why. Food security cannot be addressed by one strategy alone, and all aspects of the food system need to be considered, as well as the human behaviours of individuals and factors that influence this behaviour. There is a need to work with communities to design and implement innovative and creative strategies that are responsive to their needs and that address the various factors that influence fruit and vegetable consumption patterns, including the creation of an environment that supports adequate fruit and vegetable consumption.

\subsection{RECOMMENDATIONS}

Communication between all stakeholders needs to be improved. Health and nutrition workers in the area and community members need to work together with civil society organisations and the private sector in order to understand the role that each can have in addressing the problems of undernutrition (including micronutrient malnutrition) and overnutrition in this community.

The information gathered in this study needs to be shared widely with all relevant stakeholders and used as a basis for further discussion, in order to improve the understanding of fruit and vegetable consumption in the Mitchells Plain community. This is important to enable all stakeholders to jointly decide on how fruit and vegetable consumption (and general eating practices) can be improved in this community. The results of this study should be shared with the following groups:

- The study participants, who include key informants in the Mitchells Plain community, and also others who did not take part in the study but that could be influential in the food system or in encouraging behaviour change in the community (e.g. managers of supermarkets in Mitchells Plain, informal vendors and health workers in public and private practice). This will be done by liaison with community leaders who were participants in the study, to determine the most appropriate method to share the results with the wider community. Results sharing will possibly take the form of information feedback sessions, where community members would have an opportunity to provide their opinion and interpretation of the results and would also be able to ask questions. This will take place during 2014.

- Industry, NGOs, faith-based organisations and government departments that operate in Mitchells Plain. Workshops could be held with all relevant stakeholders and further discussion 
could be facilitated on how to address the predominant barriers to fruit and vegetable consumption.

- Nutrition and health workers in the Mitchells Plain sub-district, in order to improve their understanding of eating behaviours in the community and consequently influence the manner in which nutrition education is provided. The results could be shared with nutrition staff working in other areas of the District and Province (that have communities with similar sociodemographics).

- Universities and training institutions that provide nutrition training as a component of courses to ensure that new graduates have an improved understanding of some of the factors that influence fruit and vegetable consumption and eating behaviours.

- Western Cape Government departments of (amongst others) Health, Education, Social Development and Agriculture to ensure that those responsible for the creation of policies and guidelines, as well as the monitoring of programmes, have improved understanding of some behaviours in communities.

- City of Cape Town Health and Urban Agriculture departments (for the same reason as described above).

\subsubsection{Recommendations for the Mitchells Plain community}

- There is a need for the food environment of Mitchells Plain to be transformed into one that is supportive of healthy eating and is enabling of adequate fruit and vegetable consumption. This will require engagement of relevant stakeholders, including store and food outlet owners, educators, community leaders and others in the government, private and NGO sector. Furthermore, policy change is required that would facilitate change in structural and environmental factors that obstruct adequate fruit and vegetable consumption, such as the availability and accessibility of fruit and vegetables and cultural norms with regard to the prioritisation of fruit and vegetable consumption in relation to the consumption of other foods.

- Efforts need to be made to improve education, awareness creation and advocacy on fruit and vegetable promotion. Creative and innovative strategies are required to revitalise interest in preparing healthy meals, with the use of traditional recipes that incorporate fruit and vegetables. A wide range of behaviour change communication strategies to influence behaviour should be considered. Some examples of such strategies are described in the Discussion, and include actions such as education and counselling, promotional community events and activities, and the original use of social media and social marketing. The community should be consulted at all stages of such interventions. The results from this study could be used as the basis for the development of educational activities that build on existing positive traditions. 


\subsubsection{Recommendations for provincial and national policy}

- It is recommended that South Africa sign the ICESCR, in order to improve the State's accountability with regard to the facilitation of the progressive realisation of the right to adequate food for all.

- Improved coordination between various government departments (such as Health, Education, Social Development and Agriculture) is essential to create an environment that supports healthy eating practices and the sufficient consumption of fruit and vegetables.

- When nutrition and food security policies are being developed at the local (sub-district and substructure) and provincial levels, results of research such as this study, as well as other local research that has been conducted should be considered and incorporated into the policy development process.

- Attempts should be made to revitalise organisations such as the 5-a-day for Better Health Trust and in doing so, adequate financial and human resources should be allocated and links between such organisations and government departments should be established.

- Key tables and some information from the Results and Discussion could be compiled into a manual that could be provided to new health and nutrition staff when they undergo orientation to the Mitchells Plain sub-district (especially to Community Service appointments or staff who have not worked in the Mitchells Plain area before). It could be determined whether this information could also be valuable to provide to new staff working in other areas of the Metropole (and even throughout South Africa) where similar eating behaviours are observed.

\subsubsection{Recommendations for future research}

- Similar in-depth and consultative research, combined with quantitative research that documents levels of fruit and vegetable consumption, should be conducted with other population groups in South Africa (e.g. in rural areas or with groups of different sociodemographics).

- Further research in this community should be interactive and action-orientated; research on behaviour change and the collection of quantitative information on fruit and vegetable consumption patterns of this specific community that includes a baseline assessment and measures change over time is recommended.

- Research should be conducted with community members to determine low-cost fruit and vegetable dishes that are palatable and desirable to the majority of the community.

- The suggestions made by community members that could increase fruit and vegetable consumption, described in Section 3.5 of the Results (such as improved education, fun 
activities and the provision of practical ideas and advice) should be consumer-tested in the community, to determine which interventions would have the most impact.

It is clear that alternative strategies are needed, but that interventions should be developed with more consideration of the community's needs and with more community and stakeholder engagement. There are benefits to using a human rights-based approach to develop strategies such as that being suggested from this research, to improve nutrition and food security. A human rights-based approach would ensure that all relevant stakeholders are engaged appropriately and that community participation is not neglected; this assists in ensuring that community members are actively involved in achieving their right to adequate food and nutrition. A human rights-based approach also recommends that vulnerable groups (in this case, children, those who rely on food provision, the sick and poor) are prioritised in the development of policies and strategies; that there is no discrimination in the implementation of programmes, and that resources are allocated appropriately. Furthermore, suggested interventions should be piloted or field-tested, adjusted as necessary, and continuously monitored and evaluated in order to ensure the progressive realisation of the right to adequate food and the achievement of food and nutrition security. 


\section{REFERENCES}

1. United Nations Standing Committee on Nutrition (UNSCN). Meeting of the minds: Nutrition impact of food systems. PowerPoint presentation on Food and Nutrition Security. Presented by: Dr M Wüstefeld. 25 - 28 March 2013. Available [Online] http://www.unscn.org/files/Annual_Sessions/UNSCN_Meetings_2013/Wustefeld_Final_MoM_F NS_concept.pdf (Accessed 24 November 2013.)

2. Food and Agricultural Organisation (FAO). Voluntary Guidelines to support the progressive realisation of the right to adequate food in the context of national food security. Adopted by the $127^{\text {th }}$ Session of the FAO Council. Rome: FAO. November 2004. Available [Online] http://www.fao.org/righttofood/publi_01_en.htm (Accessed 20 July 2011.)

3. Committee on Economic, Social and Cultural Rights (CESCR). General Comment 12: The right to adequate food. United Nations document E/C 12/1999/5. 1999. Available [Online] http://www2.ohchr.org/english/bodies/cescr/comments.htm (Accessed 20 July 2011.)

4. United Nations Development Group (UNDG). The human rights-based approach to development cooperation towards a common understanding among UN agencies. Statement of Common Understanding developed at the Interagency Workshop on a human rights-based approach in the context of UN reform. 3-5 May, 2003. Stamford: UNDG. 2003. Available [Online] http://www.undg.org/archive_docs/6959-

The_Human_Rights_Based_Approach_to_Development_Cooperation_Towards_a_Common_ Understanding_among_UN.pdf (Accessed 2 February 2014).

5. The World Bank Website. Data: Middle income countries. Available [Online] http://data.worldbank.org/income-level/MIC (Accessed 2 February 2014)

6. Gross, R., Schoeneberger, H., Pfeifer, H. \& Preuss, H.A. The four dimensions of food and nutrition security: Definitions and concepts. GTZ version. 2000. Available [Online] http://www.foodsec.org/DL/course/shortcourseFA/en/pdf/P-01_RG_Concept.pdf (Accessed 30 November 2013.)

7. Shisana, O., Labadarios, D., Rehle, T., Simbayi, L., Zuma, K., Dhansay, A., Reddy, P., Parker, W., Hoosain, E., Naidoo, P., Hongoro, C., Mchiza, Z., Steyn, N.P., Dwane, N., Makoae, M., Maluleke, T., Ramlagan, S., Zungu, N., Evans, M.G., Jacobs, L., Faber, M., \& the SANHANES1 Team. South African National Health and Nutrition Examination Survey (SANHANES-1). Cape Town: Human Sciences Research Council Press. 2013.

8. Love, P. \& Sayed, N. Eat plenty of vegetables and fruits every day. South African Journal of Clinical Nutrition. 2001; 14(3): S24-32.

9. Food and Agricultural Organisation / World Health Organisation (FAO/WHO). Workshop on Fruit and Vegetables for Health: Report of a joint FAO/WHO workshop, 1-3 September, 2004. 
Kobe, Japan. Available [Online]

http://www.who.int/dietphysicalactivity/publications/fruit_vegetables_report.pdf (Accessed 15 January 2012.)

10. Steffen, L. Five or more servings of fruit and vegetables each day for better health. Chapter 21 in Watson, R.R., ed. Complementary and Alternative Therapies and the Aging Population. United States of America: Elsevier Inc. 2009. Pg 417-431.

11. Hyson, D.A. Fruit, vegetables and health: A scientific overview. Produce for Better Health Foundation. 2011. Available [Online] http://www.pbhfoundation.org/pdfs/about/res/pbh_res/PBH_Health_Benefit_Review.pdf (Accessed 21 March 2013.)

12. Dias, J.S. Nutritional quality and health benefits of vegetables: A review. Food and Nutrition Sciences. 2012; 3: 1354-1374.

13. Naude, C. Would an increase in vegetable and fruit intake help to reduce the burden of nutrition-related disease in South Africa? An umbrella review of the evidence. South African Journal of Clinical Nutrition. 2013; 26(3):104-114.

14. Beaglehole, R., Bonita, R., Horton, R., Adams, C., Alleyne, G., Asaria, P., Baugh, V., Bekedam, H., Billo, N., Casswell, S., Cecchini, M., Colagiuri, R., Colagiuri, S., Collins, T., Ebrahim, S., Engelgau, M., Galea, G., Gaziano, T., Geneau, R., Haines, A., Hospedales, J., Jha, P., Keeling, A., Leeder, S., Lincoln, P., McKee, M., Mackay, J., Magnusson, R., Moodie, R., Mwatsama, M., Nishtar, S., Norrving, B., Patterson, D., Piot, P., Ralston, J., Rani, M., Reddy, K.S., Sassi, F., Sheron, N., Stuckler, D., Suh, I., Torode, J., Varghese, C. \& Watt, J. for The Lancet NCD Action Group and the NCD Alliance. Priority actions for the noncommunicable disease crisis. Lancet. 2011; 377(9775): 1438-47.

15. World Health Organisation (WHO). Infant and young child feeding. Fact Sheet No. 342. Updated September 2013. Available [Online] http://www.who.int/mediacentre/factsheets/fs342/en/ (Accessed 23 November 2013.)

16. United Nations Children's Fund (UNICEF). Improving child nutrition: The achievable imperative for global progress. New York: UNICEF. 2013. Available [Online] http://www.unicef.org/media/files/nutrition_report_2013.pdf (Accessed 23 November 2013.)

17. World Cancer Research Fund (WCRF) International \& NCD Alliance. Joint brief on food, nutrition, diet and non-communicable diseases. 2013. Available [Online] http://www.wcrf.org/PDFs/PPA_NCD_Alliance_Nutrition.pdf (Accessed 14 November 2013.)

18. World Health Organisation (WHO). Global strategy on diet, physical activity and health. Geneva: World Health Organisation. 2004. Available [Online] http://www.who.int/dietphysicalactivity/strategy/eb11344/strategy_english_web.pdf (Accessed 20 July 2011.) 
19. Department of Health. South African Food-based Dietary Guidelines. Pretoria: Department of Health, Nutrition Directorate. 2004.

20. 5-a-day for Better Health Trust website. Available [Online] http://www.5aday.co.za/ (Accessed 20 July 2011.)

21. Labadarios, D., Swart, R., Maunder, E.M.W., Kruger, H.S., Gericke, G.J., Kuzwayo, P.M.N., Ntsle, P.R., Steyn, N.P., Schloss, I., Dhansay, M.A., Jooste, P.L., Dannhauser, A., Nel, J.H., Molefe, D. \& Kotze, T.JvW. Executive summary: National Food Consumption Survey Fortification Baseline (NFCS-FB-1) South Africa, 2005. South African Journal of Clinical Nutrition. 2008; 21(3)(Suppl. 2): 245-300.

22. Love, P. \& Sayed, N. Eat plenty of vegetables and fruits every day. South African Journal of Clinical Nutrition. 2001; 14(3): S24-32.

23. Love, P., Maunder, E., Green, M., Ross, F., Smale-Lovely, J. \& Charlton, K. South African Food-Based Dietary Guidelines: Testing of the preliminary guidelines among women in Kwazulu-Natal and the Western Cape. South African Journal of Clinical Nutrition. 2001; 14(1): 9-19.

24. Kearney, J.M. \& McElhane, S. Perceived barriers in trying to eat healthier. British Journal of Nutrition. 1999; 81 (Suppl. 2): S133-S137.

25. Carter, O.B., Pollard, C.M., Atkins, J.F., Marie Milliner, J. \& Pratt, I.S. 'We're not told why we're just told': qualitative reflections about the Western Australia Go for $2 \& 5 \AA$ fruit and vegetable campaign. Public Health Nutrition. 2011; 14(6): 982-8.

26. Caldwell, E.N., Miller Kobayashi, M., Du Bow, W.M. \& Wytinck, S.M. Perceived access to fruit and vegetables associated with increased consumption. Public Health Nutrition. 2009; 12 : 1743-1750.

27. Chopra, M. \& Poane, T. Prevention of diabetes throughout an obesogenic world. Diabetes Voice. 2003; 48: 24-26.

28. Groenewald, P., Bradshaw, D., Daniels, J., Matzopoulos, R., Bourne, D., Blease, D., Zinyakatira, N. \& Naledi, T. Causes of death and premature morality in Cape Town, 2001 2006. Cape Town: South African Medical Research Council. 2008.

29. Provincial Government of the Western Cape: Department of Health. HIV and Syphilis prevalence in the Western Cape: Results of the 2010 HIV and Syphilis antenatal provincial and Sub-district surveys. 2010.

30. Willett, W.C., Koplan, J.P., Nugent, R., Dusenbury, C., Puska, P., \& Gasiano, T.A. Prevention of chronic disease by means of diet and lifestyle changes. In: Jamison, D.T., Breman, J.G. \& Measham, A.R., eds. Disease Control Priorities in Developing Countries. $2^{\text {nd }}$ Edition. Washington, DC: The World Bank. 2006: 833-850. Available [Online] http://www.dcp2.org/pubs/DCP/44 (Accessed 15 January 2012.) 
31. Crowe, F.L., Roddam, A.W., Key, T.J., Appleby, P.N., Overvad, K., Jakobsen, M.U., Tjønneland, A., Hansen, L., Boeing, H., Weikert, C., Linseisen, J., Kaaks, R., Trichopoulou, A., Misirli, G., Lagiou, P., Sacerdote, C., Pala, V., Palli, D., Tumino, R., Panico, Bueno-deMesquita, H. B., Boer, J., van Gils, C.H., Beulens, J.W.J., Barricarte, A, Rodrı'guez, L., Larran, Sa'nchez, M., Tormo, M., Buckland, G., Lund, E., Hedblad, B., Melander, O., Jansson, J., Wennberg, P., Wareham, N.J., Slimani, N., Romieu, I., Jenab, M., Danesh, J., Gallo, V., Norat, T., \& Riboli, E. European Prospective Investigation into Cancer and Nutrition (EPIC)-Heart Study Collaborators. Fruit and vegetable intake and mortality from ischaemic heart disease: results from the European Prospective Investigation into Cancer and Nutrition (EPIC)-Heart study. European Heart Journal. 2011; 10:1235-43.

32. Lock, K., Pomerleau, J., Causer, L., McKee, M. Low fruit and vegetable consumption. In: Ezzati, M., Lopez, A.D., Rodgers, A., Murray, C.J.L., eds. Comparative quantification of health risks: Global and regional burden of disease Attributable to Selected Major Risk Factors. Geneva: World Health Organization. 2004: 597-728.

33. World Health Organisation (WHO). Global health risks: Mortality and burden of disease attributable to selected major risks. 2009. Available [Online] http://www.who.int/healthinfo/global_burden_disease/GlobalHealthRisks_report_full.pdf (Accessed 24 March 2013.)

34. Dragsted, L. O., Krath, B., Ravn-Haren, G., Vogel, U.B., Vinggaard, A.M., Jensen, P.B., Loft, S., Rasmussen, S.E., Sandstrom, B.M. \& Pedersen, A. Biological effects of fruit and vegetables. Symposium on Phytochemicals: The Summer Meeting of the Nutrition Society, hosted by the Institute of Food Research. University of East Anglia, Norwich. 28 June-1 July 2005. Proceedings of the Nutrition Society. 2006; 65: 61-67.

35. Clarke, J.D., Riedl, K., Bella, D., Schwartz, S.J., Stevens, J.F., \& Ho, E. Comparison of Isothiocyanate metabolite levels and Histone Deacetylase activity in human subjects consuming broccoli sprouts or broccoli supplement. Journal of Agricultural and Food Chemistry. 2011; 59: 10955-10963.

36. Academy of Science of South Africa (ASSAf). HIV, AIDS, TB and Nutrition: Scientific inquiry into the nutritional influences on human immunity with special reference to HIV infection and active TB in South Africa. 2007. Available [Online] http://www.assaf.co.za/wpcontent/uploads/reports/evidence_based/3060\%20ASSAf\%20HIV\%20TB\%20and\%20Nutrition. pdf (Accessed 12 October 2013.)

37. Food and Agricultural Organisation (FAO). Rome Declaration on World Food Security and World Food Summit Plan of Action. 13 - 17 November. Rome: FAO. 1996. http://www.fao.org/docrep/003/w3613e/w3613e00.htm (Accessed 25 November 2013) 
38. Food and Agricultural Organisation (FAO). Declaration of the World Summit on Food Security. 16 - 18 November. Rome: FAO. 2009. Available [Online] ftp://ftp.fao.org/docrep/fao/Meeting/018/k6050e.pdf (Accessed 25 November 2013)

39. Food and Agricultural Organisation (FAO). The State of Food Insecurity in the World: When people must live with hunger and fear starvation. Rome: FAO. 1999. Available [Online] ftp://ftp.fao.org/docrep/fao/007/x3114e/x3114e00.pdf (Accessed 25 November 2013.)

40. Food and Agricultural Organisation, World Food Programme and International Fund for Agricultural Development (FAO, IFAD and WFP). The State of Food Insecurity in the World 2013. The multiple dimensions of food security. Rome: FAO. 2013. Available [Online] http://www.fao.org/docrep/018/i3434e/i3434e.pdf (Accessed 14 November 2013.)

41. Crush, J. \& Frayne, B. The invisible crisis: Urban food security in Southern Africa. Urban Food Security Series No. 1. Kingston and Cape Town: Queen's University and African Food Security Urban Network (AFSUN). 2010.

42. Rocha, C. \& Lessa, I. Urban governance for food security: The alternative food system in Belo Horizonte, Brazil. International Planning Studies. 2009; 14(4): 389-400.

43. Ryerson University. Centre for Studies in Food Security website. Food security defined. Available [Online] http://www.ryerson.ca/foodsecurity/ (Accessed 29 November 2013.)

44. United Nations Standing Committee on Nutrition (UN SCN). $6^{\text {th }}$ Report on the World Nutrition Situation: Progress in Nutrition (Regional Trends, Maternal Nutrition, Nutrition Security). 2010. Available [Online] http://www.unscn.org/files/Publications/RWNS6/report/SCN_report.pdf (Accessed 24 March 2013.)

45. Labadarios, D., Steyn, N.P., Maunder, E., Maclntyre, U., Gericke, G., Swart, R., Huskisson, J., Dannhauser, A., Vorster, H.H., Nesamvuni, A.E. \& Nel, J.H. The National Food Consumption Survey (NFCS): South Africa, 1999. Public Health Nutrition. 2005; 8(5): 533-543.

46. International Food Policy Research Institute (IFPRI), Concern Worldwide \& Welthungerhilfe and Green Scenery. Global Hunger Index. The challenge of hunger: Ensuring sustainable food security under land, water and energy stresses. Bonn/Washington DC/Dublin. 2012. Available [Online] http://www.ifpri.org/sites/default/files/publications/ghi12.pdf (Accessed 17 October 2013.)

47. Du Toit, D.C. Food security. Directorate Economics Services and Production Economics Unit. Department of Agriculture, Fisheries \& Forestry. 2011. Available [Online] http://www.nda.agric.za/docs/GenReports/FoodSecurity.pdf (Accessed 17 October 2013.)

48. Battersby, J. The state of urban food insecurity in Cape Town. Urban Food Security Series No. 11. Kingston and Cape Town: Queen's University and AFSUN. 2011.

49. United Nations Population Division (UNPD). World Urbanisation Prospects: The 2011 Revision, Highlights. New York: Department of Economic and Social Affairs, Population Division. 2012. 
Available [Online] http://esa.un.org/unpd/wup/pdf/WUP2011_Highlights.pdf (Accessed 17 June 2012.)

50. United Nations Economic and Social Affairs (UNESA). Population Division of the Department of Economic and Social Affairs of the United Nations Secretariat. World Urbanization Prospects: The 2007 Revision. Available [Online] http://esa.un.org (Accessed 17 June 2012.)

51. Crush, J. \& Frayne, B. Pathways to insecurity: Urban food supply and access in Southern African cities. Urban Food Security Series No. 3. Kingston and Cape Town: Queen's University and AFSUN. 2010.

52. Crush, J., Hovorka, A. \& Tevera, D. Urban food production and household food security in Southern African cities. Urban Food Security Series No. 4. Queen's University and AFSUN: Kingston and Cape Town. 2010.

53. United Nations Standing Committee on Nutrition (UNSCN). Statement on nutrition security of urban populations. 2012. Available [Online] http://www.unscn.org/files/Statements/August_31_UNSCN_World_Urban_Forum_6-_Statement_final_3108_finalfinal.pdf (Accessed 3 March 2013.)

54. Food and Agricultural Organisation (FAO). Urban agriculture for sustainable poverty alleviation and food security. 2008. Available [Online] http://www.fao.org/fileadmin/templates/FCIT/PDF/UPA_-WBpaper-Final_October_2008.pdf (Accessed 20 October 2013.)

55. Schuftan, C. \& Holla, R. Two contemporary challenges: Corporate control over food and nutrition and the absence of a focus on the social determinants of nutrition. In Brot für die Welt (Bread for the World), Food First Information and Action Network (FIAN) International \& Interchurch Cooperative for Development (ICCO) Cooperation. Right to Food \& Nutrition Watch 2012: Who decides about global food and nutrition? Strategies to regain control. Available [Online] http://www.rtfn-watch.org/fileadmin/media/rtfnwatch.org/ENGLISH/pdf/Watch_2012/R_t_F_a_N_Watch_2012_eng_web_rz.pdf (Accessed 4 October 2012)

56. Hammond, R. A. \& Dubé, L. A systems science perspective and trans-disciplinary models for food and nutrition security. Proceedings of the National Academy of Sciences of the United States of America. 2012; 109 (3): 12356-12363. Available [Online] http://www.pnas.org/content/109/31/12356.full (Accessed 20 October 2013.)

57. Food and Agricultural Organisation, World Food Programme \& International Fund for Agricultural Development (FAO, WFP \& IFAD). The State of Food Insecurity in the World 2012: Economic growth is necessary but not sufficient to accelerate reduction of hunger and malnutrition. Rome: FAO. 2012. Available [Online] http://www.fao.org/docrep/016/i3027e/i3027e.pdf (Accessed 24 March 2013.) 
58. Drimie, S. \& McLachlan, M. Food security in South Africa - First steps toward a transdisciplinary approach. Food Security. 2013; 5: 217-226.

59. Stellenbosch University Food Security Initiative (FSI) website. Available [Online] http://blogs.sun.ac.za/fsi/ (Accessed 14 November 2013.)

60. Southern Africa Food Lab (SAFL) website. Available [Online] http://www.southernafricafoodlab.org/ (Accessed 14 November 2013.)

61. Popkin, B.M., Adair, L.S. \& Ng, S.W. Global nutrition transition and the pandemic of obesity in developing countries. Nutrition Reviews. 2011; 70(1): 3-21.

62. Basiotis, P.P. \& Lino, M. Food insufficiency and prevalence of overweight among adult women. Nutrition Insights. 2002; 26: 1-2.

63. Barker, D. J. P. Maternal nutrition, fetal nutrition, and disease in later life. Nutrition. 1997; 13 (9): 807-813.

64. Norris, S., Osmond, C., Gigante, D., Kuzawa, C.W., Ramakrishnan, L., Lee, N.R., Ramirezzea, M., Richter, L.M., Stein, A.D., Tandon, N., Fall, C.H.D. \& The Cohorts Group. Size at birth, weight gain in infancy and childhood, and adult diabetes risk in five low and middle income country birth cohorts. Diabetes Care. 2011; 35 (1): 72-79.

65. Uauy, R., Kain, J. \& Corvalan, C. How can the Developmental Origin of Health and Disease [DOHaD] yypothesis contribute to improving health in developing countries? American Journal of Clinical Nutrition. 2011; 94 (6) (Supplement): 1759

66. Victora, C.G., de Onis, M., Hallal, P.C., Blössner, M. \& Shrimpton, R. Worldwide timing of growth faltering: revisiting implications for interventions. Pediatrics. 2010; 125(3): e473-80.

67. Black, R.E., Victora, C.G., Walker, S.P., Bhutta, Z.A., Christian, P., de Onis, M., Ezzati, M., Grantham-McGregor, S., Katz, J., Martorell, R., Uauy, R. \& the Maternal and Child Nutrition Study Group. Maternal and child undernutrition and overweight in low-income and middleincome countries. Lancet. 2013; 382: 427-51.

68. Reynolds, R.M., Allan, K.M., Raja, E.A., Bhattacharya, S., McNeill, G., Hannaford, P.C., Sarwar, N., Lee, A.J., Bhattacharya, S., \& Norman, J.E. Maternal obesity during pregnancy and premature mortality from cardiovascular event in adult offspring: follow-up of 1323275 person years. British Medical Journal. 2013; 347.

69. Ludwig, D.S. \& Currie, J. The association between pregnancy weight gain and birthweight: a within-family comparison. Lancet. 2010; 376: 984-90.

70. Lozano, R., Naghavi, M., Foreman, K., Lim, S., Shibuya, K., Aboyans, V. et al. Global and regional mortality from 235 causes of death for 20 age groups in 1990 and 2010: a systematic analysis for the Global Burden of Disease Study 2010. The Lancet. 2012; 380: 2095-128.

71. World Health Organisation (WHO). Global strategy for the prevention and control of noncommunicable diseases. Fifty third World Health Assembly. Agenda Item 12.11. A53/14. 2000. 
Available [Online] http://www.who.int/nmh/publications/wha_resolution53_14/en/ (Accessed 12 October 2013.)

72. The World Bank Website. Data: Middle income countries. Available [Online] http://data.worldbank.org/income-level/MIC (Accessed 2 February 2014)

73. Department of Health (DOH). South African Declaration on the prevention and control of noncommunicable diseases. South African Summit on the Prevention and Control of Noncommunicable Diseases. Gauteng: Department of Health. 12-13 September 2011. Available [Online]

http://www.health.uct.ac.za/usr/health/research/groupings/cdia/downloads/SA_NCD_Declaratio n.pdf (Accessed 21 February 2012.)

74. Mayosi, B.M., Lawn, J.E., van Niekerk, A., Bradshaw, D. Abdool Karim, S.S. \& Coovadia, H.M. for The Lancet South Africa team. Health in South Africa: changes and challenges since 2009. Lancet. 2012; 380: 2029-43.

75. Department of Health. South Africa National HIV and Syphilis Prevalence Survey. Pretoria: Department of Health. 2008.

76. World Health Organization (WHO). Global Tuberculosis Control 2009 - Epidemiology, Strategy, Financing. Geneva: World Health Organization. 2009. Available [Online] http://www.who.int/tb/publications/global_report/2009/update/tbu_9.pdf (Accessed 5 February 2012.)

77. Schneider, M., Norman, R., Steyn, N., Bradshaw, D. \& the South African Comparative Risk Assessment Collaborating Group. Estimating the burden of disease attributable to low fruit and vegetable intake in South Africa in 2000. South African Medical Journal. 2007; 97(8): 717-723.

78. World Health Organisation (WHO). Every Woman, Every Child: Strengthening Equity and Dignity through Health: the second report of the independent Expert Review Group (iERG) on information and accountability for women's and children's health. Geneva: World Health Organisation. 2013. Available [Online] http://apps.who.int/iris/bitstream/10665/85757/1/9789241505949_eng.pdf (Accessed 23 November 2013.)

79. Bradshaw, D., Norman, R., Lewin, S., Joubert, J., Schneider, M., Nannan, N., Groenewald, P., Laubscher, R., Matzopolous, R., Nojilana, B., Pieterse, D., Steyn, K., Vos, T. \& the South African Comparative Risk Assessment Collaborating Group. Strengthening public health in South Africa: Building a stronger evidence base for improving the health of the nation. South African Medical Journal. 2007; 97(8): 643-649.

80. Muthayya, S., Rah, J.H., Sugimoto, J.D., Roos, F.F., Kraemer, K., \& Black, R.E. The Global Hidden Hunger Indices and Maps: An advocacy tool for action. PLoS ONE. 2013; 8(6): e67860. doi:10.1371/journal.pone.0067860 Available [Online] 
http://www.plosone.org/article/info:doi\%2F10.1371\%2Fjournal.pone.0067860 (Accessed 12 October 2013.)

81. United Nations Children's Fund, World Health Organization \& The World Bank. UNICEF-WHOWorld Bank Joint Child Malnutrition Estimates. New York: UNICEF; Geneva: WHO; Washington, DC: The World Bank. 2012. Available [Online] http://www.who.int/nutgrowthdb/jme_unicef_who_wb.pdf (Accessed 12 October 2013.)

82. Black, R.E., Victora, C.G., Walker, S.P., Bhutta, Z.A., Christian, P., de Onis, M., Ezzati, M., Grantham-McGregor, S., Katz, J., Martorell, R., Uauy, R. \& the Maternal and Child Nutrition Study Group. Maternal and child undernutrition and overweight in low-income and middleincome countries. Lancet. 2013; 382: 427-51.

83. World Health Organisation (WHO). Fact Sheet 311: Obesity and overweight. Updated March 2013. Available [Online] http://www.who.int/mediacentre/factsheets/fs311/en/ (Accessed 14 November 2013.)

84. Dalal, S., Beunza, J.J., Volmink, J., Adebamowo, C., Bajunirwe, F., Njelekela, M., Mozaffarian, D., Fawzi, W., Willett, W., Adami, H. \& Holmes, M.D. Non-communicable diseases in subSaharan Africa: What we know now. International Journal of Epidemiology. 2011; 40: 885-901.

85. Ruel, M.T., Alderman, H. \& The Maternal and Child Nutrition Study Group. Nutrition-sensitive interventions and programmes: how can they help to accelerate progress in improving maternal and child nutrition? Lancet. 2013; 382: 536-51.

86. Herforth, A., Jones, A. \& Pinstrup-Andersen, P. Health, Nutrition, and Population Discussion Paper. Prioritizing nutrition in agriculture and rural development: Guiding Principles for operational investments. Washington DC: World Bank. 2012. Available [Online] http://dyson.cornell.edu/faculty_sites/pinstrup/pdfs/HerforthJonesPPA.pdf (Accessed 5 November 2013.)

87. Bhutta, Z.A., Das, J.K., Rizvi, A., Gaffey, M.F., Walker, N., Horton, S., Webb, P., Lartey, A., Black, R.E. \& The Lancet Nutrition Interventions Review Group, and the Maternal and Child Nutrition Study Group. Evidence-based interventions for improvement of maternal and child nutrition: What can be done and at what cost? Lancet. 2013; 382: 452-77.

88. World Health Organisation (WHO). Fruit and Vegetable Promotion Initiative: Report of the meeting. Geneva; 25-27 August 2003. Available [Online] http://www.who.int/dietphysicalactivity/publications/f\&v_promotion_initiative_report.pdf (Accessed 22 October 2011.)

89. Government Gazette. Regulations relating to the labelling and advertising of foodstuffs. R. 146 of the Foodstuffs, Cosmetics and Disinfectants Act, 1972 (Act 54 of 1972). 1 March 2010. Government Printer. 
90. South African Government News Agency website. Rise in alcohol, cigarette prices. 27 February 2013. Available [Online] http://sanews.gcis.gov.za/south-africa/rise-alcohol-cigaretteprices (Accessed 2 February 2014).

91. Advertising Standards Authority of South Africa (ASASA). Advertising code. Appendix J: Food and beverage code. Available [Online] http://www.asasa.org.za/Default.aspx?mnu_id=114 (Accessed 2 February 2014)

92. Vorster, H.H., Love, P. \& Browne, C. Development of Food-based Dietary Guidelines for South Africa - The process. South African Journal of Clinical Nutrition. 2001; 14(3): S3-S6.

93. Food and Agricultural Organisation / World Health Organisation (FAO/WHO) Consultation. Preparation and use of food-based dietary guidelines. Nutrition Programme WHO/NUT 96.6. Geneva: World Health Organisation. 1996: 1-9. Available [Online] http://www.fao.org/docrep/x0243e/x0243e00.htm (Accessed 16 October 2013.)

94. Department of Health. Information for consumers: The South African Guidelines for healthy eating and food guide. Pretoria: National Department of Health. 2012.

95. Department of Health. Press Release: Suggested guidance on the use of the Department of Health Guidelines for healthy eating and the food guide. Pretoria: Department of Health, Nutrition Directorate. October 2012. Available [Online] http://www.nutritionweek.co.za/NNW2012/50pressrelease.html (Accessed 14 November 2013.)

96. National Nutrition Week 2012 website. Available [Online] http://nutritionweek.co.za/NNW2012/ (Accessed 14 November 2013.)

97. Vorster, H.H., Badham, J. \& Venter, C.S. An introduction to the revised food-based dietary guidelines for South Africa. South African Journal of Clinical Nutrition. 2013; 26(3)(Suppl): S5S12.

98. Schönfeldt, H.C., Hall, N. \& Bester, M. Relevance of food-based dietary guidelines to food and nutrition security: A South African perspective. British Nutrition Foundation Nutrition Bulletin. 2013; 38: 226-235.

99. Personal communication. Jane Badham. Past CEO for the 5-a-day for Better Health Trust. October 2013.

100. Department of Agriculture, Forestry and Fisheries (DAFF). Draft National Integrated Food Security Strategy for South Africa. Pretoria. 2002.

101. Richards, R. \& Taylor, S. Changing land use on the periphery: Case study of urban agriculture and food gardening in Orange Farm. 2012. Report Series produced by the South African Research Chair in Development Planning and Modelling, School of Architecture and Planning, University of the Witwatersrand. Available [Online] http://wiredspace.wits.ac.za/handle/10539/12376 (Accessed 3 February 2014).

102. Personal communication. Meeting between officials from the National Department of Agriculture, Forestry and Fisheries (including Steve Mohlabi, Director: Subsistence Farming) 
and the Master's in Nutrition, Human Rights and Governance (NOMA track) 2011 Student Group. Pretoria. 14 July 2011.

103. Department of Agriculture, Forestry and Fisheries (DAFF). Strategic Plan for the DAFF: 2012/2013 - 2016/2017. Pretoria. 2012. Available [Online] http://www.nda.agric.za/docs/stratplan2012/201213-201617.pdf (Accessed 17 October 2013.)

104. City of Cape Town. Urban Agricultural Policy. Cape Town. 2007. Available [Online] http://www.capetown.gov.za/en/ehd/Documents/EHD__Urban_Agricultural_Policy_2007_8102007113120_.pdf (Accessed 2 October 2011.)

105. Ekurhuleni Metropolitan Municipality (EMM). Agricultural development policy, strategy and process. Prepared by EPA Agricultural and Resource Management (Pty) Limited. June 2002. Available [Online] http://www.ekurhuleni.gov.za/92-pol-012/file (Accessed 3 February 2014).

106. State of the Nation Address of the President of South Africa, Kgalema Motlanthe, to the Joint Sitting of Parliament. Cape Town. 6 February 2009. Available [Online] http://www.info.gov.za/speeches/2009/09020611061001.htm (Accessed 3 October 2011.) 107. Provincial Government of the Western Cape (PGWC). The Cape Town Declaration on Wellness. Signed at the Provincial Wellness Summit. Cape Town. 8 November 2011. Available [Online] http://www.westerncape.gov.za/eng/pubs/news/2011/dec/235471 (Accessed 21 February 2012.)

108. Democratic Alliance (DA). Freedom from Hunger: The Food Crisis in South Africa and the DA's Plan to fix it. 2012. Available [Online] https://docs.google.com/file/d/OB_-slGu8FTxYktFcjRsWUY4ZIU/edit?pli=1 (Accessed 16 May 2012.)

109. Constitution of the Republic of South Africa. Act 108 of 1996 of the Republic of South Africa. Pretoria: Government Printer. 1996. Available [Online] http://www.gov.za/documents/constitution/1996/a108-96.pdf (Accessed 19 October 2013.)

110. Committee on Economic, Social and Cultural Rights (CESCR). International Covenant on Economic, Social and Cultural Rights (ICESCR). United Nations. 1966. Available [Online] http://www.ohchr.org/EN/Professionallnterest/Pages/CESCR.aspx (Accessed 1 December 2013)

111. United Nations Treaty Collection (UNTC) Website. Chapter IV: Human Rights. No.3 International Covenant on Economic, Social and Cultural Rights. Status as at 19-10-2013. Available [Online] http://treaties.un.org/Pages/ViewDetails.aspx?src=TREATY\&mtdsg_no=IV3\&chapter=4\&lang=en (Accessed 19 October 2013.)

112. Government Communication and Information System (GCIS). Statement on Cabinet meeting of 10 October 2012. Republic of South Africa. Pretoria. 2012. Available [Online] http://www.gcis.gov.za/content/newsroom/media-releases/cabstatements/11/ct2012 (Accessed 19 October 2013.) 
113. International Covenant on Economic, Social and Cultural Rights (ICESCR) Ratification Campaign Driver Group (comprising of Black Sash, Community Law Centre of University of the Western Cape, Global Call to Action Against Poverty South Africa, National Welfare Forum, People's Health Movement South African, Socio-Economic Rights Institute of SA and Studies in Poverty and Inequality Institute). South Africa to Ratify International Socio-economic Rights Covenant: Press Release. 12 October 2012. Available [Online] http://www.ngopulse.org/pressrelease/south-africa-ratify-international-socio-economic-rights-covenant (Accessed 19 October 2013.)

114. United Nations General Assembly. Human Rights Council. 19 ${ }^{\text {th }}$ Session. January 2012. Report of the Special Rapporteur on the right to food, Olivier De Schutter: Mission to South Africa. A/HRC/19/59/Add.3 Available [Online] http://www.srfood.org/images/stories/pdf/officialreports/20120306_southafrica_en.pdf (Accessed 19 October 2013.)

115. Hall, J.N., Moore, S., Harper, S.B. \& Lynch, J.W. Global variability in fruit and vegetable consumption. American Journal of Preventative Medicine. 2009; 35(5): 402-409.

116. Nel, J.H. \& Steyn, N.P. Report on South Africa food consumption studies undertaken amongst different population groups (1983-2000): Average intakes of foods most commonly consumed. Pretoria: National Department of Health, Directorate Food Control. 2002. Available [Online] http://www.doh.gov.za/docs/reports/2002/food/ (Accessed 14 January 2012.)

117. Steyn, N.P., Nel, J.H. \& Casey, A. Secondary data analyses of dietary surveys undertaken in South Africa to determine usual food consumption of the population. Public Health Nutrition. 2003; 6: 631-644.

118. Igumbor, E.U., Sanders, D., Puoane, T.R., Tsolekile, L., Schwarz, C., Purdy, C., Swart, R., Durao, S. \& Hawkes, C. "Big Food," the consumer food environment, health, and the policy response in South Africa. PLoS Medicine. 2012; 9(7): e1001253. doi:10.1371/journal.pmed.1001253. 2012.

119. Kamphuis, C.B.M., Giskes, K., de Bruijn, G., Wendel-Vos3, W., Brug, J. \& van Lenthe, F.J. Environmental determinants of fruit and vegetable consumption among adults: a systematic review. British Journal of Nutrition. 2006; 96: 620-635.

120. Emmett, P., de Lauzon-Guillain, B., Jones, L., Oliveira, A., Moschonis, G., Betoko, A., Lopes, C., Moreira, P., Manios, Y., \& Charles, M.A. Critical periods for eating habit development; results from cohort studies in France, Portugal, Greece and UK. Annals of Nutrition \& Metabolism. 2013; 63 (Supplement 1): 38

121. HabEat Project website. Available [Online] http://www.habeat.eu/ (Accessed 1 February 2014). 
122. Statistics South Africa. Census 2001. Pretoria: Statistics South Africa. 2003. Available [Online] http://www.statssa.gov.za/census01/html/C2001publications.asp (Accessed 28 April 2012.)

123. Norman, R., Bradshaw, D., Schneider, M., Joubert, J., Groenewald, P., Lewin, S., Steyn, K., Vos, T., Laubscher, R., Nannan, N., Nojilana, B., Pieterse, D. \& the South African Comparative Risk Assessment Collaborating Group. A comparative risk assessment for South Africa in 2000: Towards promoting health and preventing disease. South African Medical Journal. 2007; 97(8): 637-641.

124. Blumenthal-Barby, J.S. \& Burroughs, H. Seeking better health care outcomes: The ethics of using the "nudge". The American Journal of Bioethics. 2012; 12(2): 1-10.

125. Atkins, L. \& Michie, S. Changing eating behaviour: What can we learn from behavioural science? British Nutrition Foundation Nutrition Bulletin. 2013; 38: 30-35.

126. Michie, S., van Stralen, M.M. \& West, R. The behaviour change wheel: A new method for characterising and designing behaviour change interventions. Implementation Science. 2011; 6: $42-52$.

127. Variyam, J.N., Shim, Y. \& Blaylock, J. Consumer misperceptions of diet quality. Journal of Nutrition Education. 2001; 33: 314-321.

128. Spahn, J.M., Reeves, T.S., Keim, K.S., Laquatra, I., Kellogg, M., Jortberg, B. \& Clark, N.A. State of the art evidence regarding behaviour change theories and strategies in nutrition counseling to facilitate health and food behaviour change. Journal of the American Dietetic Association. 2010; 110: 879-891.

129. Watson, R. \& Wyness, L. 'Don't tell me what to eat!' - Ways to engage the population in positive behaviour change. British Nutrition Foundation Nutrition Bulletin. 2013; 38: 23-29.

130. Skinner, D. Qualitative methodology: An introduction. In: Joubert, G., Ehrlich, R., eds. Epidemiology: A Research Manual for South Africa. $2^{\text {nd }}$ Edition. Cape Town: Oxford University Press Southern Africa. 2007: 318-327.

131. City of Cape Town. 2001 Census. A population profile of Mitchells Plain: Socio-economic information from the 2001 Census. Compiled by Information Management and Knowledge Department, City of Cape Town. 2005. Available [Online] http://www.capetown.gov.za/en/stats/CityReports/Documents/Population\%20Profiles/A_Popula tion_Profile_of_Mitchell_s_Plain_1052006141827_359.pdf (Accessed 28 April 2012.)

132. Statistics South Africa. 2011 Census. Suburb profiles: Mitchells Plain. (July 2013). Compiled by Strategic Development Information and GIS Department, City of Cape Town, using 2011 Census data supplied by Statistics South Africa. Available [Online] http://www.capetown.gov.za/en/stats/Pages/2011-Census-Suburb-Profiles-land.aspx?group=2 (Accessed 5 November 2013.) 
133. Personal communication. Census 2011 statistics for Mitchells Plain. Ms Kelebogile Olifant: User Information Services. Statistics South Africa. May 2013.

134. Parliamentary Monitoring Group (PMG). Zero Hunger Programme Provincial Implementation: Department of Agriculture, Forestry \& Fisheries Briefing. 15 May 2012. Available [Online] http://www.pmg.org.za/report/20120515-department-human-agricultureforestry-and-fishing-zero-hunger-program (Accessed 23 November 2013.)

135. City of Cape Town website. Councillors Online: List of all Wards. Available [Online] http://www.capetown.gov.za/en/councilonline/Pages/ViewWardDetails.aspx?FirstWardSequenc eNo=1\&LastWardSequenceNo=10 (Accessed 30 March 2012.)

136. Department of Provincial and Local Governnment (DPLG) \& Business Trust. Mitchells Plain nodal economic development profile for the Nodal economic profiling project. 2007. Available [Online] http://www.btrust.org.za/library/assets/uploads/documents/5_CIPPN_Mitchells\%20Plain\%20na rrative.pdf (Accessed 29 January 2014)

137. Statistics South Africa. 2011 Census. 2012. Pretoria: Statistics South Africa. Available [online] http://www.statssa.gov.za (Accessed on 9 February 2014.

138. City of Cape Town. Integrated Development Plan and Organisational Performance Management. Annexure H: HIVIAIDS \& TB Plan 2010-2011. Available [Online] http://www.capetown.gov.za/en/IDP/Statutory\%20plans\%202011\%20\%202012/AnnexureH_Cit y_Health_HIV_AIDS_TB_Plan_2010_2011.pdf (Accessed 25 July 2012.)

139. Draper, B., Pienaar, D., Parker, W. \& Rehle, T. Recommendations for policy in the Western Cape for the prevention of major infectious diseases, including HIVIAIDS and Tuberculosis. Human Sciences Research Council and University of Cape Town. 2007.

140. Department of Health. National antenatal sentinel HIV and Syphilis prevalence survey in South Africa, 2009. Pretoria: Department of Health. 2010. Available [Online] http://www.healthe.org.za/documents/85d3dad6136e8ca9d02cceb7f4a36145.pdf (Accessed 26 July 2012.)

141. Provincial Government of the Western Cape. Department of Health: Annual Performance Plan 2011-2012. Republic of South Africa. Government Printers. Available [Online] http://www.westerncapegov.za (Accessed 25 July 2012.)

142. Dawson, S. \& Manderson, L. A manual for the use of focus groups. Methods for social research in disease. Boston, USA: International Nutrition Foundation for Developing Countries (INFDC). 1993.

143. Joubert, G. \& Katzenellenbogen, J. Population and sampling. In: Joubert, G., Ehrlich, R., eds. Epidemiology: A Research Manual for South Africa. $2^{\text {nd }}$ Edition. Cape Town: Oxford University Press Southern Africa. 2007: 94-105.

144. Betts, N.M., Baranowski, T. \& Hoerr, S.L. Recommendations for planning and reporting focus group research. Journal for Nutrition Education. 1996; 28: 279-281. 
145. Cohen, B. United States Department of Agriculture (USDA) Community Food Security Assessment Toolkit (Appendix B: Focus Group Guide; Pg 94-136). Electronic Publications from the Food Assistance and Nutrition Research Programme. 2002. Available [Online] http://www.ers.usda.gov/publications/efan02013/efan02013appb.pdf (Accessed 16 March 2012.)

146. Mack, N., Woodsong, C., MacQueen, K.M., Guest, G. \& Namey, E. Qualitative Research Methods: A Data Collector's Field Guide. Family Health International (FHI). 2005. Available [Online] http://www.fhi360.org/nr/rdonlyres/emgox4xpcoyrysqspsgy5ww6mq7v4e44etd6toiejyxalhbmk5 sdnef7fqlr3q6hlwa2ttj5524xbn/datacollectorguideenrh.pdf (Accessed 8 January 2012.)

147. Roncaglia, I. Analyzing recorded interviews: making sense of oral history. Forum: Qualitative Social Research. 2004; 5(1): 20.

148. Quinn, G.P., Albrecht, T.L., Mahan, C., Bell-Ellison, B.A., Akintobi, T.H., Reynolds, B. \& Jeffers., D. The photo essay: A visual research method for educating obstetricians and other health care professionals. The Qualitative Report. 2006; 11(2): 229-250. Available [Online] http://www.nova.edu/ssss/QR/QR11-2/quinn.pdf (Accessed 3 June 2012.)

149. Walia, S. \& Leipert, B. Perceived facilitators and barriers to physical activity for rural youth: an exploratory study using photovoice. Rural and Remote Health. 2012; 12: 1842. Available [Online] http://www.rrh.org.au (Accessed 3 June 2012.)

150. Health of Philadelphia Project website. Available [Online] http://www.visualepi.com/about.html (Accessed 24 September 2011.)

151. Stellenbosch University. Short Course 2013: Qualitative Research Methods for Health Sciences. Course Description. Available [Online] http://www.saslha.co.za/images/Advert_Qualitative_methods_short_course_2013.pdf (Accessed 24 November 2013.)

152. Western Cape Health Research Committee. Guidelines for approval of health research in the Western Cape. Provincial Government of the Western Cape and City of Cape Town. 2009. Available [Online] http://www.westerncape.gov.za/other/2011/10/guidelines_for_approval_of_health_research_in _the_western_cape.pdf (Accessed 6 May 2012.)

153. Naude, C.E. "Eat plenty of vegetables and fruit every day": A food-based dietary guideline for South Africa. South African Journal of Clinical Nutrition. 2013; 26(3)(Suppl.): S46-S56.

154. Popkin, B.M. Global nutrition dynamics: The world is shifting rapidly toward a diet linked with non-communicable diseases. American Journal of Clinical Nutrition. 2006; 84: 289-98.

155. Abrahams, Z., Mchiza, Z. \& Steyn, N.P. Diet and mortality rates in Sub-Saharan Africa: Stages in the nutrition transition. Public Health. 2011; 11: 801. 
156. Feeley, A., Pettifor, J.M. \& Norris, S.A. Fast-food consumption among 17-year-olds in the birth to twenty cohort. South African Journal of Clinical Nutrition. 2009; 22(3): 118-123.

157. Feeley, A., Musenge, E., Pettifor, J.M. \& Norris, S.A. Changes in dietary habits and eating practices in adolescents living in urban South Africa: The birth to twenty cohort. Nutrition. 2012; 28: e1-e6.

158. Steyn, N.P., Labadarios, D. \& Nel, J.H. Factors which influence the consumption of street foods and fast foods in South Africa: A national survey. Nutrition Journal. 2011; 10: 104.

159. Temple, N.J. \& Steyn, N.P. The cost of a healthy diet: A South African perspective. Nutrition. 2011; 27: 505-508.

160. Resource Centres on Urban Agriculture and Food Security (RUAF) Foundation. 2010: RUAF-FSST (From Seed To Table) programme. Available [Online] http://www.ruaf.org/node/1970 (Accessed 14 November 2013.)

161. Faber, M., Witten, C. \& Drimie, S. Community-based agricultural interventions in the context of food and nutrition security in South Africa. South African Journal of Clinical Nutrition. 2011; 24(1): 21-30.

162. Altman, M., Hart, T. \& Jacobs, P. Food security in South Africa. Human Sciences Research Council. 2009.

163. Statistics South Africa. Community Survey 2007 (Revised version): Stastical Release.

Pretoria: Statistics South Africa. 2007. Available [Online]

http://www.statssa.gov.za/publications/P0301/P0301.pdf (Accessed 4 Decebmer 2013)

164. de Marchi, R.J., Hugo, F.N., Padilha, D.M.P., Hilgert, J.B., Machado, D.B., Durgante, P.C. \& Antunes, M.T. Edentulism, use of dentures and consumption of fruit and vegetables in South Brazilian community-dwelling elderly. Journal of Oral Rehabilitation. 2011; 38: 533-540.

165. Naidoo, S. Oral health and nutrition for children under five years of age: a paediatric foodbased dietary guideline. South African Journal of Clinical Nutrition. 2013; 26(3) (Supplement): S150-S155.

166. Hetherington, M., Caton, S., Cecil, J.E., Cooke, E., Croden, F., Fildes, A., de Graaf, C., Lopes, C., Jackson, D., Jager, G., Madrelle, J., Moreira, P., Moschonis, G., Moller, P., Nicklaus, S., Olsen, A.M., Remy, E., Schwartz, C., Vereitjken, C., Warren, J., Weenen, H., de Wilde, V. \& Issanchou, S. Learning to like vegetables: applying learning theory to the acquisition of preferences for novel vegetables from $6-36 \mathrm{~m}$. Results from HabEat and VIVA. Annals of Nutrition \& Metabolism. 2013; 63 (Supplement 1):39

167. Riediger, D., Shooshtari, S. \& Moghadasian, M.H. The influence of socio-demographic factors on patterns of fruit and vegetable consumption in Canadian adolescents. Journal of the American Dietetic Association. 2007; 107: 1511-1518. 
168. Krige, S.M., Mahomoodally, F.M., Subratty, A.H. \& Ramasawmy, D. Relationship between socio-demographic factors and eating practices in a multicultural society. Food and Nutrition Sciences. 2012; 3: 286-295.

169. Makiwane, M. The changing patterns of intergenerational relations in South Africa. Pretoria: Human Sciences Research Council. 2011. Available [Online] http://www.un.org/esa/socdev/family/docs/egm11/EGM_Expert_Paper_Monde_Makiwane.pdf (Accessed 18 November 2011.)

170. Steyn, N.P., Bradshaw, D., Norman, R., Joubert, J.D., Schneider, M. \& Steyn, K. Dietary changes and the health transition in South Africa: Implications for health policy. Cape Town: South African Medical Research Council. 2006.

171. Bauer, K.W., Hearst, M.O., Escoto, K., Berge, J.M. \& Neumark-Sztainer, D. Parental employment and work-family stress: Associations with family food environments. Social Science \& Medicine. 2012; 75: 496 - 504.

172. Fulkerson, J.A., Kubik, M. Y., Rydell, S., Boutelle, K.N., Garwick, A., Story, M., NeumarkSztainer, D. \& Dudovitz, B. Groups with working parents of school-aged children: What's needed to improve family meals? Journal of Nutrition Education and Behaviour. 2011; 43: 189193.

173. Ryan, P. Integrated theory of health behaviour change. Clinical Nurse Specialist. 2009; 23(3): 161-172.

174. Pharmadynamics and Heart and Stroke Foundation of South Africa. Cooking from the Heart. Cape Town: Interpak Books. 2012. Available [Online] http://www.cookingfromtheheart.co.za/wp-content/uploads/2013/04/Cooking-from-the-heart.pdf (Accessed 12 November 2013.)

175. Hawkes, C., Jewell, J. \& Allen, K. A food policy package for healthy diets and the prevention of obesity and diet-related non-communicable diseases: the NOURISHING framework. Obesity Reviews. 2013; 14 (Suppl. 2): 159-168.

176. Strengthening Partnerships Results and Innovation in Nutrition Globally (SPRING) website: Social and behaviour change for nutrition. Available [Online] http://www.springnutrition.org/technical-areas/sbcc-for-nutrition. (Accessed 17 November 2013.)

177. World Health Organisation (WHO). Recommendations on Marketing of Foods and nonalcoholic Beverages to Children. 2010. Geneva: WHO. Available [Online] http://whqlibdoc.who.int/publications/2010/9789241500210_eng.pdf (Accessed 8 February 2014)

178. World Health Organisation (WHO). A framework for implementing the set of recommendations on the marketing of foods and non-alcoholic beverages to children. 2012. Geneva: WHO. Available [Online] 
http://www.who.int/dietphysicalactivity/MarketingFramework2012.pdf (Accessed 8 February 2014).

179. Unites States Department of Agriculture (USDA). Food and Nutritrion Service. 7 CFR Parts 210 and 220. National School Lunch Program and School Breakfast Program: Nutrition Standards for All Foods Sold in School as Required by the Healthy, Hunger-Free Kids Act of 2010; Interim Final Rule. Federal Register. 28 June 2013; 78 (125): 39068-39120. Availble [Online] http://www.gpo.gov/fdsys/pkg/FR-2013-06-28/pdf/2013-15249.pdf (Accessed 8 February 2014).

180. ICF Incorporated. FNS Coding and Comment Analysis. Proposed Rule on Nutrition Standards for All Foods Sold in School as Required by the Healthy, Hunger-Free Kids Act of 2010: Final Summary of Public Comments. Docket FNS-2011-0019. June 21, 2013. Available [Online] http://www.fns.usda.gov/cnd/Governance/Legislation/allfoods_commentsummary.pdf (Accessed 8 February 2014)

181. Nielsen website. Mobile phones dominate in South Africa. Posted on 30 September 2011. Available [Online] http://www.nielsen.com/us/en/newswire/2011/mobile-phones-dominate-insouth-africa.html (Accessed 18 November 2011.)

182. United Nations Children's Fund (UNICEF) website. Communication for development: Social mobilisation. Available [Online] http://www.unicef.org/cbsc/index_42347.html (Accessed 17 November 2013.)

183. Hausler, H. \& Wills, C. Behaviour Change Communication and Social Mobilisation Guidelines. URC/ TASC II Project. University of the Western Cape. March 2007. Available [Online]

http://dev.tbsouthafrica.org/Documents/ACSM/Behaviour\%20Change\%20Communication\%20a nd\%20Social\%20Mobilisation\%20Guidelines\%20Final\%2018-03-07.pdf (Accessed 10 November 2013.)

184. South African National Aids Council (SANAC). The National HIV Counseling and Testing Campaign. 2010. Available [Online] http://www.westerncape.gov.za/other/2010/6/hct_campaign_strategy_2_3_10_final.pdf (Accessed 10 November 2013.)

185. Department of Health. Directorate: Nutrition. Roadmap for Nutrition in South Africa 2013 2017. Pretoria: Department of Health. 2013.

186. Brot für die Welt (Bread for the World), Food First Information and Action Network (FIAN) International \& Interchurch Cooperative for Development (ICCO) Cooperation. Right to Food and Nutrition Watch 2013: Alternatives and resistance to policies that generate hunger. 2013. Available [Online] http://www.rtfn-watch.org/ (Accessed 14 November 2013) 


\section{ADDENDA}

ADDENDUM A: Map of the Cape Metropole District representing the division of the District into eight sub-districts (one of which is the Mitchells Plain sub-district)

ADDENDUM B: Map of the Mitchells Plain area representing the divisions of Mitchells Plain.

ADDENDUM C: Letter to Ward Councillor to request permission to conduct research in Ward 79

ADDENDUM D: Information flyer to recruit participants (English)

ADDENDUM E / BYLAE E: Information flyer to recruit participants (Afrikaans) / Inligtingsbiljet om deelnemers te werf

ADDENDUM F: Volunteer information sheet (English)

ADDENDUM G (BYLAE G): Volunteer information sheet (Afrikaans) / Inligtingsblad vir vrywilligers

ADDENDUM H: Volunteer written informed consent form (English)

ADDEUNDUM I (BYLAE I): Volunteer written informed consent form (Afrikaans) / Vrywilliger geskrewe ingeligte toestemmingsvorm

ADDENDUM J: Question guide for focus group discussions and in-depth interviews

ADDENDUM K: Information provided to participants (on ways to increase fruit and vegetable consumption)

ADDENDUM L: Budget expenditure for research study 
ADDENDUM A: Map of the Cape Metropole District representing the division of the District into eight sub-districts (one of which is the Mitchells Plain subdistrict)

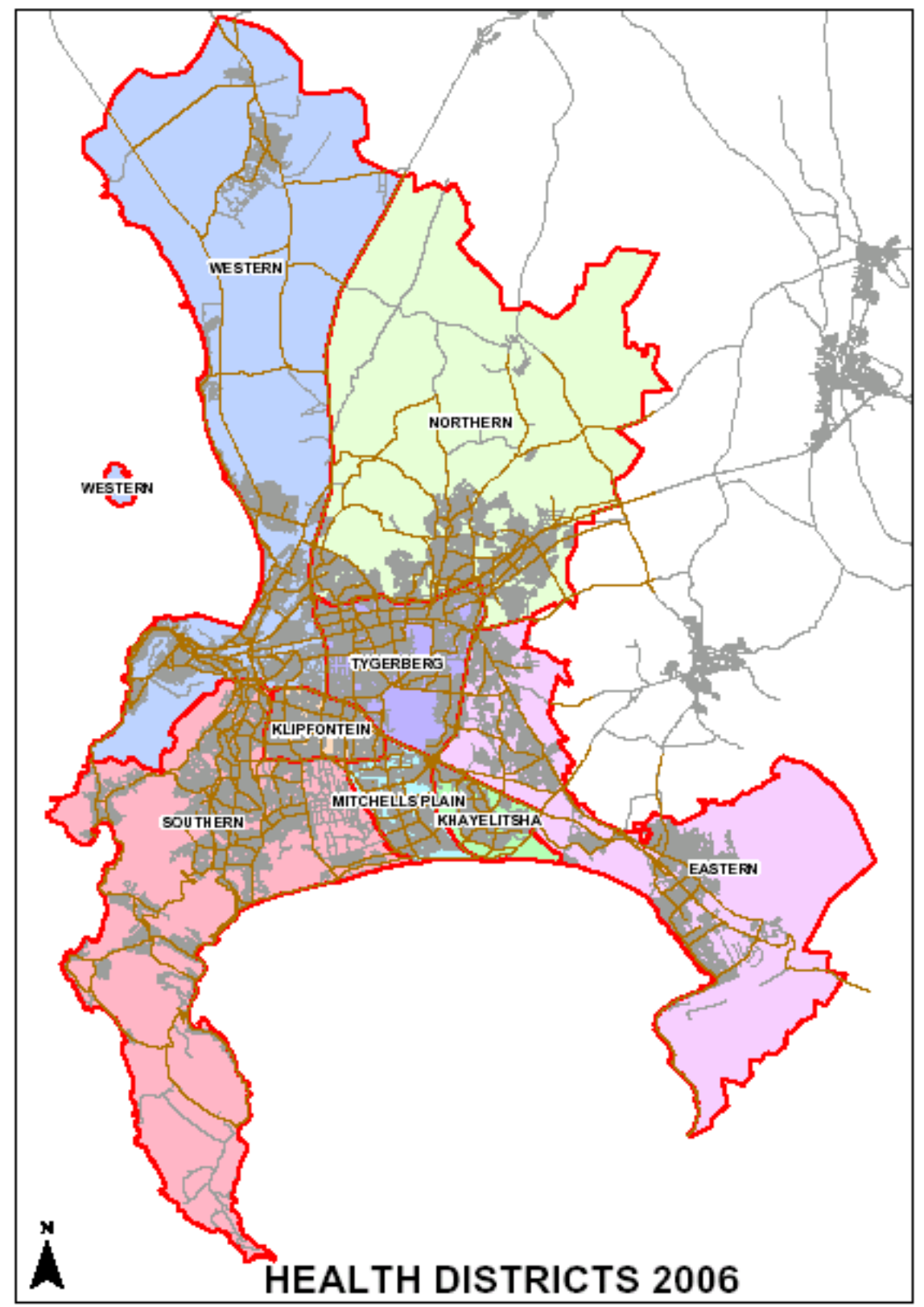

Reference: Provincial Government of the Western Cape 
ADDENDUM B: Map of the Mitchells Plain area representing the divisions of Mitchells Plain into smaller sub-areas

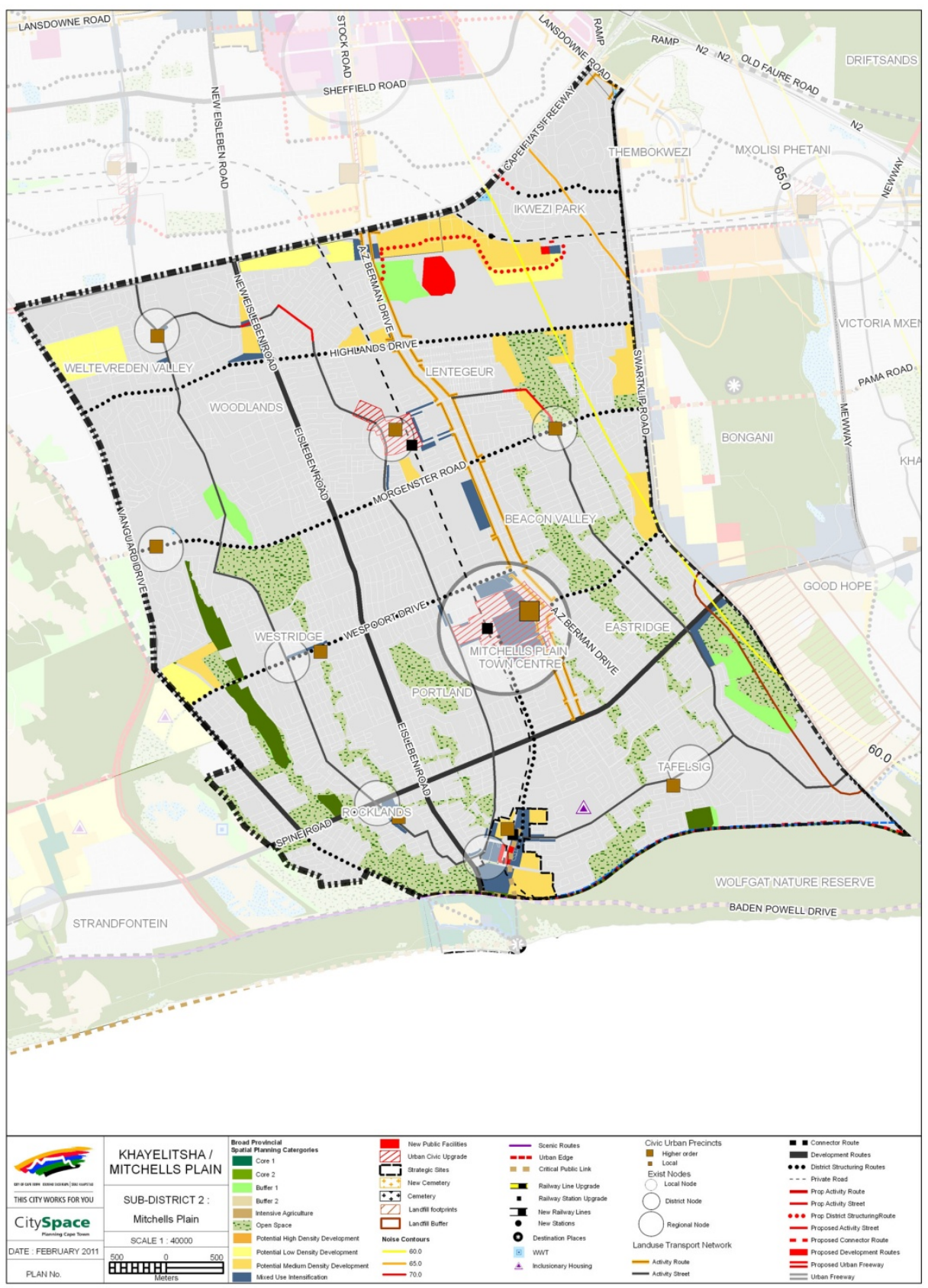

Reference: City of Cape Town 


\section{ADDENDUM C: Letter to Ward Councillor to request permission to conduct research in Ward 79}

Catherine (Katie) Pereira

Unit 42 Regent Park

Smuts Avenue

Somerset West

7130

6 November 2012

Ward Councillor for Ward 79: Mr Solomon Philander

Parks \& Bathing Building

Merrydale Avenue

Lentegeur

7798

RE: REQUEST FOR PERMISSION TO CONDUCT DATA COLLECTION FOR A RESEARCH PROJECT IN WARD 79

Dear Mr Philander,

I would hereby like to request permission to collect data, by way of the facilitation of focus group discussions and in-depth interviews with various individuals in Sub-council 12: Ward 79. I am currently enrolled in a Master's in Nutrition through Stellenbosch University. This data collection forms part of the fulfilment of the requirements for my Master's thesis, entitled "Understanding fruit and vegetable consumption: A qualitative investigation in the Mitchells Plain sub-district of Cape Town."

I would like to do research on this topic, because, in South Africa most people do not consume the recommended amount of fruit and vegetables on a daily basis. By holding group discussions and one-on-one interviews, I will be able to identify some of the underlying reasons for low fruit and vegetable consumption in Mitchells Plain. I feel that this is needed, to be able to develop interventions that could encourage individuals to consume more fruit and vegetables and therefore impact positively on individuals' nutrition and health status. The reason that I would like to do this in Ward 79, specifically, is that I have been working in the Mitchells Plain area for the past six years, 
as a Dietitian for the Department of Health. I think that this research would be beneficial to the work that the Department of Health is doing in the area.

I am planning to do three focus group discussions, with eight individuals each and then ten indepth interviews with one person each. To recruit the participants, I have developed a flyer that can be put up at certain points in the community. I propose that the focus group discussions take place at a community venue, and that the in-depth interviews would be conducted in people's houses or workplaces. Attached is a two-page summary of my protocol, which explains what I plan to do.*

Thank you for taking the time to consider this request. I would appreciate your consent for this research project. If you require any additional information, please let me know and I will gladly provide it.

I look forward to hearing from you.

Yours sincerely,

Catherine Pereira

Tel (Work): (021) 3705017

Tel (Cell): 0825040901

Email: $\underline{\text { catherinejanepereira@gmail.com or Catherine.Pereira@pgwc.gov.za }}$

\footnotetext{
* The document entitled Protocol Synopsis (a two-page summary of the full protocol) is attached as one of the supporting documents as part of complete application to the Health Research Ethics Committee.
} 


\section{ADDENDUM D: Information flyer to recruit participants (English) \\ VOLUNTEERS NEEDED TO TAKE PART IN RESEARCH PROJECT Come and join a conversation on eating habits!}

A research project will be conducted in the Mitchells Plain area that aims to assess some of the underlying factors that influence the types of food that people eat, or do not eat.

If you are a man or a woman between the ages of 18 and 60, and resident in Beacon Valley or Eastridge, we would like you to be involved in a focus group discussion, which is where a group of about eight people will come together and be asked to answer certain questions, and to discuss certain topics amongst themselves. This is expected to take approximately one hour of your time.

\section{DATE:}

TIME:

\section{VENUE:}

Please contact me (Katie) if you are interested in taking part in the study.

CONTACT PERSON: Katie Pereira

Tel: 0213705017

Email: Catherine.Pereira@pgwc.gov.za 


\section{ADDENDUM E I BYLAE E: Information flyer to recruit participants (Afrikaans) I Inligtingsbiljet om deelnemers te werf}

\section{VRYWILLIGERS WORD BENODIG OM AAN 'N NAVORSINGSPROJEK DEEL TE NEEM Kom gesels saam oor eetgewoontes!}

'n Nvorsingsprojek word in die Mitchells Plein-omgewing uitgevoer, om beter te verstaan waarom mense sekere kosse eet of nie eet nie.

Indien u 'n manlike of vroulike persoon tussen die ouderdomme 18 en 60 jaar is en in Beacon Valley of Eastridge woon, nooi ons u graag om aan 'n fokus-groepbespreking deel te neem.

Dit is: 'n groep van ongeveer agt persone sal gevra word om vrae en onderwerpe i.v.m. eetgewoontes onderling te bespreek. Dit sal ongeveer ' $n$ uur van u tyd in beslag neem.

DATUM:

TYD:

\section{VERGADERPLEK:}

Kontak Katie asb indien u belangstel om aan die studie deel te neem.

KONTAK PERSOON: Katie Pereira

Tel: 0213705017

E-pos: Catherine.Pereira@pgwc.gov.za 


\section{ADDENDUM F: Volunteer information sheet (English)}

\section{VOLUNTEER INFORMATION SHEET}

TITLE OF THE RESEARCH PROJECT: "Understanding fruit and vegetable consumption: A qualitative investigation in the Mitchells Plain sub-district of Cape Town"

ETHICS REFERENCE NUMBER: S12/08/211

PRINCIPAL INVESTIGATOR: Catherine Pereira ${ }^{1}$

Supervisor and Co-supervisor: Prof. Milla McLachlan ${ }^{1}$, Dr Jane Battersby-Lennard ${ }^{2}$

1 = Stellenbosch University; 2 = University of Cape Town

ADDRESS OF PRINCIPAL INVESTIGATOR: Klipfontein / Mitchells Plain Substructure Office

Lentegeur Psychiatric Hospital

Highlands Avenue

Mitchells Plain, 7785

CONTACT NUMBER: 0213705017 / 0825040901

\section{Dear Volunteer,}

I would like to ask if you would be willing to take part in a research project that will be assessing factors that affect eating practices and habits. Please could you take the time to read this information sheet and then decide whether or not you will agree to be involved in the study. Please would you ask the study staff any questions about any part of this study that you do not fully understand. It is important that you clearly understand what this research entails and how you will be involved.

This study has been approved by the Health Research Ethics Committee at Stellenbosch University and will be conducted according to the ethical guidelines and principles of the international Declaration of Helsinki, South African Guidelines for Good Clinical Practice and the Medical Research Council Ethical Guidelines for Research.

Interviews will be conducted, during September and October 2012, with residents of the Mitchells Plain area. We would like to gain in-depth understanding of what influences choices that people make with regard to eating. 
You will either be asked to take part in one of the following two things:

- A Focus group discussion: This is like a group interview, where about eight people are asked to come together and are asked different questions, and asked to discuss the topics amongst themselves.

- An In-depth interview: This is where the researcher will just sit with you, one-on-one, and ask some more questions, but go into a bit more detail with you.

The discussions and interviews will probably take approximately one hour of your time. They will need to be recorded on a tape recorder (so that the information can be analysed at a later stage).

By signing the Volunteer written informed consent form, it means that you are participating in the research project voluntarily and of your own free will, without coercion or pressure from any other person. You may withdraw from the study at any time, without stating any reasons why and there will not be any negative consequences if you decide to withdraw. You may choose not to answer certain questions if you do not feel comfortable doing so. There are no perceived risks associated with taking part in the study. There are no expected benefits that will affect you personally, but it is hoped that the project will benefit the community, by guiding more appropriate future interventions to be implemented. You will not be paid to take part in the study, but you will be given something as a token of appreciation for your participation in the study*. Transport costs will be reimbursed and you will receive some light refreshments after your participation in the study. There will be no costs involved for you, if you do decide to take part in the study.

By accepting to take part in the research project, you are requested to answer questions honestly, and to provide truthful and accurate information. If false information is provided, it will mean that the research results will not be accurate.

All information that you provide will be treated in confidence. This means that when answers or results are discussed, comments that you have made will remain confidential and the researchers will not refer to you by name in the results or discussions sections of the research. The sponsors of the study or the Health Sciences Research Ethics Committee may access the study records.

You can contact the Health Research Ethics Committee at Stellenbosch University on 021938 9207 if you have any concerns or complaints that have not been adequately addressed by the study investigator. You will receive a copy of this information and consent form, for your own records.

Thank you for taking the time to consider being involved in this research project. Should you wish to contact me for further information regarding the research, please do not hesitate to do so. (See contact details below.) 
Catherine Pereira (Principal Investigator)

Tel: (021) 3705017 / (082) 5040901

Fax: (021) 3705036

Email: Catherine.Pereira@westerncape.gov.za

* Please note that a bag of about 3-4 different vegetables will be given to each participant as a token of appreciation for participating in the study. For example, one participant could receive a bag of carrots, three green peppers and a container or blueberries following participation in the study. 


\section{ADDENDUM G (BYLAE G): Volunteer information sheet (Afrikaans) I Inligtingsblad vir vrywilligers}

\section{INLIGTINGSBLAD VIR VRYWILLIGERS}

TITEL VAN NAVORSINGSPROJEK: "Insig in die menslike verbruik van vrugte en groente: 'n Kwalitatiewe ondersoek in Mitchells Plein-omgewing, Kaapstad"

ETIEK VERWYSINGSNOMMER: S12/08/211

HOOFNAVORSER: Catherine Pereira ${ }^{1}$

Promotor en mede-Promotor: Prof. Milla McLachlan ${ }^{1}$, Dr Jane Battersby-Lennard ${ }^{2}$ 1 = Stellenbosch Universiteit; 2 = Universiteit Kaapstad

ADRES VAN HOOFNAVORSER: Klipfontein/Mitchells Plein Substruktuur Kantoor Lentegeur Psigiatriese Hospitaal

Highlands Rylaan

Mitchells Plein

7785

TEL NO: 0213705017 / 0825040901

Geagte Vrywilliger,

Ek wil u graag uitnooi om deel te neem aan 'n navorsingsprojek, in verband met die faktore wat eetgebruike en - gewoontes beïnvloed. Vergewis $u$ asseblief eers van die inhoud van die inligtingsblad en besluit dan of $u$ wil deelneem of nie. Dit is belangrik dat $u$ op hoogte is van die besonderhede van die studie en $u$ deelname daaraan en daarom is $u$ welkom om enige onduidelikhede met die studiespan te bespreek.

Die studie is deur die Gesondheidsnavorsing Etiekkomitee van Universiteit Stellenbosch goedgekeur en sal ooreenkomstig die beginsels en etiese riglyne van Internasionale Deklarasie van Helsinki, Suid-Afrikaanse Riglyne vir Goeie Kliniese Praktyke en die Etiese Riglyne vir Navorsing van die Mediese Navorsingsraad, uitgevoer word.

Onderhoude sal gedurende September en Oktober 2012 met inwoners van Mitchells Pleinomgewing, Kaapstad gevoer word. Vergewis u asseblief eers met die inhoud van die inligtingsblad en besluit dan of $u$ wil deelneem of nie.

U sal gevra word om as volg deel te neem: 
- Of deur middel van 'n Fokus groepbespreking. Hierdie is soos 'n groep-ondersoek, waardeur agt persone verskillende gestelde vrae onderling moet bespreek

- Of ' $n$ In-diepte onderhoud. Hier sal die navorser ' $n$ een-tot-een, meer gedetailleerde onderhoud met u voer.

Die besprekings en onderhoude sal ongeveer ' $n$ uur duur en word op band opgeneem vir latere verwerking van die inligting.

Met ondertekening van die aangehegte: Vrywilliger geskrewe inligting toestemmingsvorm, beteken dit dat $u$ sonder dwang of onder druk van enige persoon, vrywilliglik aan 'n navorsingsprojek deelneem. $U$ mag te enige tyd, sonder om redes te verskaf, aan die onderhoude of besprekings onttrek. Daar sal geen negatiewe gevolge wees nie. Indien u nie gemaklik voel met van die vrae nie, hoef $u$ dit nie te beantwoord nie. Daar is geen voorsiene risiko's verbonde aan deelname nie. $\mathrm{U}$ word nie vir u deelname vergoed nie, maar ontvang ' $\mathrm{n}$ verskeidenheid vars groente as blyk van waardering. Vervoerkoste is terugbetaalbaar en ligte verversings word na $u$ deelname voorsien. Daar word gehoop dat die projek die gemeenskap sal bevoordeel deur meer gepaste programme/projekte te implementeer.

Met $u$ besluit om deel te neem, word u versoek om vrae noukeurig te beantwoord en om eerlike en akkurate inligting te verskaf. Verkeerde inligting sal meebring dat die resultate van die navorsing nie akkuraat sal wees nie.

Alle inligting deur $u$ verskaf, word streng vertroulik hanteer. Die navorsers sal nie by name na $u$ verwys in resultate of besprekingsdele van die navorsing nie. Die borge van die studie en/of Gesondheidsnavorsing Etiekkomitee mag toegang verkry tot die studieverslae.

Indien enige aangeleentheid of klagte wat $u$ onder die navorser se aandag gebring het, en dit na $u$ mening nie voldoende hanteer is nie, is u welkom om die Gesondheidsnavorsing Etiekkomitee te Universiteit Stellenbosch by 021-938 9207 te skakel. 'n Afskrif van die inligting en toestemmingsvorm sal aan u voorsien word.

Baie dankie vir u tyd en deelname. Indien u verdere inligting in verband met die navorsing verlang, is $u$ welkom om my te kontak. (Besonderhede onderaan).

Catherine Pereira (Hoof Navorser)

Tel: (021) 3705017 / (082) 5040901

Faks: (021) 3705036

E-pos: Catherine.Pereira@westerncape.gov.za 


\section{ADDENDUM H: Volunteer written informed consent form (English)}

\section{VOLUNTEER WRITTEN INFORMED CONSENT FORM}

"Understanding fruit and vegetable consumption: A qualitative investigation in the Mitchells Plain sub-district of Cape Town"

Catherine Pereira ${ }^{1}$, Prof. Milla McLachlan ${ }^{1}$, Dr Jane Battersby-Lennard ${ }^{2}$

$1=$ Stellenbosch University

2 = University of Cape Town

\section{Respondent consent:}

I, (name of respondent), agree to take part in this research project.

I have read the Volunteer information sheet and I understand what the study is about and the purpose of the research. I have been given the opportunity to contact the investigators regarding any questions that I had about the study. I understand that there are no foreseen risks of taking part in the study and that there will be community benefits of my participation in the study. I feel satisfied that my confidentiality will be maintained during the research process. I was not pressurised or coerced into taking part in the study, and am participating of my own free will. I am aware that I can withdraw from the study at any time, without stating any reasons. I know and understand what is expected of me during the research process.

I document my informed consent by signing my name below:

Signature:

Date:

\section{Investigator declaration:}

I, (name of investigator) declare that I have explained the information in the Volunteer information sheet clearly to (respondent).

I gave him / her the opportunity to ask questions, and I answered accordingly. I am satisfied that he/she understands what is required to participate in this study.

Signature:

Date: 


\section{ADDENDUM I (BYLAE I): Volunteer written informed consent form (Afrikaans) I Vrywilliger geskrewe ingeligte toestemmingsvorm}

\section{VRYWILLIGER GESKREWE INLIGTING TOESTEMMINGSVORM:}

"Insig in die menslike verbruik van vrugte en groente:

'n Kwalitatiewe ondersoek in Mitchells Plein-omgewing, Kaapstad"

NAVORSERS: Catherine Pereira ${ }^{1}$, Milla McLachlan ${ }^{1}$, Dr Jane Battersby-Lennard ${ }^{2}$

1 = Universiteit Stellenbosch, 2 = Universiteit Kaapstad

\section{Deelnemers toestemming:}

Ek, (naam van deelnemer), stem in om deel te neem aan hierdie navorsingsprojek.

Ek het die Vrywilligers inligtingsblad gelees en ek begryp die doel daarvan en die rede vir die navorsing. Ek is die geleentheid gegun om die navorsers te kontak indien ek enige vrae i.v.m die studie het. Ek is verseker dat my privaatheid gehandhaaf sal word tydens die navorsing. Ek begryp dat daar geen voorsiene risiko's verbonde aan die deelname is nie, maar dat daar wel voordele aan verbonde is vir my gemeenskap. Ek is nie geforseer of gedwing om deel te neem aan die studie nie en ek neem uit vrye wil deel. Ek is bewus daarvan dat ek te eniger tyd kan onttrek van die studie sonder om redes te verstrek. Ek weet en verstaan wat van my verwag word gedurende die navorsingsproses.

Ek dokumenteer my ingeligte toestemming deur middel van my handtekening hieronder:

Handtekening:

Datum:

\section{Ondersoek verklaring:}

Ek, (naam van ondersoeker) verklaar dat ek die inligting in die Vrywilliger inligtingsblad duidelik uiteengesit het aan (respondent).

Ek het hom/haar die geleentheid gegun om vrae te vra, wat ek dienooreenkomstig geantwoord het. Ek is seker dat hy/sy verstaan wat van hom/haar verwag word om deel te neem aan die navorsing.

Handtekening:

Datum: 


\section{ADDENDUM J: Question guide for focus group discussions and in-depth interviews}

\section{Question Guide: Understanding factors that influence fruit and vegetable consumption}

Potential questions to be asked during focus group discussions and in-depth interviews:

\section{Introduction:}

Greet the participants and introduce the facilitator, observer and note-taker.

Thank the participants for their participation in this discussion.

\section{Explanation:}

I am going to be asking you a few questions about certain eating habits. You will be given some time to answer the questions and discuss your opinions amongst each other.

Please try to be as honest as possible. This is not a test, there are no right or wrong answers, we are just trying to get an idea of the underlying factors that are related to the reasons for why people eat certain things and do not eat other things.

Please allow one person to speak at a time, and respect each other's comments.

All of your responses will be confidential and only used for the purpose of this research.

We will be using a tape recorder, to tape the discussion so that we can analyse it properly at a later stage. We will hopefully take about one hour.

\section{Ice-breaker:}

Before we start, can everyone please introduce themselves to the rest of the group and tell us one thing about yourself? (E.g. what is your favourite food or do you have any children?)

We are now going to start the discussion and will start recording.

The following information should be recorded by the scribe:

- The dynamics of the group. (Are certain members quieter and more reserved and are others louder?)

- The types of responses elicited by each question. (Does the question immediately cause a lot of discussion or are people quiet and hesitant to answer?)

- Observe body language. (Are people open and relaxed or closed and uncomfortable?)

- Observe facial expressions.

- Does the group generally agree with each other's responses? Or is there disagreement and debate? 
Themes and examples of specific questions

THEME 1: (General healthy eating questions)

Do you think it is important to eat healthily? Why or why not?

- Do you think that it is easy / difficult to eat healthily?

- Do you think that you already eat healthily enough?

- What types of food items would you consider to be healthy?

- What do you think good quality or adequate food means?

- What factors do you feel would help you to eat healthier? What factors stop you from eating healthier?

- What could be done to improve the quality or adequacy of food that you eat?

THEME 2: (Moving towards fruit and vegetable questions)

Why do you eat and why do you buy fruit and vegetables?

- What motivates you to eat fruit and vegetables?

- Do you know what the health benefits are of fruit and vegetables? Do you know why it is important to eat fruit and vegetables? Do you know how much fruit and vegetables you are supposed to eat?

- Do you like the taste of fruit and vegetables?

THEME 3: (Favourite / commonly eaten fruit and vegetables)

What are your favourite fruits? (Name up to 3 favourite fruits)

What are your favourite vegetables? (Name up to 3 favourite vegetables)

- What are your favourite fruit and / or vegetable dishes or recipes?

- Do you have favourite recipes that include fruit and vegetables, that have been handed down from your parents or other family members and are associated with your culture? If so, what are these? (top 3)

THEME 4: (Perceptions surrounding fruit and vegetables)

What are positive I good connotations/ thoughts that you associate with eating fruit and vegetables?

What are negative I bad perceptions / thoughts that you associate with eating fruit and vegetables? 
THEME 5: (Purchasing patterns surrounding or access to fruit and vegetables)

Where do you get or buy your fruit and vegetables from? What factors influence where you buy your fruit and vegetables?

- Are fruit and vegetables readily available and accessible in the area where you live?

- Where do you usually do your main grocery shopping? What sense of priority do you give to fruit and vegetables when shopping? (i.e. do you buy fruit and vegetables first? Or last?)

- How often do you buy fruit and vegetables? (Probe - once/week, every day, 2-3 times/week)

- Do you buy pre-peeled or pre-sliced fruit and vegetables? Why? Or Why not? Do you have a fridge to store vegetables in?

- Do you buy fresh or frozen or tinned fruit or vegetables? (If yes, which fruit and vegetables do you buy in this form?)

THEME 6: (Fruit and vegetable consumption patterns)

How do you eat, prepare or cook your fruit and vegetables?

When do you eat fruit \& vegetables? (Probe - as a snack, with a meal - lunch I supper, every day?)

- How much fruit/vegetables have you eaten in the past $24 \mathrm{hrs}$, or in the past week?

- What is your average consumption of fruit and vegetables per day?

- What fruit and vegetables do you consume the most of (in terms of amount of or frequency of consumption)?

- Do you think that you could consume five fruit and vegetables per day, every day for a longterm period? Is this a realistic recommendation? (Why or why not?)

Thank you for taking the time to answer these questions! Your input has been very valuable to us. 


\section{ADDENDUM K: Information provided to participants}

The following two lists were given, together with a bag of three or four fresh fruit and vegetables to the participants as a token of appreciation for their participation:

\section{Practical suggestions for increasing vegetable and fruit consumption ${ }^{22}$}

- Try a new vegetable and fruit each week

- Double your normal serving sizes of vegetables

- Eat raw and dried fruit and raw vegetables, and drink fruit or vegetable juices, as snacks

- Use fruit in your cereal in the morning (bananas, apples, grapes, berries, etc.)

- Make a fruit salad or try baked fruit for dessert (use fruit in season: apples, bananas, peaches)

- Make fruit kebabs for the kids

- Eat a vegetarian dinner at least once a week

- Enjoy a raw vegetable platter at parties

- Add vegetables to your favourite pasta and rice dishes

- Use vegetables in your egg dishes (onions, peppers, tomatoes, mushrooms)

- Enjoy international cuisine that makes use of vegetables - Spanish paellas, Chinese stir-fries, Greek moussaka, Provencal ratatouille, Mexican enchiladas, Indian curries

Maximising nutrients from vegetables and fruit:

- Do your vegetable and fruit shopping weekly and use up as soon as possible

- Check the 'sell-by' dates on packages when selecting

- Do not cut vegetables and fruit and leave to stand exposed to air or soaking in water

- Try using all parts of the plant, e.g. beetroot bulb and leaves, carrot tops

- Cook vegetables for the shortest time, using minimum amount of water

Saving money on vegetable and fruit shopping:

- Buy vegetables and fruit in season

- Plan your week's menu before shopping so that you do not buy excess that only spoils

- Store vegetables and fruit properly to maximise shelf-life, e.g. bananas outside of fridge

- When buying in bulk, consider your storage space at home first

- Pre-processed foods cost more, e.g. peeled and cut pumpkin

- Compare the costs of fresh and frozen

- Match the quality/grade of food to suit your intended purpose, e.g. not feasible to use extra choice grade pineapple rings in a punch 


\section{Healthy Recipes from Cooking from the Heart ${ }^{174}$ \\ PASTA WITH TUNA and PEAS (Serves 6)}

A simple, yet tasty family supper.

\section{Ingredients}

- $250 \mathrm{~g}$ elbow noodles

- 1 tsp $(5 \mathrm{ml})$ salt

- 2 tbsp (30ml) sunflower oil

- 1 onion, chopped

- 1 green pepper, seeds removed and chopped
- 1 tsp (5ml) curry powder

- $2 \times 170 \mathrm{~g}$ tins tuna in brine, drained

- 1 x 410g tin cream style sweetcorn

- $1 / 4$ cup $(60 \mathrm{ml})$ low-fat or fat-free milk

- 1 cup (250ml) frozen peas, rinsed

- lemon juice and black pepper to taste

\section{Methods}

1. Bring a large pot of water to the boil. Add pasta and $1 / 2$ tsp of the salt. Cook until tender and drain well. Stir in 1 tbsp of the oil and keep warm.

2. Preheat oven to $180^{\circ} \mathrm{C}$. Meanwhile, heat rest of oil in a pot and fry onion and green pepper.

3. Add curry powder and fry for a few minutes.

4. Remove from the heat and stir in remaining ingredients with the rest of the salt.

5. Mix sauce with warm pasta and season with lemon juice and pepper.

6. Spoon into an oven dish and bake for 20 minutes or until golden brown.

\section{BUTTERNUT and SWEETCORN BAKE (Serves $4-6$ )}

Butternut is a versatile veggie with a naturally sweet flavour. The creamy sweetcorn makes this a sweet and delicious side dish without the need for cream or butter.

\section{Ingredients}

- $400 \mathrm{~g}$ butternut, cut in cubes

- $400 \mathrm{~g}$ sweet potatoes with the skin, cut in cubes

- $\quad 1 / 2$ onion, halved and sliced

Methods

1. Preheat oven to $180{ }^{\circ} \mathrm{C}$.

2. Mix butternut, sweet potatoes, onion and oil together in an oven dish.

3. Bake for 30 minutes or until the veggies are just cooked.

4. Pour sweetcorn over veggies and season with nutmeg and pepper.

5. Bake for another 15 min or until golden brown. Serve as side dish with meat / chicken / braai.
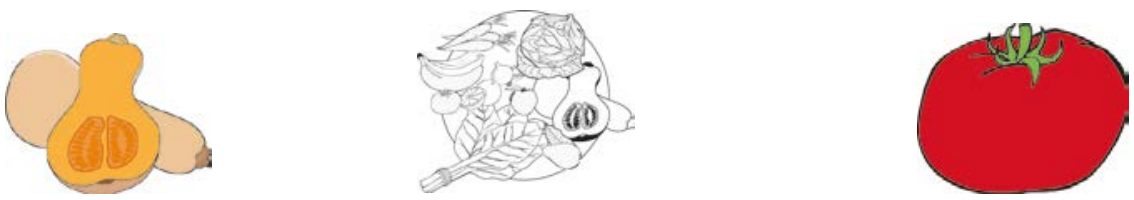


\section{CHICKEN PASTA with BROCCOLI (Serves 6)}

Kids love pasta as a meal, making this ideal for the whole family.

\section{Ingredients}

- 1 tbsp (15ml) sunflower oil

- 3 chicken breasts on the bone, halved and skin and all fat removed

- 2 tsp (10ml) dried mixed herbs

- 1 cup $(250 \mathrm{ml})$ water

- 2 onions, chopped

- 1 green / red pepper, seeds removed \& chopped
- 2 cloves of garlic, finely chopped

- 3 tbsp (45ml) cake flour

- 1 cup $(250 \mathrm{ml})$ low-fat or fat-free milk

- $200 \mathrm{~g}$ broccoli, cut in small pieces

- 2 tsp $(10 \mathrm{ml})$ prepared mustard

- 1 tsp (5ml) salt

- lemon juice and black pepper to taste

- $\quad 250 \mathrm{~g}$ fusilli or any pasta of your choice

\section{Methods}

1. Heat 1 tsp of the oil in a pot, fry chicken until golden brown. Reduce heat, add herbs with water.

2. Cover with a lid and simmer for 20 minutes or until cooked. Spoon out and remove bones. Keep liquid aside.

3. Heat another $1 \mathrm{tsp}$ of oil in the same pot; fry onions, green pepper and garlic for a few minutes.

4. Stir in the flour until absorbed. Slowly stir in the cooking liquid until it forms a sauce.

5. Stir in the milk and simmer for a few minutes until the sauce thickens.

6. Add the chicken, broccoli, mustard, $1 / 2$ tsp of the salt and season with lemon juice and pepper.

7. Simmer until the broccoli is just tender, about 10 minutes.

8. Meanwhile, bring a large pot of water to the boil. Add pasta and the other $1 / 2$ tsp of salt. Cook until tender and drain well. Stir the remaining 1 tsp of oil into the warm pasta.

9. Stir the sauce into the pasta and serve warm.

\section{Tips}

1. Use left-over chicken or meat and add in step 6 or use 2 tins of tuna in brine, drained.

2. Pasta bake: Spoon pasta mixture into an oven dish. Sprinkle with $1 / 4$ cup of grated Cheddar cheese, preferably reduced fat, and bake at $180^{\circ} \mathrm{C}$ until golden brown.

\section{APPLE and CINNAMON MUFFINS (Makes 12 muffins)}

\section{Ingredients}

- 1 cup (250ml) cake flour

- 1 cup $(250 \mathrm{ml})$ whole-wheat flour

- 1 tbsp (15ml) baking powder

- 2 tsp (10ml) ground cinnamon

- $\quad 1 / 2$ cup $(125 \mathrm{ml})$ sugar

- 1 cup $(250 \mathrm{ml})$ grated apples
- 1 cup $(250 \mathrm{ml})$ finely grated carrots

- 3 eggs, beaten

- $100 \mathrm{ml}$ low-fat or fat-free milk

- $\quad 1 / 2$ cup $(125 \mathrm{ml})$ sunflower oil

- 1 tsp $(5 \mathrm{ml})$ vanilla essence 


\section{Methods}

1. Preheat oven to $180^{\circ} \mathrm{C}$ and place paper muffin cups into a 12-hole muffin pan.

2. Mix dry ingredients together in a mixing bowl. Stir in apples and carrots until blended.

3. Beat eggs, milk, oil and vanilla together. Stir egg mixture into the dry ingredients until just mixed through. Take care not to over-mix.

4. Divide batter between muffin cups, bake for 15-20 min/until golden brown and cooked through. Tips

1. Mix 2 tsp sugar with a pinch of ground cinnamon and sprinkle on muffins before baking.

2. To serve as a tea time treat, decorate muffins with a lemon icing. Mix $1 / 2$ cup icing sugar with 1 tbsp lemon juice and drizzle over muffins.

3. Bake as a cake in a $20 \mathrm{~cm}$ cake tin for 30-35 minutes. Use icing in tip 2.

4. The apples can be replaced with more carrots for a carrot muffin or cake.

\section{VEGETABLE CURRY BUNNY CHOW (Serves 6)}

A bunny chow is a delicious meal for many people. This vegetarian version is filling and comforting.

\section{Ingredients}

- 1 tbsp (15ml) sunflower oil

- 1 onion, chopped

- 2 cloves of garlic, finely chopped

- 3 carrots, chopped

- 1-2 green chillies, chopped (optional)

- 3 curry leaves (optional)

- $1 / 2 \mathrm{tsp}(2.5 \mathrm{ml})$ turmeric

- 1 tbsp (15ml) curry powder or to taste

- 1 tsp $(5 \mathrm{ml})$ masala of your choice

- 3 tomatoes, chopped
- 2 potatoes, peeled and chopped

- 1 brinjal, chopped

- $1 / 2 \operatorname{cup}(125 \mathrm{ml})$ water

- $1 / 2$ tsp $(2.5 \mathrm{ml})$ salt

- 1 cup chopped cauliflower/green beans

- $1 / 4$ medium cabbage, chopped

- $1 \times 410 \mathrm{~g}$ tin baked beans in tomato sauce

- lemon juice and black pepper to taste

- $4 \mathrm{~cm}$ thick slice whole-wheat bread per person

\section{Methods}

1. Heat oil in a large pot and fry onion, garlic, carrots, chillies, curry leaves and spices.

2. Add tomatoes and simmer for a few minutes. Stir in potatoes, brinjal, water and salt.

3. Bring to the boil, reduce the heat and simmer with a lid for 20 minutes.

4. Stir in cauliflower, cabbage and baked beans and simmer for another 20 minutes or until the potatoes are tender. Season with lemon juice and black pepper.

5. Hollow out the thick slices of bread and spoon the curry inside.

\section{Tips}

1. Substitute baked beans for any other beans of your choice and add more tomatoes if necessary.

2. Make this vegetable curry as spicy as you would like and serve with chopped fresh coriander. 


\section{GREEN GODDESS PASTA SALAD (Serves 6)}

The name of this recipe was a way for Margot to convince her kids to eat fresh veggies.

\section{Ingredients}

- $250 \mathrm{~g}$ shell noodles or other small pasta

- $1 / 2$ cucumber, chopped shapes

- 2 tomatoes, chopped

- $1 / 2 \operatorname{tsp}(2.5 \mathrm{ml})$ salt

- 1 green chilli, finely chopped (optional)

- 3 tbsp (45ml) sunflower oil

- 1 cup $(250 \mathrm{ml})$ frozen whole kernel corn or

- 1 tsp $(5 \mathrm{ml})$ prepared mustard peas, rinsed

- 3 tbsp (45ml) lemon juice

- 3 tbsp (45ml) chopped fresh

- 1 tsp (5ml) sugar parsley/coriander

- 1 green/red pepper, seeds removed and - black pepper to taste chopped

\section{Methods}

1. Bring a large pot of water to the boil. Add pasta and salt. Cook until tender and drain well.

2. Meanwhile mix the oil, mustard, lemon juice and sugar.

3. Pour half of this dressing over the warm pasta and mix through. Allow to cool.

4. Mix remaining ingredients with the pasta and dressing and season with pepper

\section{Tips}

1. When in season, an avocado is delicious in this salad.

2. You can add left-over chicken or tuna for a light meal.

3. This salad can be made with 2 cups cooked brown rice instead of pasta.
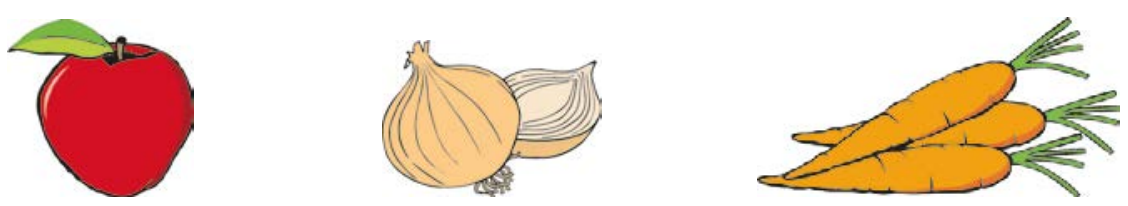


\section{ADDENDUM L: Total budget expenditure for research study}

An amount of almost R15, 000 was received from the NOMA funding to fund all expenses required for this research study. See below for an overall summary of the budgetary expenditure and Addendum $\mathrm{M}$ for a full breakdown of the expenses for this project.

Table 7.1: Summary of budget expenditure

\begin{tabular}{|c|c|c|c|}
\hline COMPONENT & $\begin{array}{l}\text { AMOUNT } \\
\text { BUDGETED } \\
\text { FOR }\end{array}$ & AMOUNT SPENT & $\begin{array}{l}\text { FUNDING } \\
\text { SOURCE }\end{array}$ \\
\hline $\begin{array}{l}\text { Batteries (for voice recorders): } \\
\text { +/-R14 each; } 6 \text { batteries bought }\end{array}$ & none & R84 & \multirow{9}{*}{ 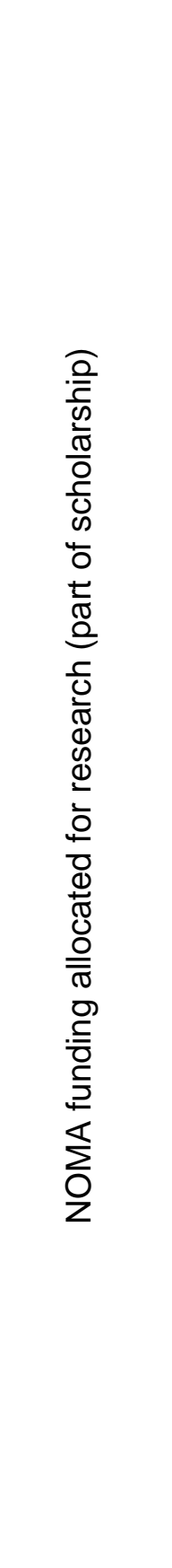 } \\
\hline $\begin{array}{l}\text { PERSONNEL: } \\
26 \text { full days ( } 8 \text { hours per day) of field worker } \\
\text { assistance (i.e. } 2 \text { field workers for } 13 \text { days } \\
\text { each) - for observing, note-taking, and } \\
\text { transcription of discussions and interviews. } \\
\text { (@ R300 per day, i.e. R300/8 hours) }\end{array}$ & R7 800 & $\begin{array}{c}\mathrm{R} 9300 \\
\text { (some transcriptions took } \\
\text { longer than expected) }\end{array}$ & \\
\hline $\begin{array}{l}\text { REFRESHMENTS FOR FOCUS GROUPS: } \\
\text { Tea / coffee and sandwiches for } 3 \text { focus } \\
\text { groups of } 8 \text { people each, and for } 10 \\
\text { interviews = } 34 \text { people (@ +/- R20 per } \\
\text { person) }\end{array}$ & R680 & \multirow[t]{2}{*}{$\begin{array}{l}\text { R3 } 598 \\
\text { (had not budgeted for } \\
\text { pilot study) }\end{array}$} & \\
\hline $\begin{array}{l}\text { INCENTIVE (TOKEN OF APPRECIATION): } \\
\text { Bag of vegetables each } \\
\text { (for } 34 \text { people @ +/-R75 per bag) }\end{array}$ & $\begin{array}{l}\text { R2 } 550 \\
\text { (R3 } 230 \text { for } \\
\text { both) }\end{array}$ & & \\
\hline $\begin{array}{l}\text { LANGUAGE EDITING (of final thesis): } \\
\text { comprehensive editing option for }+/-100 \\
\text { pages }\end{array}$ & $\begin{array}{l}\mathrm{R} 2000-\mathrm{R} 3 \\
000\end{array}$ & R3 000 & \\
\hline$\frac{\text { DISPOSABLE (DIGITAL) CAMERAS: }}{\text { X } 10 @ \text { R132 per camera }}$ & R1320 & $\begin{array}{l}\mathrm{R} 400 \\
\text { (photo documentation did } \\
\text { not work as planned) }\end{array}$ & \\
\hline$\frac{\text { Developing of photographs: }}{\text { X } 200 \text { photos @R3 I photo }}$ & R600 & $\begin{array}{l}\mathrm{R} 100 \\
\text { (photo documentation did } \\
\text { not work as planned) }\end{array}$ & \\
\hline $\begin{array}{l}\text { MISCELLANEOUS: } \\
\text { Paper, printing, telephone calls, petrol and } \\
\text { other miscellaneous administration costs }\end{array}$ & $\begin{array}{c}\text { (was not budgeted } \\
\text { for) }\end{array}$ & +/- R1500 & \\
\hline TOTAL & R15 950 & R17 982 & \\
\hline
\end{tabular}

